UNIVERSIDADE DE SÃO PAULO

ESCOLA POLITÉCNICA

HERICK GARCIA TAKIMOTO

ESTUDO DE POLIFLUORENOS COMO CAMADA EMISSORA DE DISPOSITIVOS ELETROLUMINESCENTES EFICIENTES 


\title{
ESTUDO DE POLIFLUORENOS COMO CAMADA EMISSORA DE DISPOSITIVOS ELETROLUMINESCENTES EFICIENTES
}

\author{
Dissertação apresentada ao Departamento \\ de Engenharia Metalúrgica e de Materiais \\ da Escola Politécnica da Universidade de \\ São Paulo, para obtenção do título de \\ Mestre em Ciências.
}

Área de concentração:

Engenharia Metalúrgica e de Materiais

Orientadora: Prof ${ }^{\mathrm{a}} \mathrm{Dr}^{\mathrm{a}}$ Wang Shu Hui 
Este exemplar foi revisado e corrigido em relação à versão original, sob

responsabilidade única do autor e com a anuência de seu orientador.

São Paulo, 07 de junho de 2013.

Assinatura do autor: Herick Garcia fakimoto

Assinatura do orientador:

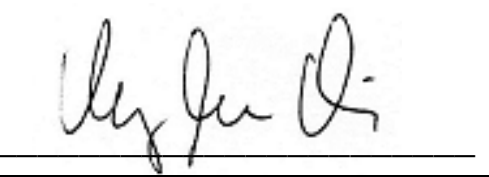

FICHA CATALOGRÁFICA

Takimoto, Herick Garcia

Estudo de polifluorenos como camada emissora de dispo-

sitivos eletroluminescentes eficientes / H.G. Takimoto. -- versão corr. -São Paulo, 2013.

$118 \mathrm{p}$.

Dissertação (Mestrado) - Escola Politécnica da Universidade de São Paulo. Departamento de Engenharia Metalúrgica e de Materiais.

1.Polímeros (Materiais) 2.Síntese orgânica 3.Dispositivos eletrônicos I.Universidade de São Paulo. Escola Politécnica. Departamento de Engenharia Metalúrgica e de Materiais II.t. 
Aos meus avós Benedita e Raul (in memoriam) e Hiroko e Hirozo (in memoriam) pela base familiar.

Aos meus pais Crisleide e Francisco, pela compreensão e incentivo em todos os momentos.

Ao meu irmão Kaio e à minha namorada Moniky. 


\section{AGRADECIMENTOS}

À Prof. ${ }^{a}$ Dr. ${ }^{a}$ Wang Shu Hui, por suas idéias, orientações e suporte necessário para realização deste trabalho;

Ao MSc. Fábio Conte Correia, pelos conhecimentos iniciais, dicas e conselhos;

Aos colegas do grupo: Fernanda Barberato, Aurianny Lima, Prof. Dr. Walker Soares Drummond, Dra. Telma Nagano de Moura, MSc. Fabio Conte Correia e Dr. Emerson Roberto Santos, Satoru Yoshida pelo auxílio no desenvolvimento deste trabalho;

Ao Dr. Emerson Roberto Santos e principalmente ao Prof. ${ }^{\circ}$ Dr. Roberto Koji Onmori e ao Dr. Gerson dos Santos, pela ajuda nas montagens e caracterizações dos dispositivos produzidos neste trabalho;

Ao Prof. Dr. Fernando Josepetti Fonseca e ao Prof. Dr. Roberto Koji Onmori por permitirem a utilização da infraestrutura do Grupo de Eletrônica Molecular (GEM) para a fabricação dos PLEDs;

Ao CNPq pelo suporte financeiro durante o Mestrado. 


\section{RESUMO}

Este trabalho tem como principais objetivos: desenvolver procedimentos sintéticos e novos materiais poliméricos que apresentem boa condutividade elétrica, estudar o comportamento eletro-óptico dos polímeros obtidos, desenvolver procedimentos para a construção de dispositivos eletroluminescentes, caracterizá-los e correlacionar as características eletro-ópticas observadas com a constituição da camada ativa polimérica.

Foram realizadas diversas sínteses objetivando a preparação de polifluorenos com diferentes estruturas químicas a partir de monômeros difuncionais aromáticos boronados e bromados, utilizando uma mesma rota de acoplamento de Suzuki. Assim, foram preparados três polímeros, poli[2,7-(9,9-dioctilfluoreno)] (PF, polifluoreno), poli[1,4-fenileno-alt-2,7(9,9-dioctilfluoreno)] [ $\mathrm{PF}_{\mathrm{P}}$, poli(fluoreno-fenileno)] e poli[(1,4-fenileno-2-flúor)-alt-2,7-(9,9dioctilfluoreno)] [PF $\mathrm{PF}_{\mathrm{PF}}$, poli(fluoreno-fenileno)fluorado].

Para obtenção destes polifluorenos com bom rendimento e com pureza adequada para a preparação de dispositivos poliméricos eletroluminescentes, foi necessário testar diversas condições de reação, até a otimização de um procedimento sintético robusto.

Os polifluorenos preparados foram exaustivamente purificados por extração e solubilização-precipitação.

Todos os polifluorenos tiveram a sua estrutura e composição químicas caracterizadas e confirmadas pelas técnicas de espectroscopia no infravermelho (FTIR), espectroscopia de ressonância magnética nuclear de hidrogênio ( $\left.{ }^{1} \mathrm{HNMR}\right)$ e espectroscopia de energia dispersiva de raios-X (EDX). As massas molares médias e a polidispersão foram determinadas por cromatografia de permeação em gel (GPC).

Soluções em clorofórmio dos polifluorenos foram analisadas por espectroscopias de absorção e emissão no UV-Vis. Estes resultados nos forneceram informações importantes quanto às propriedades de fotoluminescência dos polifluorenos obtidos. Até o momento, sabese que todos os três polímeros emitem cor azul e dentre as três estruturas estudadas, o $\mathrm{PF}_{\mathrm{PF}}$ apresentou maior intensidade de fluorescência.

Para a fabricação dos P-OLEDs (Diodos Orgânico-Polimérico Emissor de Luz) foram feitas soluções de clorofórmio em concentrações de 1\% dos três tipos de polímeros. Também foi estudada a influência dos compostos ETL (electron transport layer) (Alq ${ }_{3}$ ou butyl-PBD) com concentrações de $0,5 \%$.

Quando aplicada uma tensão no dispositivo, o $\mathrm{PF}_{\mathrm{PF}}$ apresentou menor tensão de operação entre os polímeros estudados. A partir das curvas de tensão vs. corrente, verificou-se que a adição do butyl-PBD nos três tipos de polímeros diminui a tensão de limiar em comparação com os dispositivos sem composto ETL. Os comprimentos de onda de eletroluminescência dos dispositivos polarizados permaneceram constante mesmo com a adição dos dois compostos ETL (Alq $q_{3}$ ou butyl-PBD).

Palavras-chave: P-OLEDs, ITO, reação Suzuki, Polifluoreno. 


\section{ABSTRACT}

This work has as main objectives: develop synthetic procedures and new electroluminescent polymeric materials that have good electrical conductivity, study the behavior of polymer systems thus obtained, and develop procedures for the construction of electroluminescent devices, characterize them and correlate the photo- electrical behavior with the features of the constitutive active polymeric layer

Several syntheses were performed aiming at preparing polyfluorenes with different structures from boronated and brominated difunctional aromatic monomers using a Suzuki coupling route. So far, three polymers were prepared, poly[2,7-(9,9-dioctylfluorene)] (PF, polyfluorene), poly[1,4-phenylene-alt-2,7-(9,9-dioctylfluorene)] [PF,$\quad$ poly(fluorenephenylene)] and poly[1,4-phenylene-2-fluoro)-alt-2,7-(9,9-dioctylfluorene)] [PF $\mathrm{PF}_{\mathrm{PF}}$ fluorinated poly(fluorene-phenylene)].

To obtain these polyfluorenos with good yield and purity suitable for preparing polymeric electroluminescent devices, it was necessary to test various reaction conditions and to optimize a robust synthetic procedure.

The polyfluorenes prepared were thoroughly purified by extraction and solubilizationprecipitation.

All polyfluorenes have had their structures and chemical composition characterized and confirmed by infrared spectroscopy (FTIR), and hydrogen and carbon-13 nuclear magnetic resonance spectroscopy $\left({ }^{1} \mathrm{HNMR}\right.$ and $\left.{ }^{13} \mathrm{CNMR}\right)$. The average molar masses and polydispersity were determined by gel permeation chromatography (GPC).

Polyfluorenes in chloroform solutions were analyzed by the UV-Vis absorption and emission spectroscopy. These results provided us with important information regarding the photoluminescence properties of polyfluorenes thus obtained. Until now, it is known that all three polymers emit in the blue region and among the three structures, the $\mathrm{PF}_{\mathrm{PF}}$ has the highest fluorescence intensity.

The construction of PLEDs was carried out from the chloroform solutions at concentrations of $1 \%$ for each of the all three types of polymers. The influence of an ETL (electron transport layer) compound (Alq3, PBD) was also studied, and its concentration was kept constant at $5 \%$ in the polymer solution.

Tests of the devices under applied voltage have shown a higher stability for $\mathrm{PF}_{\mathrm{PF}}$ among all. From the voltage vs. current curves, it was possible to observe that the addition of PBD decreased the threshold voltage for the devices prepared from the three types of polymers. The wavelength of electroluminescence remained constant despite the addition of the ETL compound (Alq3 or butyl-PBD).

Keywords: P-OLEDs, ITO, Suzuki reaction, Polyfluorene. 


\section{LISTA DE ILUSTRAÇÕES}

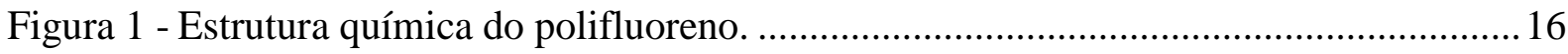

Figura 2 - Estrutura do poliacetileno: a) estrutura trans; b) estrutura de ressonância. ............. 18

Figura 3 - Estrutura de alguns tipos de polímeros conjugados............................................. 19

Figura 4 - Representação dos orbitais híbridos $s p^{2}$ (ligação $\sigma$ ) e orbitais $p_{z}$ (ligação $\pi$ ).........20

Figura 5 - Disposição eletrônica na hibridização sp $^{2}$..........................................................20

Figura 6 - a) Rota de acoplamento de Yamamoto e b) Rota de acoplamento de Suzuki. ........21

Figura 7 - Esquema de acoplamento entre duas arilas (Ar - Ar') por reação de acoplamento

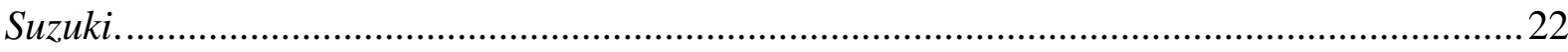

Figura 8 - Esquema de acoplamento entre arilas halogenadas e boronadas por reação de

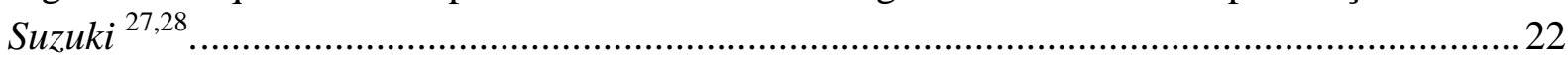

Figura 9 - Estrutura química do fluoreno (numeração de acordo com a IUPAC)...................24

Figura 10 - Dois exemplos de transições eletrônicas que tem diferentes probabilidades pelo

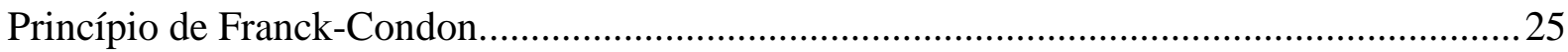

Figura 11 - Diagrama de energia dos orbitais moleculares e suas possíveis transições...........25

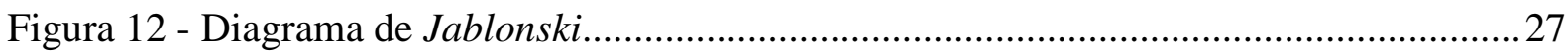

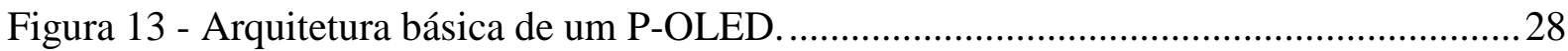

Figura 14 - Estrutura química do poli(3,4-etilenodioxitiofeno) : poli(4-sulfonato de estireno),

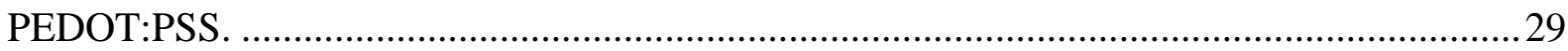

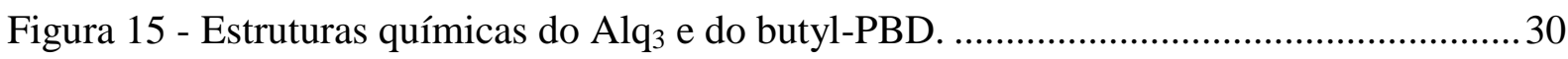

Figura 16 - Estrutura química dos monômeros utilizados nas sínteses. ................................... 34

Figura 17 - a) Câmara glove-box b) Sistema utilizados na realização das sínteses dos

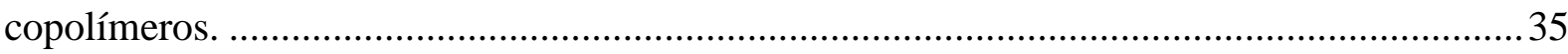

Figura 18 - Rota sintética para obtenção do polímero poli[2,7-(9,9-dioctilfluoreno)], (polímero

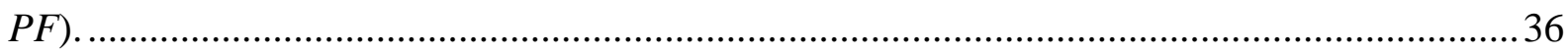

Figura 19 - Rota sintética para a obtenção do poli[(1,4-fenileno-alt-2,7-(9,9-dioctilfluoreno)]

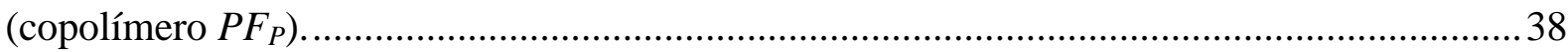

Figura 20 - Rota sintética para a obtenção poli[1,4-fenileno-alt-2,7-(9,9-dioctilfluoreno)],

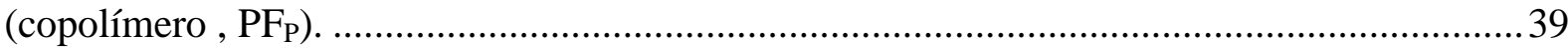

Figura 21- Rota sintética para a obtenção do poli[(1,4-fenileno-2-flúor)-alt-2,7-(9,9-

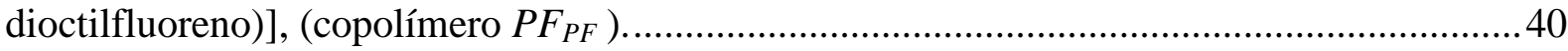

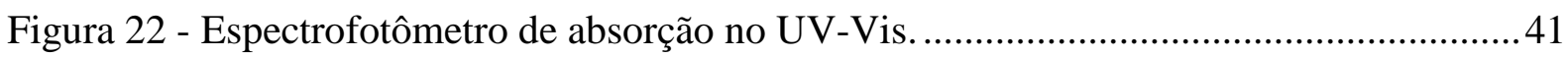

Figura 23 - Espectrofotômetro de fluorescência.................................................................... 41

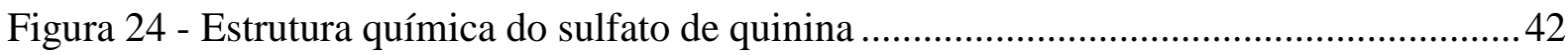

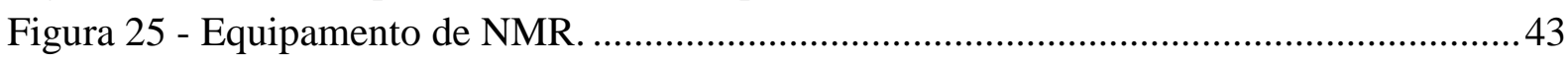

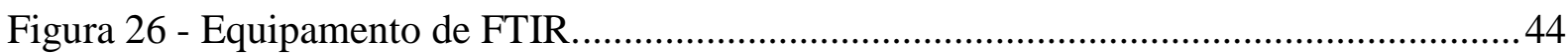

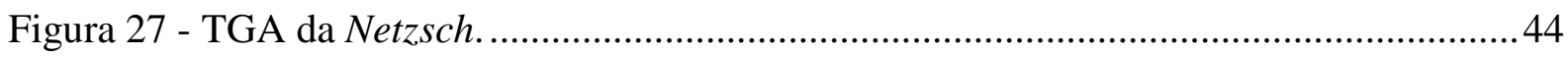

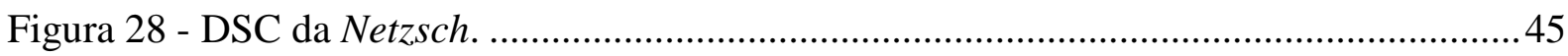

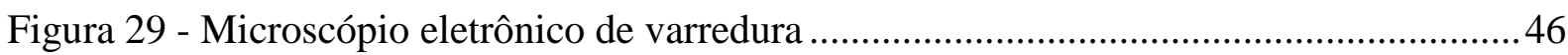

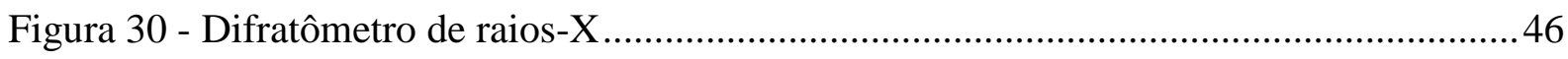


Figura 31 - Geometria das máscaras de cobre para formação de P-OLEDs com área ativa de a) $9 \mathrm{~mm}^{2}$ e b) $25 \mathrm{~mm}^{2}$.

Figura 32 - Registro fotográfico das máscaras de cobre dos P-OLEDs com área ativa de a) 9 $\mathrm{mm}^{2}$ e b) $25 \mathrm{~mm}^{2}$.

Figura 33 - a) Lâmina de vidro recoberta com ITO; geometria do ITO com área ativa de b) $9 \mathrm{~mm}^{2}$ e c) $25 \mathrm{~mm}^{2}$. .48

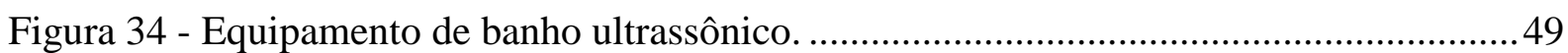

Figura 35 - Esquema do reator utilizado para tratamento superficial do ITO.........................50

Figura 36 - Reator montado em funcionamento para tratamento superficial do ITO. .............50

Figura 37 - Spinner montado com um motor de disco rígido................................................51

Figura 38 - Geometria dos substratos após a deposição do PEDOT:PSS e processo de decapagem, para P-OLEDs com área ativa de a) $9 \mathrm{~mm}^{2}$ e b) $25 \mathrm{~mm}^{2}$......................................52

Figura 39 - Geometria dos subtratos após deposição e processo de decapagem dos copolímeros emissores, para P-OLEDs com área ativa de a) $9 \mathrm{~mm}^{2}$ e b) $25 \mathrm{~mm}^{2}$................53

Figura 40 - Evaporadora térmica no interior de uma glove-box. .........................................54

Figura 41 - Câmara de metalização e o planetário com os porta-amostras...............................54

Figura 42 - Estrutura dos dispositivos com: a) $9 \mathrm{~mm}^{2}$ e b) $25 \mathrm{~mm}^{2}$ de área ativa.....................55

Figura 43 - Fontes de energia: a) montada sob encomenda e b) Keithley, modelo 2420.........56

Figura 44 - Espectrorradiômetros a) Luzchem e b) Ocean Optics.............................................57

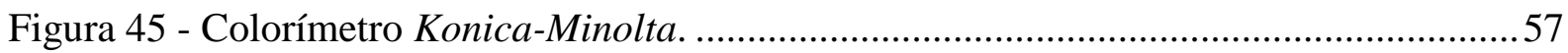

Figura 46 - Polímeros sintetizados e suas respectivas massas molares de seus meros. ............58

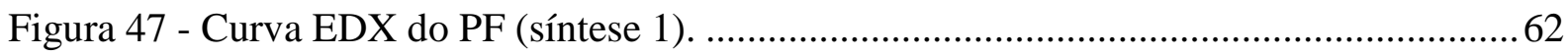

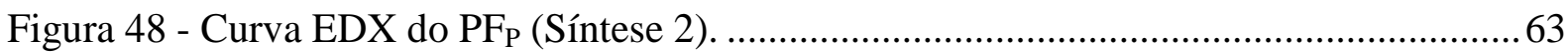

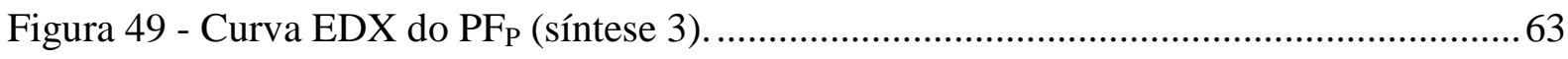

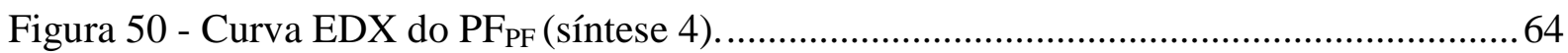

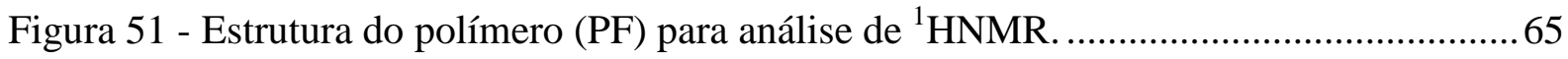

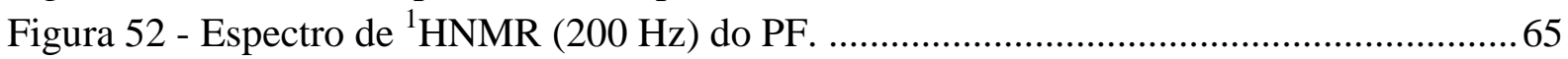

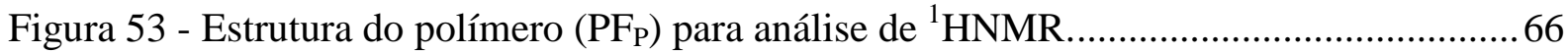

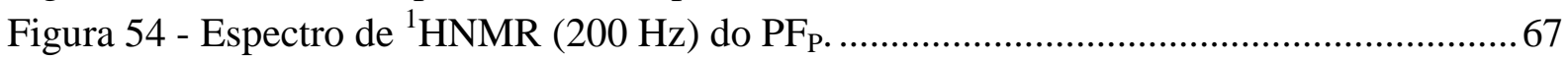

Figura 55 - Estrutura do polímero $\left(\mathrm{PF}_{\mathrm{PF}}\right)$ para análise de ${ }^{1} \mathrm{HNMR}$.........................................6 68

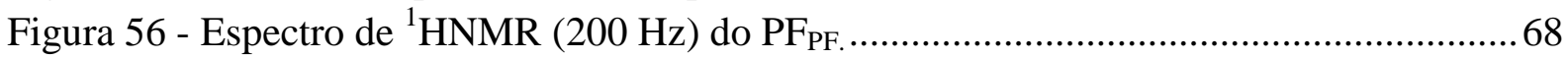

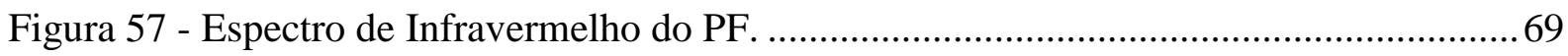

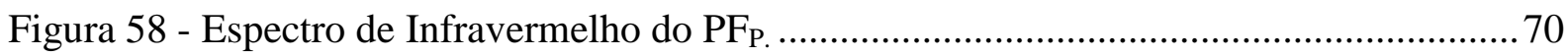

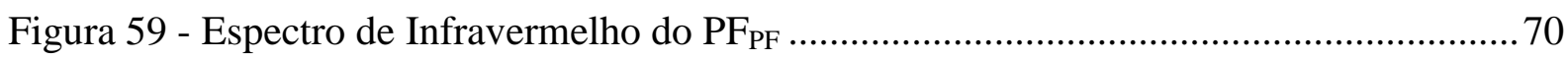

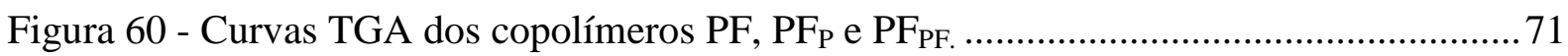

Figura 61 - Derivada da curva TGA do PF. ........................................................................ 72

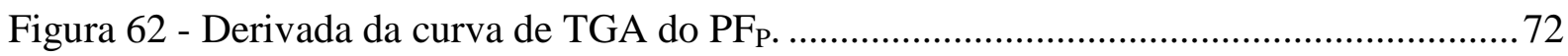

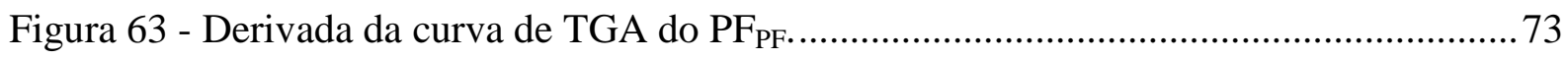

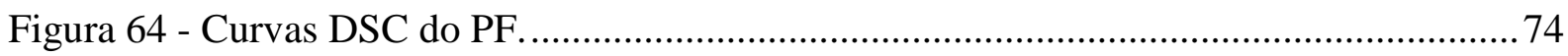

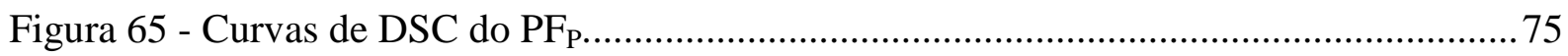

Figura 66 - Curvas de DSC do PF

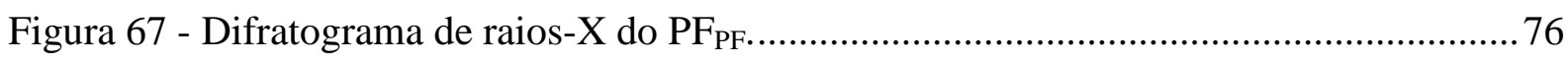

Figura 68 - Espectro de absorbância no UV-Vis dos copolímeros PF, $\mathrm{PF}_{\mathrm{P}}$ e $\mathrm{PF}_{\mathrm{PF}}$ nas mesmas concentrações molares $\left(2 \times 10^{-6} \mathrm{~mol} / \mathrm{L}\right)$. 
Figura 69 - Espectros de absorção no UV-Vis do polímero PF. ............................................78

Figura 70 - Espectros de absorção no UV-Vis do copolímero $\mathrm{PF}_{\mathrm{P}}$...........................................78

Figura 71 - Espectros de absorção no UV-Vis do polímero $\mathrm{PF}_{\mathrm{PF}}$............................................ 79

Figura 72 - Gráfico de intensidade de absorção vs. variação da concentração molar, para os copolímeros, para pico de $385 \mathrm{~nm}(\mathrm{PF})$, pico de $360 \mathrm{~nm}\left(\mathrm{PF}_{\mathrm{P}}\right)$ e pico de $365 \mathrm{~nm}\left(\mathrm{PF}_{\mathrm{PF}}\right) \ldots \ldots . . .79$ Figura 73 - Espectros de fluorescência dos copolímeros excitados em seus respectivos comprimentos de onda com máxima intensidade $\left(2 \times 10^{-6} \mathrm{~mol} / \mathrm{L}\right)$........................................ 80

Figura 74 - Espectro de fluorescência do PF em diferentes concentrações...............................81

Figura 75 - Espectro de fluorescência do $\mathrm{PF}_{\mathrm{P}}$ em diferentes concentrações. ........................... 81

Figura 76 - Espectros de fluorescência do $\mathrm{PF}_{\mathrm{PF}}$ em diferentes concentrações......................... 82

Figura 77 - Intensidade de emissão em função da concentração dos copolímeros indicados. .82

Figura 78 - Espectro de fluorescência do sulfato de quinina em diferentes concentrações. ....83

Figura 79 - Curva de densidade de corrente e luminância vs. tensão do PF (s/ETL)...............85

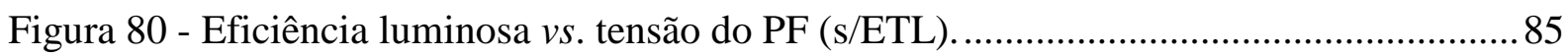

Figura 81 - Espectro de eletroluminescência do PF (s/ETL). ................................................ 86

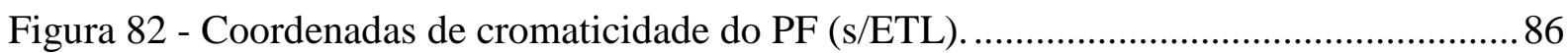

Figura 83 - Fotos dos P-OLEDs polarizados de PF (s/ETL) .................................................. 86

Figura 84 - Curva de densidade de corrente e luminância vs. tensão do PF (c/Alq $\left.{ }_{3}\right)$...............87

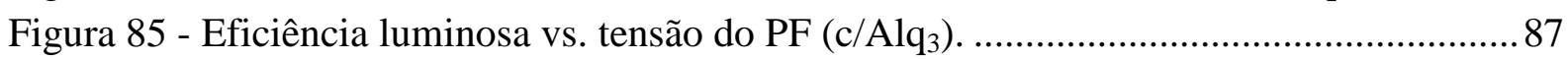

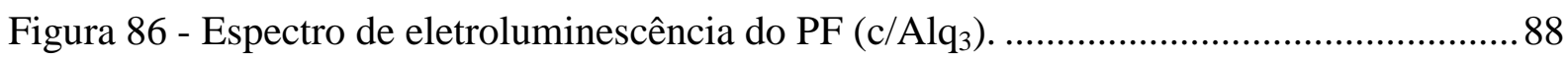

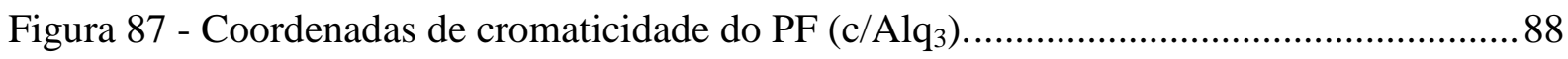

Figura 88 - Fotos dos P-OLEDs de PF (c/Alq3) polarizados................................................ 89

Figura 89 - Curva de densidade de corrente e luminância vs. tensão do PF (c/ butyl-PBD)....89

Figura 90 - Curva de eficiência luminosa vs. tensão do PF (c/ butyl-PBD)............................90

Figura 91 - Espectro de eletroluminescência do PF (c/ butyl-PBD). ....................................... 90

Figura 92 - Coordenadas de cromaticidade do PF (c/ butyl-PBD) ..........................................91

Figura 93 - Fotos dos P-OLEDs de PF (c/ butyl-PBD) polarizados........................................91

Figura 94 - Curva de densidade de corrente e luminância vs. tensão do $\mathrm{PF}_{\mathrm{P}}$ (s/ETL). ............92

Figura 95 - Eficiência luminosa vs. tensão do $\mathrm{PF}_{\mathrm{P}}$ (s/ ETL). ..................................................92

Figura 96 - Espectro de eletroluminescência do $\mathrm{PF}_{\mathrm{P}}$ (s/ ETL).................................................93

Figura 97 - Coordenadas de cromaticidade do $\mathrm{PF}_{\mathrm{P}}(\mathrm{s} / \mathrm{ETL})$. ................................................. 93

Figura 98 - Fotos dos P-OLEDs de PFP (s/ETL) polarizados................................................94

Figura 99 - Curva de densidade de corrente e luminância vs. tensão do $\mathrm{PF}_{\mathrm{P}}\left(\mathrm{c} / \mathrm{Alq}_{3}\right)$............94

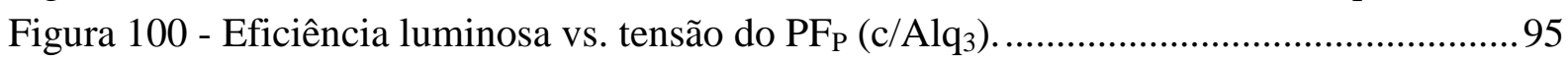

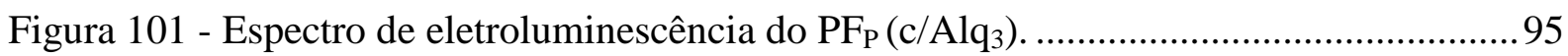

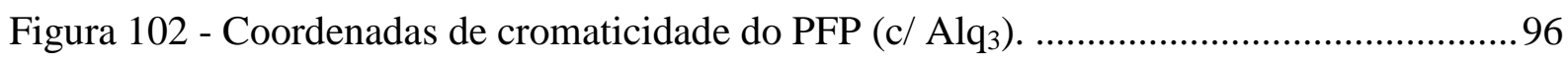

Figura 103 - Foto do P-OLED de PFP (c/ Alq3) polarizado ..................................................96

Figura 104 - Curva de densidade de corrente e luminância vs. tensão do $\mathrm{PF}_{\mathrm{P}}$ (c/ butyl PBD).97

Figura 105 - Eficiência luminosa vs. tensão do $\mathrm{PF}_{\mathrm{P}}$ (c/ butyl-PBD)....................................... 97

Figura 106 - Espectro de eletroluminescência do $\mathrm{PF}_{\mathrm{P}}(\mathrm{c} /$ butyl-PBD).......................................98

Figura 107 - Coordenadas de cromaticidade do $\mathrm{PF}_{\mathrm{P}}$ (c/ butyl-PBD). ......................................98

Figura 108 - Fotos dos P-OLEDs de PFP (c/ butyl-PBD) polarizados. ................................... 98

Figura 109 - Curva de densidade de corrente e luminância vs. tensão do $\mathrm{PF}_{\mathrm{PF}}$ (s/ETL)......... 99

Figura 110 - Curva de eficiência luminosa vs. tensão do $\mathrm{PF}_{\mathrm{PF}}(\mathrm{s} / \mathrm{ETL})$................................ 100 
Figura 111 - Espectro de eletroluminescência do $\mathrm{PF}_{\mathrm{PF}}$ (s/ ETL).......................................... 100

Figura 112 - Coordenadas de cromaticidade do $\mathrm{PF}_{\mathrm{PF}}$ (s/ETL) ......................................... 101

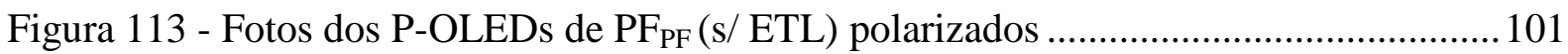

Figura 114 - Curva de densidade de corrente e luminância vs. tensão do $\mathrm{PF}_{\mathrm{PF}}\left(\mathrm{c} / \mathrm{Alq}_{3}\right) \ldots . . . .102$

Figura 115 - Eficiência luminosa vs. tensão do $\mathrm{PF}_{\mathrm{PF}}\left(\mathrm{c} / \mathrm{Alq}_{3}\right)$............................................ 102

Figura 116 - Espectro de eletroluminescência do $\mathrm{PF}_{\mathrm{PF}}\left(\mathrm{c} / \mathrm{Alq}_{3}\right)$......................................... 103

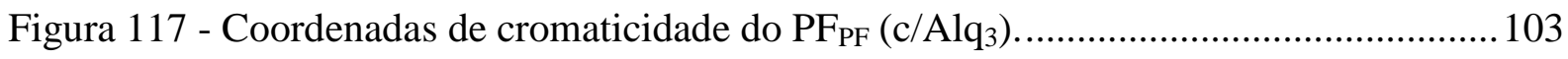

Figura 118 - Fotos dos P-OLEDs de PFPF (c/ Alq3) polarizados. ......................................... 103

Figura 119 - Curva de densidade de corrente e luminância vs. tensão do $\mathrm{PF}_{\mathrm{PF}}$ (c/ butyl PBD).

Figura 120 - Curva de eficiência luminosa vs. tensão do $\mathrm{PF}_{\mathrm{PF}}$ (c/ butyl-PBD)....................... 104

Figura 121 - Espectro de eletroluminescência do $\mathrm{PF}_{\mathrm{PF}}$ (c/ butyl-PBD). ................................ 105

Figura 122 - Coordenadas de cromaticidade do $\mathrm{PF}_{\mathrm{PF}}$ (c/ butyl-PBD)................................... 105

Figura 123 - Fotos dos P-OLEDs de $\mathrm{PF}_{\mathrm{PF}}$ (c/ butyl-PBD) polarizados ................................... 106 


\section{LISTA DE TABELAS}

Tabela 1 - Massas molares e massas utilizadas nas sínteses dos copolímeros.

Tabela 2 - Comparação entre o estado físico, o rendimento de reação e suas massas molares dos copolímeros sintetizados.

Tabela 3 - Massas molares dos polímeros determinadas por GPC utilizando-se THF como solvente e poliestireno como padrão.

Tabela 4 - Porcentagem atômica dos elementos químicos na estrutura dos copolímeros........64

Tabela 5 - Deslocamentos químicos observados no espectro de ${ }^{1}$ HNMR do PF.....................66

Tabela 6 - Deslocamentos químicos observados no espectro de ${ }^{1} \mathrm{HNMR}$ do PF $\mathrm{P}$. ..................67

Tabela 7 - Deslocamentos químicos observados no espectro de ${ }^{1} \mathrm{HNMR}$ do $\mathrm{PF}_{\mathrm{PF}}$..................69

Tabela 8 - Valores de perdas de massa dos polímeros .............................................................. 73

Tabela 9 - Rendimentos quânticos dos polímeros ................................................................ 84

Tabela 10 - Comparação entre as características eletro-ópticas dos P-OLEDs de PF. ............91

Tabela 11 - Comparação entre as características eletro-ópticas dos P-OLEDs de PFP............99

Tabela 12 - Comparação entre as características eletro-ópticas dos P-OLEDs de PF PF. ........ 106 


\section{LISTA DE ABREVIATURAS E SIGLAS}

A

$\mathrm{Alq}_{3}$

butyl-PBD

$\mathrm{cd} / \mathrm{m}^{2}$

$\mathrm{CDCl}_{3}$

DSC

DTA

EDX

de raios- $X$

EL

ETL

$\mathrm{eV}$

FTIR

GEM

GPC

HD

${ }^{1} \mathrm{HNMR}$

HTL

$\mathrm{Hz}$

ITO

IUPAC

IR

LCT

LME

$\mathrm{m}$

$\mathrm{mcd} / \mathrm{A}$

mmol
Ampère

tris-8-hydroxyiquinoline aluminum

2-(4-tert-butylphenyl)-5-(4-biphenyl)-1,3,4-oxadiazole

Candela por metro quadrado

Clorofórmio deuterado

Differential Scanning Calorimetry - Calorimetria Diferencial

Exploratória

Differencial Thermal Analysis - Análise Térmica Diferencial

Energy-Dispersive X-ray Spectroscopy - Espectroscopia de Energia Dispersiva

Eletroluminescência

Electron transport layer - Camada transportadora de elétron

Elétron-volt

Fourier Transform Infrared Spectroscopy - Espectroscopia de

Infravermelho por Transformada de Fourier

Grupo de Eletrônica Molecular

Gel Permeation Chromatography - Cromatografia de permeação em gel

Hard Disk - Disco Rígido

Hydrogen Nuclear Magnetic Resonance - Ressonância Magnética

Nuclear de Hidrogênio

Hole transport layer - Camada transportadora de buracos

Hertz

Indium Tin Oxide - Óxido de Índio e Estanho

International Union of Pure and Applied Chemistry - União Internacional de

Química Pura e Aplicada

Infravermelho

Laboratório de Caracterização Tecnológica

Laboratório de Microeletrônica

Massa molar do mero

Milicandela por Ampère

Milimol 
$\mathrm{M}_{\mathrm{n}} \quad$ Massa molar média numérica

$\mathrm{M}_{\mathrm{w}} \quad$ Massa molar média ponderada

$\mathrm{Mz} \quad$ Massa molar média z

nm Nanômetro

P.A Para Análise

P-OLED Polymer-Organic Light Emitting Diode - Diodo Orgânico-Polimérico Emissor de Luz

PEDOT:PSS Poli(3,4-etilenodioxitiofeno):poli(4-sulfonato de estireno)

PET Poli(tereftalato de etileno)

PF $\quad$ poli[2,7-(9,9-dioctilfluoreno)] - (polifluoreno)

$\mathrm{PF}_{\mathrm{P}} \quad$ poli[1,4-fenileno-alt-2,7-(9,9-dioctilfluoreno)] - [poli(fluoreno-fenileno)]

$\mathrm{PF}_{\mathrm{PF}} \quad$ poli[1,4-fenileno-2-flúor)-alt-2,7-(9,9-dioctilfluoreno)] - [poli(fluoreno-

fenileno)fluorado]

PL Photoluminescence - Fotoluminescência

PMT Departamento de Engenharia Metalúrgica e de Materiais

ppm Partes por milhão

PS Poliestireno

rpm Rotações por minuto

STA Simultaneous Thermal Analysis - Análise Térmica Simultânea

$\mathrm{T}_{\mathrm{g}} \quad$ Transição vítrea

TGA Termogravimetric Analysis - Análise Termogravimétrica

THF Tetrahidrofurano

USP Universidade de São Paulo

UV-O 3 Ultravioleta-ozônio

UV-Vis Ultravioleta-visível

V Volt

XRD X-ray Diffraction - Difração de Raios-X

$X_{n} \quad$ Grau de polimerização 


\section{LISTA DE SÍMBOLOS}

$\begin{array}{ll}\mathrm{Al} & \text { Alumínio } \\ \mathrm{HCl} & \text { Ácido Clorídrico } \\ \mathrm{KBr} & \text { Brometo de Potássio } \\ \mathrm{K}_{2} \mathrm{CO}_{3} & \text { Carbonato de Potássio } \\ \lambda & \text { Comprimento de onda (nm) } \\ \Omega & \text { Ohm } \\ \pi & \text { Orbital molecular ligante } \pi \\ \sigma & \text { Orbital molecular ligante } \sigma \\ \phi_{\mathrm{a}} & \text { Rendimento Quântico da amostra } \\ \phi_{\mathrm{p}} & \text { Rendimento Quântico do padrão } \\ \mathrm{Grad}_{\mathrm{A}} & \text { Área da curva de emissão da amostra } \\ \mathrm{Grad}_{\mathrm{P}} & \text { Área da curva de emissão do padrão } \\ \eta_{\mathrm{A}} & \text { Índice de refração do solvente da amostra } \\ \eta_{\mathrm{P}} & \text { Índice de refração do solvente do padrão } \\ \mathrm{P}_{\left(\mathrm{Ph}_{3}\right)_{4} \mathrm{Pd}} & \text { Tetrakis(triphenylphosphine)palladium } \\ \mu \mathrm{L} & \text { Microlitros } \\ \mu \mathrm{m} & \text { Micrometros }\end{array}$




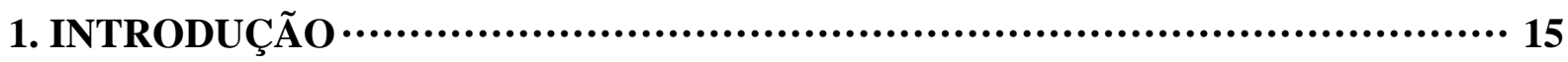

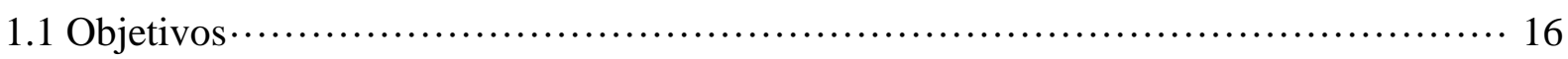

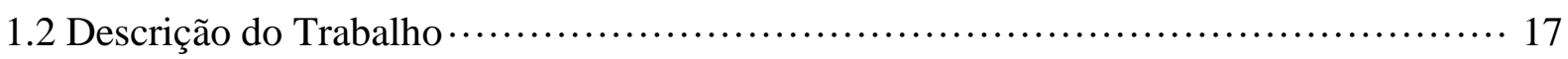

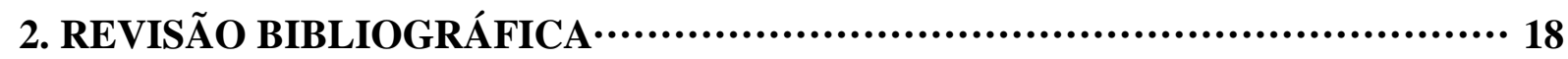

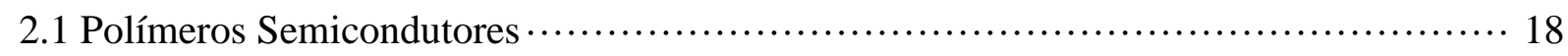

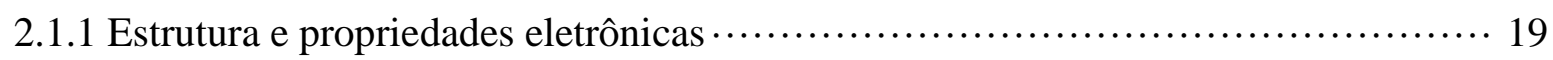

2.1.2 Rotas sintéticas para a obtenção de polímeros conjugados …..................... 21

2.1.2.1 Reação de acoplamento de Suzuki ………............................... 21

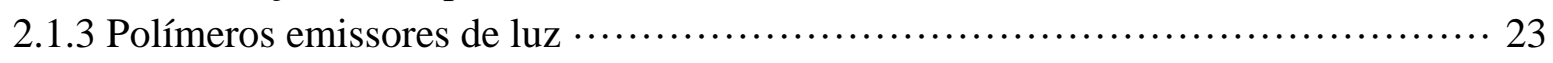

2.1.3.1 Polímeros contendo grupos fluoreno ……................................. 23

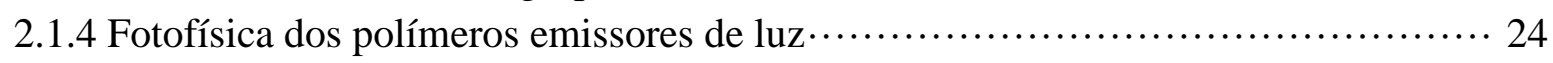

2.1.4.1 Princípios de absorção de energia …............................................ 24

2.1.4.2 Dissipação de Energia ……................................................ 26

2.2 Diodos Poliméricos-Orgânicos Emissores de luz (P-OLEDs) …........................ 27

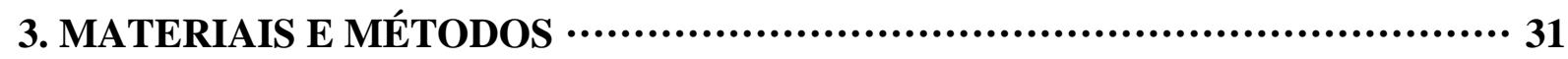

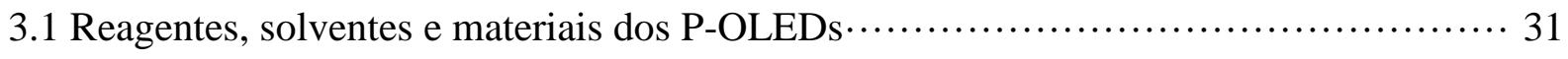

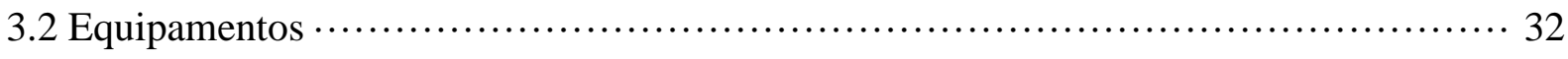

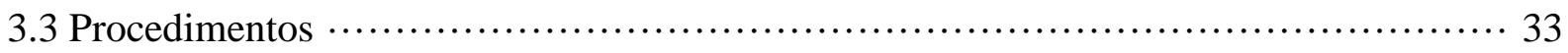

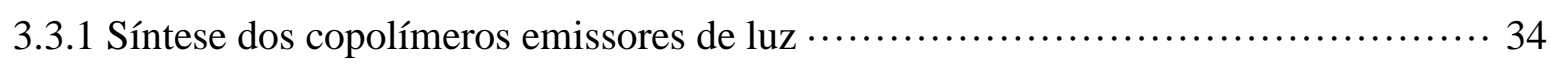

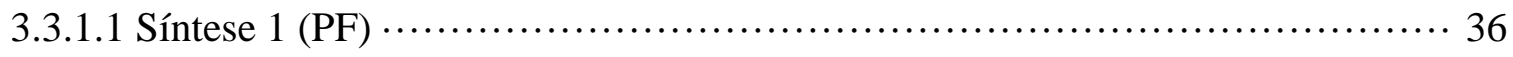

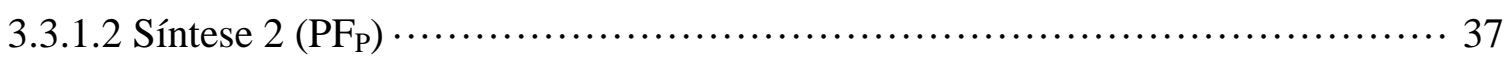

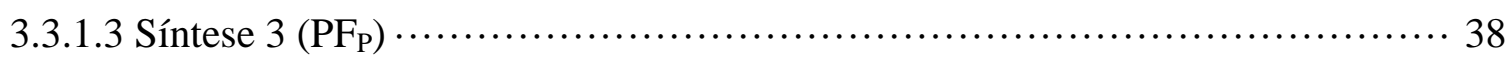

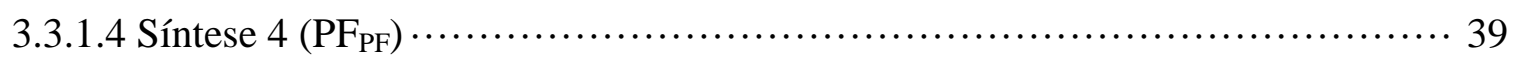

3.3.2 Caracterização dos copolímeros emissores de luz ….............................. 40

3.3.2.1 Espectroscopia de absorção no UV-Vis ….................................... 40

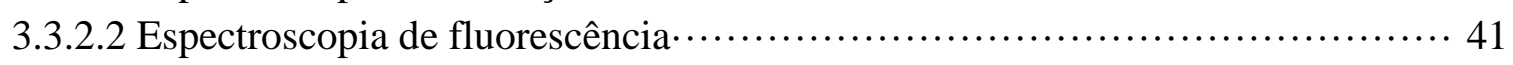

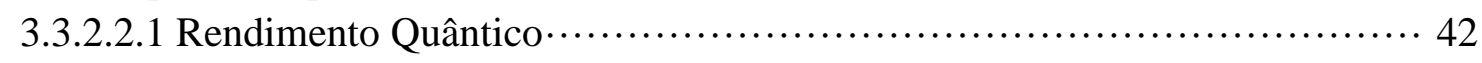

3.3.2.3 Espectroscopia de ressonância magnética nuclear de hidrogênio ( $\left.{ }^{1} \mathrm{HNMR}\right) \cdots \cdot 43$

3.3.2.4 Espectroscopia no infravermelho (FTIR) ……........................... 43

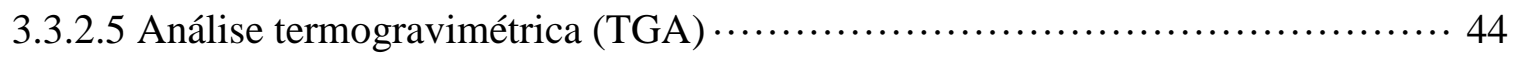

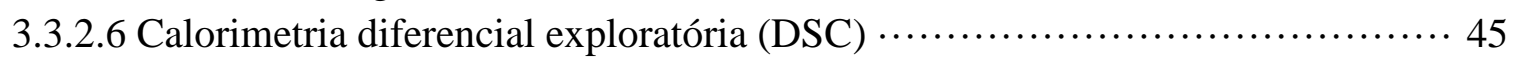

3.3.2.7 Cromatografia de permeação em gel (GPC) ….............................. 45

3.3.2.8 Espectroscopia de energia dispersiva de raios-X (EDX) …................... 46

3.3.2.9 Difração de raio-X (XRD) ……............................................ 46 


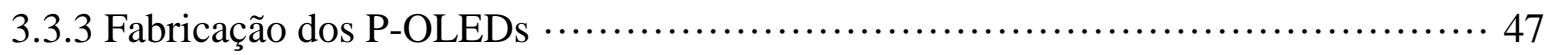

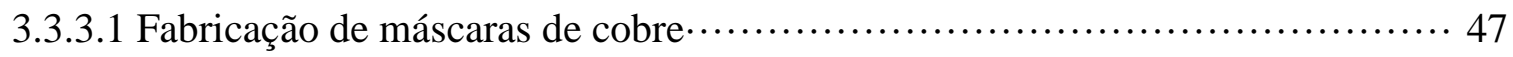

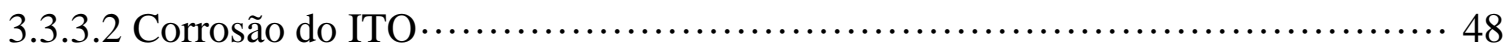

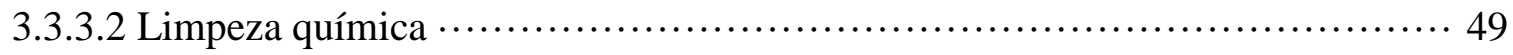

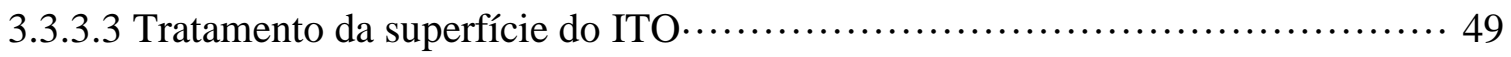

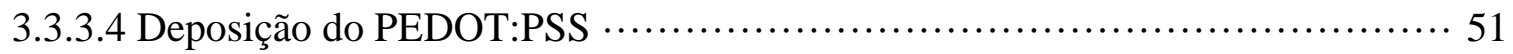

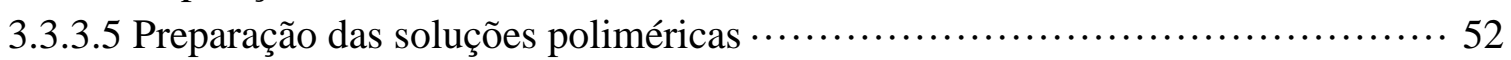

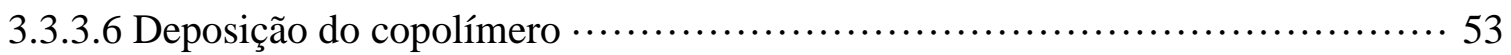

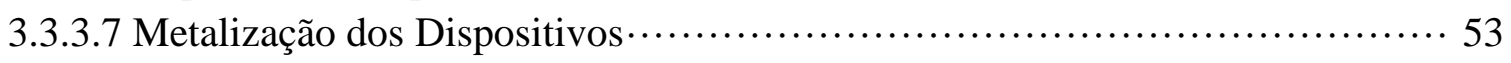

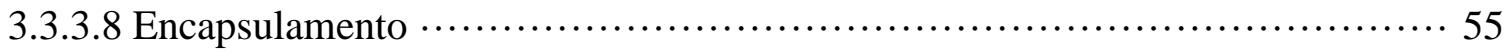

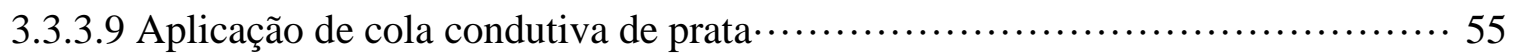

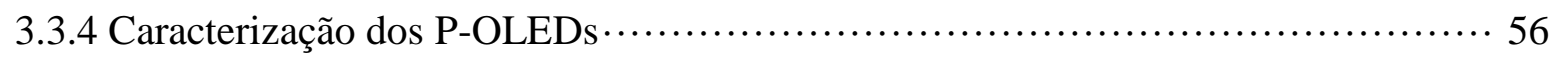

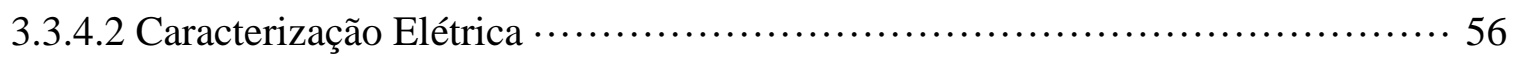

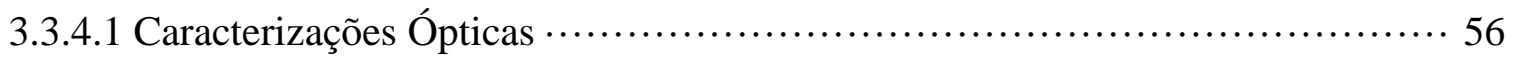

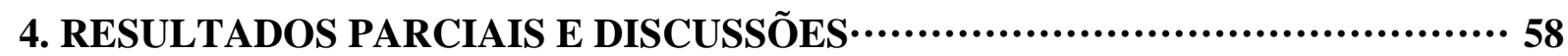

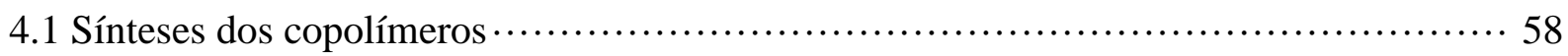

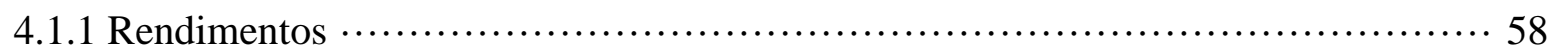

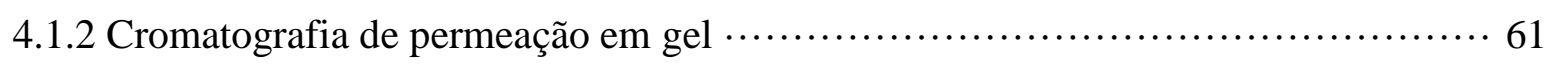

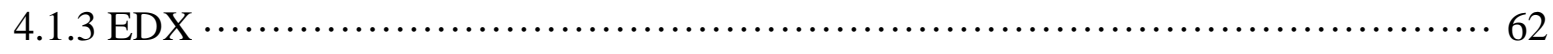

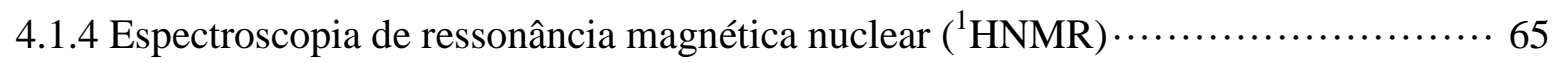

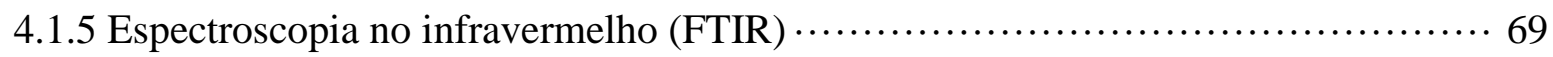

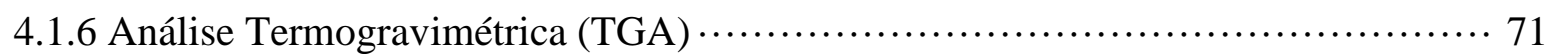

4.1.7 Análise de Calorimetria Diferencial Exploratória (DSC) ….................... 74

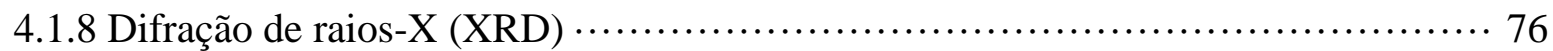

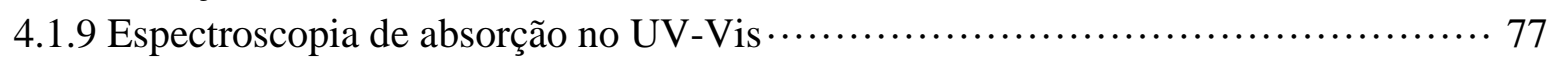

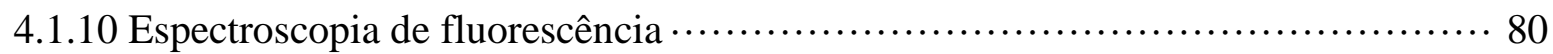

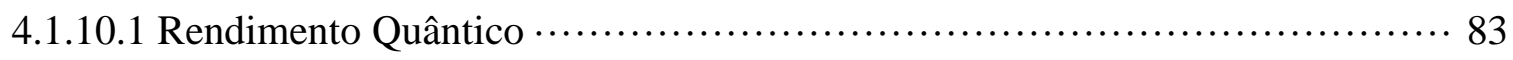

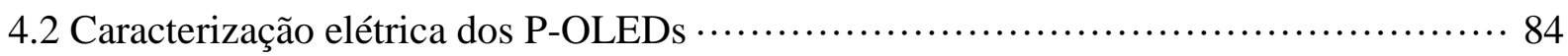

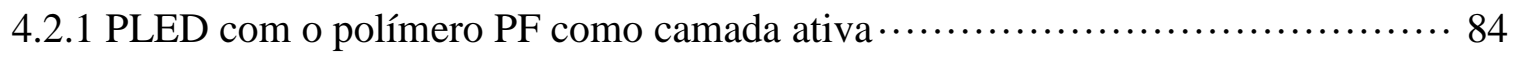

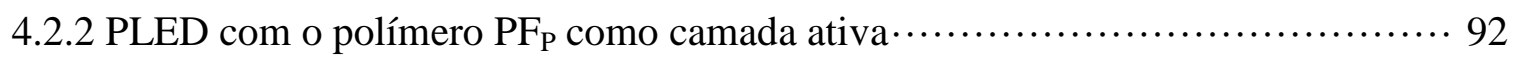

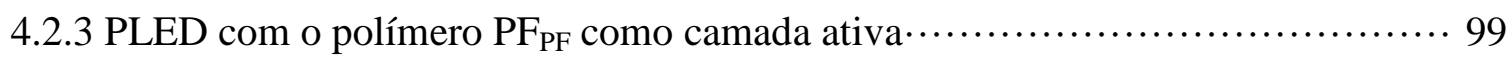

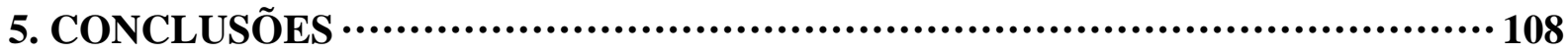

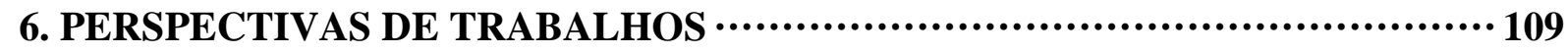

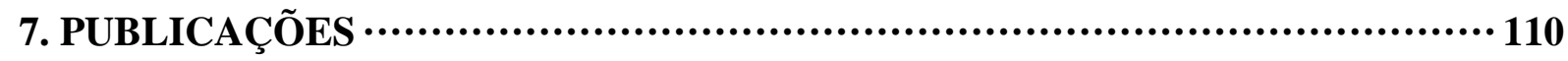

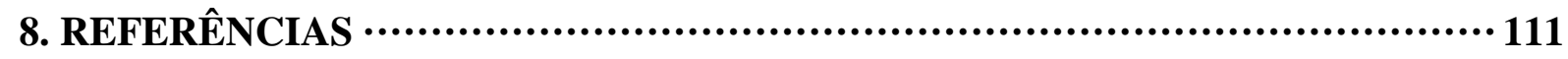




\section{INTRODUÇÃO}

As pesquisas com polímeros semicondutores aumentaram na década de 70, com a descoberta acidental do poliacetileno com propriedades elétricas, demonstrada por Shirakawa e $I k e d a^{1,2}$, que obtiveram um filme prateado ao invés de um pó com coloração preta, a partir de um erro na quantidade de catalisador. Em 1977, Shirakawa em colaboração com MacDiarmid e Heeger, verificou que através de uma dopagem do poliacetileno com iodo, a condutividade elétrica era significativamente superior, cerca de sete ordens de grandeza ${ }^{3,4}$.

Os polímeros semicondutores eram geralmente chamados de "metais sintéticos" por possuírem propriedades elétricas, magnéticas e ópticas de metais, mas o adequado seria chamá-los de polímeros conjugados, pois possuem cadeias com duplas ligações de carbono $(\mathrm{C}=\mathrm{C})$ conjugadas, ou seja, há uma alternância de ligações simples e duplas ao longo da cadeia, sendo que essa conjugação permite a criação de um fluxo de elétrons, tornando-os materiais com propriedades semicondutoras 5 .

Entre os campos de utilização destes polímeros conjugados, aparecem tecnologias de células solares $^{6,7}$, transistores ${ }^{8,9}$, emissores tipo laser $^{10,11}$, circuitos integrados poliméricos ${ }^{12} \mathrm{e}$ os P-OLEDs ${ }^{13,14}$ ("Polymer-Organic Light Emitting Diode" - Diodo Polimérico-Orgânico Emissor de Luz), que possuem vantagens em relação aos sistemas com base em semicondutores inorgânicos, devido às múltiplas possibilidades de estruturas químicas, à flexibilidade, leveza, e forma de montagem dos dispositivos, aliadas ao alto desempenho e menor custo de produção ${ }^{15}$. Porém existem alguns problemas tecnológicos, como a menor estabilidade química e tempo de vida útil quando comparados com materiais inorgânicos e organometálicos.

Com o crescente estudo relacionado aos polímeros conjugados, foi relatado pela primeira vez na década de 80 o fenômeno de eletroluminescência (EL) ${ }^{16}$ em dispositivos optoeletrônicos, conhecidos como P-OLEDs, que possuem como princípio básico de funcionamento, a recombinação de elétrons e lacunas, ocasionando uma emissão de luz em resposta à aplicação de corrente elétrica.

Existem muitos polímeros conjugados sendo empregados como materiais eletroluminescentes, principalmente poli(p-vinilenofenileno)s, poli(N-vinilcarbazol), poli(tiofeno)s e os poli(fluoreno)s. O polifluoreno é um polímero conjugado, cuja estrutura química está representada na Figura 1. Nessa estrutura, existe a possibilidade de substituição 
na posição 9 do anel central, que origina uma classe de polímeros que emite na região azul do espectro de radiação eletromagnética ${ }^{17,18}$.

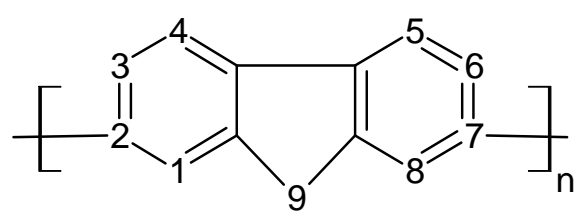

Figura 1 - Estrutura química do polifluoreno.

Os dispositivos (P-OLEDs) atualmente são montados com a presença de camadas transportadoras de lacunas (HTL - "hole transport layer") e com camadas transportadoras de elétrons (ETL - “electron transport layer"), formando uma estrutura multicamadas entre os eletrodos de ITO e alumínio (Al), com o polímero eletroluminescente situado entre ambos ${ }^{19}$. A evolução dessa tecnologia consiste na melhoria do tempo de vida útil desses dispositivos ${ }^{20}$, aprimorando tanto a síntese desses copolímeros eletroluminescentes, quanto o procedimento de montagem dos P-OLEDs.

\subsection{Objetivos}

O objetivo central do trabalho é estudar a síntese e caracterização, estrutural e fotofísica, dos polímeros eletroluminescentes desenvolvidos e a fabricação de P-OLEDs com a utilização destes polímeros como camada ativa e, consequentemente, avaliar os dados obtidos através de estudos comparativos entre os três tipos de polímeros sintetizados, o polifluoreno $(\mathrm{PF})$, o poli(fluoreno-fenileno) $\left(\mathrm{PF}_{\mathrm{P}}\right)$ e o poli(fluoreno-fenileno) fluorado $\left(\mathrm{PF}_{\mathrm{PF}}\right)$. Os polímeros foram sintetizados no Laboratório de Engenharia de Macromoléculas do Departamento de Engenharia Metalúrgica e de Materiais da Escola Politécnica da Universidade de São Paulo (USP). Para a fabricação dos P-OLEDs também foi utilizado o Laboratório do Grupo de Eletrônica Molecular (GEM) do Departamento de Engenharia de Sistemas Eletrônicos da Escola Politécnica da USP. 


\subsection{Descrição do Trabalho}

Este trabalho está dividido em oito capítulos que apresentam: introdução, revisão bibliográfica, desenvolvimento, resultados, conclusões, possibilidades de trabalhos futuros e as referências do tema desenvolvido durante o Mestrado.

A introdução apresentada no capítulo 1 discorre sobre a evolução técnico-científica de novos materiais e suas possíveis aplicações.

No capítulo 2, a revisão da literatura aborda os conceitos relacionados aos polímeros conjugados, assim como os fenômenos de fluorescência e eletroluminescência. Em seguida, são apresentadas as reações mais utilizadas na síntese desses polímeros e as características da molécula do composto contendo a unidade fluoreno, utilizada como molécula base em todas as sínteses realizadas.

O capítulo 3 descreve as técnicas de caracterização dos materiais produzidos e os processos envolvidos na fabricação dos P-OLEDs.

Os resultados obtidos estão descritos no capítulo 4 e as conclusões principais são apresentadas no capítulo 5.

No capítulo 6, possibilidades de trabalhos futuros são sugeridas pelo autor, já no capítulo 7 estão listadas as publicações realizadas durante este trabalho e a dissertação finaliza com as referências listadas no capítulo 8 . 


\section{REVISÃO BIBLIOGRÁFICA}

\subsection{Polímeros Semicondutores}

Os polímeros eram utilizados como materiais isolantes elétricos, até a década de 1970, porém a partir da descoberta de polímeros com propriedades semicondutoras, iniciou-se o desenvolvimento dessa nova classe de polímeros, chamada de polímeros conjugados. Os polímeros conjugados apresentam em sua cadeia principal, alternância de ligações simples $(\sigma)$ e ligações duplas $(\sigma+\pi)$, sendo que as ligações $\pi$ são responsáveis pelas propriedades elétricas e as ligações $\sigma$, principalmente, pelas propriedades mecânicas da macromolécula ${ }^{21}$.

O polímero conjugado mais simples é o poliacetileno, e sua forma estrutural trans, assim como sua estrutura em ressonância estão ilustradas na Figura 2.

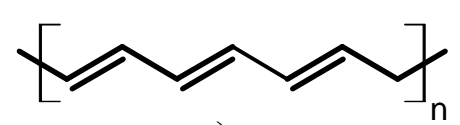

a)

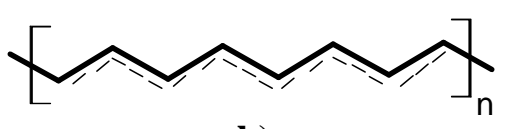

b)

Figura 2 - Estrutura do poliacetileno: a) estrutura trans; b) estrutura de ressonância.

A formação de múltiplas ligações resulta na redução física do espaço entre os átomos de carbono, ou seja, a ligação dupla é mais curta que uma ligação simples, assim sendo os elétrons das ligações $\pi$ são menos estáveis do que os das ligações $\sigma$, porém essa proximidade dos átomos permite a formação de nuvens eletrônicas ao seu redor, conferindo a esses compostos um comportamento eletrônico de caráter semicondutor ${ }^{22}$.

$\mathrm{Na}$ Figura 3, além do poliacetileno, estão apresentados os nomes e as fórmulas estruturais de alguns polímeros conjugados mais estudados ${ }^{23}$. 


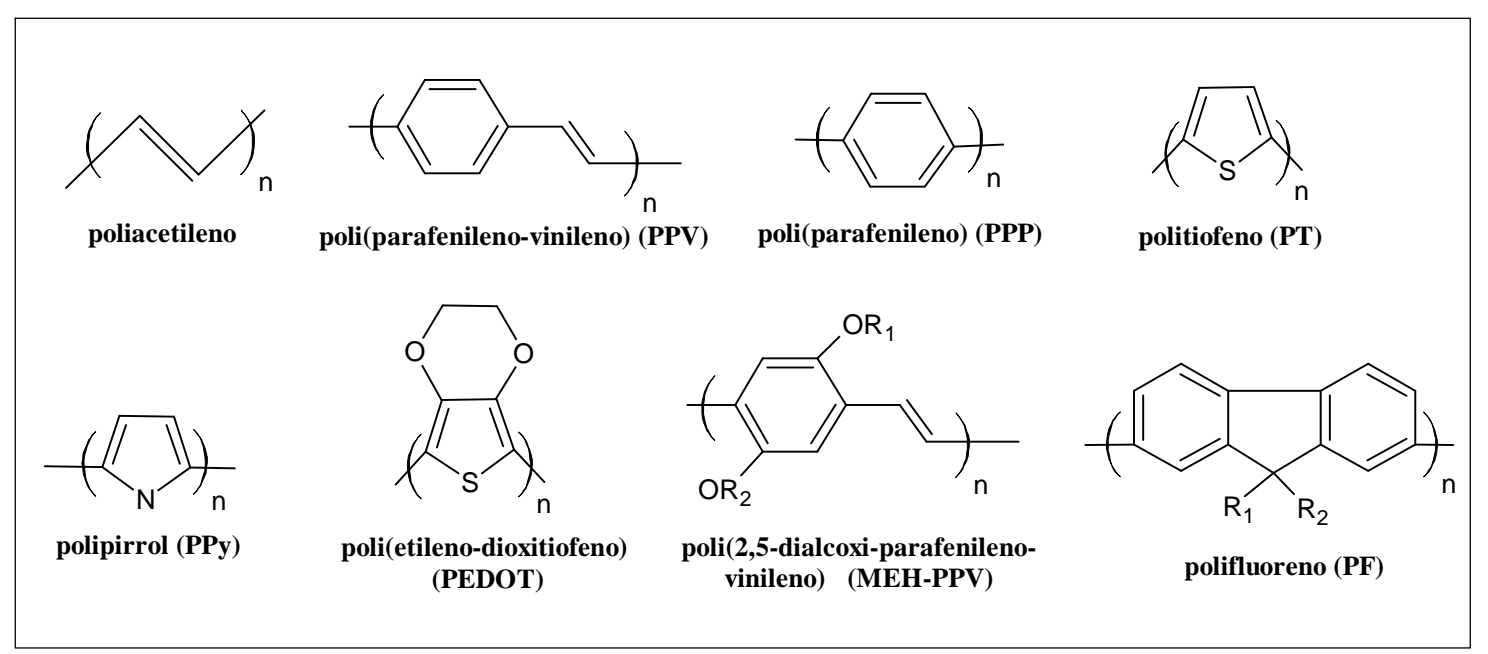

Figura 3 - Estrutura de alguns tipos de polímeros conjugados.

\subsubsection{Estrutura e propriedades eletrônicas}

Nos materiais orgânicos, as moléculas possuem estruturas, cujo elemento principal é o carbono. $\mathrm{O}$ átomo de carbono possui quatro elétrons na camada de valência, sendo que dois ocupam o orbital $s$ e os outros o orbital $p$. Como o carbono possui a capacidade de hibridizar (hibridar) seus orbitais, isso permite que se formem ligações simples, duplas ou triplas com outros átomos. Assim sendo, três tipos de hibridização são possíveis: $s p, s p^{2}$ e $s p^{3}$, que respectivamente, são responsáveis pelas ligações tripla, dupla e simples ${ }^{24}$.

Em sistemas conjugados, a hibridização apresentada é do tipo $s p^{2}$, onde a configuração final é dada por três orbitais $s p^{2}$ coplanares (plano xy), com ângulo de $120^{\circ}$ entre si e um orbital $\mathrm{p}_{\mathrm{z}}$ perpendicular a este plano. As ligações carbono-carbono podem ocorrer pela sobreposição entre orbitais $s p^{2}$ (ligações $\sigma$ ) e pela sobreposição de orbitais $p_{z}$ (ligação $\pi$ ), conforme apresentado na Figura 4. 


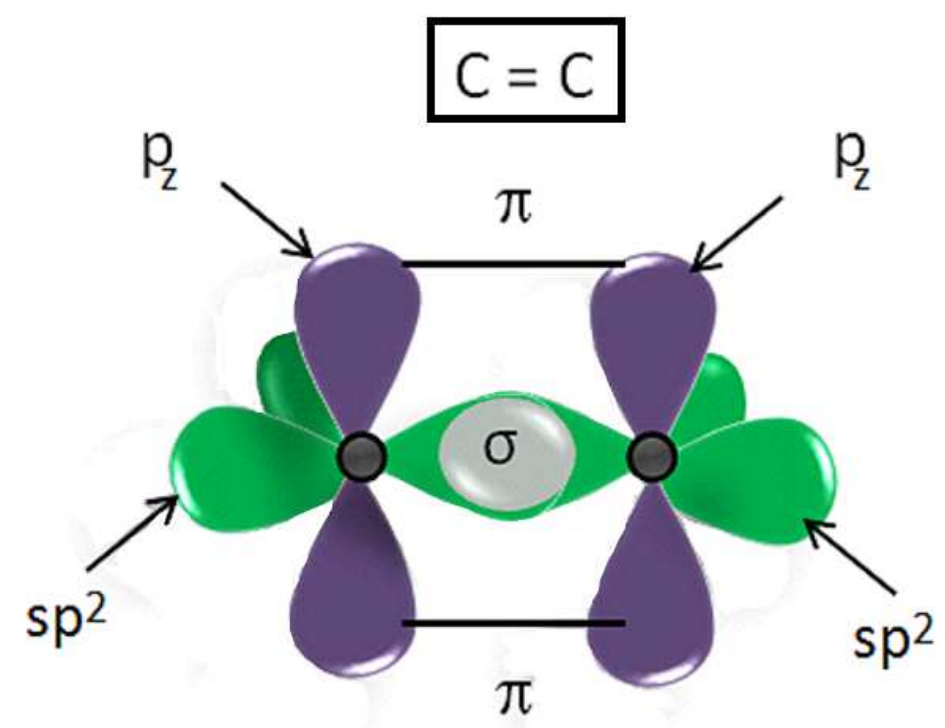

Figura 4 - Representação dos orbitais híbridos $s p^{2}$ (ligação $\sigma$ ) e orbitais $p_{z}$ (ligação $\pi$ ).

A sobreposição desses orbitais $\mathrm{p}_{z}$ gera deslocalização das ligações $\pi$, estendendo-se ao longo da cadeia polimérica, formando ligações simples e duplas em alternância, chamado de sistema $\pi$-conjugado deslocalizado ${ }^{25,26}$.

A disposição eletrônica na hibridização $\mathrm{sp}^{2}$, em comparação com seu estado fundamental está apresentada na Figura 5, onde no estado híbrido, os elétrons passam a ocupar um estado intermediário aos orbitais s e $\mathrm{p}$, nomeado de $\mathrm{sp}^{2}$.
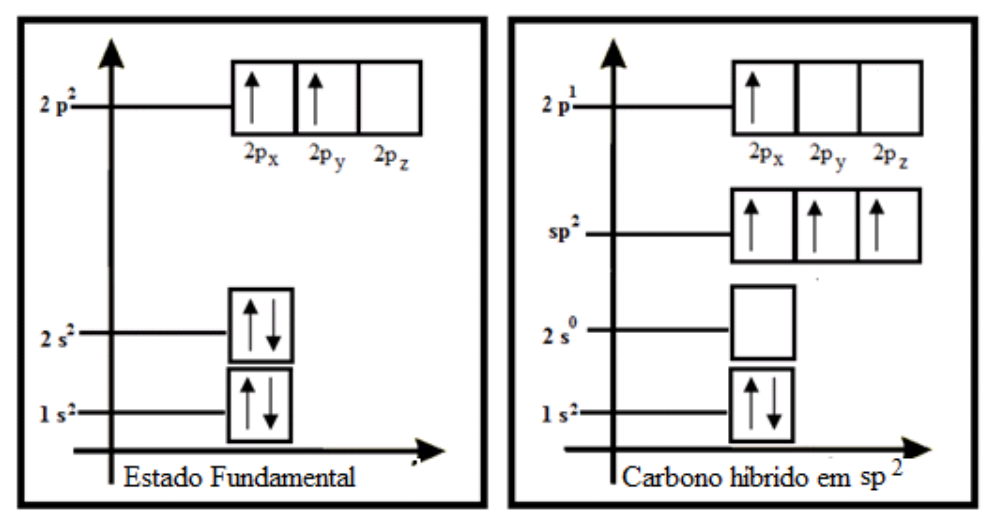

Figura 5 - Disposição eletrônica na hibridização $\mathrm{sp}^{2}$. 


\subsubsection{Rotas sintéticas para a obtenção de polímeros conjugados}

Os tipos mais comuns de rotas sintéticas de acoplamento entre carbonos para a produção de polímeros conjugados emissores de luz, são: reações de acoplamento de Suzuki e reações de Yamamoto.

Nas reações de acoplamento de $S u z u k i^{27,28}$ e de Yamamoto $^{29}$, a polimerização ocorre pelo acoplamento de carbonos aromáticos na presença de um catalisador. Na reação de acoplamento de Suzuki, ocorre entre uma arila boronada e uma arila halogenada, na presença de um catalisador à base de paládio $(\mathrm{Pd})$, e na reação de Yamamoto, ocorre entre duas arilas halogenadas na presença de um catalisador a base de níquel (Ni). Na Figura 6 estão ilustradas as duas rotas.

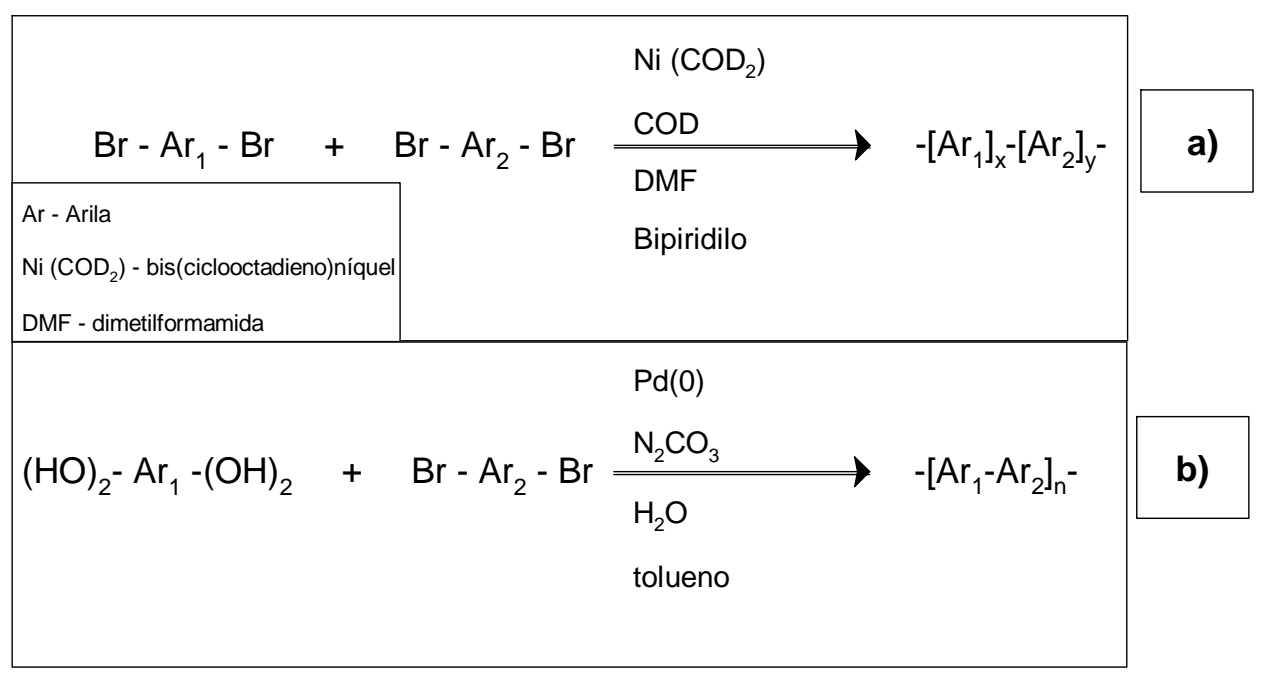

Figura 6 - a) Rota de acoplamento de Yamamoto e b) Rota de acoplamento de Suzuki.

\subsubsection{Reação de acoplamento de Suzuki}

A reação de acoplamento de $S u z u k i^{27,28}$ ocorre na presença de um catalisador à base de paládio, como forma de obter ligações entre carbonos, promovendo o acoplamento entre grupos organo-boronados e organo-halogenados. Se as arilas halogenadas e boronadas forem iguais, o acoplamento fornecerá um homopolímero, e, se forem diferentes, o copolímero obtido será perfeitamente alternado (Figura 7). As vantagens deste tipo de reação são: não ser 
afetada pela presença de água, tolerância a grupos funcionais, apresenta régio e estereosseletividade e seus subprodutos da reação são facilmente removidos.

$\mathrm{Ar}-\mathrm{X} \quad \mathrm{Ar}-\mathrm{B}(\mathrm{OH})_{2} \longrightarrow \mathrm{Ar}-\mathrm{Ar}^{\prime}$
$\mathrm{Ar}, \mathrm{Ar}$ - Arilas
$\mathrm{X}$ - Halogênio

Figura 7 - Esquema de acoplamento entre duas arilas (Ar - Ar') por reação de acoplamento Suzuki.

A Figura 8 esquematiza como ocorre o processo de acoplamento entre as arilas na presença de um catalisador à base de paládio. Primeiramente, o complexo de paládio sofre oxidação e ocorre o acoplamento com a sua inserção entre a arila e o halogênio ( $\mathrm{Ar}-\mathrm{Pd}(\mathrm{II})$ $\mathrm{X}$ ), em seguida com uma solução básica, o halogênio é substituído por uma hidroxila que irá reagir com o composto boronado de outra arila formando o composto $\mathrm{B}(\mathrm{OH})_{4}$, liberando assim essa outra arila que se unirá ao paládio formando a estrutura (Ar'- Pd(II) - Ar), e, para finalizar o processo, o complexo de paládio sofre redução e é eliminado, liberando as arilas (Ar' - Ar) acopladas.

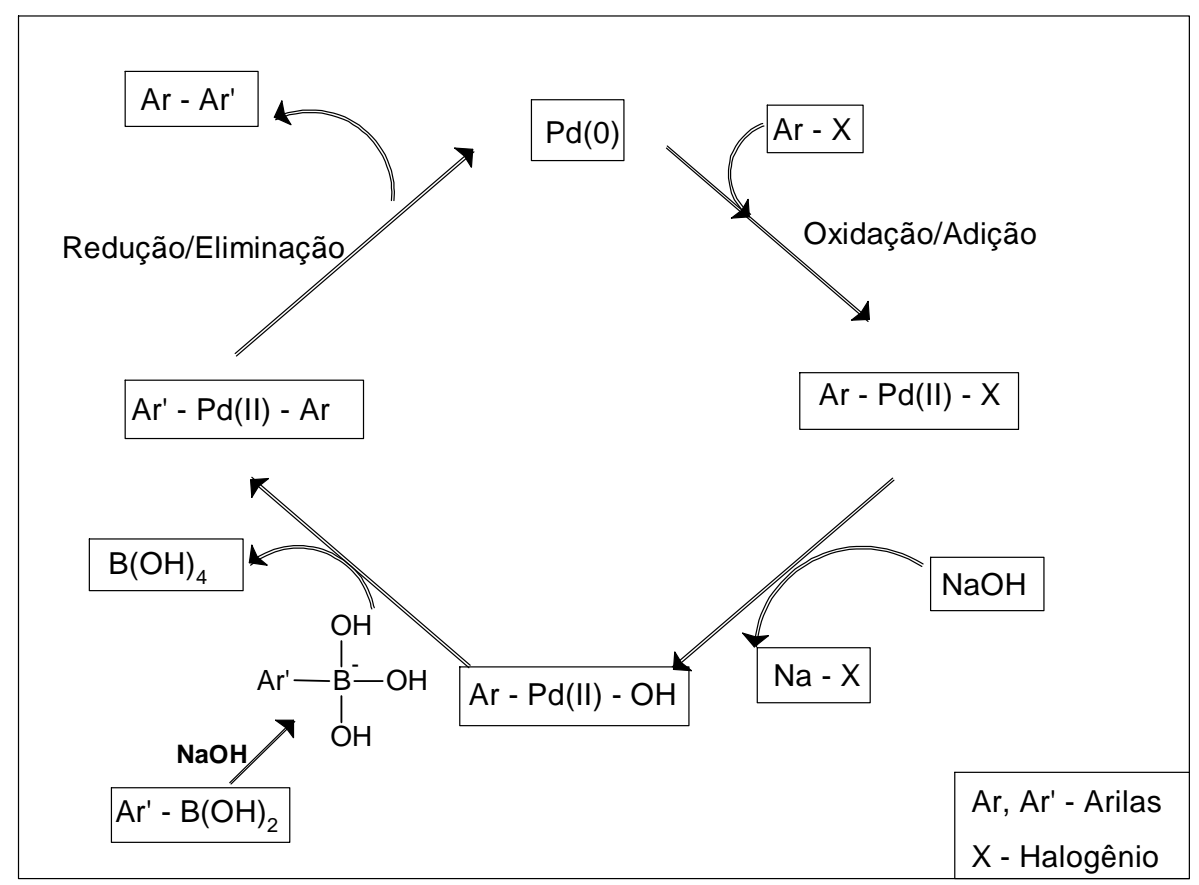

Figura 8 - Esquema de acoplamento entre arilas halogenadas e boronadas por reação de $S u z u k i^{27,28}$. 
Essa síntese de acoplamento de Suzuki está sendo frequentemente estudada para a formação de novos polímeros conjugados ${ }^{30,31}$.

\subsubsection{Polímeros emissores de luz}

As diferentes formas de emissão de luz são chamadas de luminescência, exceto as emissões geradas pelo aquecimento do material, denominada incandescência ${ }^{32}$. Assim, os tipos de fontes de energia determinam os diferentes tipos de luminescência, como por exemplo, a eletroluminescência (EL), que é produzida pela passagem de uma corrente elétrica $^{33}$, e a fotoluminescência (PL) é gerada pela absorção de luz na região espectral entre o ultravioleta e o infravermelho.

\subsubsection{Polímeros contendo grupos fluoreno}

A utilização de polímeros derivado do fluoreno, na construção e no desenvolvimento de dispositivos eletroluminescentes, deve-se ao fato de poderem ser sintentizados com inúmeras estruturas e apresentarem grande variedade na emissão de cores, porém emitindo especialmente na região azul do espectro de radiação eletromagnética, além de apresentarem alto rendimento quântico, e estabilidades química, térmica e oxidativa ${ }^{34,35}$.

Na Figura 9 está ilustrada a estrutura química do fluoreno e sua numeração de acordo com a IUPAC, onde o carbono-9 possui uma configuração que torna possível a substituição dos átomos de hidrogênio por grupos de radicais orgânicos que não afetam significativamente as interações eletrônicas entre os anéis aromáticos, e conferem maior solubilidade em solventes orgânicos e impedem ataques oxidativos ${ }^{36,37}$. Além disso, as reações de substituição eletrofílica aromática ocorrem somente nas posições 2 e 7 , facilitando o controle do crescimento da cadeia. 
<smiles></smiles>

Figura 9 - Estrutura química do fluoreno (numeração de acordo com a IUPAC).

\subsubsection{Fotofísica dos polímeros emissores de luz}

\subsubsection{Princípios de absorção de energia}

As transições eletrônicas ocorrem quando uma molécula é excitada através da absorção de um fóton, e resulta na promoção de um elétron de um orbital molecular de menor energia para um de maior energia, através de transições eletrônicas e processos fotofísicos baseados no Princípio de Frank-Condon, onde as configurações nucleares do estado excitado devem ser idênticas àquelas do estado fundamental ${ }^{38,39}$. Na Figura 10, temos dois exemplos de transições eletrônicas com diferentes probabilidades por conta do Princípio de FrankCondon, onde a transição denominada A tem baixa probabilidade, pois está passando de uma probabilidade máxima, na função de onda vibracional do estado fundamental, para uma probabilidade mínima, na função de onda vibracional do estado excitado. A transição denominada $\mathrm{B}$ tem maior probabilidade, porque envolve duas vibrações com probabilidades semelhantes ${ }^{39}$. 


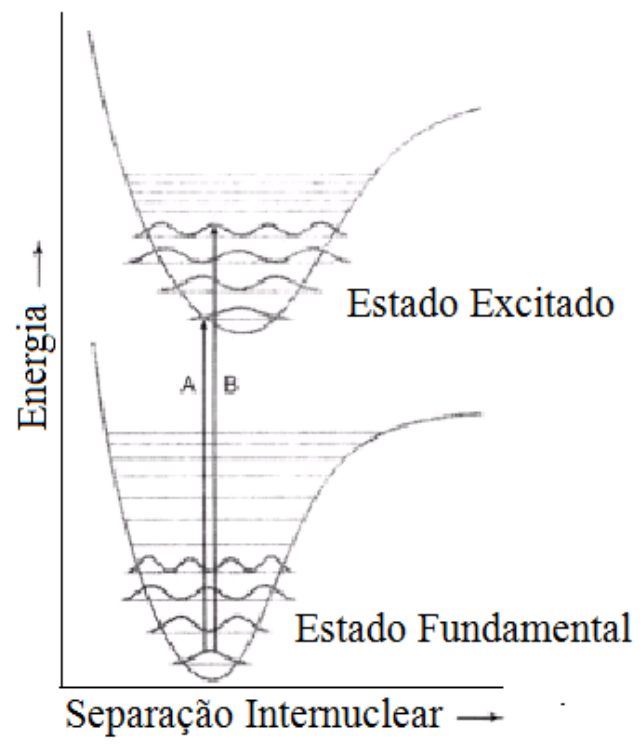

Figura 10 - Dois Exemplos de transições eletrônicas que tem diferentes probabilidades pelo Princípio de FranckCondon.

Na Figura 11, são apresentadas as possíveis transições eletrônicas entre os diferentes orbitais moleculares com a comparação entre as energias necessária para cada uma. Essas transições ocorrem com diferentes intensidades de energia, chamadas regras de seleção ${ }^{39,40,41}$.

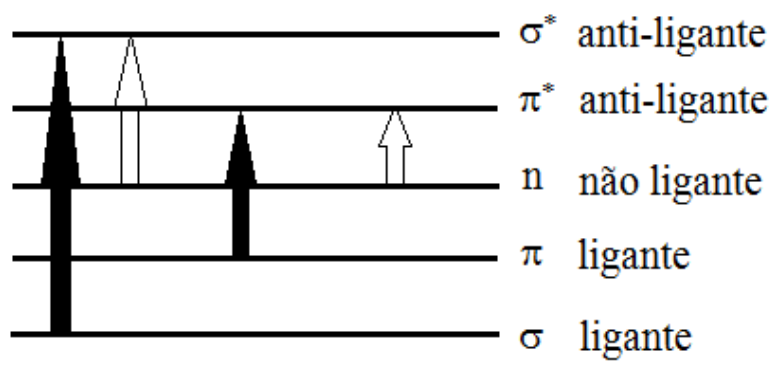

Figura 11 - Diagrama de energia dos orbitais moleculares e suas possíveis transições.

As regras de seleção foram determinadas a partir da conservação de momento angular, a qual considera que o fóton é uma onda eletromagnética, possuindo uma componente magnética e uma elétrica. Para haver interação entre a molécula e o campo elétrico do fóton, é necessário que exista um estado no qual os estados, fundamental e excitado, possuindo diferentes simetrias, formem um dipolo. Quanto maior a força deste dipolo, mais intensa a transição de dipolo elétrico, tornando-a mais permitida ${ }^{42}$. 
Também há uma ampla faixa de intensidades para as bandas num espectro de absorção. Isso ocorre porque as transições eletrônicas, correspondentes às bandas de absorção, têm probabilidades diferentes de ocorrência, ou seja, uma banda intensa está associada a uma transição de alta probabilidade (permitida), já uma banda fraca está associada com uma transição de baixa probabilidade (proibida) ${ }^{43}$.

Em moléculas complexas, como a dos polímeros conjugados, a absorção resulta em transições entre níveis rotacionais muito próximos, sendo difícil identificá-los espectroscopicamente, por isso as transições são observadas como uma banda de absorção $\operatorname{larga}{ }^{43}$.

\subsubsection{Dissipação de Energia}

A maioria das moléculas, à temperatura ambiente, está no nível vibracional mais baixo do seu estado eletrônico fundamental, e a partir da absorção de energia, podem ser excitadas a estados mais energéticos, sendo que esse estado excitado não se encontrará em equilíbrio com a sua redondeza, e terá um tempo de vida curto, devido ao grande número de processos químicos (formação de radicais livres, rearranjo intramolecular, eliminação) e físicos (conversão para energia térmica, transferência de energia, dissipação de energia) possíveis, que podem contribuir para seu retorno ao estado fundamental ${ }^{44}$. A maioria destes processos de desativação ocorrerá sem emissão de fóton.

Os estados fundamentais da maioria das moléculas são singletos, que spins eletrônicos emparelhados, após a excitação da molécula pela absorção de um fóton, a energia absorvida é suficiente para produzir um estado rotacional, vibracional, translacional e eletronicamente excitado. O modo de dissipação de energia dos estados excitados é dado pelo Diagrama de Jablonski (Figura 12). 


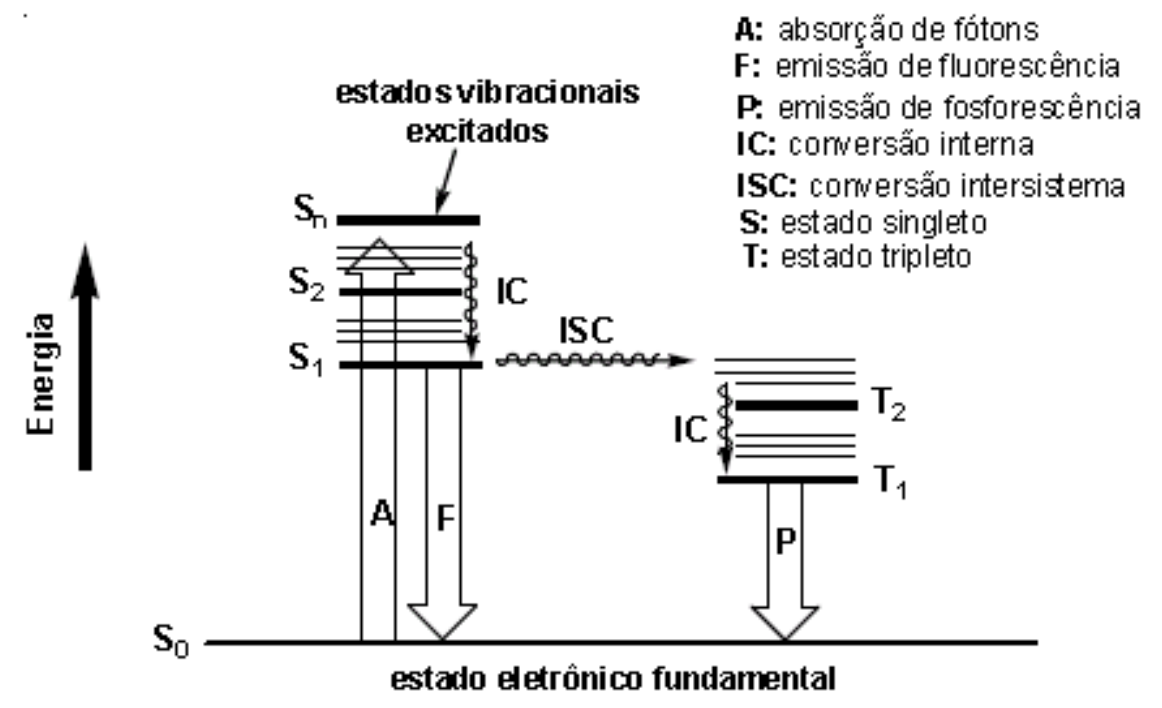

Figura 12 - Diagrama de Jablonski.

De modo geral, as conversões entre estados de multiplicidade idêntica são as conversões internas (IC - Internal Convertion) e, as conversões que ocorrem entre estados de multiplicidade diferente são os cruzamentos intersistema (ISC - Intersystem Crossing), esses dois processos (IC e ISC) são similares porque envolvem a conversão de energia eletrônica em vibracional, sem emissão de fóton, por isso denominado fenômenos não-radiativos de dissipação de energia ${ }^{38}$.

Os fenômenos resultantes dos decaimentos radiativos apresentados se diferem quanto aos estados vibracionais, excitado e fundamental, isto é, se o estado excitado for idêntico ao seu fundamental [Singleto $\left(S_{1}\right)$ - Singleto $\left(S_{0}\right)$ ], o decaimento radiativo será chamado de fluorescência $(F)$, porém se os estados vibracionais forem diferentes [Tripleto (T1) - Singleto $\left(\mathrm{S}_{0}\right)$ ], o decaimento radiativo será chamado de fosforescência ${ }^{42}$.

\subsection{Diodos Poliméricos-Orgânicos Emissores de luz (P-OLEDs)}

A arquitetura de um P-OLED, mostrada na Figura 13, consiste em um filme polimérico emissor depositado entre um ânodo transparente (ITO) e um cátodo metálico (Al), acoplado a uma fonte de energia ${ }^{55}$. 


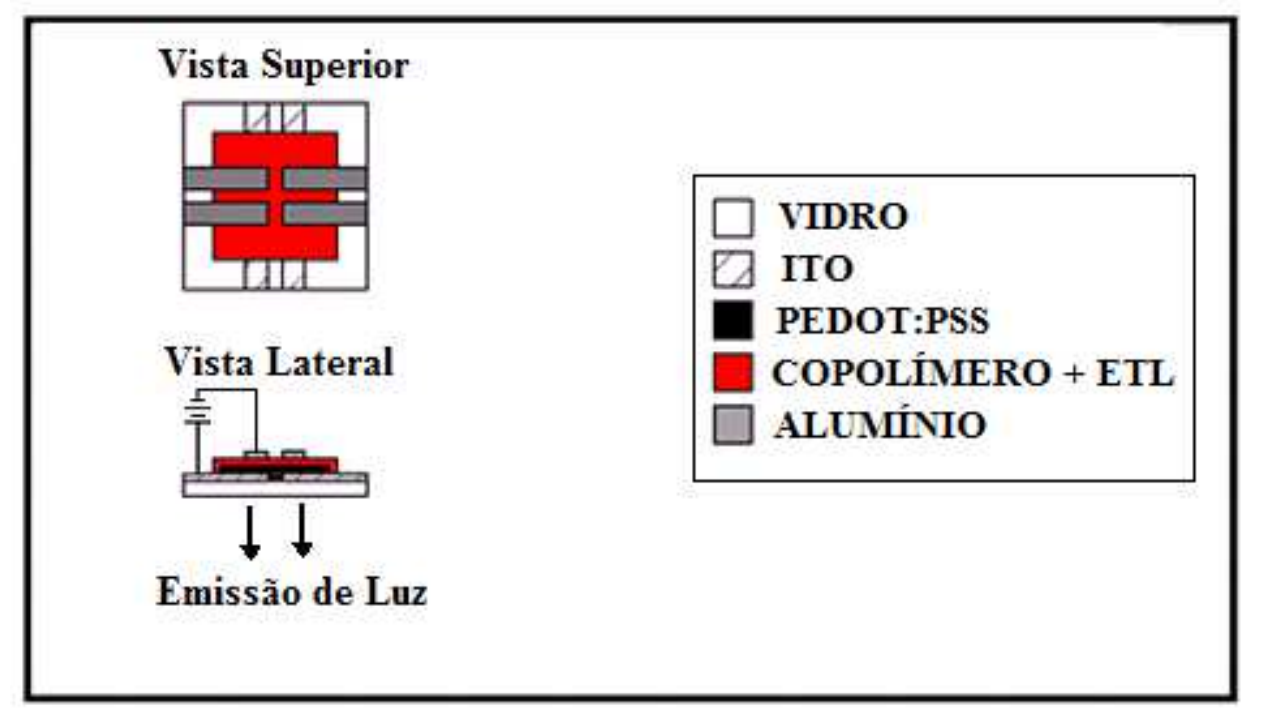

Figura 13 - Arquitetura básica de um P-OLED.

O ânodo é constituído por uma camada transparente de óxido de índio e estanho (ITO - Indium Tin Oxide), depositada em um subtrato rígido (vidro). As camadas de HTL (hole transport layer - camada transportadora de buracos), de polímero emissor com ETL (eléctron transport layer - camada transportadora de elétrons) são depositadas sequencialmente. Finalmente o cátodo, constituído de um filme metálico de alumínio, é depositado por sublimação a vácuo sobre a camada polimérica ${ }^{45,46}$.

O processo de operação de um P-OLED possui três etapas: injeção, transporte e recombinação de cargas $^{47}$.

Os P-OLEDs operam mediante uma aplicação de um campo elétrico, onde o cátodo injeta elétrons e o ânodo injeta buracos no polímero, essas cargas se movimentam dentro do polímero eletroluminescente até se encontrarem, ocorrendo recombinação, que pode originar decaimento radiativo, com emissão de um fóton ${ }^{48}$.

Para garantir o melhor desempenho destes dispositivos é necessário ter um balanço de corrente de elétrons e buracos. Para isso, são utilizadas camadas HTL, entre o ITO e o polímero, e ETL, dissolvido no polímero emissor.

O polímero mais utilizado como HTL é o PEDOT:PSS [poli(3,4-etilenodioxitiofeno) dopado com poli(4-sulfonato de estireno)], que está mostrado na Figura 14. 


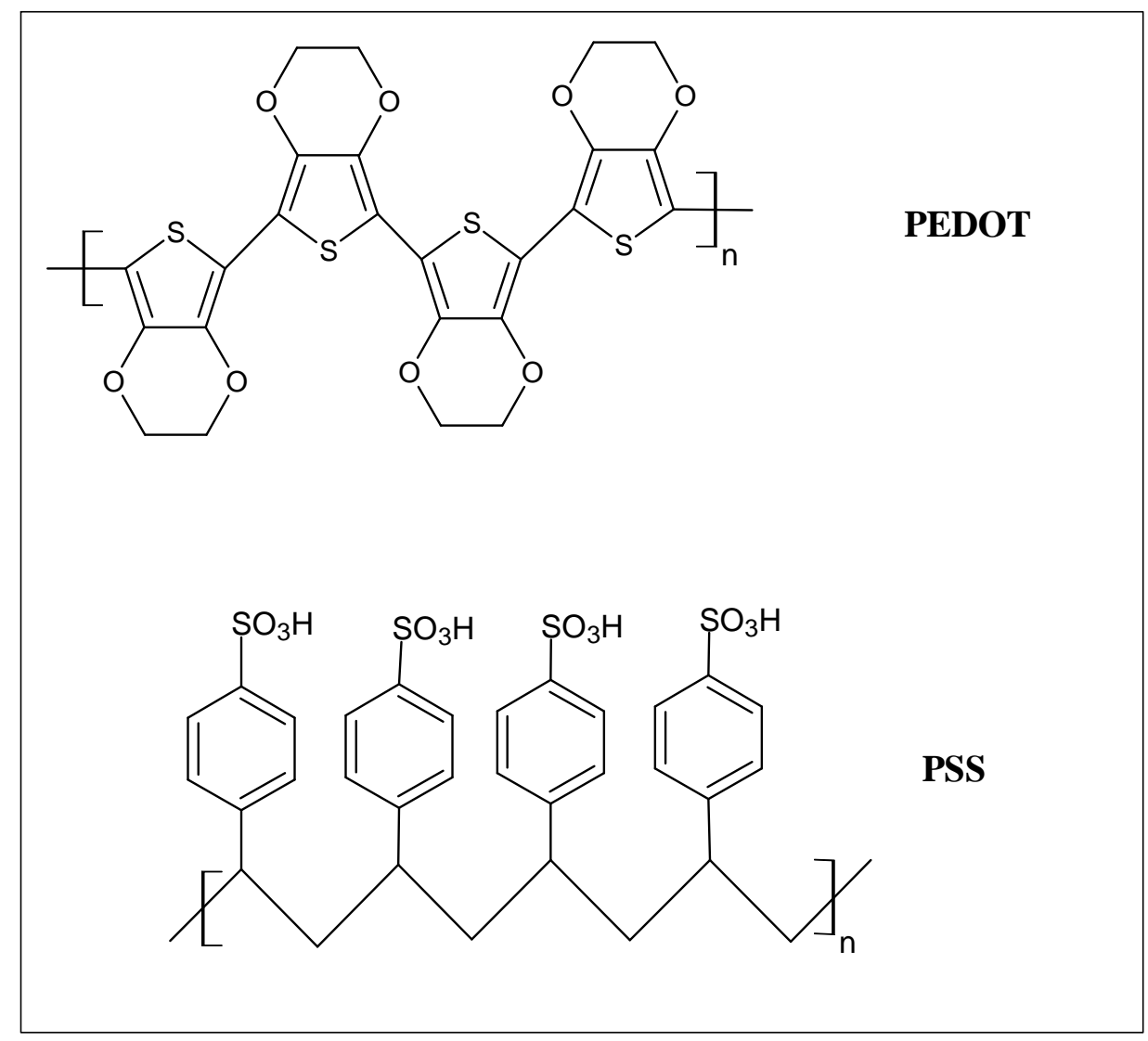

Figura 14 - Estrutura química do poli(3,4-etilenodioxitiofeno) : poli(4-sulfonato de estireno), PEDOT:PSS.

O PEDOT:PSS é uma blenda polimérica, dispersa em água e apresenta uma alta função trabalho, que facilita a injeção de buracos.

Para promover um maior balanceamento de cargas, também pode ser depositada entre o cátodo e o polímero emissor uma camada ETL, aumentando a probabilidade de recombinações elétron-lacuna, melhorando assim a eficiência luminosa. Os polímeros mais utilizados como ETL são: o tris-8-hydroxyquinoline aluminum $\left(\mathrm{Alq}_{3}\right)$ e o 2-(4-tertbutylphenyl)-5-(4-diphenyl)-1,3,4-oxadiazole (butyl-PBD), cujas estruturas químicas estão apresentadas na Figura 15. 


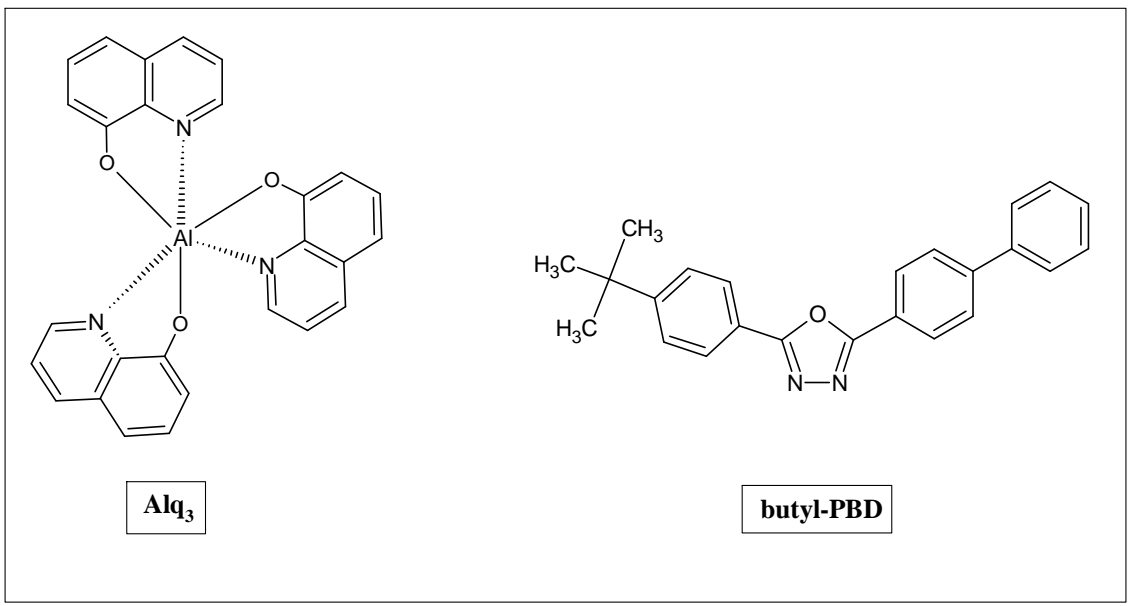

Figura 15 - Estruturas químicas do $\mathrm{Alq}_{3}$ e do butyl-PBD.

Neste trabalho, os compostos ETL não foram depositados como camadas independentes observadas em P-OLED convencional, mas dissolvidos na solução do polímero emissor. 


\section{MATERIAIS E MÉTODOS}

Neste capítulo serão apresentados os materiais, equipamentos e procedimentos utilizados neste trabalho, assim como as etapas de síntese dos polímeros eletroluminescentes, as etapas para fabricação dos P-OLEDs e as técnicas de caracterização, tanto dos polímeros, quanto dos dispositivos fabricados.

\subsection{Reagentes, solventes e materiais dos P-OLEDs}

Os reagentes utilizados, obtidos de fonte comercial sem tratamento prévio, foram os seguintes:

- 9,9-Dioctil-2,7-dibromofluoreno (Sigma-Aldrich, 99\%)

- 9,9 -Dioctilfluoreno-2,7-ácido diborônico (Sigma-Aldrich)

- 1,4-Dibromobenzeno (Sigma-Aldrich)

- 1,4-Dibromo-2-fluorobenzeno (Sigma-Aldrich)

- 1,4-Benzeno-ácido diborônico (Sigma-Aldrich)

- Acetona grau P.A. (Casa Americana)

- Ácido fenilborônico (Sigma-Aldrich, 97\%)

- Água destilada

- Aliquat 336 (Sigma-Aldrich)

- Alq3 (Sigma-Aldrich)

- Carbonato de potássio $\left(\mathrm{K}_{2} \mathrm{CO}_{3}\right)$ - (Casa Americana)

- Tetrakis(trifenilfosfina) paládio (Sigma-Aldrich)

- Cola condutiva de prata

- Clorofórmio grau P.A. (Casa Americana)

- Clorofórmio grau espectrométrico (Tedia)

- Clorofórmio deuterado (Merck, 99,8\%)

- Diclorometano grau P.A. (Casa Americana)

- Metanol grau P.A. (Casa Americana) 
- PEDOT: PSS (Sigma-Aldrich)

- Peróxido de hidrogênio $35 \%$ grau P.A.(Casa Americana)

- Tolueno grau P.A. (Casa Americana)

- $\mathrm{THF}$ - Tetra-hidrofurano grau P.A. (Casa Americana)

- Vidro com ITO com resistência de folha de aproximadamente $15 \Omega / \mathrm{cm}^{2}$ (Displaytech)

\subsection{Equipamentos}

Nesta seção são descritos os equipamentos utilizados neste trabalho e as condições experimentais usadas em cada um deles.

- Analisador térmico simultâneo (TGA, DSC, DTA): STA 449 F3 Jupiter Equipamento com dois fornos $\left(-150{ }^{\circ} \mathrm{C}\right.$ a $1000{ }^{\circ} \mathrm{C}$ e temperatura ambiente a $\left.1550{ }^{\circ} \mathrm{C}\right)$ - Netzsch;

- Calorímetro diferencial exploratório (DSC) - Equipamento DSC 200 F3 Maia (-170 ${ }^{\circ} \mathrm{C}$ a $600{ }^{\circ} \mathrm{C}$ ) com sistema de resfriamento com nitrogênio líquido - Netzsch;

- Câmara "Glove-box": Os reagentes da síntese forma adicionados em atmosfera de nitrogênio $\left(\mathrm{N}_{2}\right)$ com umidade relativa de aproximadamente $20 \%$;

- Cromatógrafo de permeação em gel (GPC): Agilent 1100 com colunas de GPC PLgel mixed C e PLgel mixed B em série, do Instituto de Física de São Carlos (IFSC-USP);

- Difratômetro de raios-X (XRD): X'Pert da Phillips, do LCT do Departamento de Engenharia de Minas e de Petróleo da USP;

- Espectrofotômetro ultravioleta-visível (UV-vis): Varian, modelo Cary 50 Conc;

- Espectrofotômetro de fluorescência: Varian, modelo Eclipse; 
- Espectrofotômetro de infravermelho (IR): Bruker, modelo Vector 22;

- Espectrômetro de ressonância magnética nuclear (RMN): Bruker DPX-300, (300 MHz) da Central Analítica do Instituto de Química da USP.

- Espectroradiômetros: - Ocean Optics,modelo HR 2000+;

- Luzchem, modelo SPR-03;

- Evaporador rotativo: Quimis

- Evaporadora: foi utilizada a evaporadora acoplada a glove-box (montada pela Prestvácuo) do LME (Laboratório de Microeletrônica), do Departamento de Engenharia de Sistemas Eletrônicos da Escola Politécnica da USP;

- Medidor de cor e luminância (Colorímetro): modelo SC100A da Konica-Minolta, do LME, do Departamento de Engenharia de Sistemas Eletrônicos da Escola Politécnica da USP;

- Microscópio eletrônico de varredura (MEV), modelo XL-30 da Phillips;

- Traçador de curvas tensão vs. corrente, Testtech;

- "Spin-coater": Aparato montado a partir de um motor de disco rígido (HD) e componente;

\subsection{Procedimentos}

Esta seção, parte experimental, foi dividida da seguinte forma: síntese e caracterização dos copolímeros, fabricação e caracterização óptica e elétrica dos P-OLEDs. 


\subsubsection{Síntese dos copolímeros emissores de luz}

Na Figura 16 estão apresentadas as estruturas moleculares dos monômeros envolvidos nas sínteses realizadas:

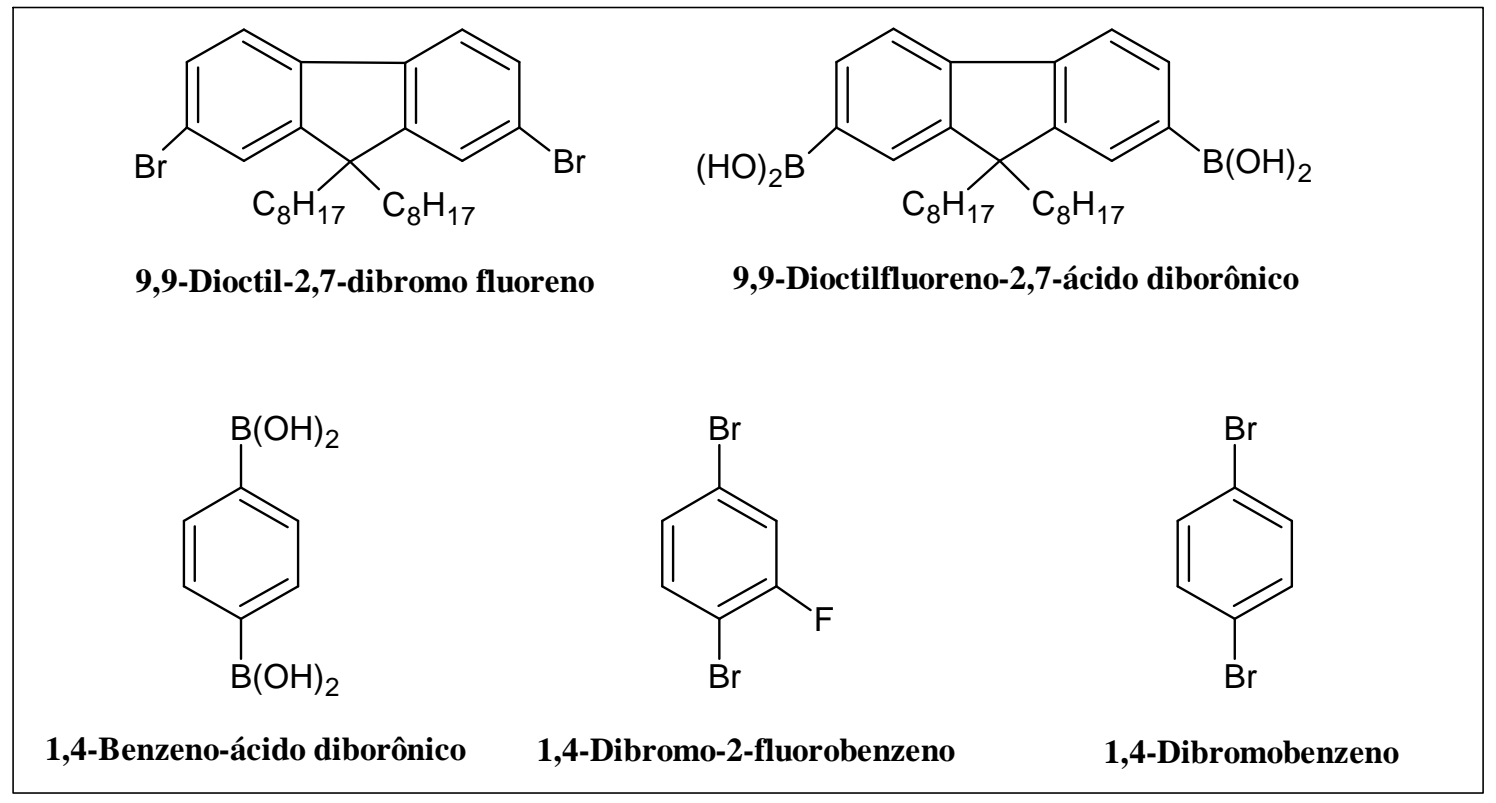

Figura 16 - Estrutura química dos monômeros utilizados nas sínteses.

A partir destes reagentes foram realizadas sínteses através da reação de Suzuki, entre grupos boronados e grupos halogenados ligados a compostos aromáticos difuncionais. As sínteses realizadas foram:

- Síntese 1 - Preparação de poli[2,7-(9,9-dioctilfluoreno)] (PF, Polifluoreno);

- Síntese 2 e 3 - Preparação de poli[1,4-fenileno-alt-2,7-(9,9-dioctilfluoreno)] $\left[P F_{P}\right.$, Poli(fluoreno-fenileno)] utilizando dois procedimentos distintos;

- Síntese 4 - Preparação de poli[(1,4-fenileno-2-flúor)-alt-2,7-(9,9-dioctilfluoreno)] $\left[P F_{P F}\right.$, Poli(fluoreno-fenileno) fluorado]. 
A Tabela 1 mostra a massa molar $(\mathrm{g} / \mathrm{mol})$ dos monômeros e as massas utilizadas na formação dos copolímeros (relação $1 \mathrm{mmol}$ ).

Tabela 1 - Massas molares e massas utilizadas nas sínteses dos copolímeros.

\begin{tabular}{|c|c|c|c|c|c|}
\cline { 3 - 6 } Monômeros & Massa Molar & $\mathbf{P F}$ & \multicolumn{2}{|c|}{$\mathbf{P F}_{\mathbf{F}}$} & $\mathbf{P F}_{\mathbf{P F}}$ \\
\hline $\mathbf{g} / \mathbf{m o l})$ & $\mathbf{1}(\mathbf{g})$ & $\mathbf{2}(\mathbf{g})$ & $\mathbf{3}(\mathbf{g})$ & $\mathbf{4}(\mathbf{g})$ \\
\hline $\begin{array}{c}\text { 9,9-Dioctilfluoreno-2,7-ácido } \\
\text { diborônico }\end{array}$ & 478,28 & 0,478 & ------- & 0,478 & 0,478 \\
\hline $\begin{array}{c}\text { 9,9-Dioctil-2,7- } \\
\text { dibromofluoreno }\end{array}$ & 528,44 & 0,548 & 0,548 & --------- & ---------- \\
\hline $\begin{array}{c}\text { 1,4-Dibromobenzeno } \\
\text { 1,4-Benzeno-ácido } \\
\text { diborônico }\end{array}$ & 235,86 & --------- & ------- & 0,235 & ---------- \\
\hline $\begin{array}{c}\text { 1,4-Dibromo-2- } \\
\text { fluorobenzeno }\end{array}$ & 165,4 & -------- & 0,165 & --------- & --------- \\
\hline
\end{tabular}

O mesmo procedimento foi utilizado para a realização das sínteses dos copolímeros. Inicialmente, na câmara "glove-box" foi injetado gás nitrogênio, para manter o ambiente inerte e com uma umidade relativa interna, inferior a $20 \%$. Assim, todos os reagentes foram adicionados dentro de um balão de duas bocas (em uma das bocas foi acoplado o condensador e na outra uma tampa de borracha natural), juntamente com uma barra magnética, para manter a reação sempre sob agitação. O balão contendo os reagentes pesados foi levado para o banho de silicone, que já estava sobre uma placa de agitação magnética e aquecimento a $70-75^{\circ} \mathrm{C}$. A Figura 17 mostra a câmara Glove-Box e aparelhagem utilizada para a realização da síntese dos copolímeros.

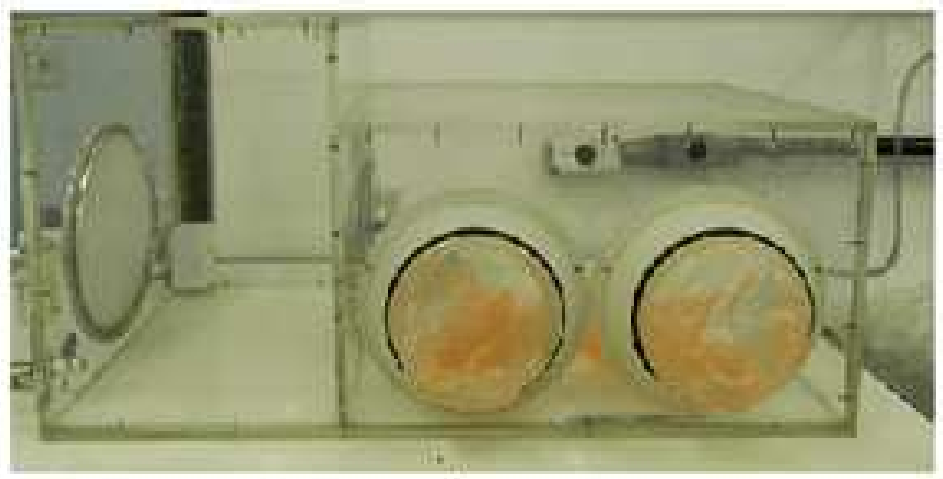

a)

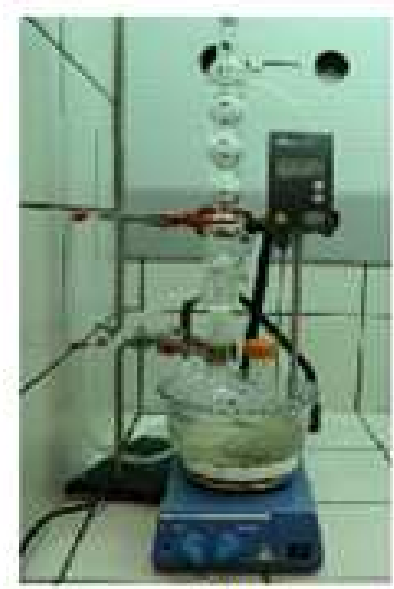

b)

Figura 17 - a) Câmara glove-box b) Sistema utilizados na realização das sínteses dos copolímeros. 


\subsubsection{Síntese 1 (PF)}

A síntese 1 corresponde ao polímero PF [poli-(2,7-(9,9-dioctilfluoreno)] obtido pela reação de acoplamento de Suzuki. Em um balão de duas bocas acoplado a um condensador Allihn (condensador de bolas), em banho de silicone aquecido a uma temperatura entre 70 e $75{ }^{\circ} \mathrm{C}$, foram adicionados $10 \mathrm{~mL}$ de tolueno, $5 \mathrm{~mL}$ de THF (tetrahidrofurano), uma solução aquosa de $\mathrm{K}_{2} \mathrm{CO}_{3}(1,65 \mathrm{~g}$ em $6 \mathrm{~mL}$ de água destilada), e 1 mmol de cada um dos monômeros: 9,9-dioctilfluoreno-2,7-ácido diborônico (0,478 g) e 9,9-Dioctil-2,7-dibromofluoreno (0,548 g). Também foram adicionadas 10 gotas de Aliquat $336(0,39 \mathrm{~g})$, que age como um agente de transferência de fase, facilitando a migração de um reagente de uma fase para outra fase, ao se localizar preferencialmente na interface, onde ocorre a reação e o catalisador à base de paládio $\left(\mathrm{P}\left(\mathrm{Ph}_{3}\right)_{4} \mathrm{Pd}\right)(0,020 \mathrm{~g})$. Esse sistema foi mantido sob agitação durante 96 horas, ficando por mais 72 horas após a adição do ácido fenilborônico $(0,121 \mathrm{~g})$, responsável por terminar a reação e eliminar possíveis grupos halogenados terminais da cadeia polimérica.

Após o término da reação, iniciou-se o processo de purificação, com a adição de água destilada em um funil de separação juntamente com a solução final da reação. Em seguida, a parte do polímero com o solvente orgânico passa por um processo de lavagem com peróxido de hidrogênio, para remoção dos compostos boronados que não reagiram e do catalisador.

A Figura 18 apresenta de forma esquemática a reação de polimerização com formação do PF.

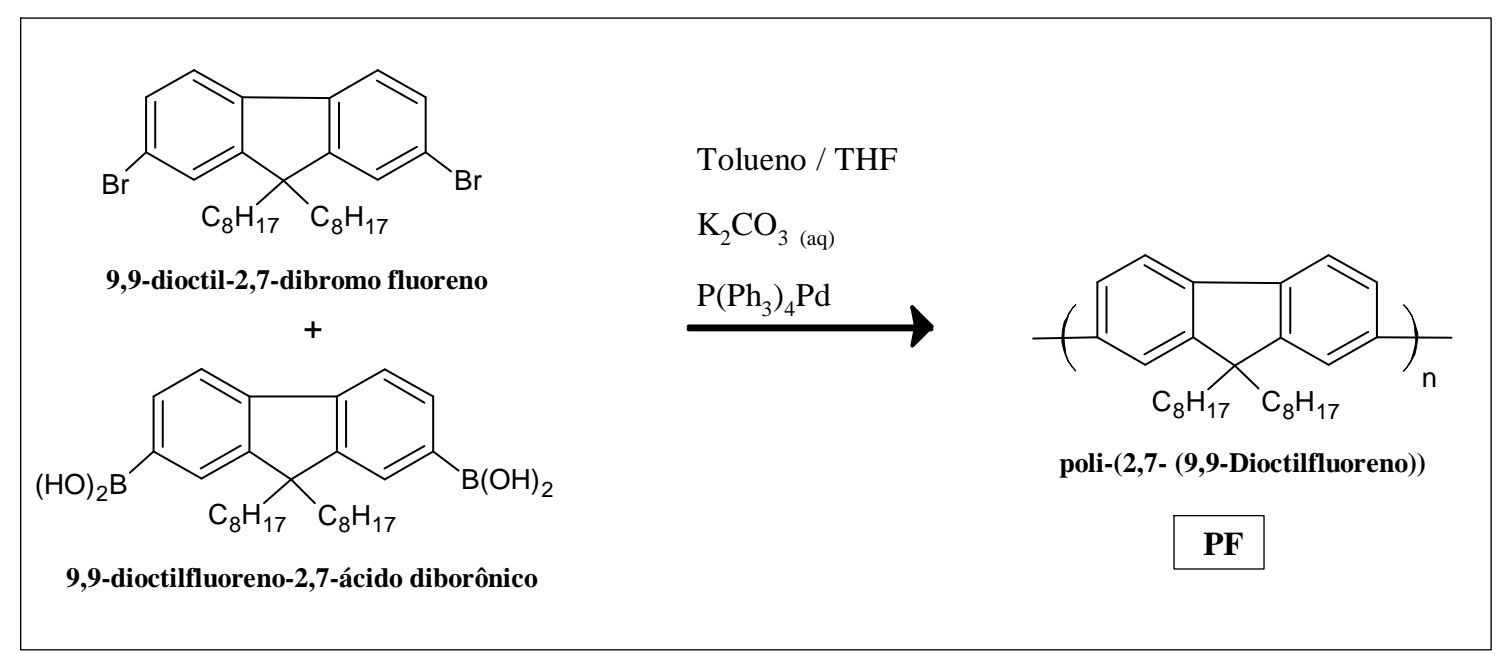

Figura 18 - Rota sintética para obtenção do polímero poli[2,7-(9,9-dioctilfluoreno)], (polímero $P F)$. 
Após o processo de purificação com peróxido de hidrogênio, o solvente orgânico foi retirado com auxílio de um evaporador rotativo, restando apenas o polímero sólido em um balão de fundo redondo. Posteriormente, esse polímero passa por um novo processo de purificação, sendo dissolvido com clorofórmio e precipitado em metanol.

O rendimento obtido na síntese foi de $95 \%$.

\subsubsection{Síntese $2\left(\mathrm{PF}_{\mathrm{P}}\right)$}

A síntese 2, que corresponde ao polímero $\mathbf{P F}_{\mathbf{P}}$ [poli(1,4-fenileno)-2,7-(9,9dioctilfluoreno)], teve como procedimento usual a reação de acoplamento de Suzuki. Em um balão de duas bocas acoplado a um condensador Allihn (condensador de bolas), em banho de silicone aquecido a uma temperatura entre 70 e $75^{\circ} \mathrm{C}$, foram adicionados $10 \mathrm{~mL}$ de tolueno, 5 $\mathrm{mL}$ de THF, uma solução aquosa de $\mathrm{K}_{2} \mathrm{CO}_{3}$ (1,65 g em $6 \mathrm{~mL}$ de água destilada), 1 mmol de cada um dos monômeros: 9,9-dioctil-2,7-dibromofluoreno (0,548 g) e 1,4-benzeno-ácido diborônico (0,165 g), 10 gotas de Aliquat $336(0,39 \mathrm{~g})$ e $\mathrm{P}\left(\mathrm{Ph}_{3}\right)_{4} \mathrm{Pd}(0,020 \mathrm{~g})$. Este sistema foi mantido sob agitação durante 96 horas, ficando por mais 72 horas após a adição do ácido fenilborônico $(0,121 \mathrm{~g})$.

O produto obtido foi purificado como descrito no item 3.3.1.1.

A Figura 19 apresenta de forma esquemática a reação de polimerização com formação do $\mathrm{PF}_{\mathrm{P}}$. 


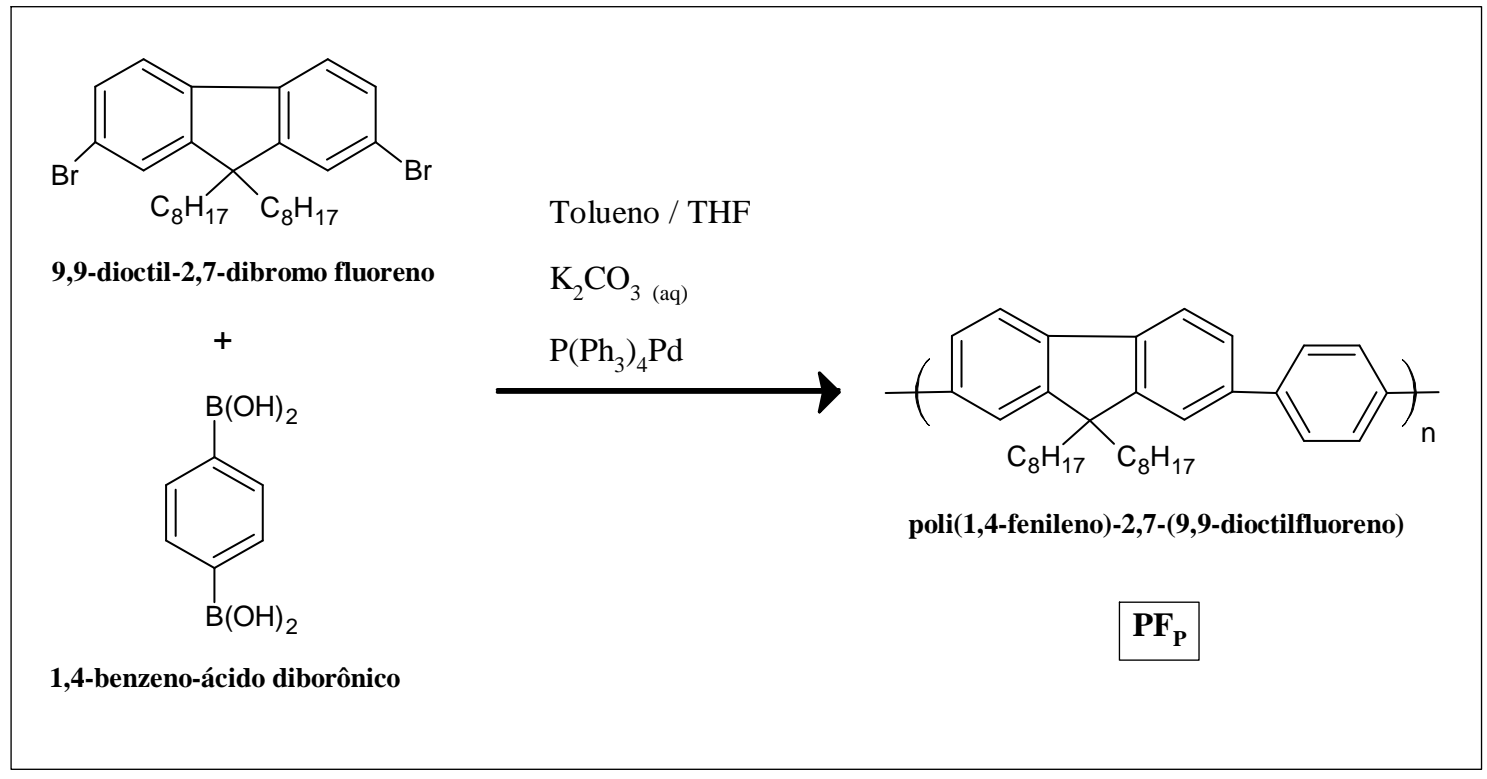

Figura 19 - Rota sintética para a obtenção do poli[(1,4-fenileno-alt-2,7-(9,9-dioctilfluoreno)] (copolímero $P F_{P}$ ).

O rendimento dessa síntese foi de $40 \%$.

O polímero obtido através dessa síntese não atingiu os padrões desejados, devido à baixa estabilidade térmica e baixo rendimento químico.

\subsubsection{Síntese $3\left(\mathrm{PF}_{\mathbf{P}}\right)$}

A síntese 3, que corresponde ao polímero $\mathbf{P F}_{\mathbf{P}}$ [poli(1,4-fenileno)-2,7-(9,9dioctilfluoreno)], teve como procedimento usual a reação de acoplamento de Suzuki. A partir de um balão de duas bocas acoplado a um condensador Allihn (condensador de bolas), em banho de silicone aquecido a uma temperatura entre 70 e $75^{\circ} \mathrm{C}$, foram adicionados $10 \mathrm{~mL}$ de tolueno, $5 \mathrm{~mL}$ de THF, uma solução aquosa de $\mathrm{K}_{2} \mathrm{CO}_{3}$ (1,65 g em $6 \mathrm{~mL}$ de água destilada), e $1 \mathrm{mmol}$ de cada um dos monômeros: 9,9-dioctilfluoreno-2,7-ácido diborônico (0,478 g) e 1,4dibromobenzeno $(0,235 \mathrm{~g}), 10$ gotas de Aliquat $(0,39 \mathrm{~g})$ e também $\mathrm{P}\left(\mathrm{Ph}_{3}\right)_{4} \mathrm{Pd}(0,020 \mathrm{~g})$. Esse sistema foi mantido sob agitação durante 96 horas, ficando por mais 72 horas após a adição do ácido fenilborônico $(0,121 \mathrm{~g})$.

O produto obtido foi purificado como descrito no item 3.3.1.1.

A Figura 20 apresenta de forma esquemática a reação de polimerização com formação do $P F_{P}$. 


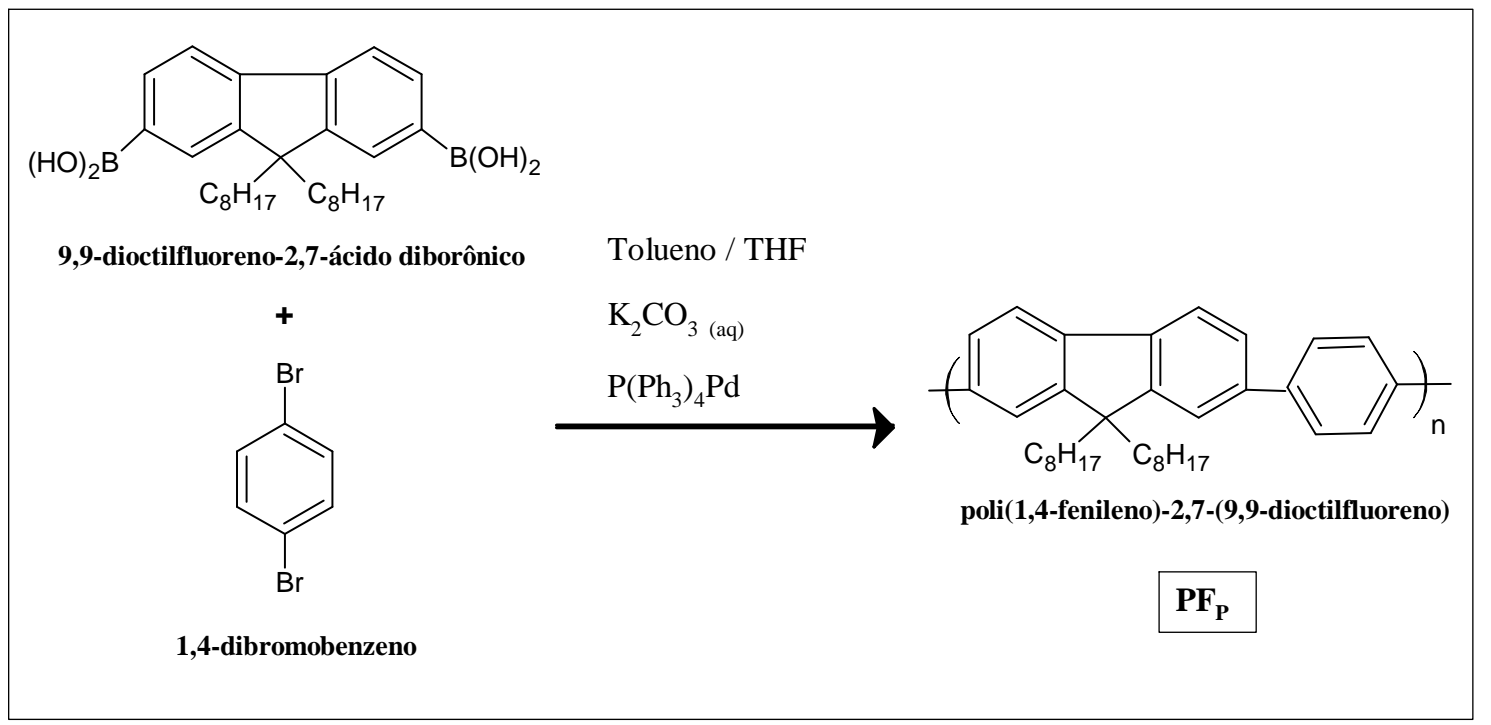

Figura 20 - Rota sintética para a obtenção poli[1,4-fenileno-alt-2,7-(9,9-dioctilfluoreno)], (copolímero, $\mathrm{PF}_{\mathrm{P}}$ ).

O rendimento obtido na síntese foi de $85 \%$.

\subsubsection{Síntese $4\left(\mathrm{PF}_{\mathrm{PF}}\right)$}

A síntese 4, que corresponde ao polímero $P F_{P F}$ [poli(1,4-fenileno-2-flúor)-2,7-(9,9dioctilfluoreno)], teve como procedimento usual a reação de acoplamento de Suzuki. A partir de um balão de duas bocas acoplado a um condensador Allihn (condensador de bolas), em banho de silicone aquecido a uma temperatura entre 70 e $75^{\circ} \mathrm{C}$, foram adicionados $10 \mathrm{~mL}$ de tolueno, $5 \mathrm{~mL}$ de THF, uma solução aquosa de $\mathrm{K}_{2} \mathrm{CO}_{3}$ (1,65 g em $6 \mathrm{~mL}$ de água destilada), 1 mmol de cada um dos monômeros: 9,9-dioctilfluoreno-2,7-ácido diborônico (0,478 g) e 1,4dibromo-2-fluorobenzeno (0,253 g), 10 gotas de Aliquat $(0,39 \mathrm{~g})$ e também $\mathrm{P}\left(\mathrm{Ph}_{3}\right)_{4} \mathrm{Pd}(0,020$ g). Esse sistema foi mantido sob agitação durante 96 horas, ficando por mais 72 horas após a adição do ácido fenilborônico $(0,121 \mathrm{~g})$.

O produto obtido foi purificado como descrito no item 3.3.1.1.

A Figura 21 apresenta de forma esquemática a reação de polimerização com formação do $\mathrm{PF}_{\mathrm{PF}}$. 


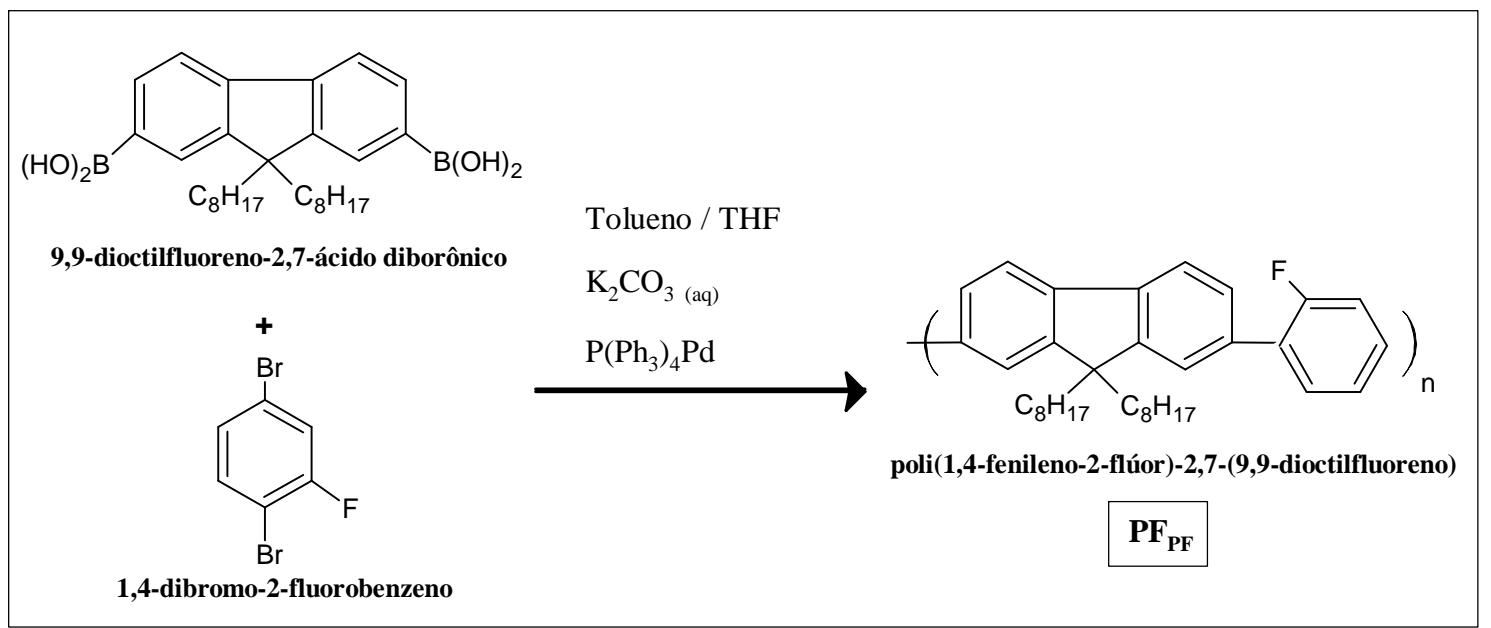

Figura 21- Rota sintética para a obtenção do poli[(1,4-fenileno-2-flúor)-alt-2,7-(9,9-dioctilfluoreno)], (copolímero $P F_{P F}$ ).

O rendimento obtido na síntese foi de $95 \%$.

\subsubsection{Caracterização dos copolímeros emissores de luz}

\subsubsection{Espectroscopia de absorção no UV-Vis}

Os espectros de absorção no UV-Vis foram realizados com auxílio de um espectrofotômetro ultravioleta-visível (UV-Vis Varian, modelo Cary 50 Conc). Os polímeros foram dissolvidos em clorofórmio grau espectrométrico, dentro de uma célula de seção transversal quadrada de quartzo de $1 \mathrm{~cm} \mathrm{x} 1 \mathrm{~cm}$ e os espectros de transmissão foram coletados de na faixa de 200 a $800 \mathrm{~nm}$. A Figura 22 apresenta o espectrofotômetro utilizado no Laboratório de Engenharia de Macromoléculas, do Departamento de Engenharia Metalúrgica e de Materiais (PMT) da Escola Politécnica da USP. 


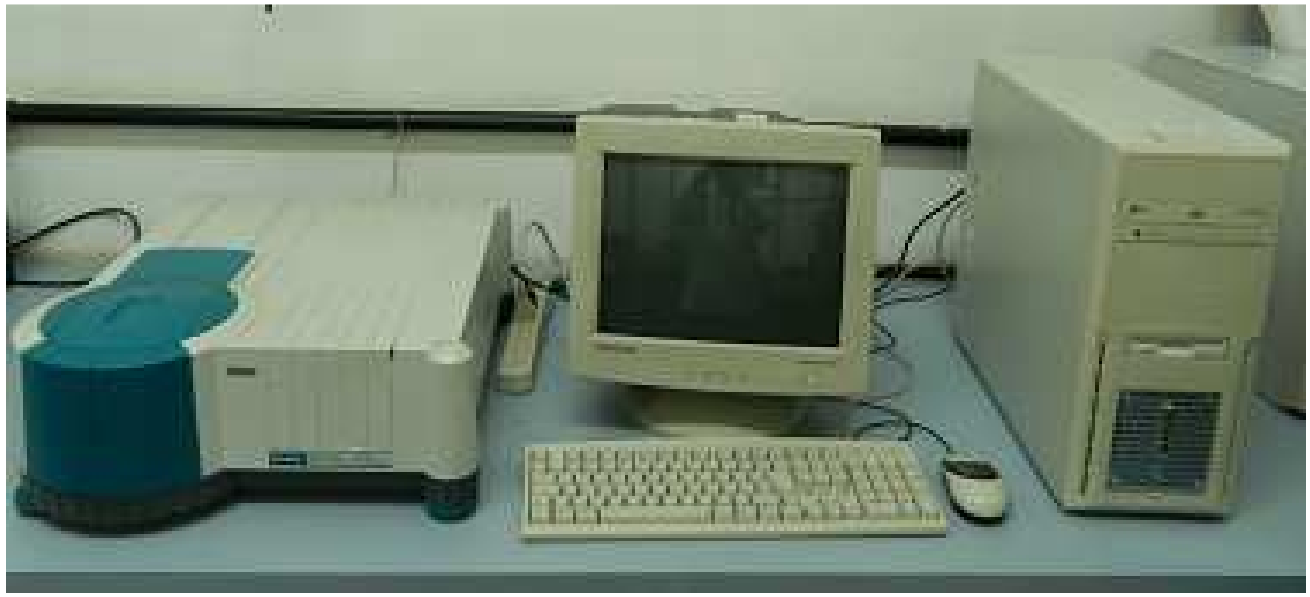

Figura 22 - Espectrofotômetro de absorção no UV-Vis.

\subsubsection{Espectroscopia de fluorescência}

Os espectros de emissão foram realizados no Espectrofotômetro de Fluorescência (Fluorímetro Varian, modelo Eclipse). Os polímeros dissolvidos em clorofórmio espectrométrico e contidos em uma célula de quartzo foram analisados por espectroscopia de absorção no UV-Vis e, subsequentemente, submetidos à irradiação no comprimento de onda correspondente ao pico máximo observado nos espectros de absorção, assim sendo, obtiveram-se os espectros de emissão na região de comprimento de onda de 200 a $600 \mathrm{~nm}$. A Figura 23 apresenta o espectrofotômetro de fluorescência utilizado no laboratório de Engenharia de Macromoléculas.

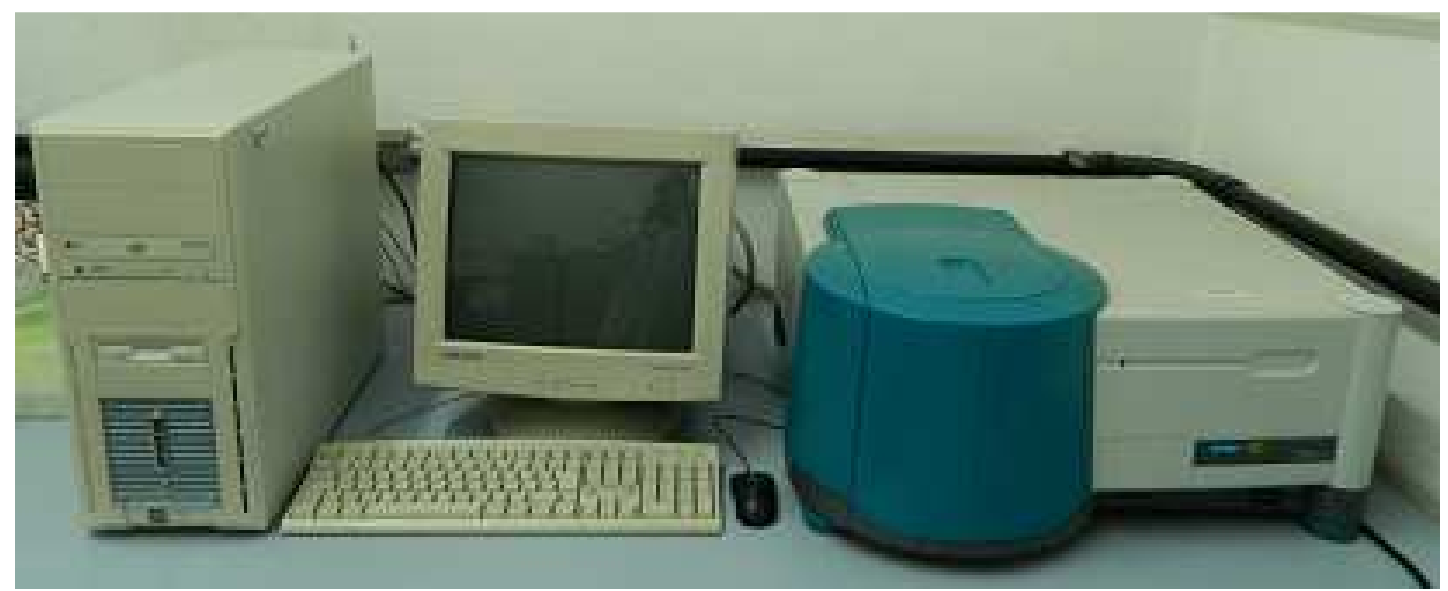

Figura 23 - Espectrofotômetro de fluorescência. 


\subsection{Rendimento Quântico}

O rendimento quântico é a fração de moléculas excitadas que voltam ao estado fundamental com emissão de fluorescência, isto é, a razão do número de fótons emitidos e o número de fótons absorvidos ${ }^{49,50}$.

O cálculo de rendimento quântico de fluorescência foi calculado a partir da comparação dos resultados de emissão dos copolímeros com uma substância de valor conhecido e pode ser obtido através da seguinte equação:

$$
\phi_{\mathrm{a}}=\phi_{\mathrm{p}} * \frac{\operatorname{grad}_{\mathrm{a}}}{\operatorname{grad}_{\mathrm{p}}} * \frac{\eta_{\mathrm{a}}^{2}}{\eta_{\mathrm{p}}^{2}}
$$

$\mathrm{Na}$ equação 1 , o $\phi$ representa o rendimento quântico, o grad é a relação da área sob a curva de emissão da amostra pela concentração molar e $\eta$ é o índice de refração, e os índices a e p estão relacionados às amostras e ao padrão, respectivamente.

Neste estudo o padrão utilizado foi o sulfato de quinina $\left[\left(\mathrm{C}_{20} \mathrm{H}_{24} \mathrm{~N}_{2} \mathrm{O}_{2}\right)_{2} \cdot \mathrm{H}_{2} \mathrm{SO}_{4}\right.$. $\left.\left.2 \mathrm{H}_{2} \mathrm{O}\right)\right]$. A estrutura química do sulfato de quinina está representada na Figura 24.

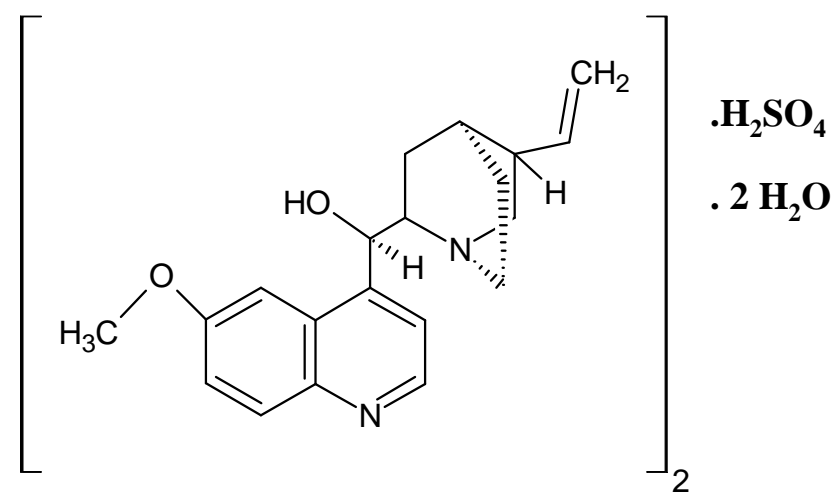

Figura 24 - Estrutura química do sulfato de quinina

O rendimento quântico do sulfato de quinina é conhecido $\left(\phi_{\mathrm{p}}=0,546\right)^{51}$, determinado em soluções em concentrações menores que $10^{-4} \mathrm{mo} / \mathrm{L}$ em solução de $1 \mathrm{~N}-\mathrm{H}_{2} \mathrm{SO}_{4}$ com comprimento de onda de excitação em $365 \mathrm{~nm}$ a $25^{\circ} \mathrm{C}$. 


\subsubsection{Espectroscopia de ressonância magnética nuclear de hidrogênio ( $\left.{ }^{1} \mathrm{HNMR}\right)$}

As análises de ressonância magnética nuclear foram realizadas na Central Analítica do Instituto de Química da USP, utilizando o equipamento AIII $300 \mathrm{MHz}$, com as amostras dissolvidas em clorofórmio deuterado $\left(\mathrm{CDCl}_{3}\right)$. $\mathrm{O}$ equipamento utilizado para estas análise está apresentado na Figura 25.

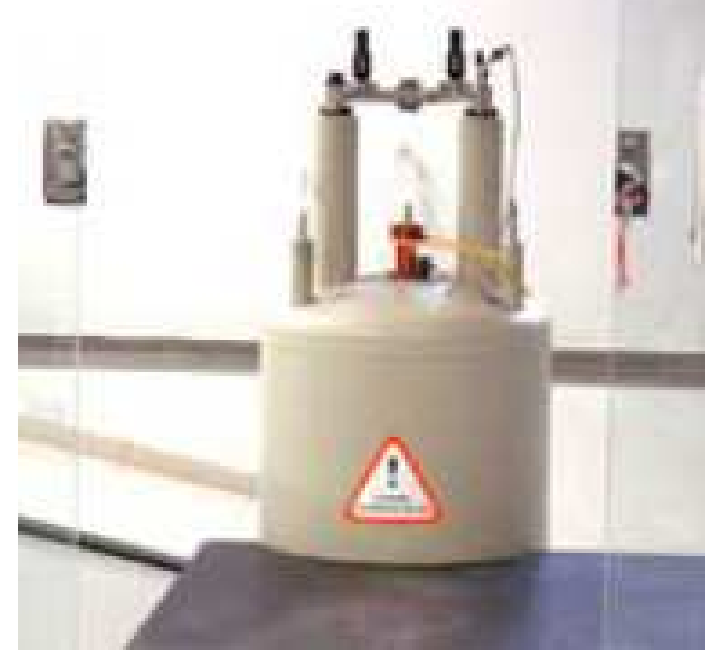

Figura 25 - Equipamento de NMR.

\subsubsection{Espectroscopia no infravermelho (FTIR)}

As análises dos copolímeros por espectroscopia no infravermelho foram realizadas com o auxílio do aluno de doutorado Douglas Morais, no Laboratório de Materiais Cerâmicos do Departamento de Engenharia Metalúrgica e de Materiais da Escola Politécnica da USP, através de pastilhas de $\mathrm{KBr}$ com os polímeros sintetizados. A Figura 26 apresenta o equipamento de FTIR da Thermo Scientific utilizado. 


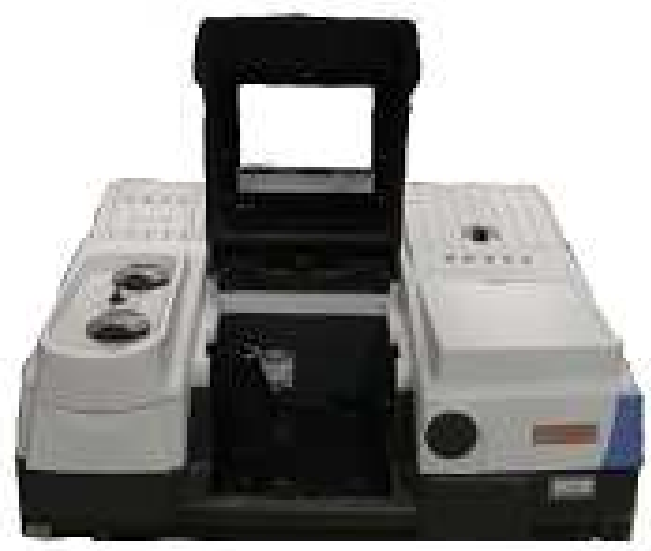

Figura 26 - Equipamento de FTIR.

\subsubsection{Análise termogravimétrica (TGA)}

As amostras dos copolímeros sintetizados foram submetidas a uma análise termogravimétrica na faixa de $25^{\circ} \mathrm{C}$ a $800{ }^{\circ} \mathrm{C}$, a uma taxa de aquecimento de $10{ }^{\circ} \mathrm{C} / \mathrm{min}$ sob fluxo de nitrogênio. Os ensaios foram realizados no laboratório de Análises Térmicas do Departamento de Engenharia Metalúrgica e de Materiais da Escola Politécnica da USP, utilizando o equipamento STA 449 F3 Jupiter, da Netzsch. A Figura 27 apresenta o analisador térmico simultâneo utilizado.

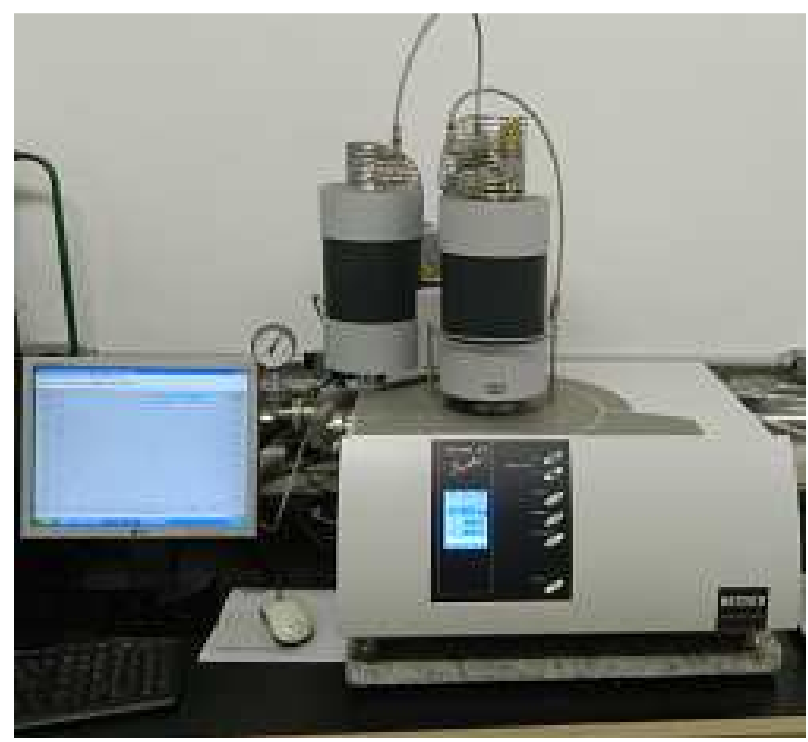

Figura 27 - TGA da Netzsch. 


\subsubsection{Calorimetria diferencial exploratória (DSC)}

As análises foram submetidas a uma variação de temperatura de $-70{ }^{\circ} \mathrm{C}$ a $250{ }^{\circ} \mathrm{C}$, a uma taxa de $10{ }^{\circ} \mathrm{C} / \mathrm{min}$ e sob fluxo de nitrogênio, no mesmo laboratório citado no item anterior, utilizando o equipamento DSC 200 F3 Maia, da Netzsch. A Figura 28 apresenta o calorímetro diferencial exploratório utilizado.

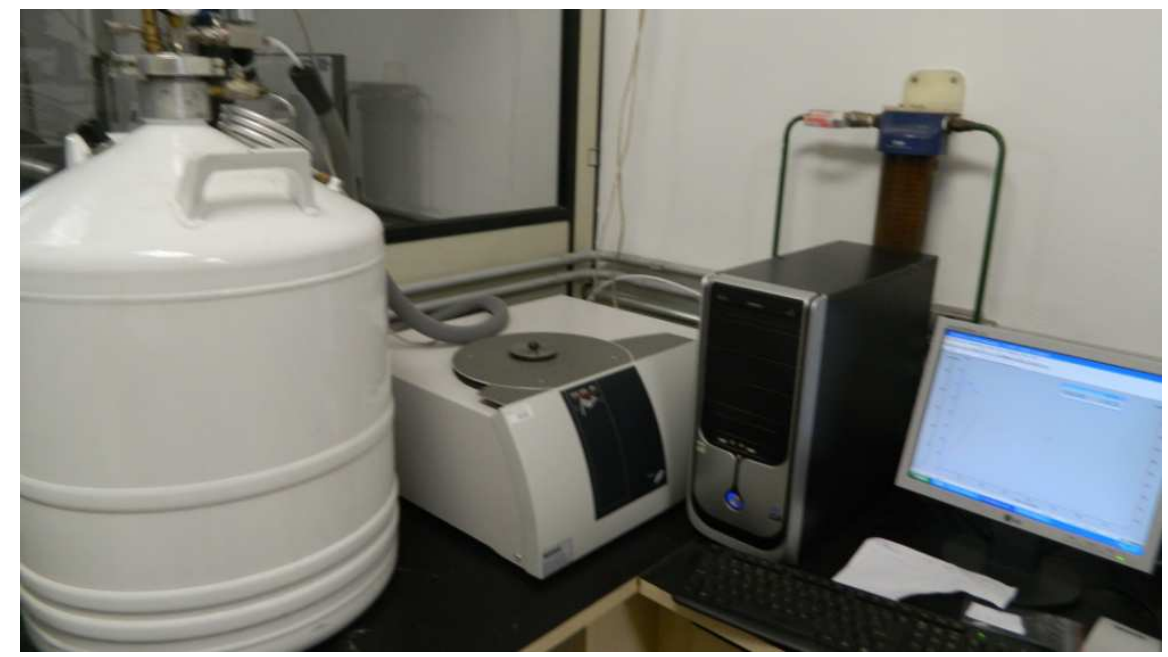

Figura 28 - DSC da Netzsch.

\subsubsection{Cromatografia de permeação em gel (GPC)}

As amostras foram analisadas no Instituto de Física de São Carlos (IFSC - USP), no equipamento Agilent 1100 com colunas de GPC PLgel mixed C e PLgel mixed B em série, com o detector de índice de refração a $35^{\circ} \mathrm{C}$, e utilizado THF como solvente a $1 \mathrm{~mL} / \mathrm{min}$. O equipamento foi calibrado com padrões de poliestireno (PS). 


\subsubsection{Espectroscopia de energia dispersiva de raios-X (EDX)}

Os polímeros foram fixados ao porta-amostra com o auxílio de uma fita de carbono. A Figura 29 apresenta o Microscópio Eletrônico de Varredura, onde foram realizadas as análises de EDX dos polímeros sintetizados.

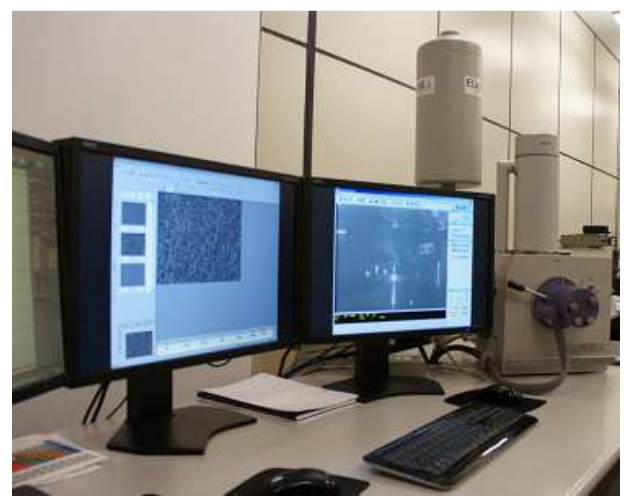

Figura 29 - Microscópio eletrônico de varredura

\subsubsection{Difração de raio-X (XRD)}

Os difratogramas de raios- $\mathrm{X}$ foram obtidos a partir de um difratômetro da marca Philips, modelo X'Pert, do Laboratório de Caracterização Tecnológica (LCT) do Departamento de Engenharia de Minas e de Petróleo da USP, o equipamento utilizado está apresentado na Figura 30 . As condições de operação foram: radiação produzida por um tubo de cobre, operação com tensão de $40 \mathrm{kV}$ e corrente de $40 \mathrm{~mA}$, intervalo angular de contagem de 2,5 a $70^{\circ}$ em $2 \theta$ com passo angular de 0,02 .

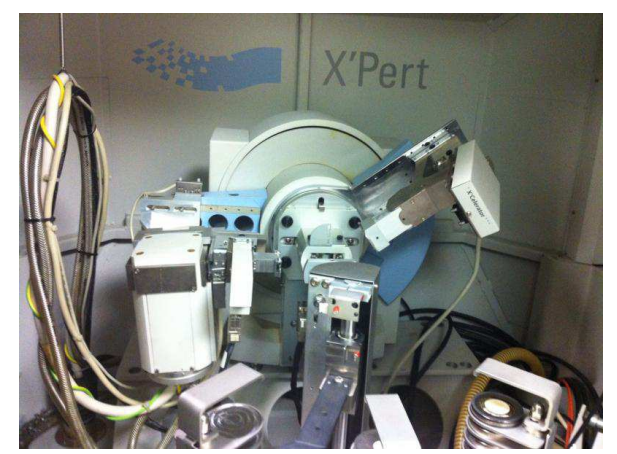

Figura 30 - Difratômetro de raios-X 


\subsubsection{Fabricação dos P-OLEDs}

A fabricação dos P-OLEDs foi dividida em quatro etapas distintas: (1) Fabricação de máscaras de cobre $(\mathrm{Cu})$ para uso na evaporadora; (2) Preparação dos subtratos (corrosão do ITO para formação da geometria da área ativa do ânodo do dispositivo, limpeza química da superfície para retirada dos particulados e tratamento superficial do ITO a partir de um reator de UV-Ozônio; (3) Deposição das camadas de PEDOT:PSS usadas como HTL (Hole Transport Layer - Camada Transportadora de Buracos), preparação e deposição da solução dos copolímeros sintetizados; e (4) Metalização por evaporação térmica do alumínio (Al) para formação do cátodo.

\subsubsection{Fabricação de máscaras de cobre}

As máscaras de cobre para uso na evaporadora foram produzidas a partir de uma folha fina de cobre com espessura de $0,1 \mathrm{~mm}$. A placa foi cortada em formato quadrado com dimensões de $30 \mathrm{~mm}$ x $30 \mathrm{~mm}$, posteriormente a geometria para formação do cátodo (Al) foi desenhada e protegida por esmalte colorido, sendo corroído com cloreto de ferro III. As Figura 31 e Figura 32 mostram, respectivamente, as geometrias utilizadas neste trabalho e os registros fotográficos das máscaras de cobre utilizadas. Os conjuntos apresentados são formados por quatro dispositivos individuais com área ativa de $9 \mathrm{~mm}^{2}$ (a) e dois dispositivos individuais com área ativa de $25 \mathrm{~mm}^{2}$ (b).

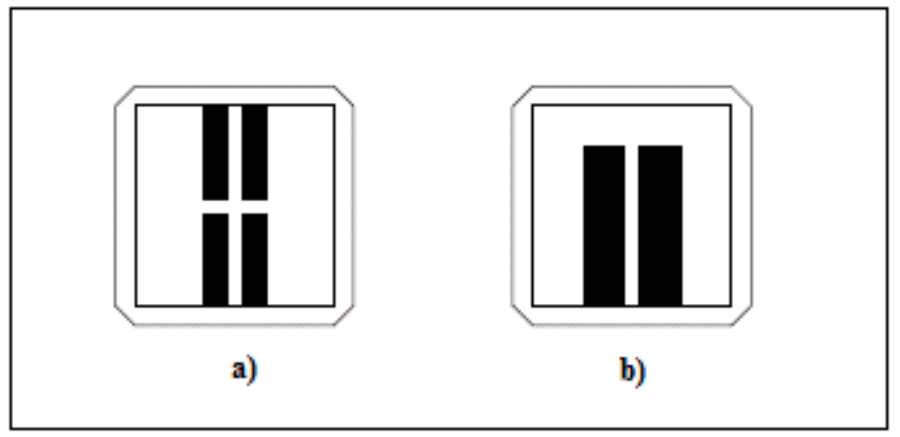

Figura 31 - Geometria das máscaras de cobre para formação de P-OLEDs com área ativa de a) 9 mm² e b) 25 $\mathrm{mm}^{2}$. 


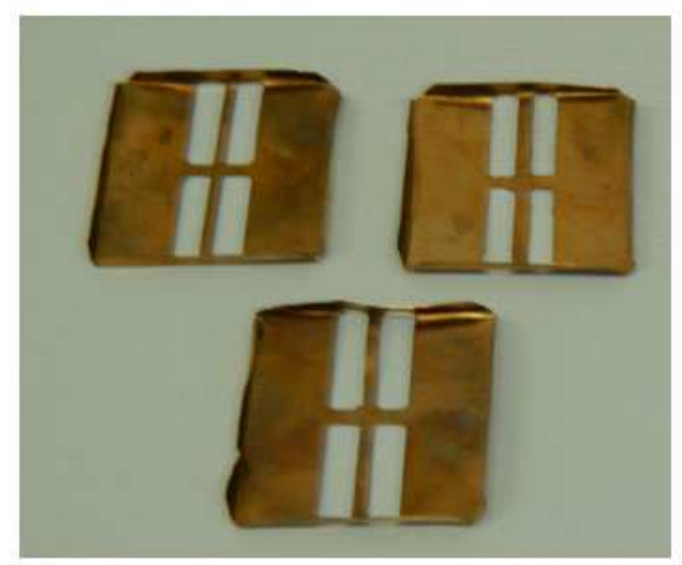

a)

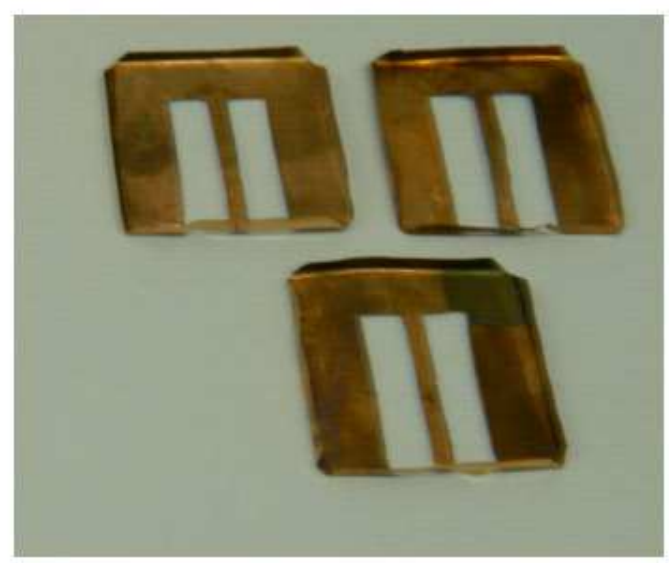

b)

Figura 32 - Registro fotográfico das máscaras de cobre dos P-OLEDs com área ativa de a) $9 \mathrm{~mm}^{2}$ e b) $25 \mathrm{~mm}^{2}$.

\subsubsection{Corrosão do ITO}

A corrosão do ITO é necessária para a formação das regiões ativas do dispositivo e do ânodo individual para cada dispositivo do conjunto.

As regiões com área ativa nos dispositivos foram protegidas com uma fita adesiva (fita mágica da $3 \mathrm{M}$ ), e a região exposta foi corroída através do friccionamento de zinco em pó aderido ao algodão umedecido em uma solução de $\mathrm{HCl}$. A geometria obtida do subtrado vidro/ITO, após esta etapa, está representada na Figura 33.

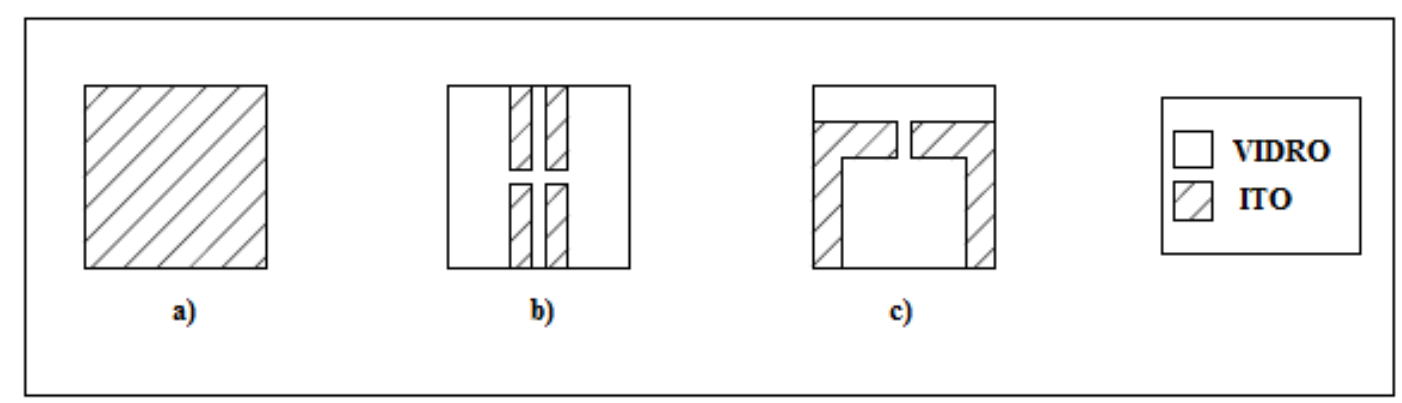

Figura 33 - a) Lâmina de vidro recoberta com ITO; geometria do ITO com área ativa de b) $9 \mathrm{~mm}^{2}$ e c) $25 \mathrm{~mm}^{2}$. 


\subsubsection{Limpeza química}

A limpeza das lâminas iniciou-se com a marcação de uma letra de identificação na área inferior do lado do vidro, com auxílio de um cortador de vidro com ponta de vídia, ou seja, o lado da lâmina que não possui tal marcação se encontra o ITO, onde serão depositados os filmes poliméricos. Após este procedimento, as lâminas foram submetidas à lavagem manual com detergente comum (doméstico) e água destilada, para remoção de impurezas, pó, particulados sobre o ITO. Na sequência, as lâminas são carregadas no porta-amostra e imersas primeiramente em álcool metílico e depois em acetona, em banho ultrassônico por 30 minutos em cada solvente. Para esta lavagem foi utilizado um equipamento de banho ultrassônico, marca Unique, modelo USC-1800A, como apresentado na Figura 34.

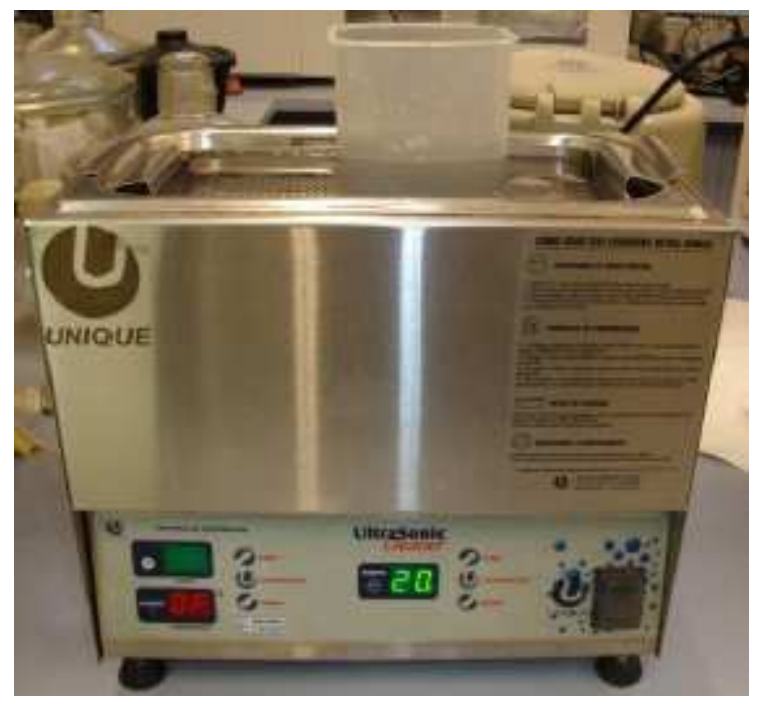

Figura 34 - Equipamento de banho ultrassônico.

\subsubsection{Tratamento da superfície do ITO}

Após o procedimento de limpeza química, as lâminas de vidro/ITO foram submetidas a um tipo de tratamento superficial. Esse tratamento tem como objetivo a remoção de outros possíveis contaminantes da superfície do ITO, como carbonos e hidrocarbonetos, com a exposição à radiação ultravioleta e ao ozônio $\left(\mathrm{UV}-\mathrm{O}_{3}\right)$, por 5 minutos. Para este procedimento 
foi utilizado um reator montado empregando como fonte de UV, um tubo de ignição interno de uma lâmpada de vapor de mercúrio sob alta pressão, cujo bulbo externo foi removido ${ }^{52}$. Para o processo de montagem deste equipamento, foi necessário, além deste tubo de ignição, um refletor com porta lâmpada, ventiladores, um reator, um porta-lâminas e uma base de madeira coberta com folha de papel alumínio. O esquema do reator utilizado está representado na Figura 35.

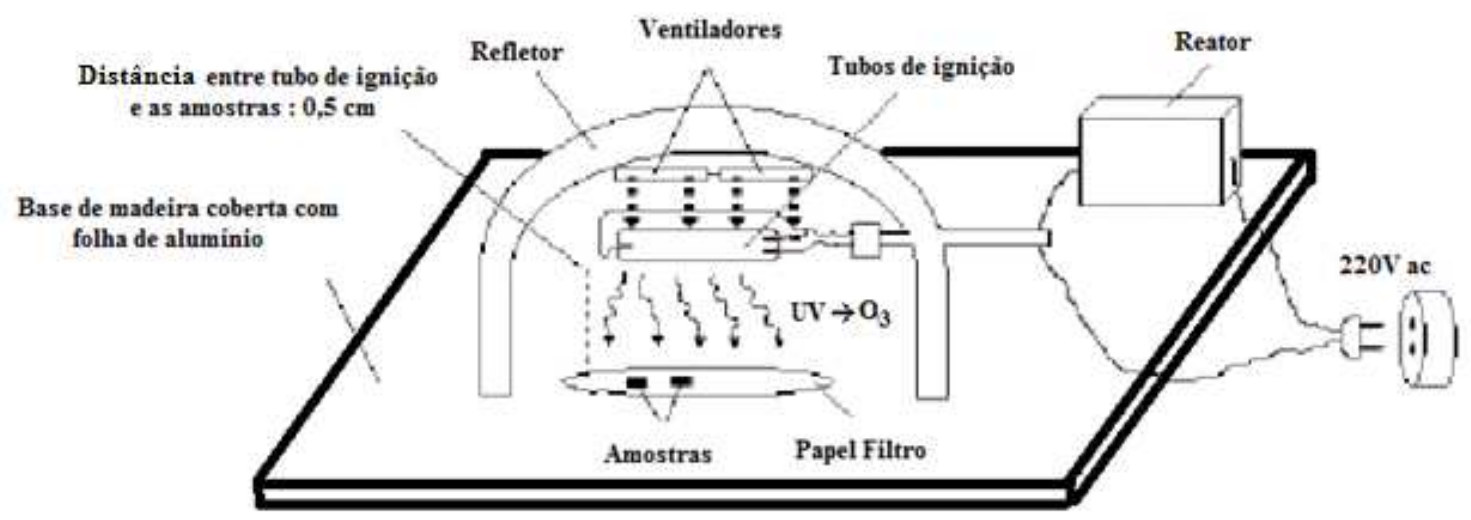

Figura 35 - Esquema do reator utilizado para tratamento superficial do ITO.

$\mathrm{Na}$ Figura 36 está apresentada uma foto do equipamento no momento de funcionamento com as amostras centralizadas no seu interior.

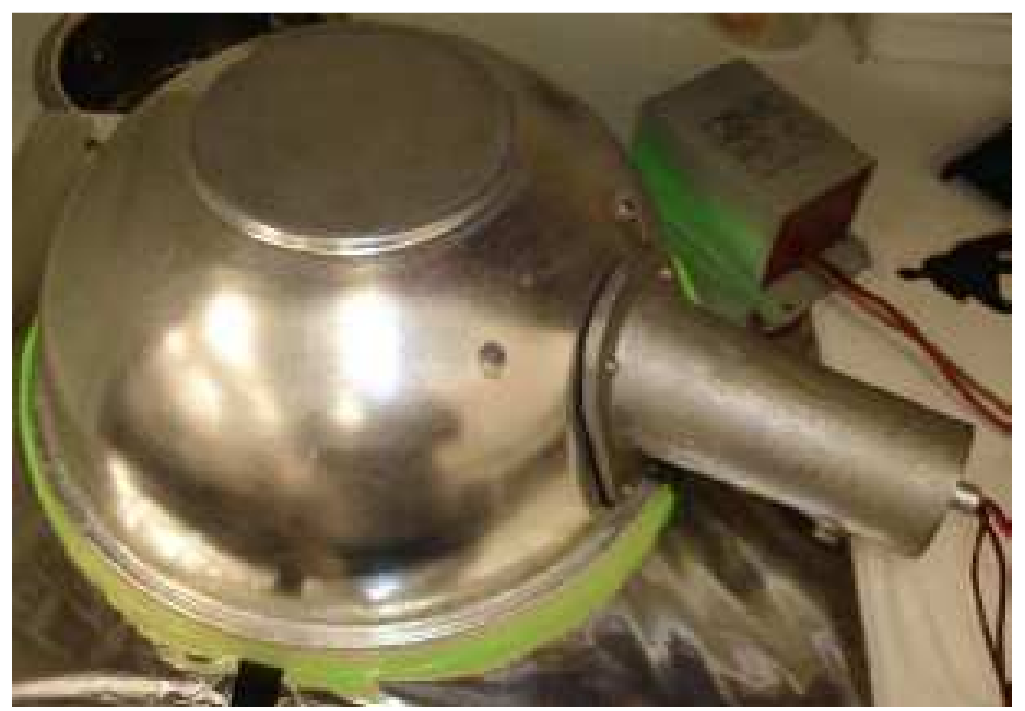

Figura 36 - Reator montado em funcionamento para tratamento superficial do ITO. 


\subsubsection{Deposição do PEDOT:PSS}

O filme de PEDOT:PSS foi a primeira camada a ser depositada sobre o ITO pelo método spin-coating (espalhamento rotativo). $\mathrm{O}$ equipamento utilizado como spinner foi montado a partir de um motor de disco rígido (Hard Disk - HD) de computador, uma fonte de alimentação, parafusos, disco metálico e fita dupla face (para segurar a amostra durante a rotação). O disco metálico foi parafusado no eixo do motor, que está fixado à sua base metálica e através do posicionamento regulável de um imã, seis posições distintas de rotação foram demarcadas nesta própria base, onde a aproximação ou afastamento do imã em relação ao disco metálico controla a rotação do motor. Os parâmetros utilizados foram a posição 4 do imã, referente a $1883 \mathrm{rpm}, 70$ segundos de rotação (2 ciclos de 35 segundos) e $300 \mu \mathrm{L}$ (microlitros) de quantidade de PEDOT:PSS por lâmina. O projeto e a montagem deste equipamento foram parte integrante do trabalho de conclusão de curso de Erick Vendruscolo Guerra, da Faculdade de Tecnologia de São Paulo ${ }^{53}$. A Figura 37 apresenta o spinner utilizado.

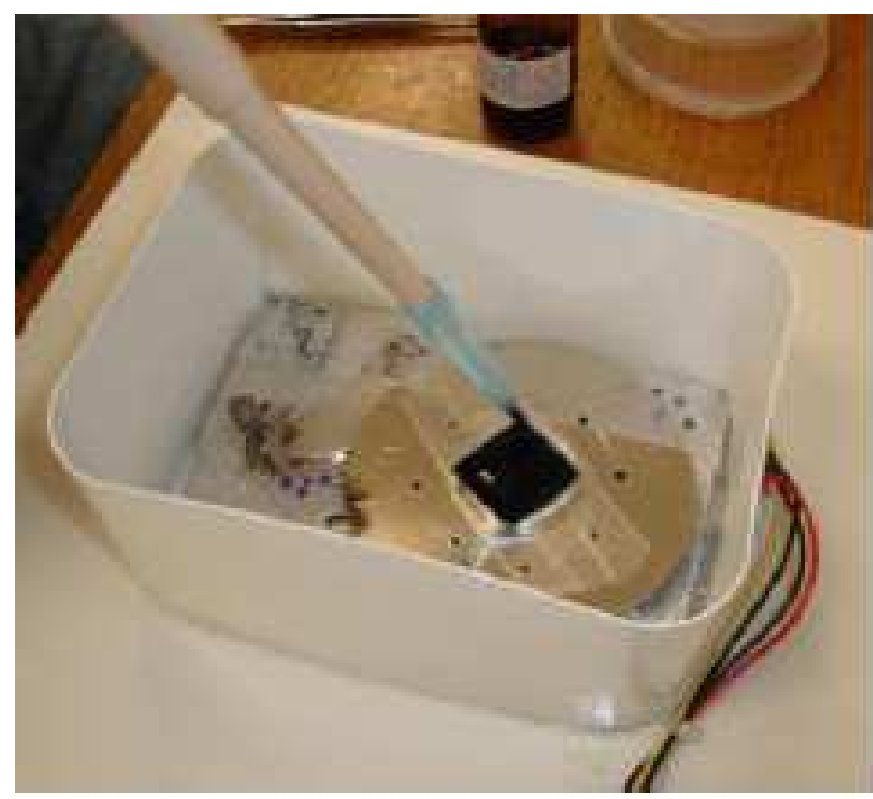

Figura 37 - Spinner montado com um motor de disco rígido.

Após os 70 segundos de rotação, as lâminas são retiradas do spinner e submetidas ao processo de decapagem, para liberar o excesso de PEDOT:PSS sobre área de contato do eletrodos (ânodo e cátodo). Para a realização deste procedimento utiliza-se algodão 
umedecido com água destilada. A Figura 38 mostra a geometria do substrato após a deposição e decapagem do filme de PEDOT:PSS.

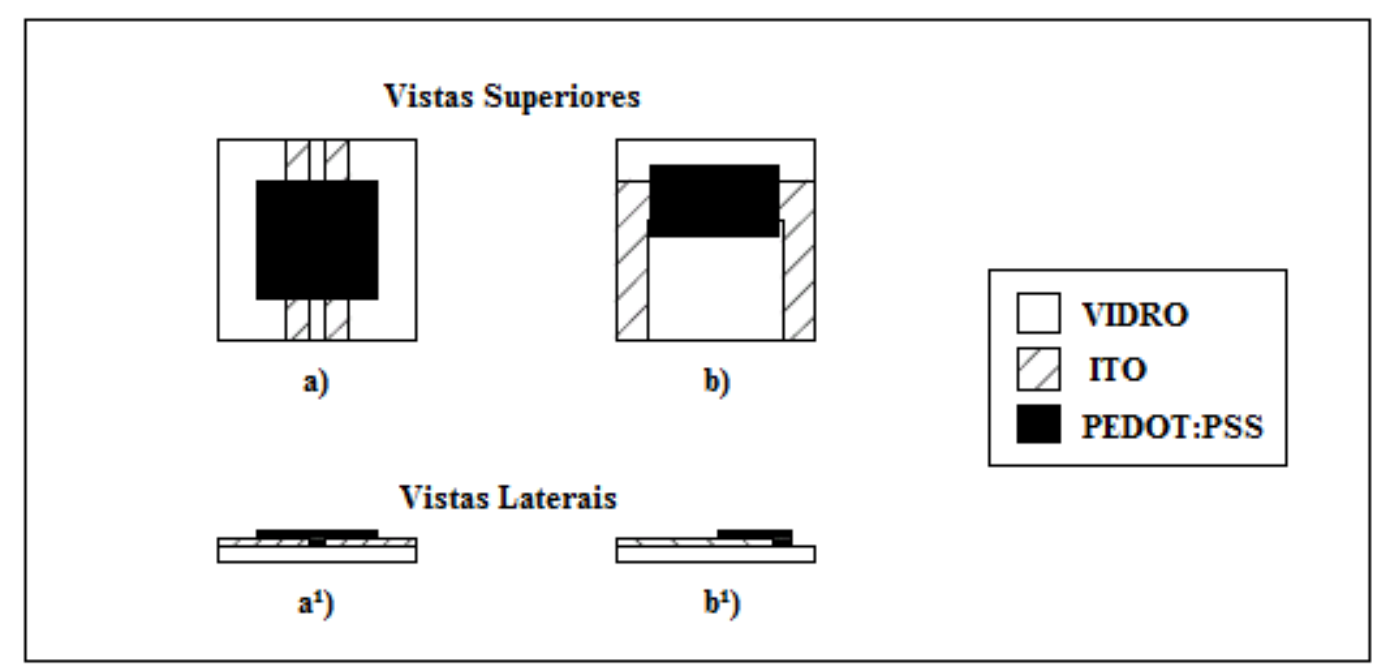

Figura 38 - Geometria dos substratos após a deposição do PEDOT:PSS e processo de decapagem, para P-OLEDs com área ativa de a) $9 \mathrm{~mm}^{2}$ e b) $25 \mathrm{~mm}^{2}$.

Após a etapa de decapagem, as lâminas foram colocadas em uma estufa a vácuo préaquecida em $100{ }^{\circ} \mathrm{C}$, por um período de 12 horas, para que o solvente, no caso a água, fosse removido.

\subsubsection{Preparação das soluções poliméricas}

As soluções poliméricas foram preparadas em concentrações de 1\% (10 mg/ml) em clorofórmio grau espectrométrico, visto que essa concentração foi considerada ideal em trabalhos realizados anteriormente, no Laboratório de Engenharia de Macromoléculas ${ }^{54,55}$.

A quantidade de solução dependerá da quantidade de lâminas a serem produzidas, sendo que para cada lâmina usa-se de 200 a $250 \mu \mathrm{L}$. Após dissolver o polímero em clorofórmio grau espectrométrico, as soluções são filtradas através de membranas de politetrafluoretileno (Millipore) de porosidade de 0,25 $\mu \mathrm{m}$. 


\subsubsection{Deposição do copolímero}

Para as deposições dos copolímeros utilizaram-se as mesmas condições do item anterior (deposição do PEDOT:PSS), variando apenas o volume de solução depositada sobre o filme de PEDOT:PSS, cerca de $200 \mu \mathrm{L}$ para cada lâmina. Após o processo de deposição, os filmes também são submetidos à decapagem com clorofórmio, assim representados na Figura 39. Também foi estudada a influência do ETL (Electron transport layer - Camada transportadora de elétrons), butyl-PBD e $\mathrm{Alq}_{3}$, que foram testados utilizando soluções a 0,5\% $(5 \mathrm{mg} / \mathrm{ml})$ em clorofórmio. Algumas amostras utilizaram esses compostos de ETL, que foram dissolvidos e misturados juntamente com a solução polimérica, formando apenas uma camada (polímero + ETL).

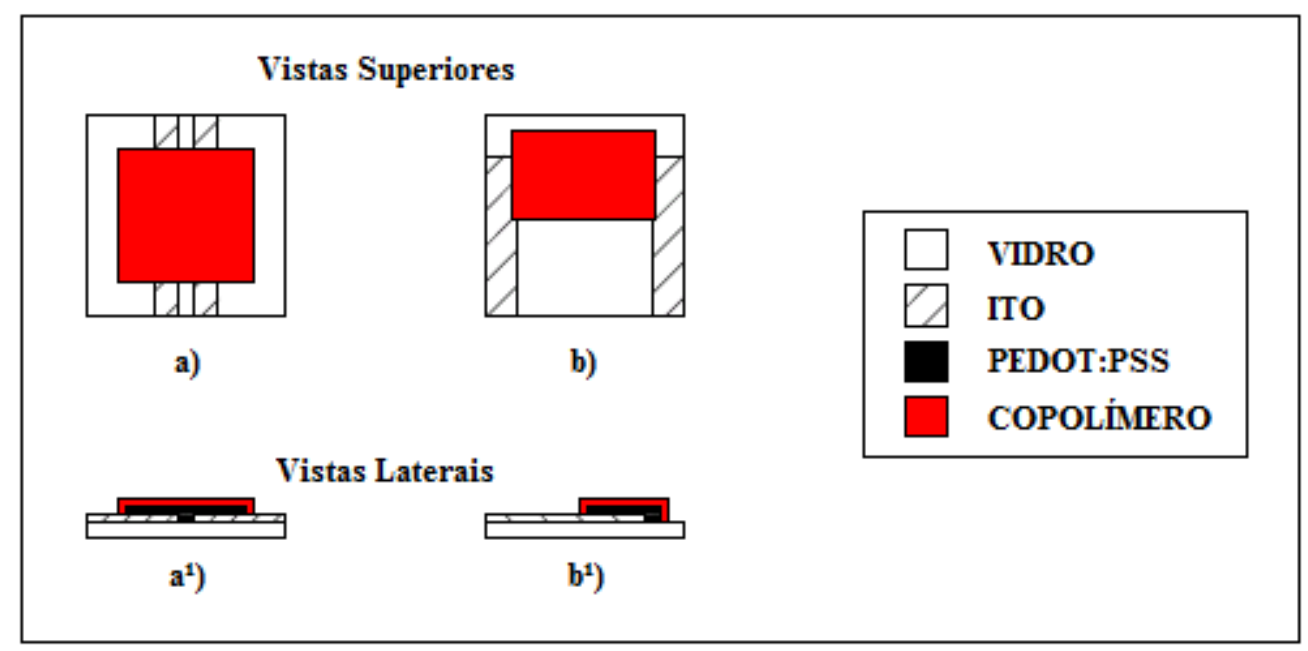

Figura 39 - Geometria dos subtratos após deposição e processo de decapagem dos copolímeros emissores, para P-OLEDs com área ativa de a) $9 \mathrm{~mm}^{2}$ e b) $25 \mathrm{~mm}^{2}$.

Em seguida ao processo de decapagem, as lâminas foram colocadas para secagem do solvente em uma estufa a vácuo pré-aqueciada a $50{ }^{\circ} \mathrm{C}$, por um período de 1 hora.

\subsubsection{Metalização dos Dispositivos}

O alumínio (cátodo) foi evaporado nos dispositivos, no Laboratório do Grupo de Eletrônica Molecular (GEM) da Escola Politécnica da USP, utilizando uma evaporadora térmica, situada no interior de uma glove-box, apresentada na Figura 40. 


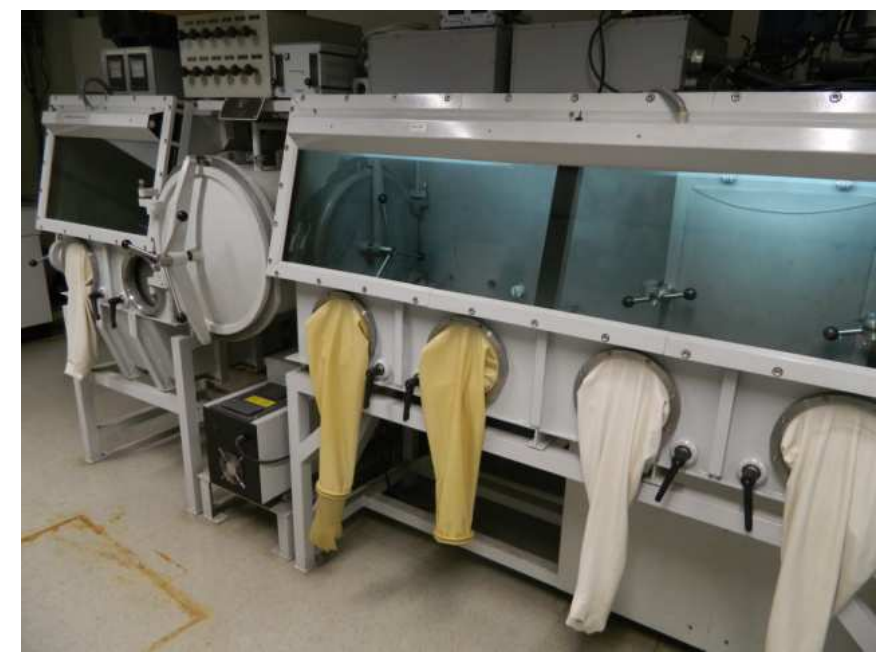

Figura 40 - Evaporadora térmica no interior de uma glove-box.

Os porta-amostras (máscara + dispositivo) foram carregados no compartimento da metalizadora (Figura 41), onde ocorre a metalização por evaporação térmica. Nesta evaporadora, o planetário se movimenta durante a metalização para garantir uma camada homogênea de alumínio em todas as amostras. O filamento de tungstênio, onde é inserido o alumínio metálico na forma de fio, é aquecido e foram obtidas espessuras de Al de até $200 \mathrm{~nm}$ a uma taxa de $10 \mathrm{~nm} / \mathrm{s}$.

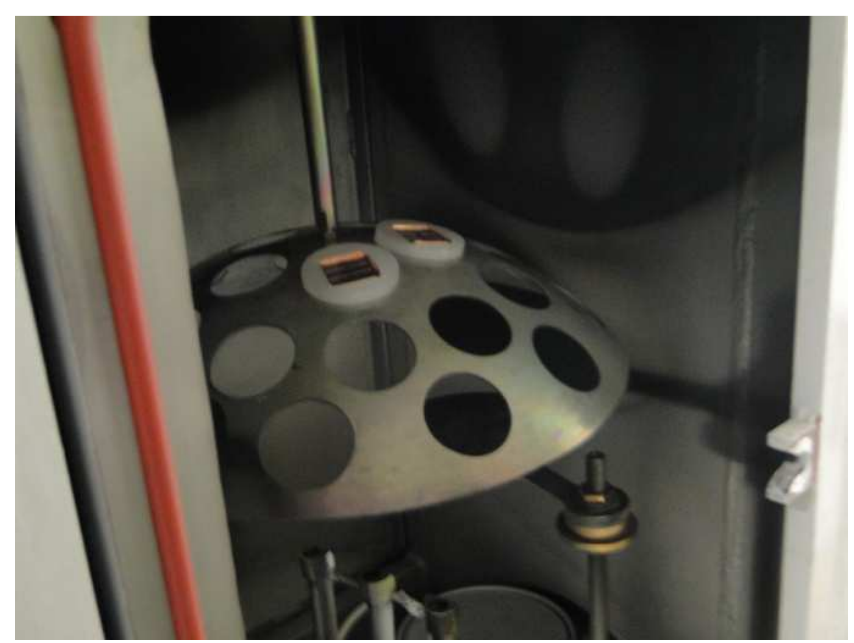

Figura 41 - Câmara de metalização e o planetário com os porta-amostras.

Para formar os eletrodos de Al foram utilizadas máscaras de cobre para P-OLEDs de $9 \mathrm{~mm}^{2}$ e $25 \mathrm{~mm}^{2}$ de área ativa, formando a estrutura do dispositivo apresentado na Figura 42. 


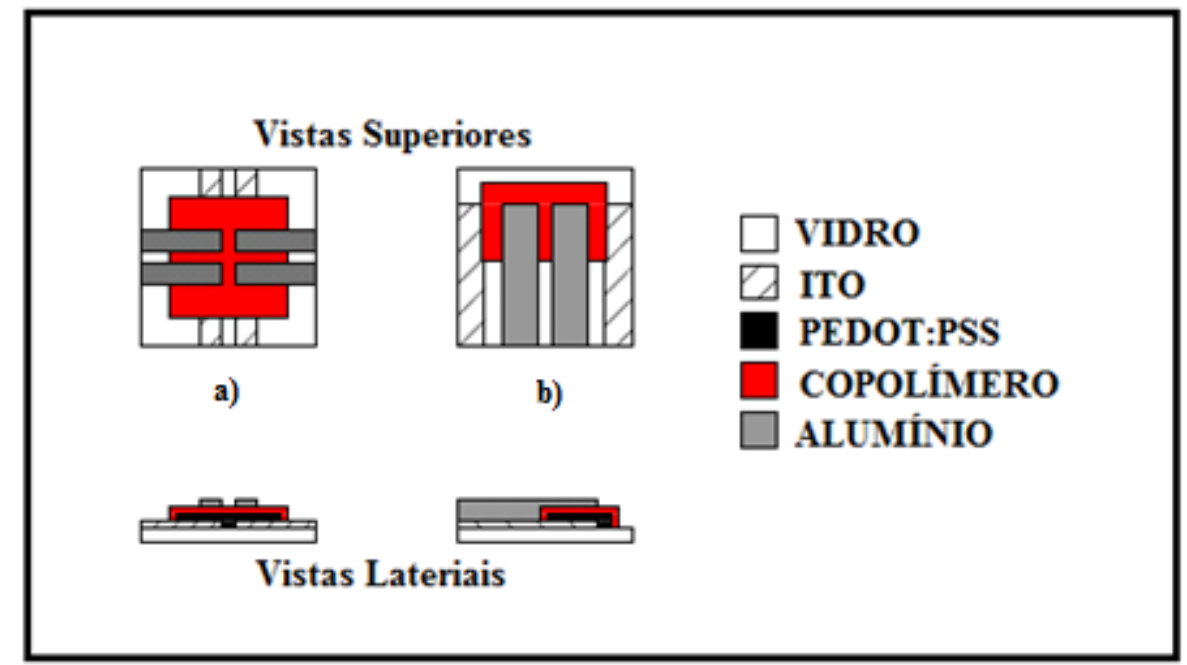

Figura 42 - Estrutura dos dispositivos com: a) $9 \mathrm{~mm}^{2}$ e b) $25 \mathrm{~mm}^{2}$ de área ativa.

\subsubsection{Encapsulamento}

O encapsulamento foi realizado após a etapa de metalização dos dispositivos com alumínio. A câmara de metalização foi despressurizada e as amostras foram transferidas internamente para a glove-box, que se encontrava em atmosfera de nitrogênio, temperatura ambiente e com aproximadamente $20 \%$ de umidade relativa. Os vidros utilizados no encapsulamento possuíam áreas de $17 \mathrm{~mm}$ x $17 \mathrm{~mm}$ (para os dispositivos com área ativa de 9 $\mathrm{mm}^{2}$ ) e de $17 \mathrm{~mm}$ x $25 \mathrm{~mm}$ (para os dispositivos com área ativa de $25 \mathrm{~mm}^{2}$ ), e que passaram pelo mesmo procedimento de limpeza descrito nos itens 3.3.3.2 e 3.3.3.3. Estas lâminas foram fixadas sobre as amostras, utilizando fita dupla-face adesiva, modelo VHB 4910, da marca $3 \mathrm{M}$.

\subsubsection{Aplicação de cola condutiva de prata}

Para proteger e melhorar a condutividade elétrica, os contatos dos eletrodos tanto o de alumínio, quanto o de ITO foram recobertos com cola condutiva de prata, melhorando assim o desempenho final dos dispositivos, durantes os testes elétricos. 


\subsubsection{Caracterização dos P-OLEDs}

\subsubsection{Caracterização Elétrica}

Para a caracterização elétrica dos P-OLEDs foram usados fontes e medidores de tensão e corrente. Os equipamentos utilizados para realização desta medição estão apresentados na Figura 43, onde: a) pertencente ao Laboratório de Engenharia de Macromoléculas (Departamento - PMT) e b) pertencente ao Laboratório de Microeletrônica (Departamento - PSI). As análises iniciam-se ao conectar as pontas de prova nos eletrodos dos dispositivos, sendo o ânodo correspondente ao ITO e o cátodo ao alumínio. As condições desse procedimento dependem da composição dos P-OLEDs, porém estes são submetidos a uma tensão máxima pré-determinada, com uma taxa de $1 \mathrm{~V} / \mathrm{s}$ e sua corrente elétrica é medida em função da tensão aplicada.

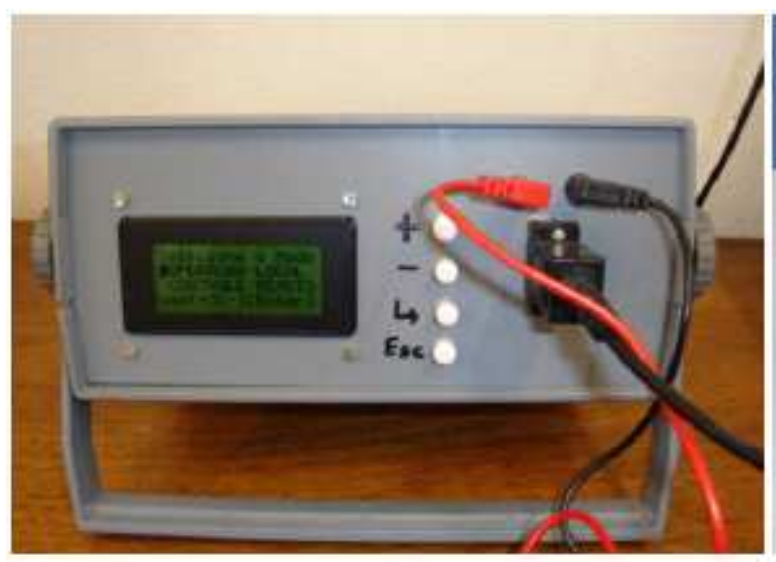

a)

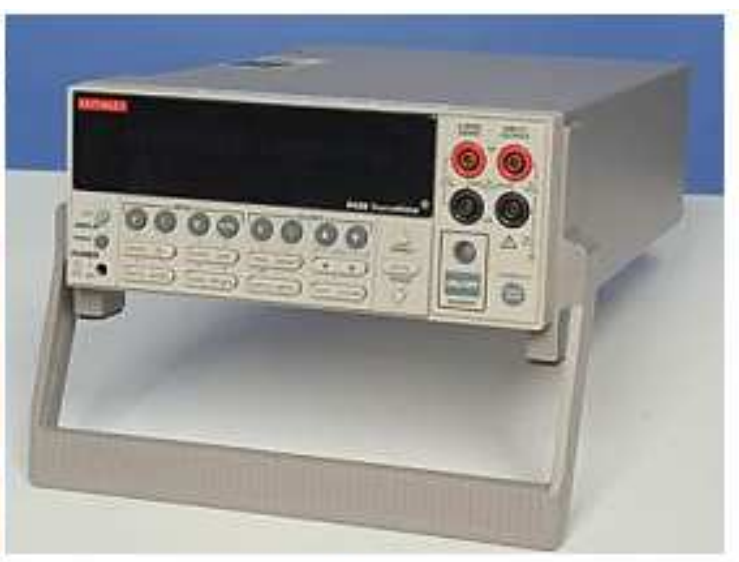

b)

Figura 43 - Fontes de energia: a) montada sob encomenda e b) Keithley, modelo 2420.

\subsubsection{Caracterizações Ópticas}

As caracterizações ópticas dos P-OLEDs foram realizadas simultaneamente à caracterização elétrica dos mesmos, onde foi avaliada a intensidade luminosa dos P-OLEDs em função do comprimento de onda emitido, utilizados dois espectrorradiômetros, um da marca Luzchem, modelo SPR-03 (pertencente ao Instituto de Física da USP), e outro da marca 
Ocean Optics modelo HR 2000+ (pertencente ao Laboratório de Microeletrônica da Escola Politécnica da USP). Ambos os equipamentos possuem uma fibra óptica acoplada e suas medições são realizadas a partir de seu posicionamento sobre a área ativa do dispositivo polarizado. A Figura 44 apresenta os dois equipamentos utilizados nessas análises.

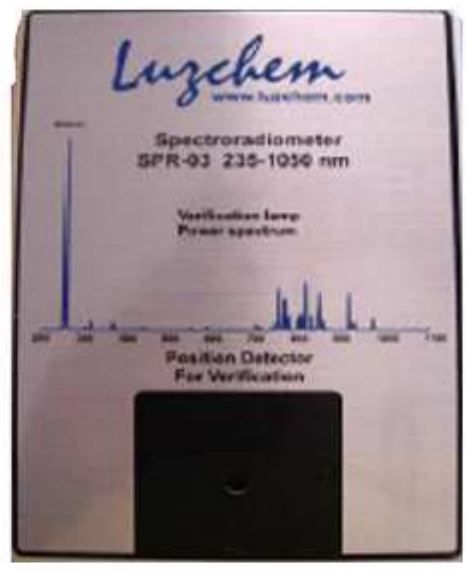

a)

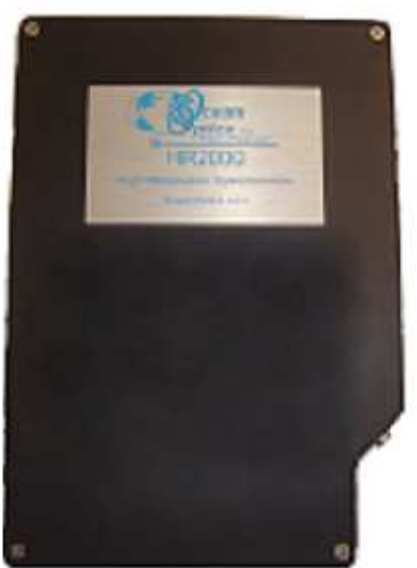

b)

Figura 44 - Espectrorradiômetros a) Luzchem e b) Ocean Optics.

Além dos espectrorradiômetros, também foi utilizado um Colorímetro, modelo SC100A da Konica-Minolta, do LME, do Departamento de Engenharia de Sistemas Eletrônicos da Escola Politécnica da USP, onde foram medidos a luminância e as coordenadas de cromaticidade dos dispositivos polarizados. A Figura 45 apresenta o equipamento utilizado.

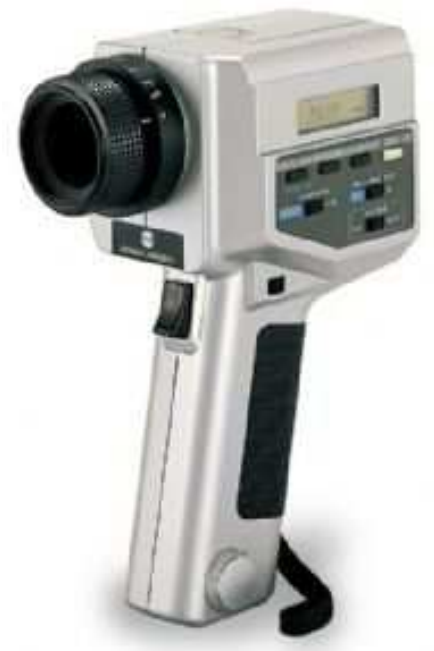

Figura 45 - Colorímetro Konica-Minolta. 


\section{RESULTADOS PARCIAIS E DISCUSSÕES}

\subsection{Sínteses dos copolímeros}

\subsubsection{Rendimentos}

Os rendimentos foram calculados a partir da razão de massa obtida pela massa teórica dos meros dos copolímeros sintetizados. A Figura 46 apresenta os monômeros utilizados em cada síntese, os polímeros formados e as respectivas massas molares dos meros de cada polímero.

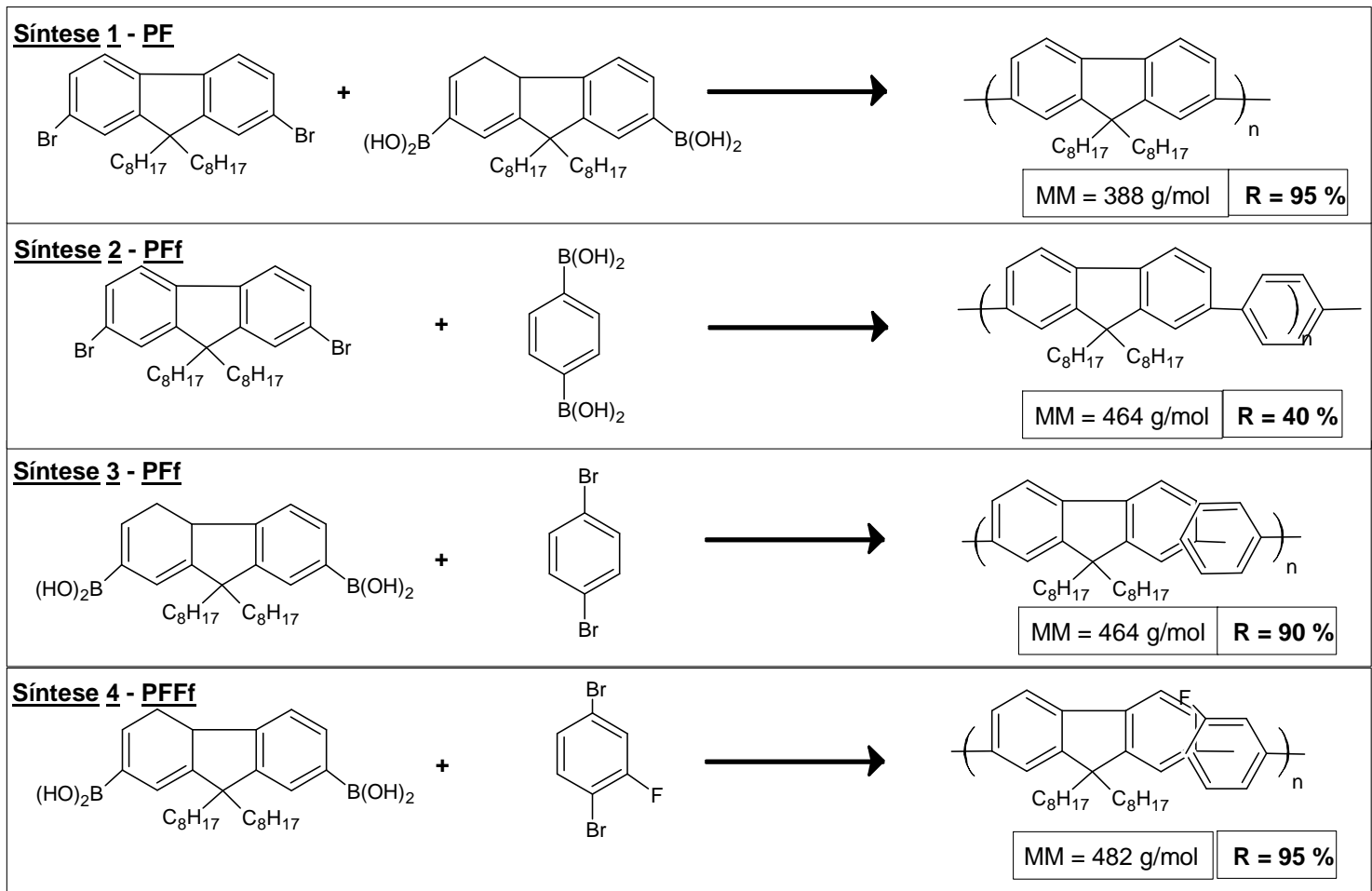

Figura 46 - Polímeros sintetizados e as respectivas massas molares de seus meros. 
Com base no cálculo dos rendimentos das sínteses dos polímeros pode ser calculada uma estimativa das massas molares dos copolímeros formados a partir da equação de Carothers.

\section{- Cálculo das massas molares dos copolímeros pela equação de Carothers}

A equação de Carothers fornece o grau de polimerização $\left(X_{n}\right)$ a partir da equação (1), onde $\mathbf{r}$ é a relação entre o número de mols dos diferentes grupos de reagentes e $\boldsymbol{P}$ é o fator de conversão, assim sendo, se reação ocorrer em quantidade equimolar dos monômeros, a equação se torna mais simplificada (equação 3$)^{56}$.

$$
\begin{aligned}
& X_{n}=\frac{1+r}{(1+r)-(2 * r * P)} \\
& X_{n}=\frac{1}{1-P}
\end{aligned}
$$

A partir cálculo do grau de polimerização, torna-se possível o cálculo da massa molar numérica do polímero, apresentado na equação (4).

$$
\mathrm{Mn}=\mathrm{MM} * \mathrm{X}_{\mathrm{n}}
$$

Assim sendo, foram calculadas as massas molares das quatro sínteses realizadas:

- Síntese $1(\mathrm{PF})$

$$
\begin{aligned}
& \mathrm{P}=0,95 \longrightarrow \mathrm{X}_{\mathrm{n}}=20 \\
& \mathrm{Mn}=388 * 20=7760 \mathrm{~g} / \mathrm{mol}
\end{aligned}
$$

- $\quad$ Síntese $2\left(\mathrm{PF}_{\mathrm{P}}\right)$

$$
\begin{aligned}
& \mathrm{P}=0,40 \longrightarrow \mathrm{X}_{\mathrm{n}}=1,67 \\
& \mathrm{Mn}=464 * 1,67=774,9 \mathrm{~g} / \mathrm{mol}
\end{aligned}
$$


- Síntese $3\left(\mathrm{PF}_{\mathrm{P}}\right)$

$$
\begin{aligned}
& \mathrm{P}=0,90 \longrightarrow \mathrm{X}_{\mathrm{n}}=10 \\
& \mathrm{Mn}=464 * 10=4640 \mathrm{~g} / \mathrm{mol}
\end{aligned}
$$

- Síntese $4\left(\mathrm{PF}_{\mathrm{PF}}\right)$

$$
\begin{aligned}
& \mathrm{P}=0,95 \longrightarrow \mathrm{X}_{\mathrm{n}}=20 \\
& \mathrm{Mn}=482 * 20=9640 \mathrm{~g} / \mathrm{mol}
\end{aligned}
$$

A Tabela 2 apresenta uma comparação entre as sínteses realizadas, o estado físico dos copolímeros, seus rendimentos e sua massa molar calculada pela equação de Carothers.

Tabela 2 - Comparação entre o estado físico, o rendimento de reação e suas massas molares dos copolímeros sintetizados.

\begin{tabular}{|c|c|c|c|c|}
\hline Síntese & Copolímero & Estado & Rendimento & Mn (Equação de Carothers) \\
\hline 1 & $\mathrm{PF}$ & Sólido & $95 \%$ & $7760 \mathrm{~g} / \mathrm{mol}$ \\
\hline 2 & $\mathrm{PF}_{\mathrm{P}}$ & Pastoso & $40 \%$ & $774,9 \mathrm{~g} / \mathrm{mol}$ \\
\hline 3 & $\mathrm{PF}_{\mathrm{P}}$ & Sólido & $90 \%$ & $4640 \mathrm{~g} / \mathrm{mol}$ \\
\hline 4 & $\mathrm{PF}_{\mathrm{PF}}$ & Sólido & $95 \%$ & $9640 \mathrm{~g} / \mathrm{mol}$ \\
\hline
\end{tabular}

Os valores calculados utilizando a equação de Carothers mostram que as sínteses 1, 3 e 4 resultaram um rendimento elevado e produziram copolímeros com $M_{n}$ bem superiores a da síntese 2, podendo ser comprovado também pelo aspecto físico dos materiais obtidos. A síntese 2 foi a única síntese que obteve um rendimento baixo e estado físico (pastoso) diferente das demais sínteses (sólidos), indicando baixa massa molar. 


\subsubsection{Cromatografia de permeação em gel}

Os resultados das análises de massas molares dos polímeros por cromatografia de permeação em gel estão apresentados na Tabela 3.

Tabela 3 - Massas molares dos polímeros determinadas por GPC utilizando-se THF como solvente e poliestireno como padrão.

\begin{tabular}{|c|c|c|c|c|c|c|}
\hline Síntese & Copolímero & $\mathbf{M}_{\mathbf{n}}(\mathbf{g} / \mathbf{m o l})$ & $\mathbf{M}_{\mathbf{w}}(\mathbf{g} / \mathbf{m o l})$ & $\mathbf{M}_{\mathbf{z}}(\mathbf{g} / \mathbf{m o l})$ & $\mathbf{M}_{\mathbf{w}} / \mathbf{M}_{\mathbf{n}}$ & $X_{n}=\mathbf{M}_{\mathbf{n}} / \mathbf{m}$ \\
\hline 1 & $\mathrm{PF}$ & 9270 & 35350 & 75830 & 3,81 & 23,8 \\
\hline 2 & $\mathrm{PF}_{\mathrm{P}}$ & 660 & 690 & 720 & 1,03 & 1,42 \\
\hline 3 & $\mathrm{PF}_{\mathrm{P}}$ & 9800 & 28830 & 58670 & 2,94 & 21,1 \\
\hline 4 & $\mathrm{PF}_{\mathrm{PF}}$ & 4230 & 21490 & 47070 & 5,08 & 8,76 \\
\hline
\end{tabular}

Os resultados mostram que os copolímeros das sínteses 1,3 e 4 apresentaram massas molares superiores ao da síntese 2, como esperado conforme o estado físico de cada polímero, sendo que apenas o copolímero da síntese 2 apresentou um estado pastoso, enquanto que os demais eram sólidos.

A polidispersão apresentada nas sínteses que obtiveram polímeros sólidos (sínteses 1, 3 e 4) mostra que os tamanhos das moléculas formadas apresentam tamanhos variados, devido a esses valores serem bem superiores a 1 , ou seja, o copolímero da síntese 4 ( $\left.\mathrm{PF}_{\mathrm{PF}}\right)$ apresentou maior valor de polidispersão, portanto o que possui tamanhos de moléculas mais variados.

Outro dado que pôde ser calculado foi o de grau de polimerização, que representa uma média da quantidade de meros existentes em uma molécula (tamanho médio da cadeia) em cada polímero. Assim, o PF (copolímero - síntese 1) foi o que apresentou maior grau de polimerização e por isso apresenta a maior cadeia polimérica dentre os polímeros sintetizados. 


\subsubsection{EDX}

As análises EDX foram realizadas para verificar os elementos químicos presentes nas estruturas dos polímeros sintetizados. Através de cada espectro foi possível comprovar a presença dos elementos químicos das amostras, ou seja, os elementos químicos previstos de pela estrutura química polimérica, possíveis contaminantes e presença de materiais de partida (monômeros das sínteses).

As Figura 47-50.apresentam espectros EDX dos copolímeros, PF (síntese 1), $\mathrm{PF}_{\mathrm{P}}$ (síntese 2), $\mathrm{PF}_{\mathrm{P}}$ (síntese 3) e $\mathrm{PF}_{\mathrm{PF}}$ (síntese 4), respectivamente.

Os espectros apresentaram baixa porcentagem atômica de elementos químicos, como cloro, boro e bromo, o que indica o sucesso na terminação das cadeias poliméricas e na etapa de eliminação de tais grupos no processo de purificação, porém o espectro referente ao PF da síntese 2 apresentou uma alta quantidade de grupos $\mathrm{Br}$, comprovando o fato de tal polímero possuir baixo rendimento químico e baixa massa molecular.

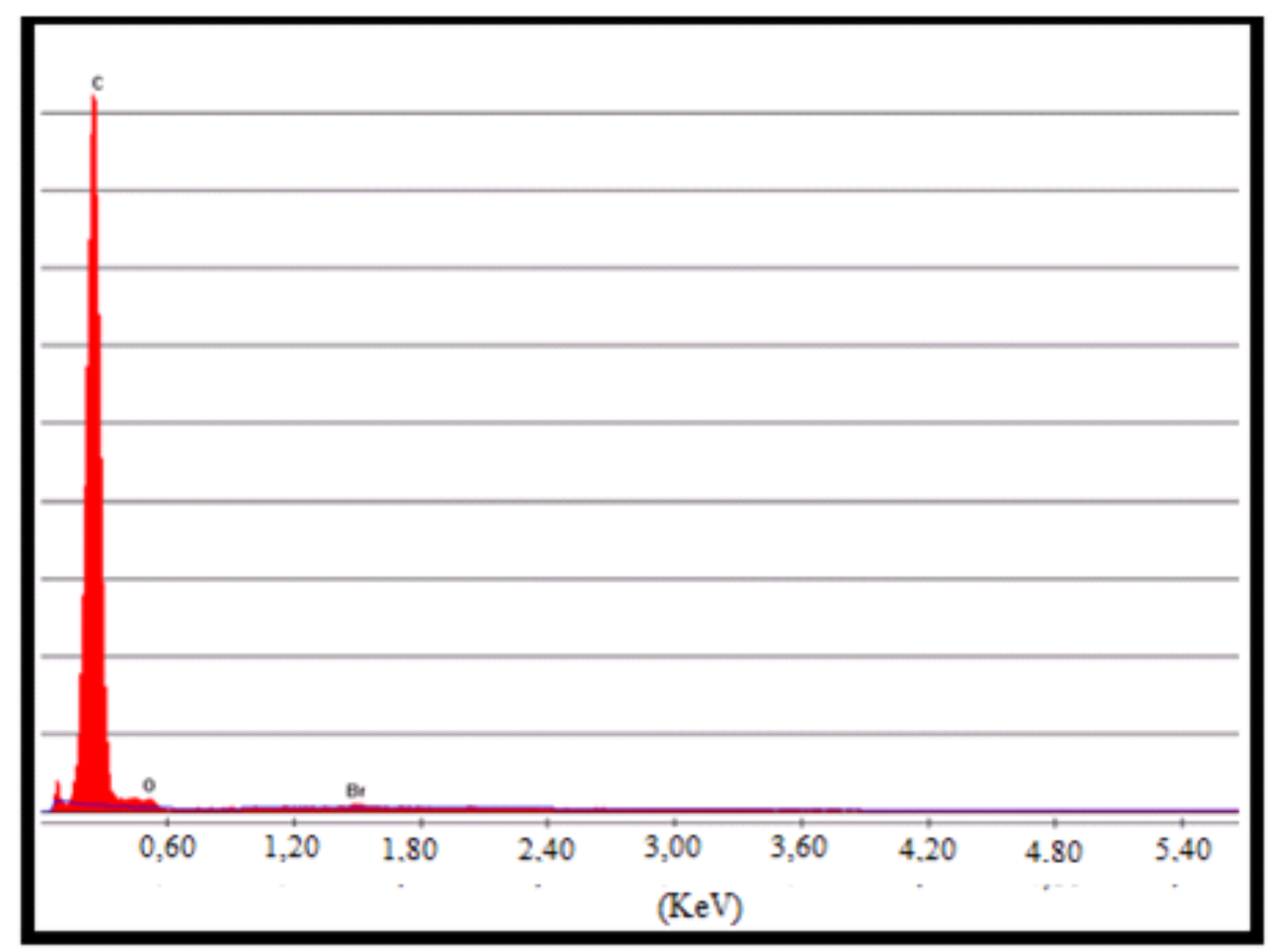

Figura 47 - EDX do PF (síntese 1). 


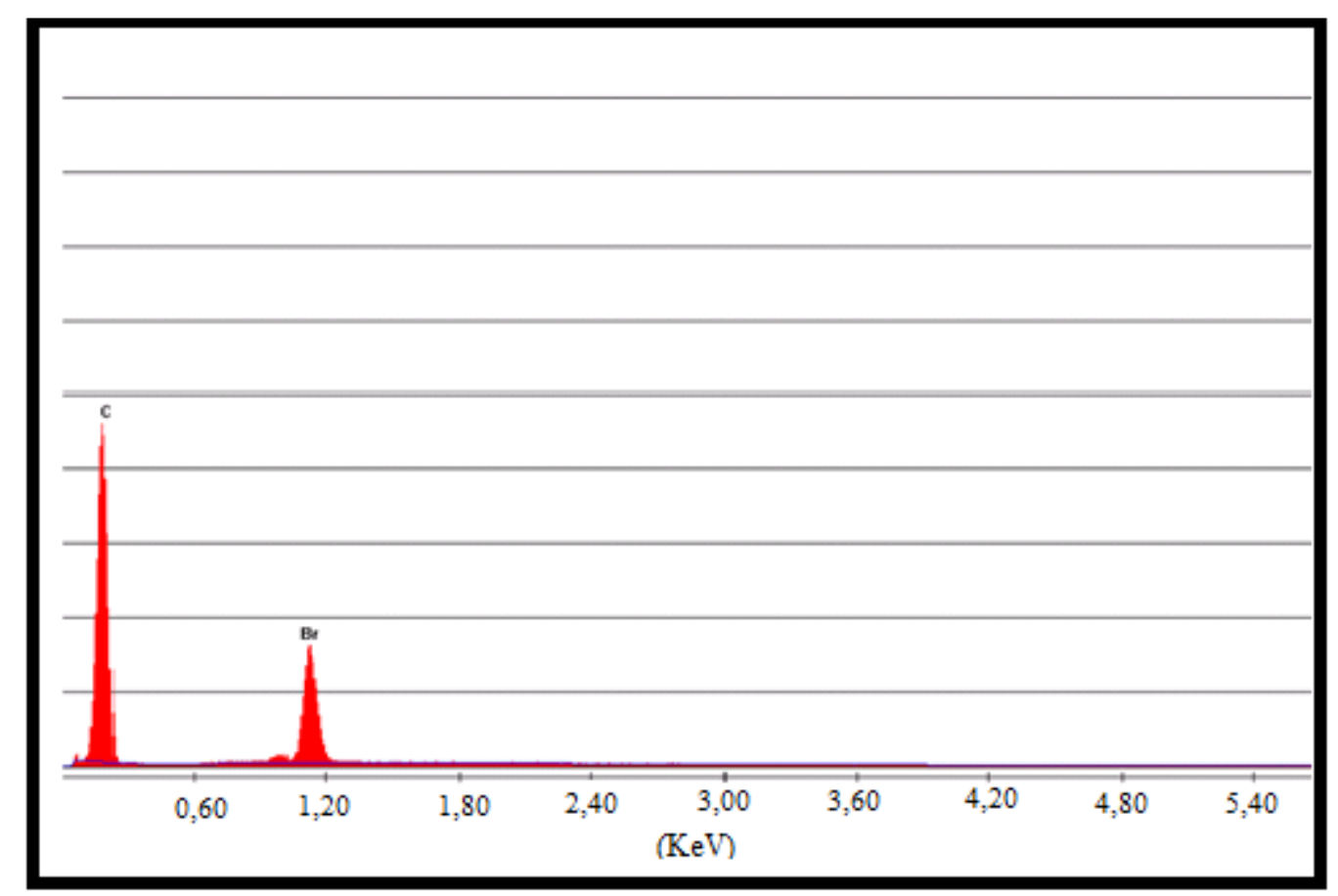

Figura 48 - EDX do $\mathrm{PF}_{\mathrm{P}}$ (Síntese 2).

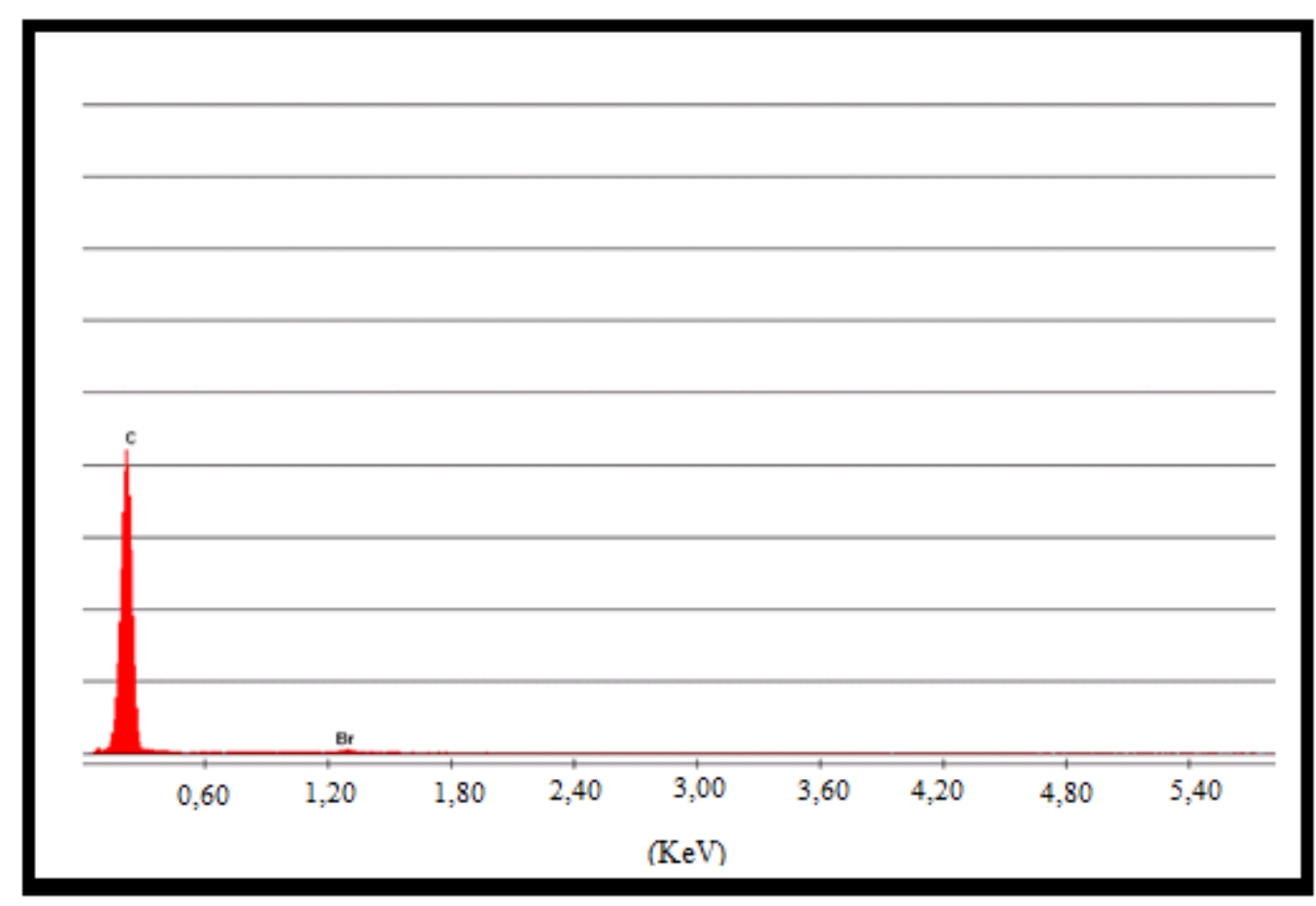

Figura 49 - EDX do $\mathrm{PF}_{\mathrm{P}}$ (síntese 3). 


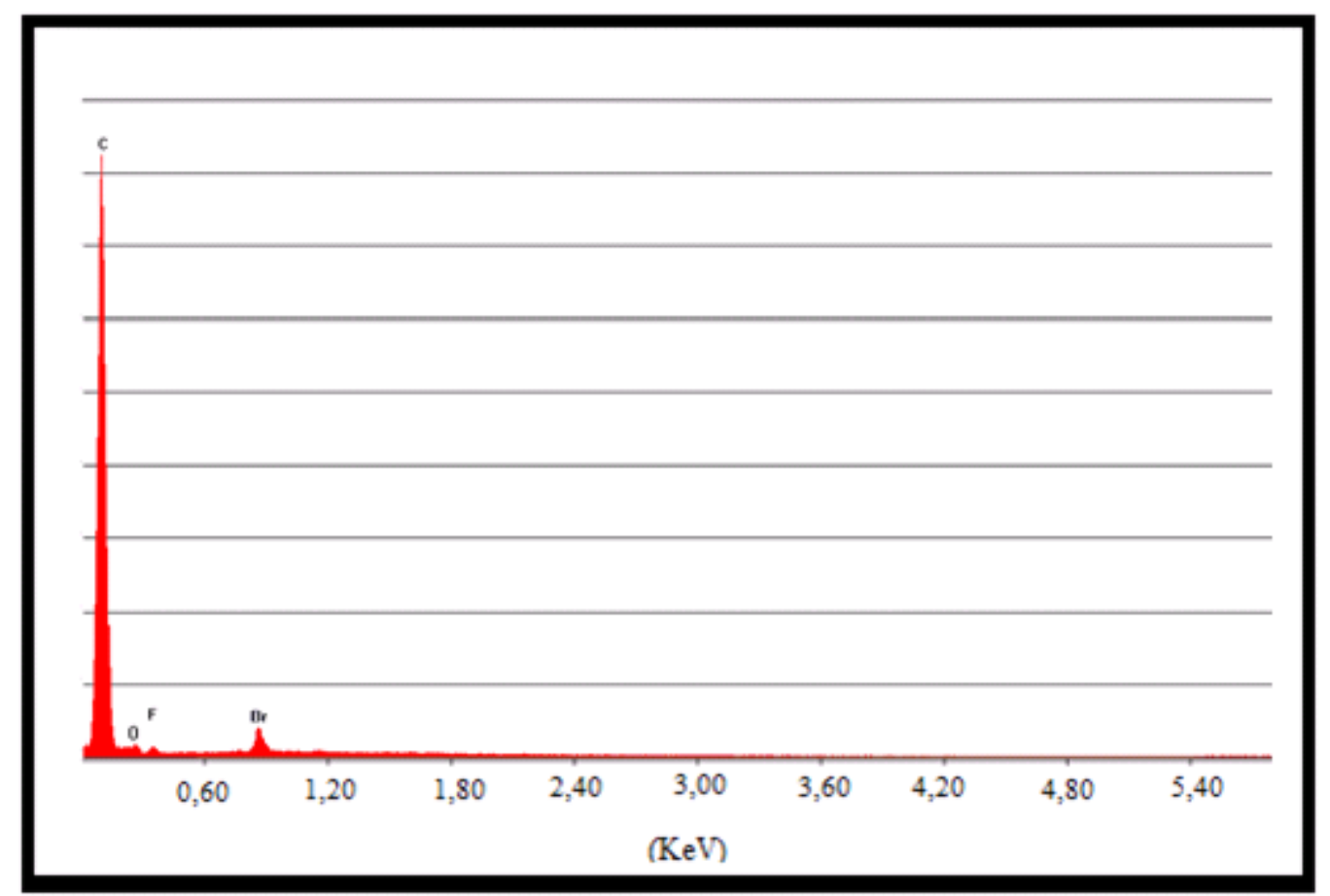

Figura 50 - EDX do $\mathrm{PF}_{\mathrm{PF}}$ (síntese 4).

A Tabela 4 apresenta a porcentagem atômica dos elementos químicos presentes na estrutura dos copolímeros sintetizados.

Tabela 4 - Porcentagem atômica dos elementos químicos na estrutura dos copolímeros.

\begin{tabular}{|c|c|c|c|c|}
\cline { 2 - 5 } \multicolumn{1}{c|}{} & \multicolumn{4}{c|}{ Elementos Químicos (\%) } \\
\hline Copolímero & C (carbono) & F (flúor) & O (oxigênio) & Br (bromo) \\
\hline$P F($ sintese 1) & 98,2 & - & 1,70 & 0,1 \\
\hline$P F_{P}$ (sintese 2) & 83,2 & - & - & 16,8 \\
\hline$P F_{P}$ (sintese 3) & 99,0 & - & - & 1,0 \\
\hline$P F_{P F}$ (síntese 4) & 95,0 & 1,0 & 2,5 & 1,5 \\
\hline
\end{tabular}

Os dados apresentados na tabela anterior confirmam a baixa concentração de oxigênio e bromo nos polímeros $\left[\mathrm{PF}, \mathrm{PF}_{\mathrm{P}}\right.$ (síntese 3) e $\mathrm{PF}_{\mathrm{PF}}$, enquanto que para o PF (síntese 2) apresentou alta porcentagem de grupos bromo, confirmando o baixo grau de polimerização e a aparência pastosa final do material. 


\subsubsection{Espectroscopia de ressonância magnética nuclear ( $\left.{ }^{1} \mathrm{HNMR}\right)$}

Os polímeros sintetizados foram analisados por ${ }^{1} \mathrm{HNMR}$, com a finalidade de se caracterizar os diferentes tipos de prótons a partir de valores de deslocamentos químicos ${ }^{57}$.

A estrutura química do polímero polifluoreno (PF) utilizada para as análises de ${ }^{1}$ HNMR está representada na Figura 51. O espetro obtido está apresentado na Figura 52, onde os picos ${ }^{1} \mathrm{H}$ característicos do polímero foram inseridos e tabelados (Tabela 5).

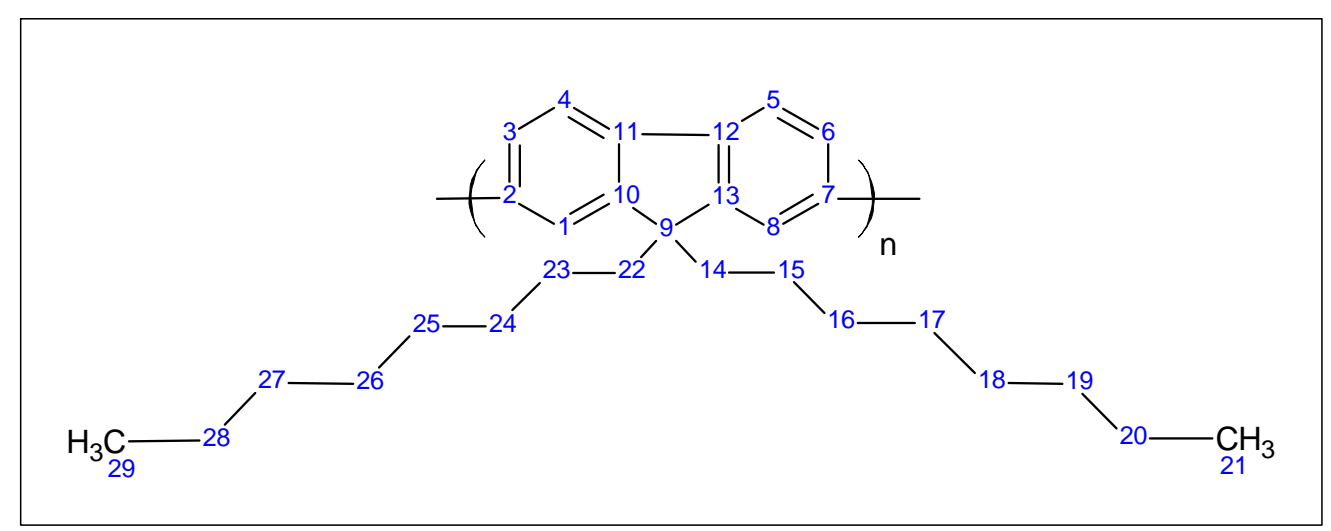

Figura 51 - Estrutura do polímero (PF) para análise de ${ }^{1} \mathrm{HNMR}$.

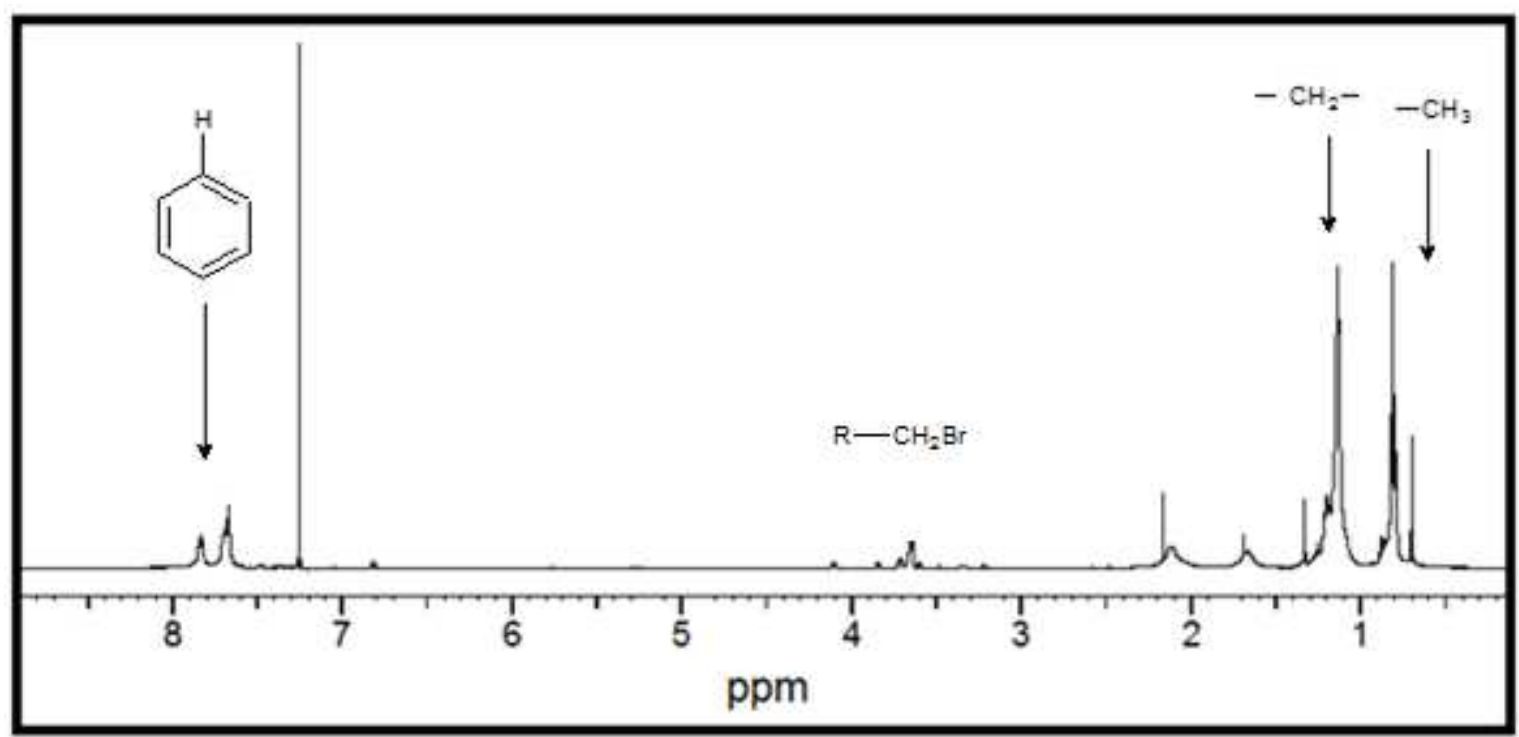

Figura 52 - Espectro de ${ }^{1} \mathrm{HNMR}(200 \mathrm{~Hz})$ do PF. 
Tabela 5 - Deslocamentos químicos observados no espectro de ${ }^{1}$ HNMR do PF.

\begin{tabular}{|c|c|}
\hline $\mathbf{N}^{\circ}$ (prótons) & Deslocamento Químico \\
\hline $1-4,5-8$ & $7,90-7,50$ \\
\hline $14-20,22-28$ & $1,70-1,00$ \\
\hline 21,29 & $0,90-0,70$ \\
\hline
\end{tabular}

Os deslocamentos químicos do $\mathrm{PF}$ apresentados na Tabela 5 correspondem à posição dos prótons na cadeia polimérica. A região de deslocamento químico entre 7,90 - 7,50 representa os prótons ligados aos anéis benzênicos, a região entre 1,70 - 1,00 se refere aos grupos $\mathrm{CH}_{2}$, e a região de 0,90 - 0,70 aos grupos laterais $\mathrm{CH}_{3}$.

A estrutura química do copolímero $\left(\mathrm{PF}_{\mathrm{P}}\right)$ utilizada para as análises de ${ }^{1} \mathrm{HNMR}$ está representada na Figura 53. O espectro obtido está representado na Figura 54, os picos ${ }^{1} \mathrm{H}$ característicos do polímero foram inseridos e tabelados (Tabela 6).

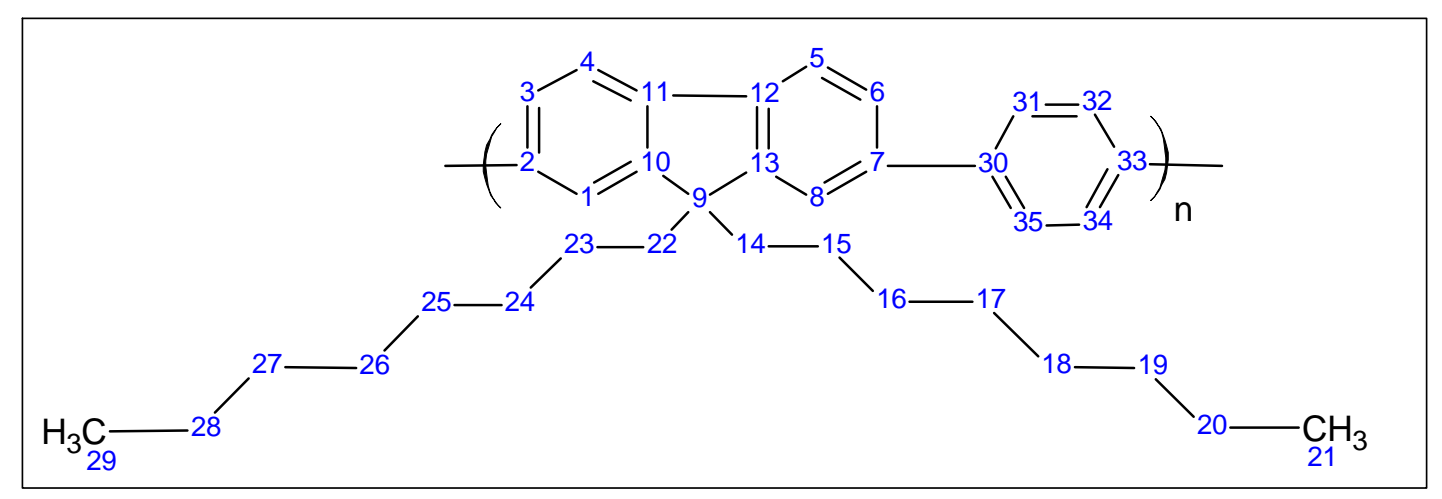

Figura 53 - Estrutura do polímero $\left(\mathrm{PF}_{\mathrm{P}}\right)$ para análise de ${ }^{1} \mathrm{HNMR}$. 


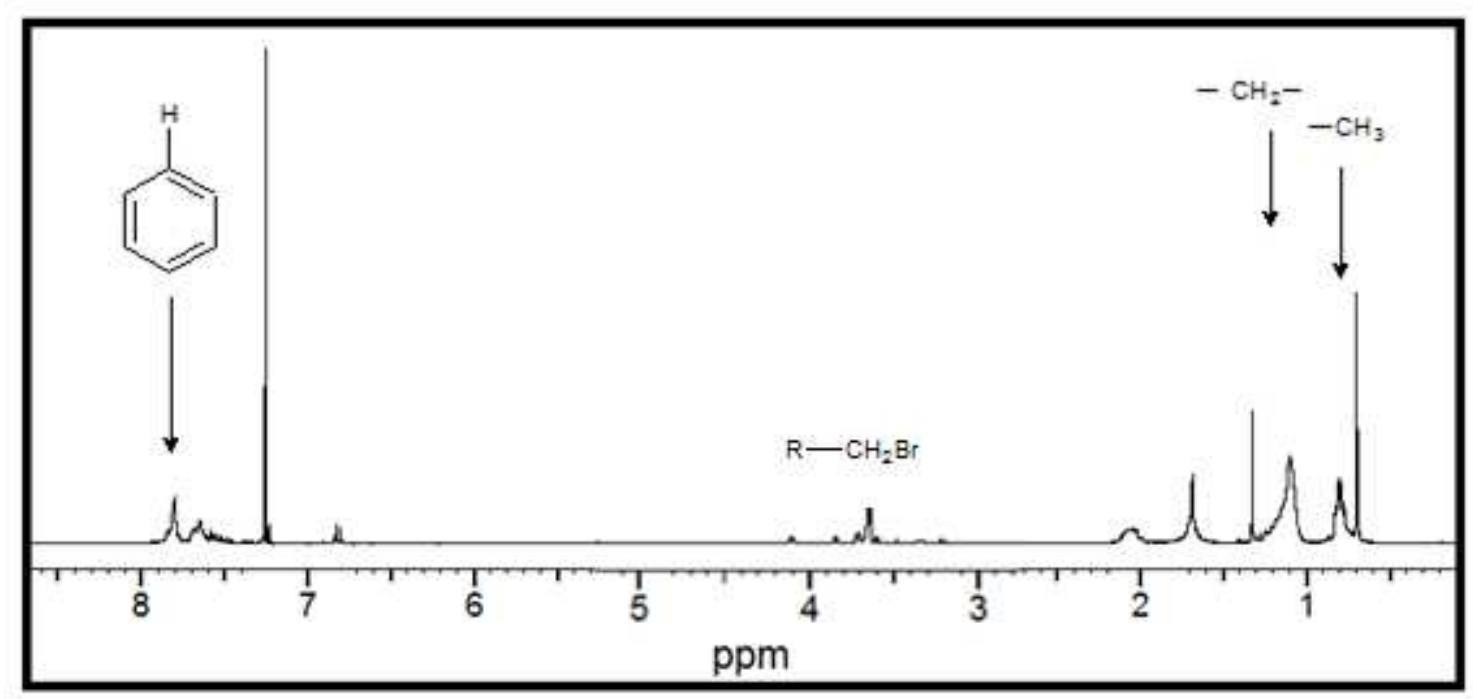

Figura 54 - Espectro de ${ }^{1} \mathrm{HNMR}(200 \mathrm{~Hz})$ do $\mathrm{PF}_{\mathrm{p}}$.

Tabela 6 - Deslocamentos químicos observados no espectro de ${ }^{1} \mathrm{HNMR}$ do $\mathrm{PF}_{\mathrm{P}}$.

\begin{tabular}{|c|c|}
\hline $\mathbf{N}^{\circ}$ (prótons) & Deslocamento Químico \\
\hline $1-4,5-8,31,32,34,35$ & $7,90-7,50$ \\
\hline $14-20,22-28$ & $1,70-1,00$ \\
\hline 21,29 & $0,90-0,70$ \\
\hline
\end{tabular}

A região de deslocamento químico entre 7,90 - 7,50 é devida aos prótons ligados aos anéis benzênicos, a região entre 1,70 - 1,00 se refere aos hidrogênios alifáticos dos grupos $\mathrm{CH}_{2}$, e a região de 0,90 - 0,70 aos grupos alifáticos terminais $\mathrm{CH}_{3}$. 
A estrutura do copolímero $\left(\mathrm{PF}_{\mathrm{PF}}\right)$ utilizada para as análises de ${ }^{1} \mathrm{HNMR}$ está representada na Figura 55.

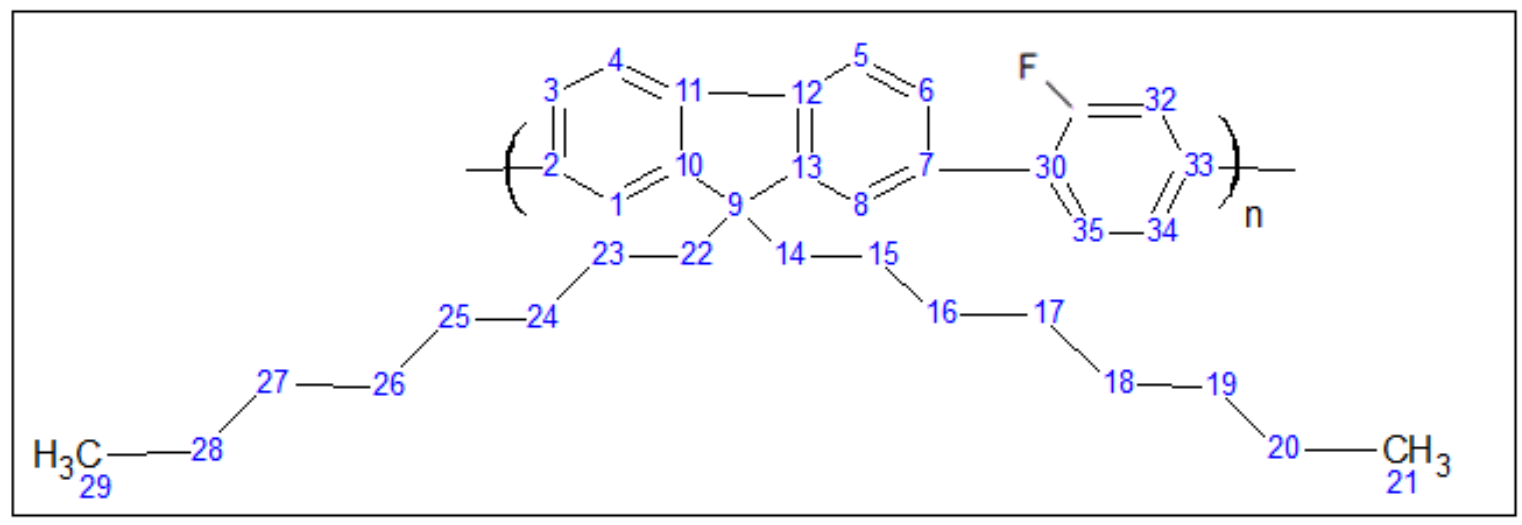

Figura 55 - Estrutura do polímero $\left(\mathrm{PF}_{\mathrm{PF}}\right)$ para análise de ${ }^{1} \mathrm{HNMR}$.

$\mathrm{O}$ espectro do $\mathrm{PF}_{\mathrm{PF}}$ obtido está apresentado na Figura 56 e os picos observados nos diferentes deslocamentos químicos foram associados aos hidrogênios da estrutura (Figura 55) e listados na

Tabela 7.

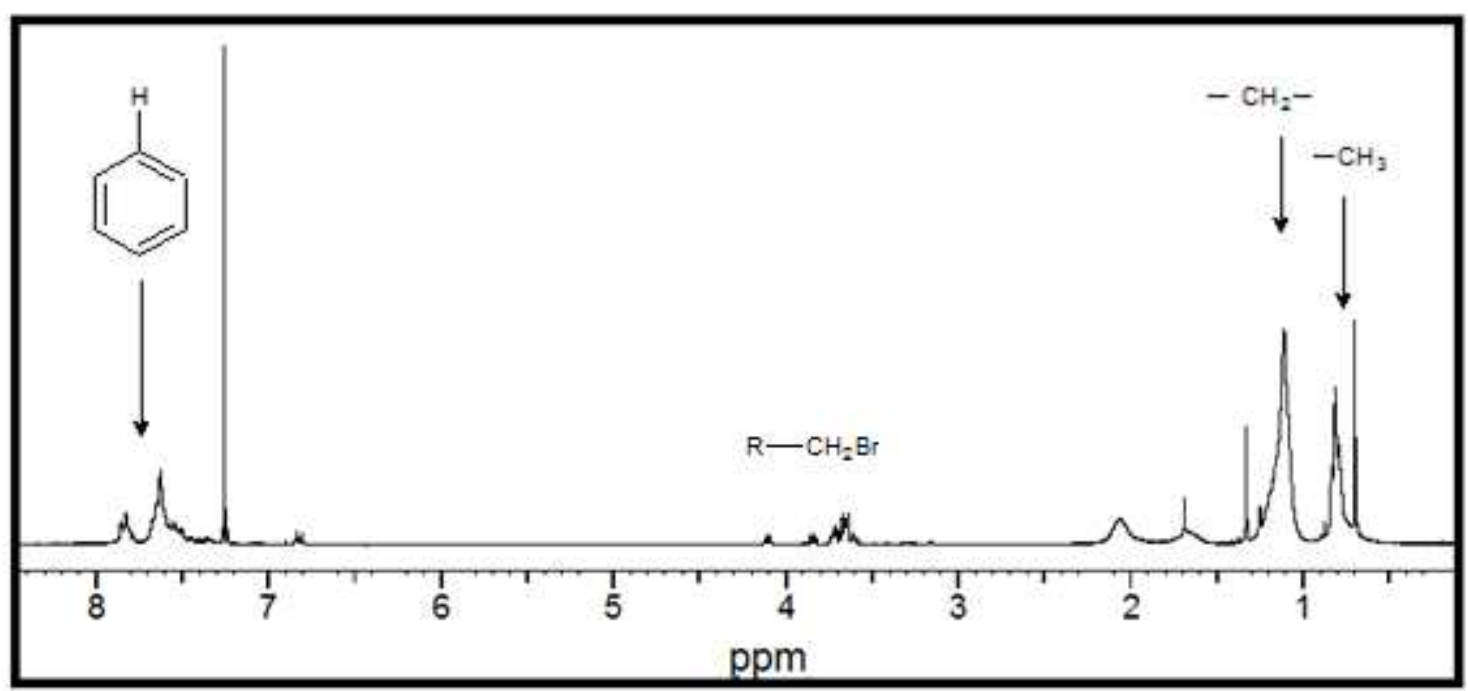

Figura 56 - Espectro de ${ }^{1} \mathrm{HNMR}(200 \mathrm{~Hz})$ do $\mathrm{PF}_{\mathrm{PF}}$. 
Tabela 7 - Deslocamentos químicos observados no espectro de ${ }^{1} \mathrm{HNMR}$ do $\mathrm{PF}_{\mathrm{PF}}$.

\begin{tabular}{|c|c|}
\hline $\mathbf{N}^{\circ}$ (prótons) & Deslocamento Químico \\
\hline $1-4,5-8,32,34,35$ & $7,90-7,50$ \\
\hline $14-20,22-28$ & $1,70-1,00$ \\
\hline 21,29 & $0,90-0,70$ \\
\hline
\end{tabular}

Os deslocamentos químicos do $\mathrm{PF}_{\mathrm{PF}}$ apresentados na

Tabela 7 correspondem à posição dos prótons na cadeia polimérica. A região de deslocamento químico entre 7,90 - 7,25 representa os prótons ligados aos anéis benzênicos, a região entre 1,70 - 1,00 se refere aos hidrogênios alifáticos dos grupos $\mathrm{CH}_{2}$, e a região de $0,90-0,70$ aos grupos alifáticos terminais $\mathrm{CH}_{3}$.

\subsubsection{Espectroscopia no infravermelho (FTIR)}

As Figuras 57-59 mostram os espectros de infravermelho dos copolímeros PF, $\mathrm{PF}_{\mathrm{P}} \mathrm{e}$ $\mathrm{PF}_{\mathrm{PF}}$, respectivamente. Os espectros obtidos possuem bandas de absorção praticamente nas mesmas regiões, sendo que o espectro $\mathrm{PF}_{\mathrm{PF}}$ apresenta-se diferenciado pelo número menor de picos de absorção.

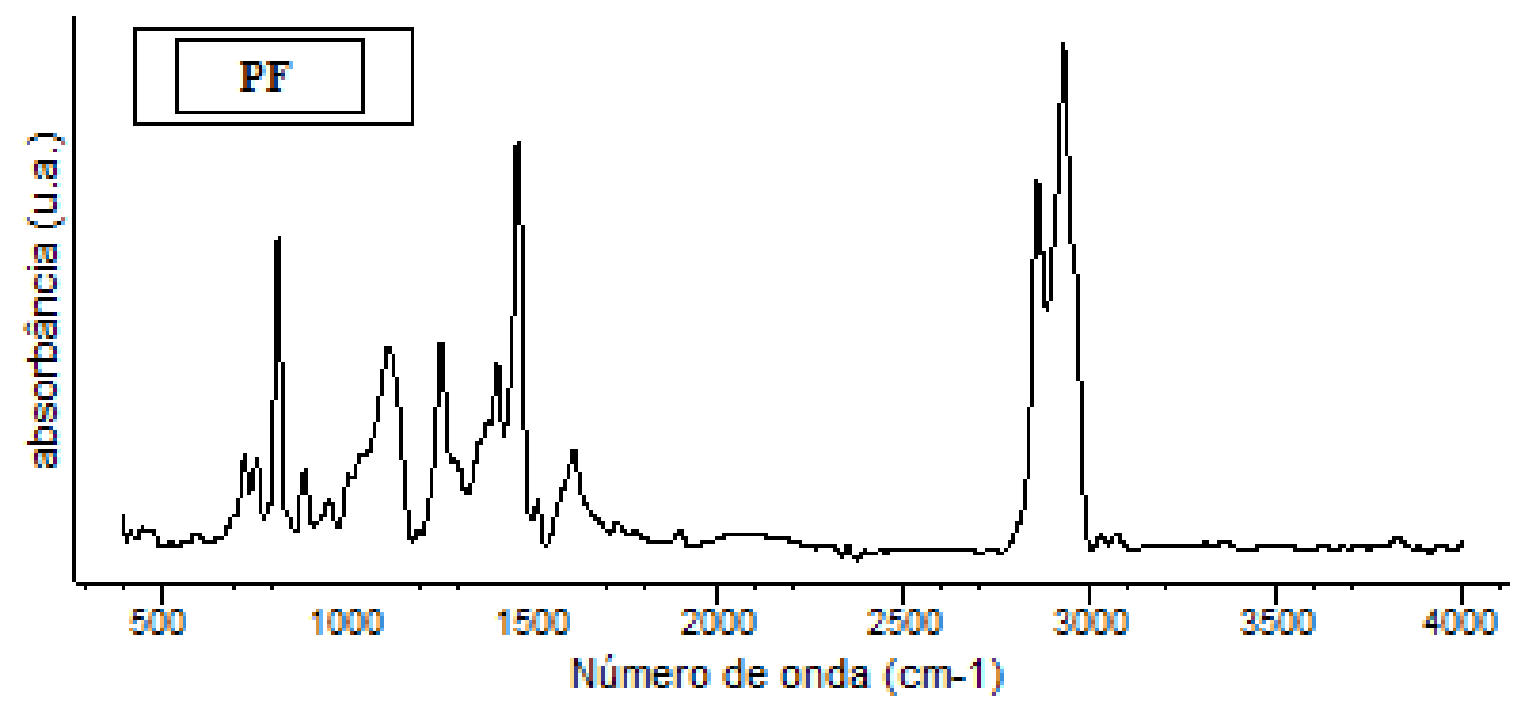

Figura 57 - Espectro de Infravermelho do PF. 


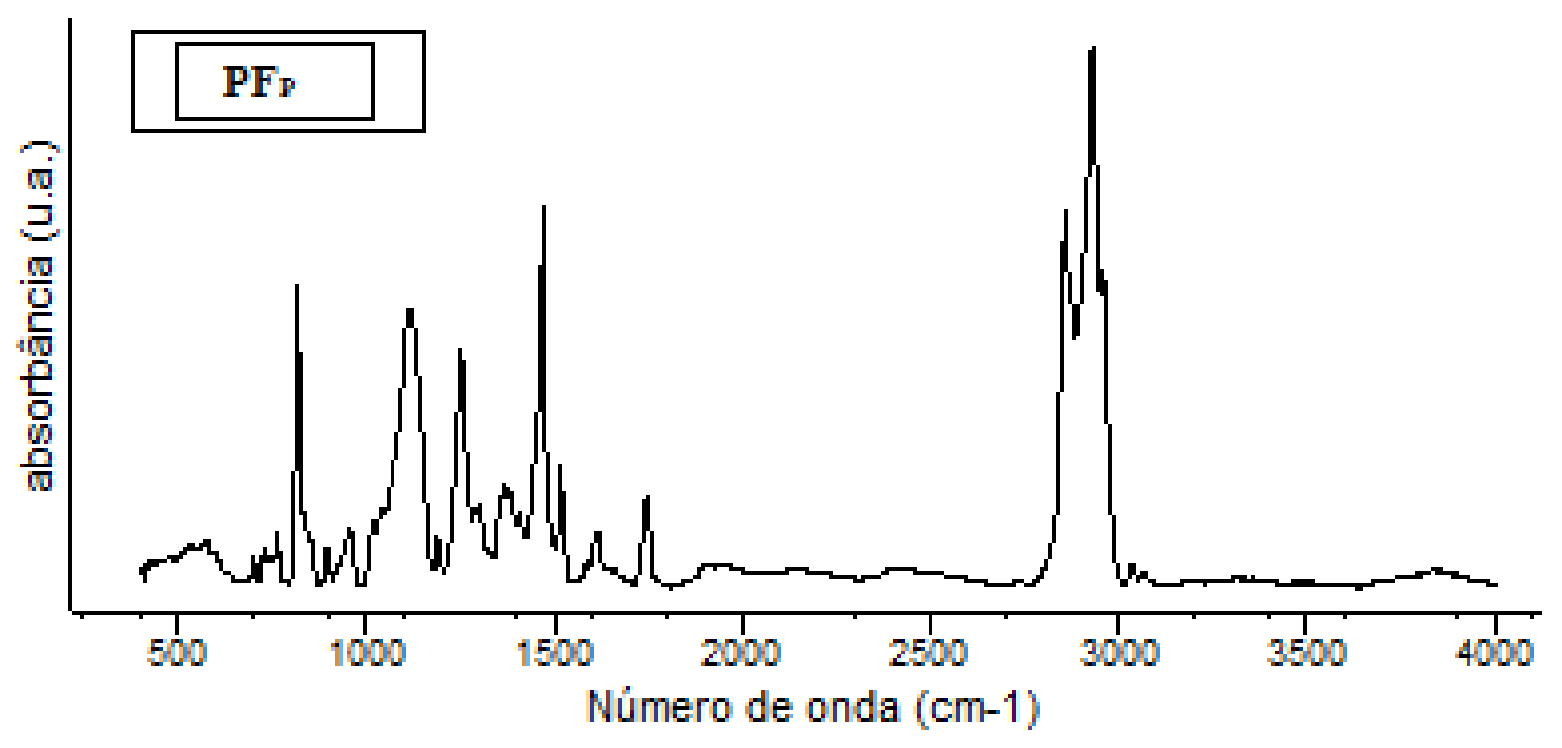

Figura 58 - Espectro de Infravermelho do $\mathrm{PF}_{\mathrm{P}}$.

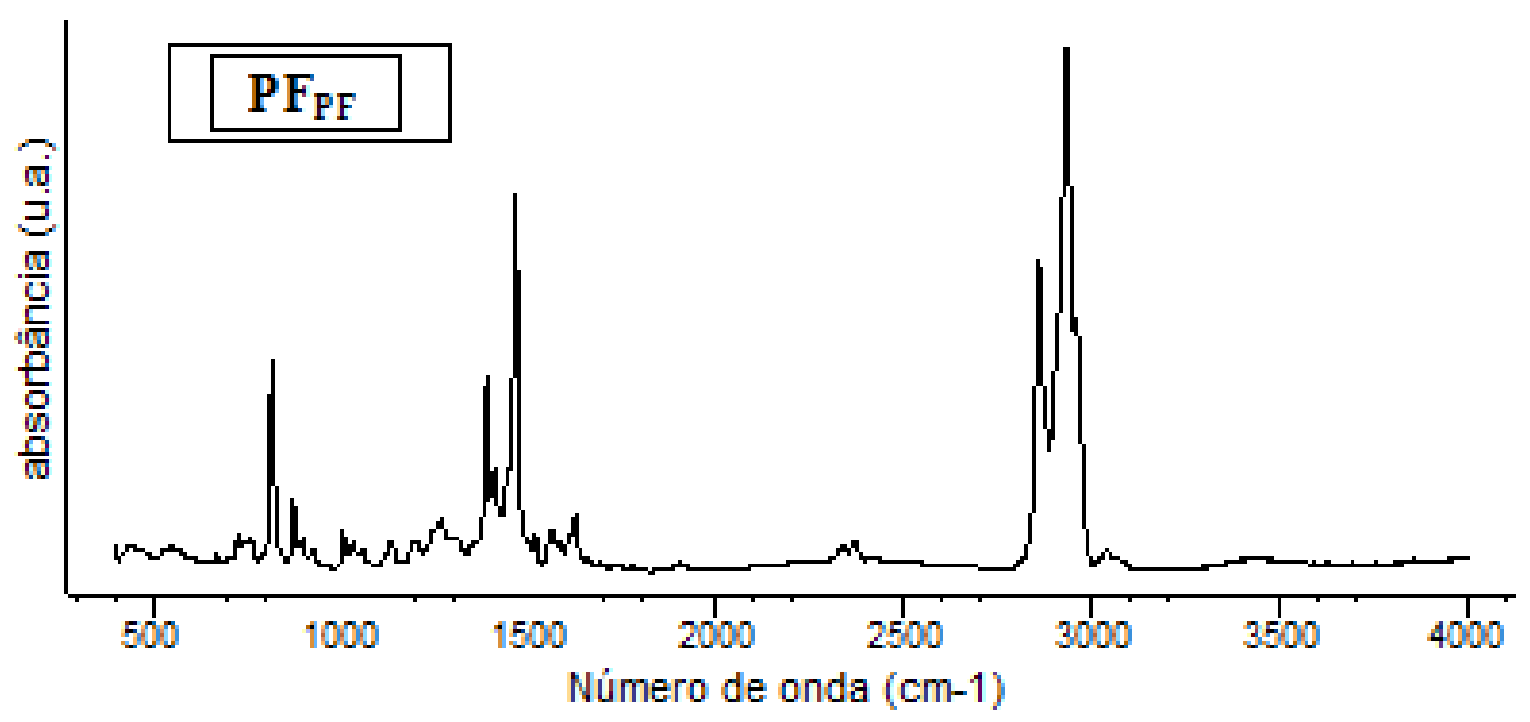

Figura 59 - Espectro de Infravermelho do $\mathrm{PF}_{\mathrm{PF}}$

Na região entre 2500 e $3200 \mathrm{~cm}^{-1}$ é possível ver a banda de intensidade alta em 2926 $\mathrm{cm}^{-1}$, que corresponde à ligação $\mathrm{C}-\mathrm{H}$ dos grupos $\mathrm{CH}_{2}$ e $\mathrm{CH}_{3}$, e da região entre 1400 a 1600 $\mathrm{cm}^{-1}$ que pode ser atribuída à ligação $\mathrm{C}-\mathrm{H}$ nos anéis aromáticos. Para hidrocarbonetos fluorados é observada banda de intensidade alta entre a região $1250-800 \mathrm{~cm}^{-1}(\mathrm{C}-\mathrm{F})$, que para o polímero sintetizado $\mathrm{PF}_{\mathrm{PF}}$ pode ser verificada como um pico bem definido de intensidade alta a $814 \mathrm{~cm}^{-1}$ (Figura 59). 


\subsubsection{Análise Termogravimétrica (TGA)}

A Figura 60 mostra a análise termogravimétrica dos copolímeros sintetizados, sendo que a faixa de temperatura na análise foi de $25{ }^{\circ} \mathrm{C}$ a $1000{ }^{\circ} \mathrm{C}$, temperatura suficiente para ocorrer à degradação dos copolímeros.

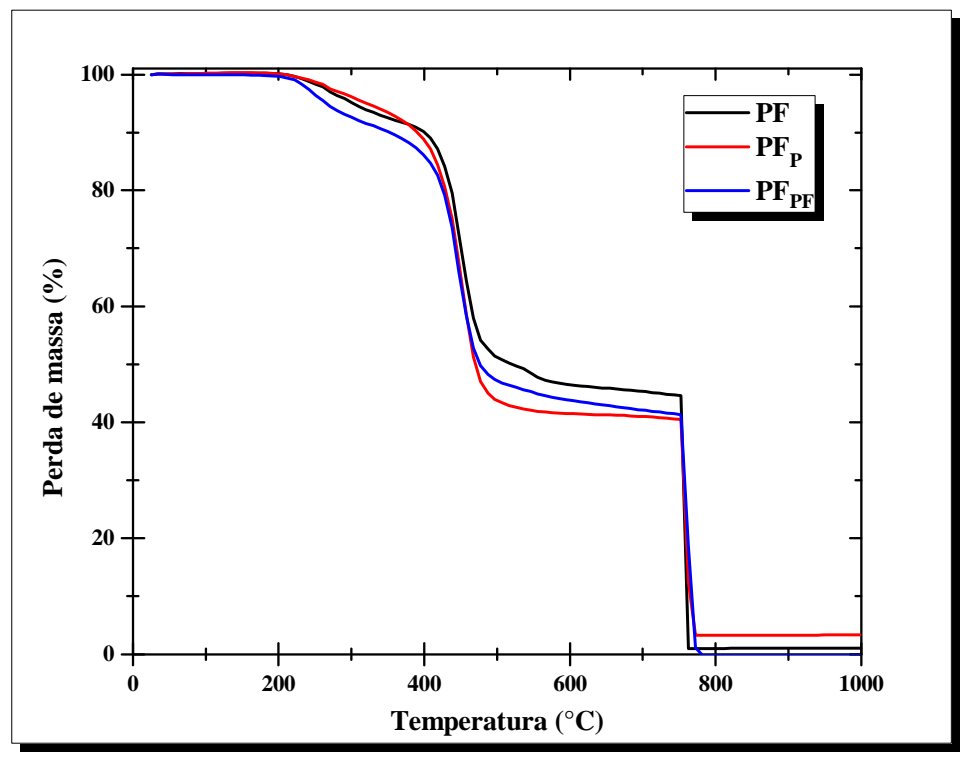

Figura 60 - TGA dos copolímeros $\mathrm{PF}, \mathrm{PF}_{\mathrm{P}}$ e $\mathrm{PF}_{\mathrm{PF}}$.

As curvas de TGA, para os três polímeros, apresentaram as temperaturas iniciais de degradação por volta de $210{ }^{\circ} \mathrm{C}$ para o $\mathrm{PF}, 210{ }^{\circ} \mathrm{C}$ para o $\mathrm{PF}_{\mathrm{P}}$ e $200{ }^{\circ} \mathrm{C}$ para o $\mathrm{PF}_{\mathrm{PF}}$.

A fim de analisar melhor as curvas de perda de massa, utilizou-se a derivada das curvas, DTG, que permite melhor observação da taxa de variação da massa em função da temperatura, assim, as curvas de perda de massa e suas respectivas derivadas estão apresentadas nas Figuras 61-63. 


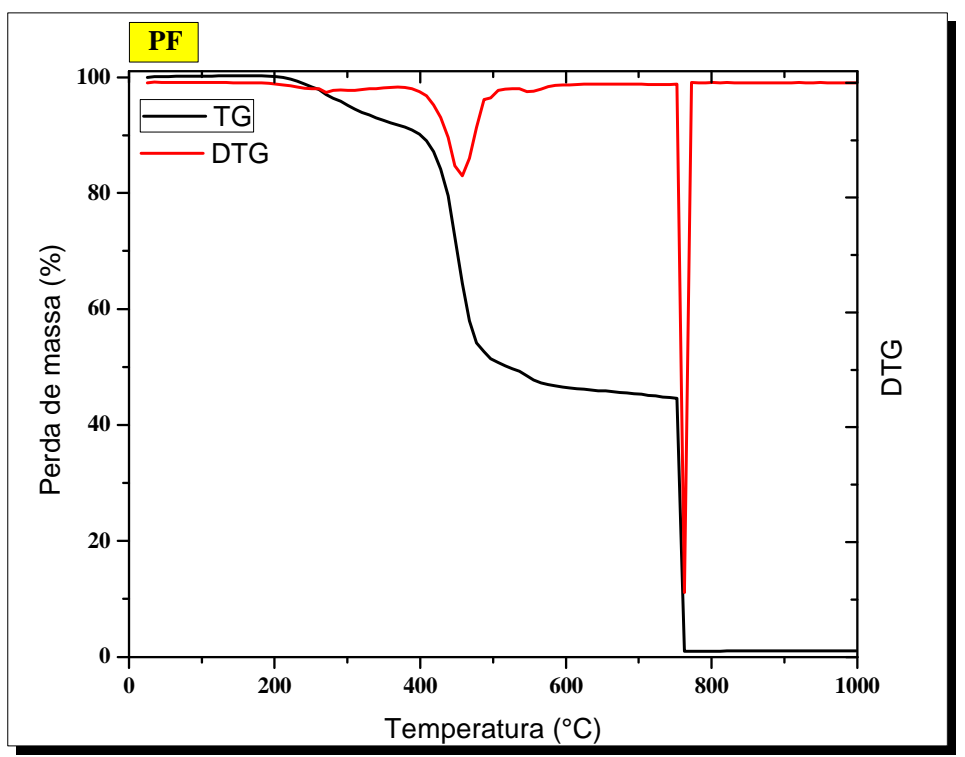

Figura 61 - Derivada do gráfico de TGA do PF.

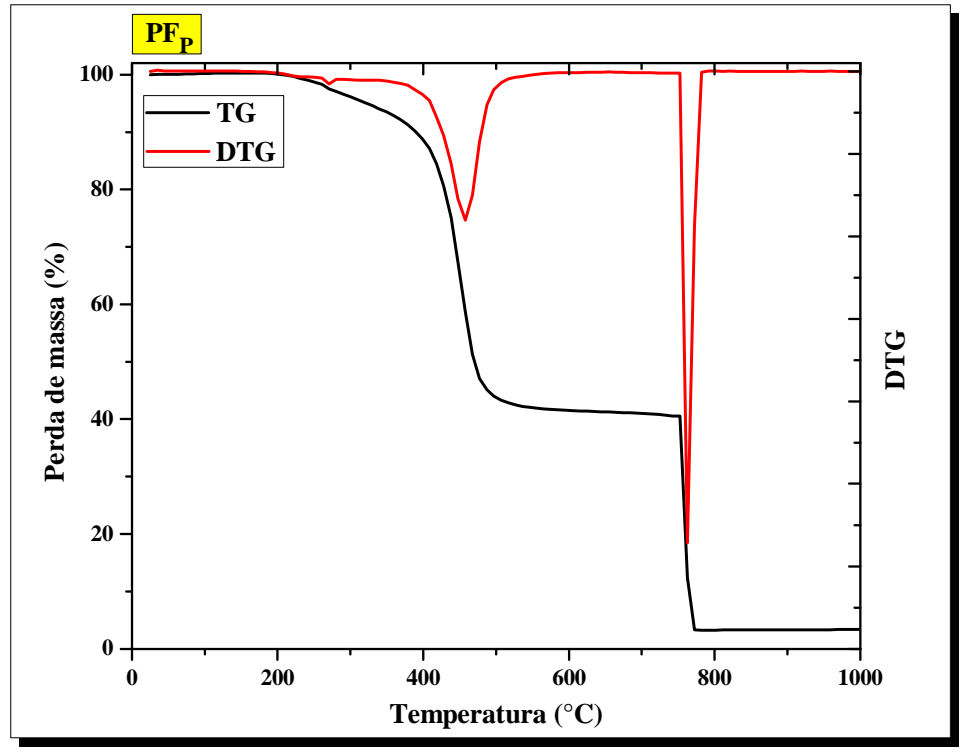

Figura 62 - Derivada do gráfico de TGA do $\mathrm{PF}_{\mathrm{P}}$. 


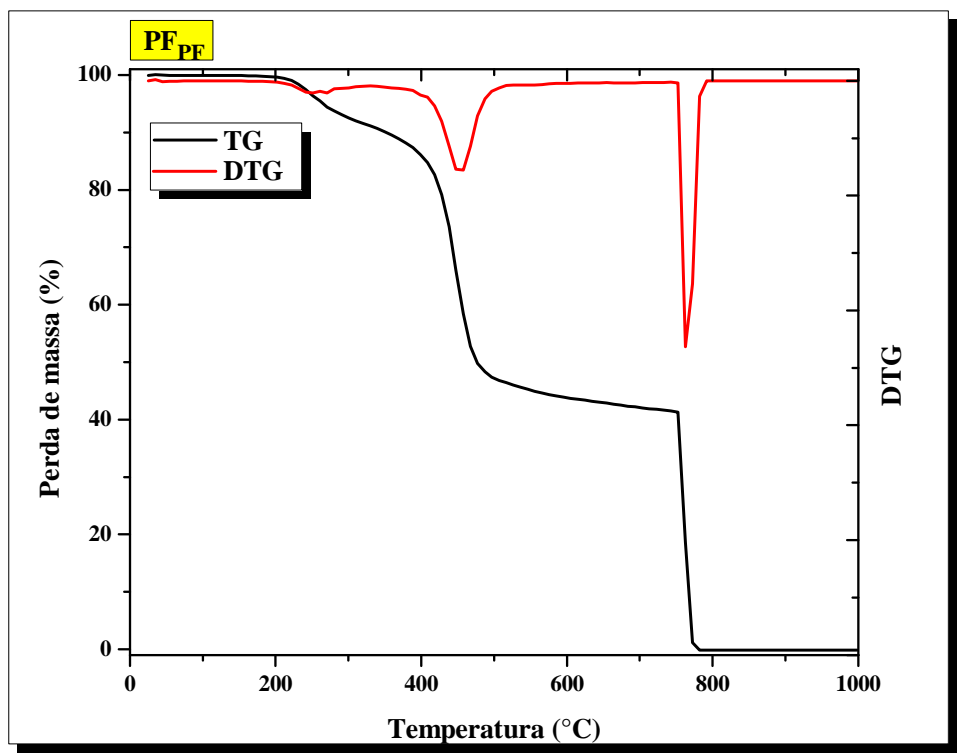

Figura 63 - Derivada do gráfico de TGA do $\mathrm{PF}_{\mathrm{PF}}$.

As curvas de TGA, para os três polímeros, apresentaram desníveis semelhantes de degradação, e os valores de perdas de massa estão apresentados na Tabela 8.

Tabela 8 - Valores de perdas de massa dos polímeros

\begin{tabular}{|c|c|c|c|}
\cline { 2 - 4 } \multicolumn{1}{c|}{} & \multicolumn{3}{c|}{ Perda de massa (\%) } \\
\hline Intervalos de temperatura $\left({ }^{\circ} \mathbf{C}\right)$ & $\underline{\mathbf{P F}}$ & $\underline{\underline{\mathbf{P F}_{\mathbf{P}}}}$ & $\underline{\underline{\mathbf{P F}_{\mathbf{P F}}}}$ \\
\hline $150-320$ & 6,0 & 5,8 & 8,5 \\
\hline $320-700$ & 48,8 & 53,2 & 49,5 \\
\hline $700-1000$ & 45,2 & 41 & 42,0 \\
\hline
\end{tabular}

A partir das curvas de DTG foi possível observar a taxa de degradação máxima de cada polímero. Assim sendo, as temperaturas de degradação máximas são: $450{ }^{\circ} \mathrm{C}$ para o $\mathrm{PF}$, $460{ }^{\circ} \mathrm{C}$ para o $\mathrm{PF}_{\mathrm{P}}$ e $450{ }^{\circ} \mathrm{C}$ para o $\mathrm{PF}_{\mathrm{PF}}$. Estes resultados indicam que os três polímeros são similares em termos de estabilidade térmica. 


\subsubsection{Análise por Calorimetria Diferencial Exploratória (DSC)}

As Figuras 64-66 mostram os gráficos de DSC dos copolímeros $\mathrm{PF}, \mathrm{PF}_{\mathrm{P}}$ e $\mathrm{PF}_{\mathrm{PF}}$, respectivamente, onde é possível observar através da inflexão das suas curvas, as suas respectivas temperaturas de transição vítrea $\left(\mathrm{T}_{\mathrm{g}}\right)$. Algumas inflexões são observadas nestas curvas, entretanto a irregularidade da linha base torna difícil fazer uma atribuição justa das temperaturas de transição vítrea $\left(\mathrm{T}_{\mathrm{g}}\right)$ para $\mathrm{PF}$ e $\mathrm{PF}_{\mathrm{PF}}$, ainda que $\mathrm{PF}_{\mathrm{P}}$ apresente uma transição característica, $\mathrm{T}_{\mathrm{g}}$, aproximadamente a $80^{\circ} \mathrm{C}$, indicando tratar-se um material completamente amorfo. Por outro lado, $\mathrm{PF}$ e $\mathrm{PF}_{\mathrm{PF}}$, embora apresentem variações na linha base, parecem possuir um valor aproximado de $105^{\circ} \mathrm{C}$ de $\mathrm{T}_{\mathrm{g}}$. $\mathrm{O} \mathrm{PF}_{\mathrm{PF}}$ apresenta temperatura de fusão por volta de $143{ }^{\circ} \mathrm{C}$. Além disso, $\mathrm{PF}_{\mathrm{PF}}$ apresentou um pico de cristalização a frio, $\mathrm{T}_{\mathrm{c}}=93{ }^{\circ} \mathrm{C}$, sugerindo a presença de fração significativa de fase cristalina no decorrer da análise DSC.

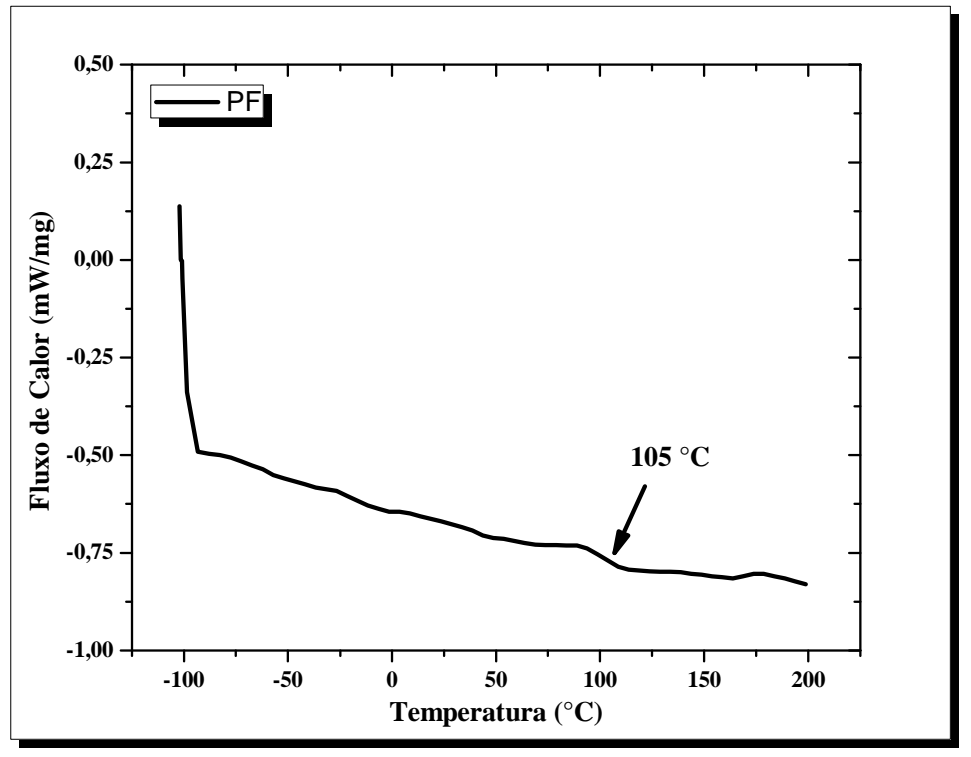

Figura 64 - Gráficos de DSC do PF. 


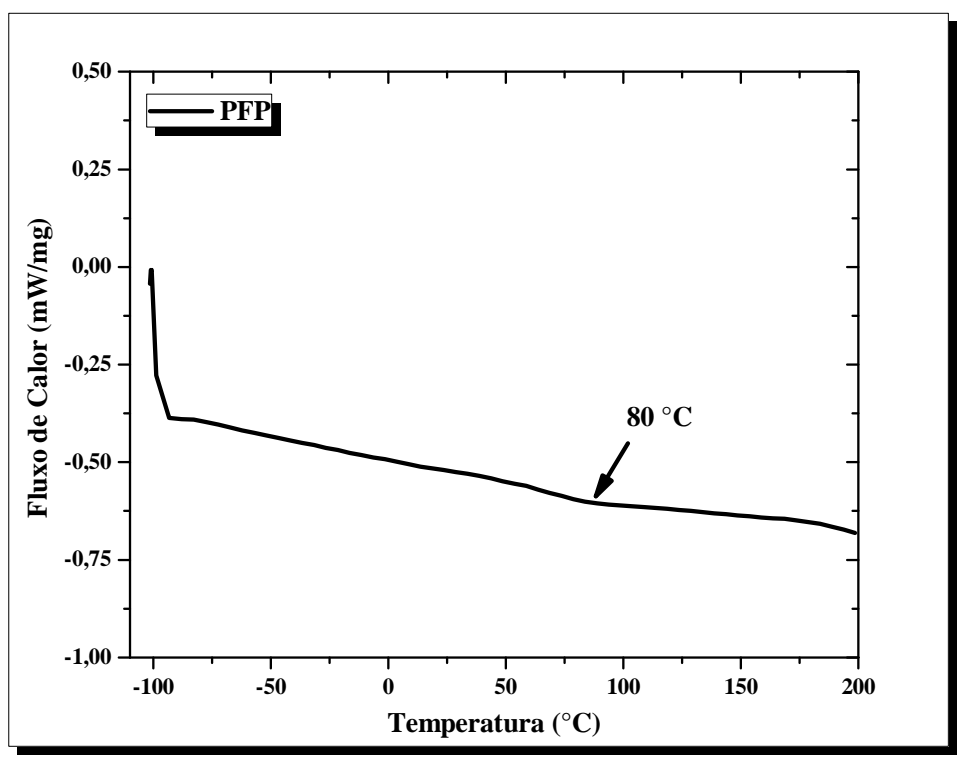

Figura 65 - Gráficos de DSC do $\mathrm{PF}_{\mathrm{P}}$.

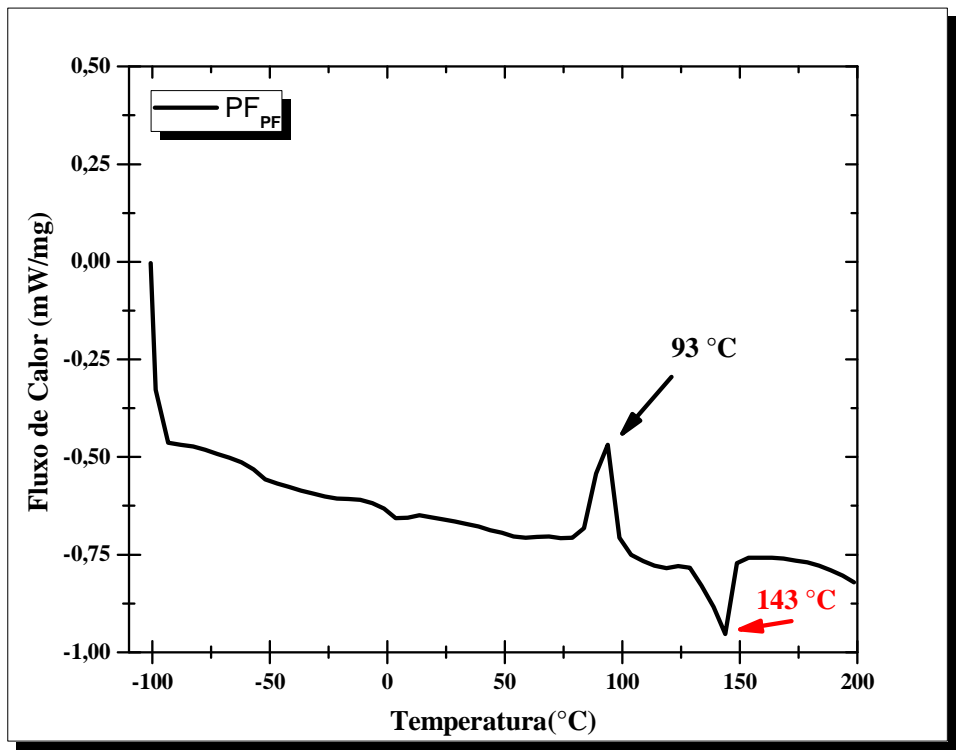

Figura 66 - Gráficos de DSC do $\mathrm{PF}_{\mathrm{PF}}$.

A partir do gráfico de DSC do $\mathrm{PF}_{\mathrm{PF}}$, que apresentou temperaturas características de materiais semicristalinos, foi realizada análise de difração de raios- $\mathrm{X}$ a fim de comprovar a presença de cristalinidade e quantificar a porcentagem cristalina do copolímero sintetizado. 


\subsubsection{Difração de raios-X (XRD)}

A análise por difratometria de raios-X foi utilizada a fim de estimar as frações cristalinas e amorfas do $\mathrm{PF}_{\mathrm{PF}}$. O difratograma obtido do $\mathrm{PF}_{\mathrm{PF}}$ está apresentado na Figura 67.

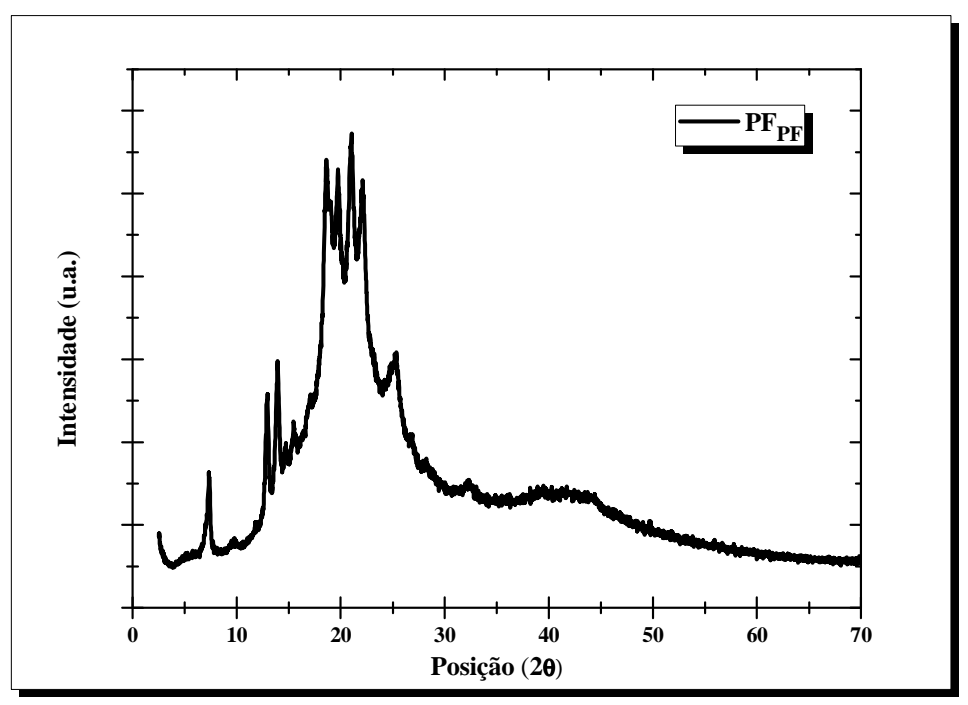

Figura 67 - Difratograma de raios-X do $\mathrm{PF}$ PF.

O grau de cristalinidade foi estimado pela relação entre a área resultante (contribuição cristalina) pela área total sob a curva (contribuições cristalina e amorfa), calculado pela equação $5^{58}$, onde $\boldsymbol{X} \boldsymbol{c}$ é o grau de cristalinidade, $\boldsymbol{A} \boldsymbol{c}$ a área dos picos do difratograma e $\boldsymbol{A \boldsymbol { a }}$ a área compreendida entre a linha sólida e a linha base.

$X c=\frac{A c}{(A c+A a)}$

O valor obtido de grau de cristalinidade para o difratograma apresentado na Figura 67 e calculado pela equação 4 para o $\mathrm{PF}_{\mathrm{PF}}$ é de 9,0\%, isto é, a região cristalina do material compreende $9,0 \%$ do total, enquanto que $91 \%$ restante compreende a região amorfa do polímero. 


\subsubsection{Espectroscopia de absorção no UV-Vis}

A Figura 68 mostra o espectro de absorção no UV-Vis dos copolímeros $\mathrm{PF}, \mathrm{PF}_{\mathrm{P}} \mathrm{e}$ $\mathrm{PF}_{\mathrm{PF}}$. Para uma mesma concentração molar dos copolímeros $\left(2,0 \times 10^{-6} \mathrm{~mol} / \mathrm{L}\right)$, pode-se notar que a intensidade de absorbância é semelhante nos três copolímeros, porém os comprimentos de onda nos picos máximos são: $385 \mathrm{~nm}$ para o $\mathrm{PF}, 360 \mathrm{~nm}$ para o $\mathrm{PF}_{\mathrm{P}}$ e $365 \mathrm{~nm}$ para o $\mathrm{PF}_{\mathrm{PF}}$. Como era esperado, o PF apresenta absorção em comprimento de onda maior devido à maior extensão da conjugação. Os polímeros aromáticos contendo grupos planares podem apresentar também conjugação por empilhamento destes grupos, sendo mais provável quando estes grupos são maiores.

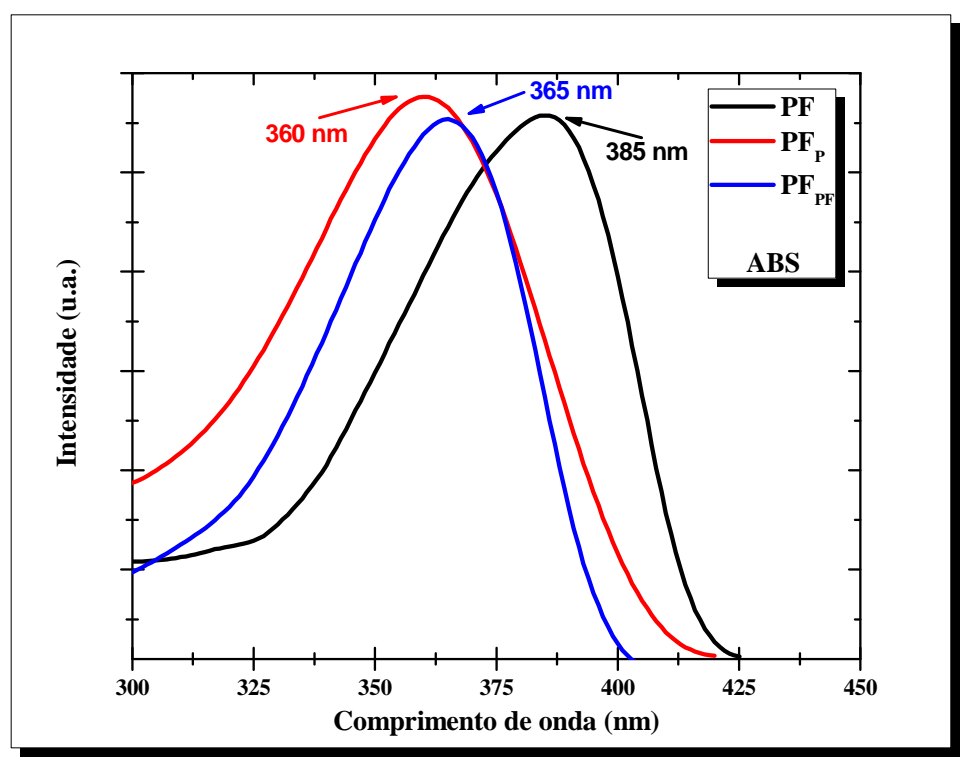

Figura 68 - Espectro de absorbância no UV-Vis dos copolímeros $\mathrm{PF}, \mathrm{PF}_{\mathrm{P}}$ e $\mathrm{PF}_{\mathrm{PF}}$ nas mesmas concentrações molares $\left(2 \times 10^{-6} \mathrm{~mol} / \mathrm{L}\right)$.

As Figuras 69-71 apresentam os gráficos de absorção no UV-Vis de soluções dos copolímeros $\mathrm{PF}, \mathrm{PF}_{\mathrm{P}}$ e $\mathrm{PF}_{\mathrm{PF}}$, respectivamente, a diferentes concentrações. Os gráficos apresentam a diminuição dos valores de intensidade nos picos máximos de absorção, relacionada com a medida decrescente nos valores de concentrações das soluções. 


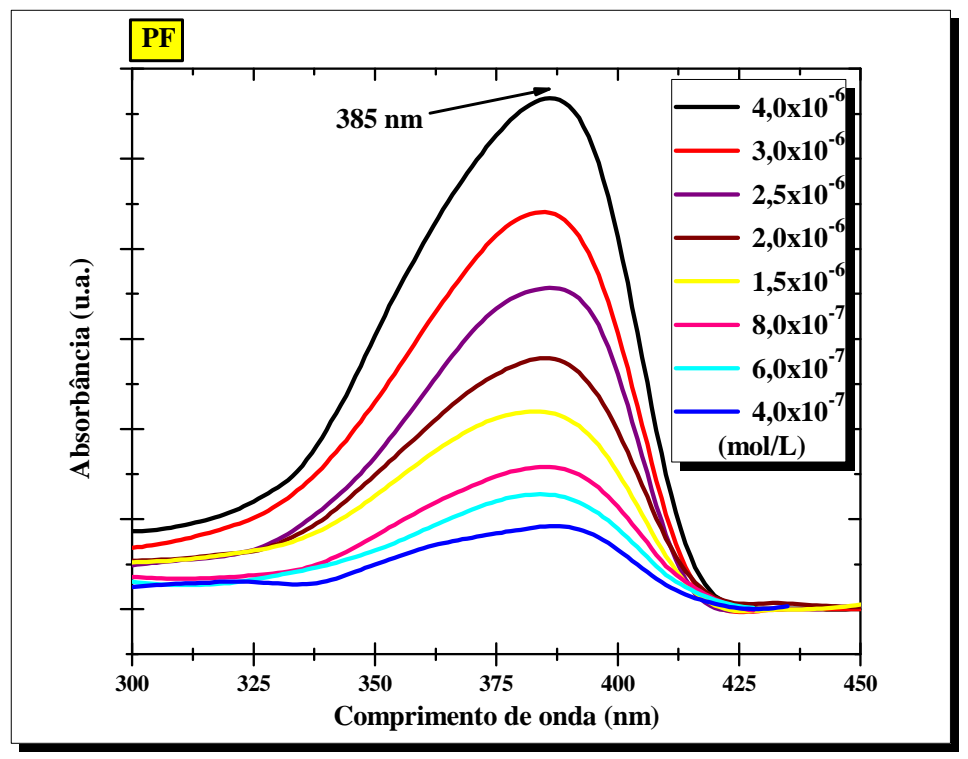

Figura 69 - Espectros de absorção no UV-Vis do polímero PF.

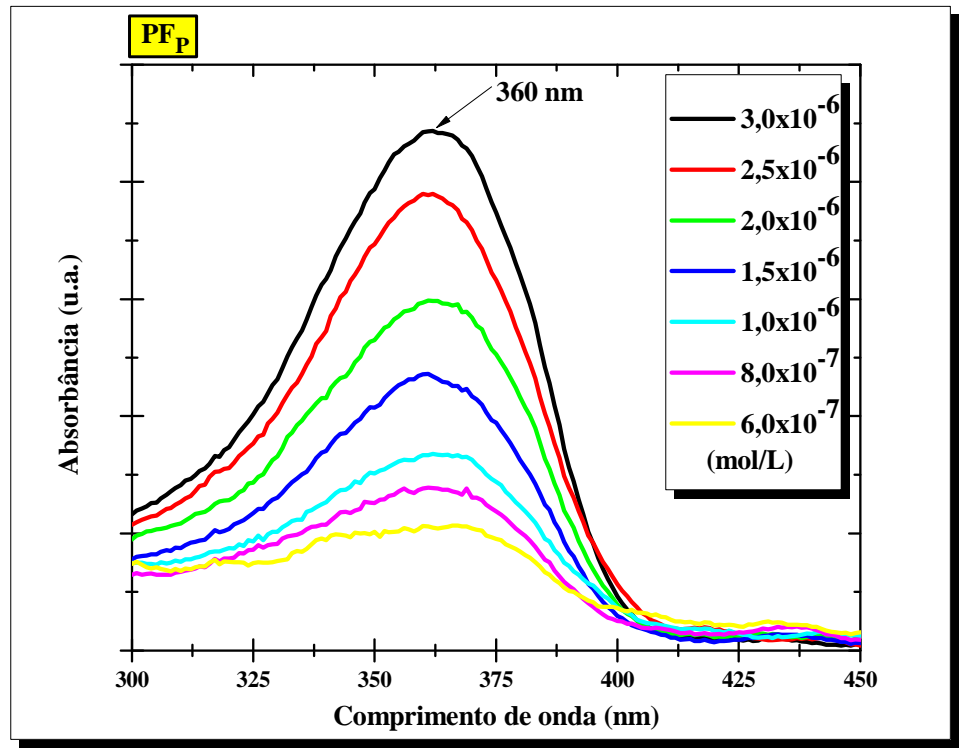

Figura 70 - Espectros de absorção no UV-Vis do copolímero $\mathrm{PF}_{\mathrm{P}}$. 


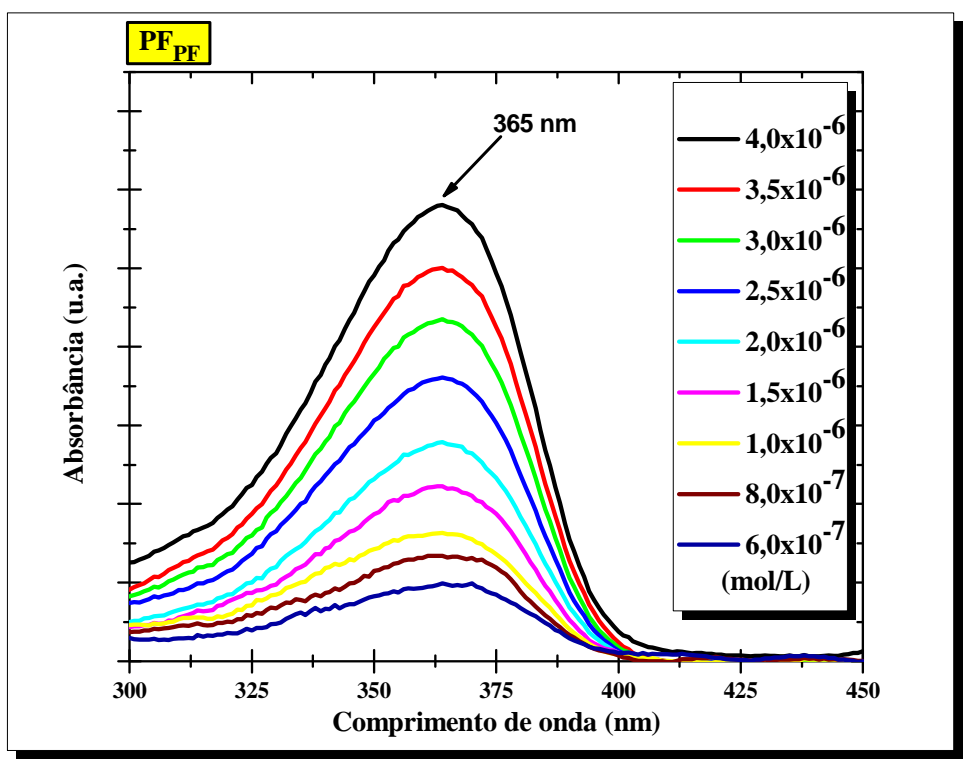

Figura 71 - Espectros de absorção no UV-Vis do polímero $\mathrm{PF}_{\mathrm{PF}}$.

O gráfico da Figura 72 faz uma correlação entre os valores de picos máximos de intensidade de absorbância e as concentrações das soluções. Pode-se observar que para soluções mais concentradas há uma maior intensidade de absorção, sendo que o PF tem um coeficiente angular maior que os demais copolímeros sintetizados, ou seja, com a mesma variação nas concentrações das soluções dos demais copolímeros, apresenta um maior valor de intensidade de absorção.

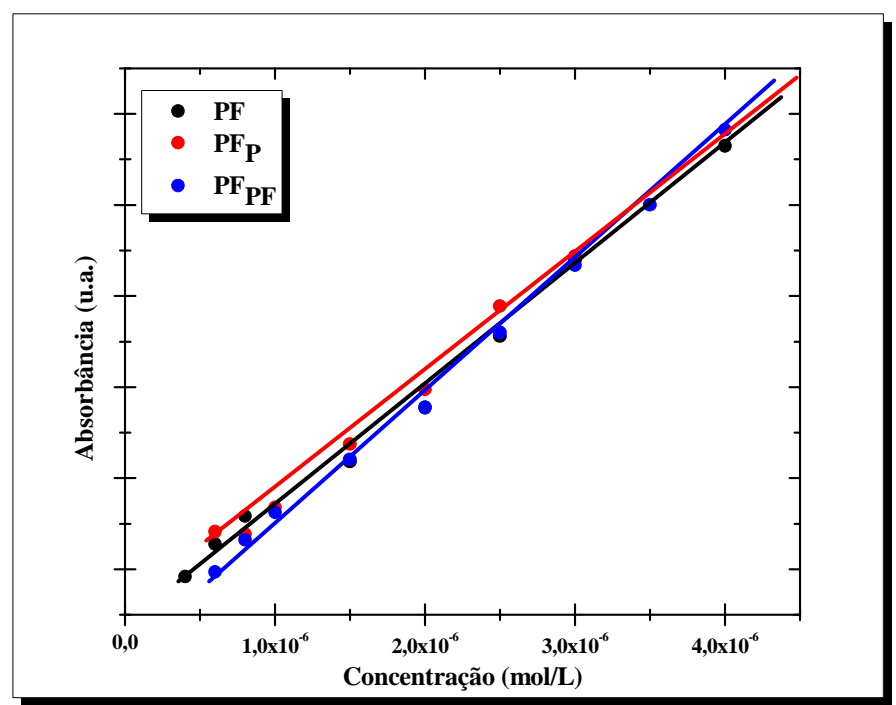

Figura 72 - Gráfico de intensidade de absorção vs. variação da concentração molar, para os copolímeros, para pico de $385 \mathrm{~nm}(\mathrm{PF})$, pico de $360 \mathrm{~nm}\left(\mathrm{PF}_{\mathrm{P}}\right)$ e pico de $365 \mathrm{~nm}\left(\mathrm{PF}_{\mathrm{PF}}\right)$. 


\subsubsection{Espectroscopia de fluorescência}

A Figura 73 mostra os espectros de fluorescência, resultantes de excitação nos comprimentos de onda dos máximos de absorção, para cada um dos materiais, com uma concentração de 2,0 x $10^{-6} \mathrm{~mol} / \mathrm{L}$. Os comprimentos de onda nos máximos de emissão são: $416 \mathrm{~nm}$ para o $\mathrm{PF}, 408 \mathrm{~nm}$ para o $\mathrm{PF}_{\mathrm{P}}$ e $404 \mathrm{~nm}$ para o $\mathrm{PF}$ PF.

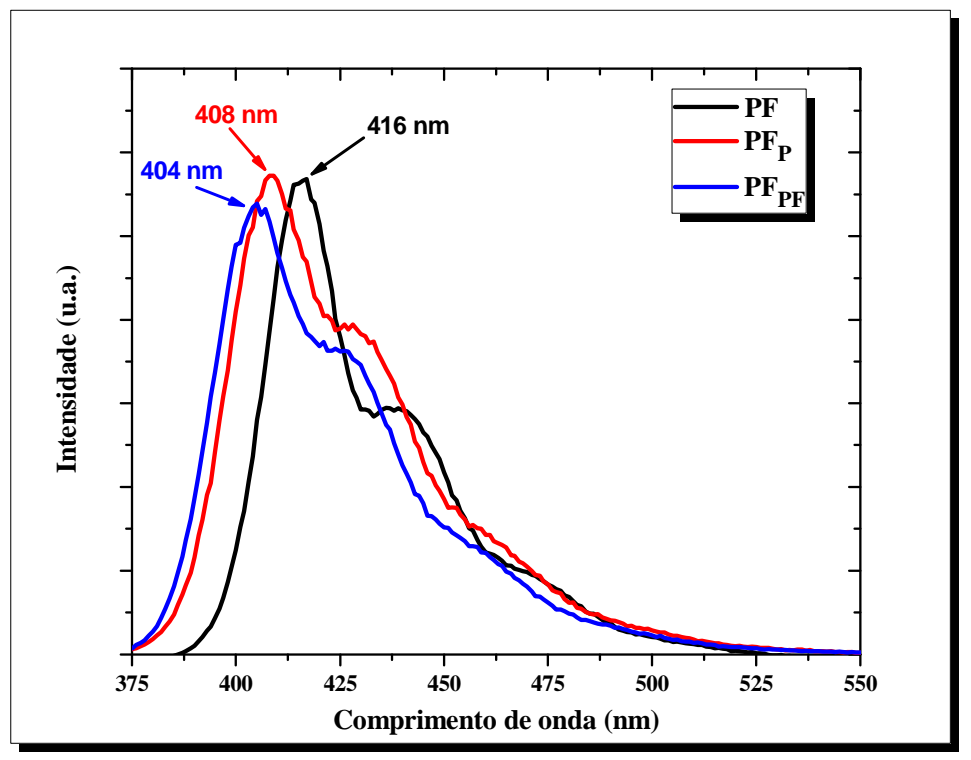

Figura 73 - Espectros de fluorescência dos copolímeros excitados em seus respectivos comprimentos de onda com máxima intensidade $\left(2 \times 10^{-6} \mathrm{~mol} / \mathrm{L}\right)$.

As Figuras 74-76 apresentam os gráficos de emissão no UV-Vis variando-se as concentrações dos copolímeros $\mathrm{PF}, \mathrm{PF}_{\mathrm{P}}$ e $\mathrm{PF}_{\mathrm{PF}}$, respectivamente. Os gráficos apresentam a diminuição dos valores de intensidade de emissão em função de valores decrescentes de concentração das soluções. 


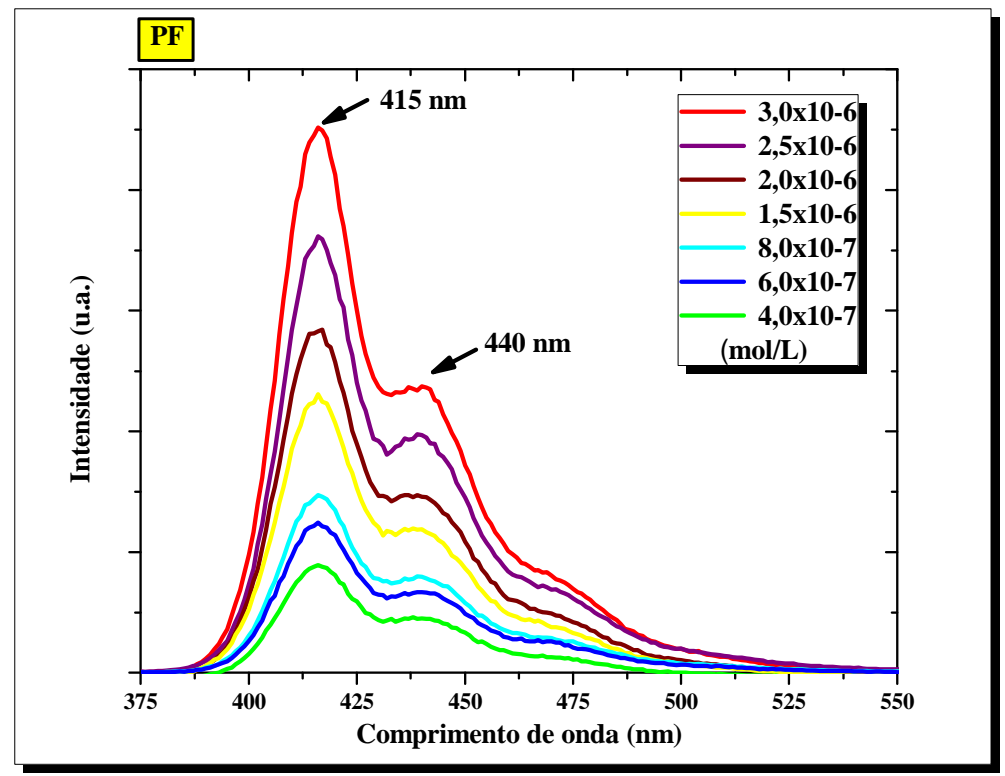

Figura 74 - Espectro de fluorescência do PF em diferentes concentrações.

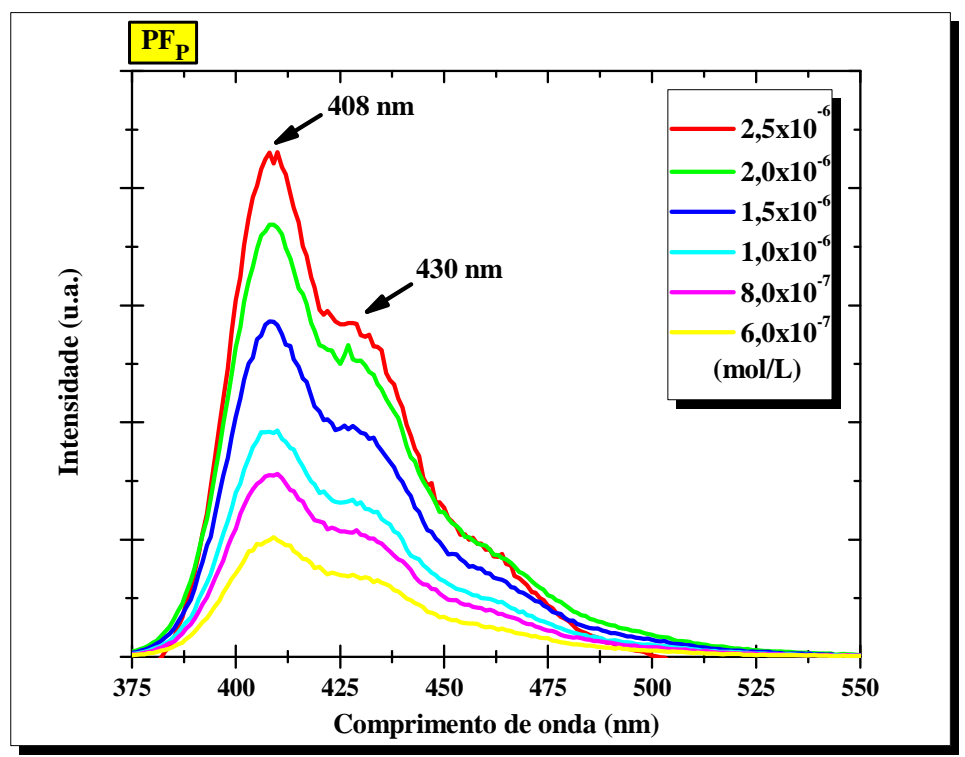

Figura 75 - Espectro de fluorescência do $\mathrm{PF}_{\mathrm{P}}$ em diferentes concentrações. 


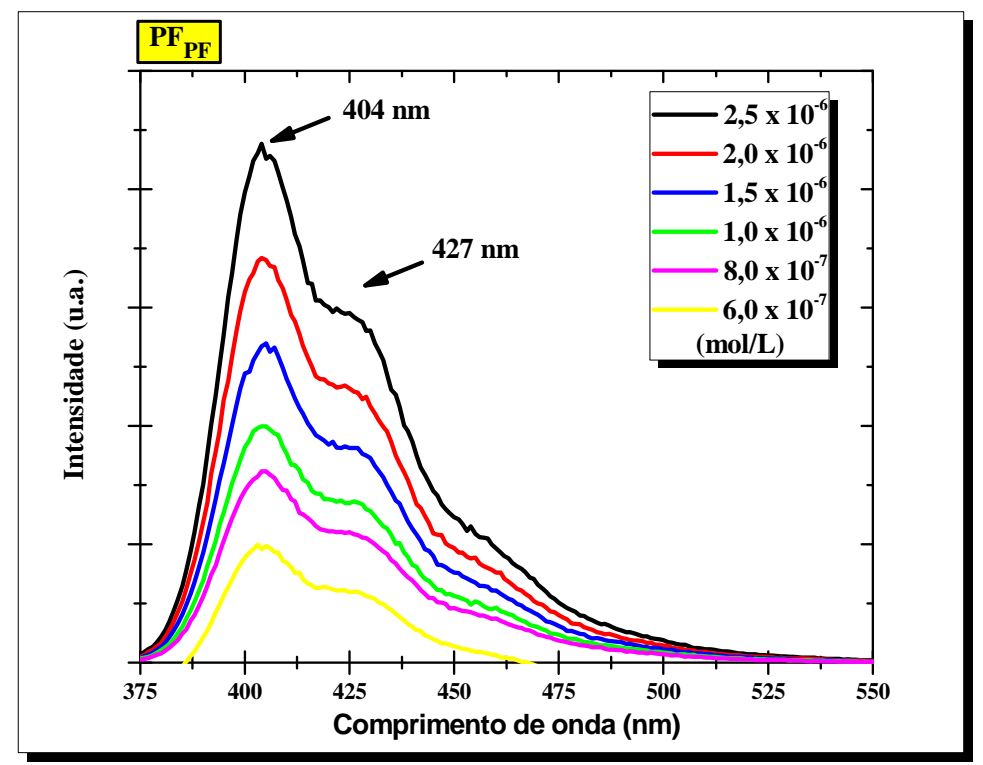

Figura 76 - Espectros de fluorescência do $\mathrm{PF}_{\mathrm{PF}}$ em diferentes concentrações.

A Figura 77 mostra o gráfico que relaciona a concentração com a variação da intensidade para os copolímeros $\mathrm{PF}, \mathrm{PF}_{\mathrm{P}}$ e $\mathrm{PF}_{\mathrm{PF}}$. Observa-se, como era esperado, que o aumento da concentração implica em aumento da intensidade de emissão para esta faixa de concentração, demonstrando linearidade de resposta e ausência de reabsorção nestas condições.

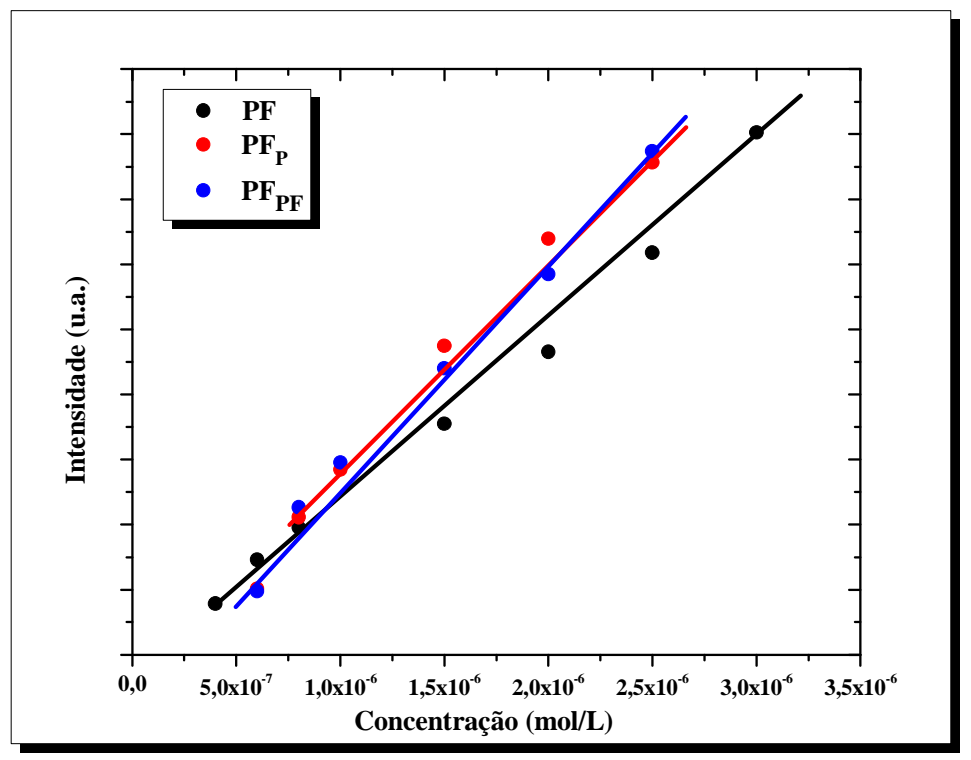

Figura 77 - Intensidade de emissão em função da concentração dos copolímeros indicados. 


\subsubsection{Rendimento Quântico}

$\mathrm{Na}$ Figura 78, os espectros de fluorescência do sulfato de quinina, que foi utilizado como padrão, estão apresentados em diferentes concentrações para o cálculo dos rendimentos quânticos dos polímeros sintetizados.

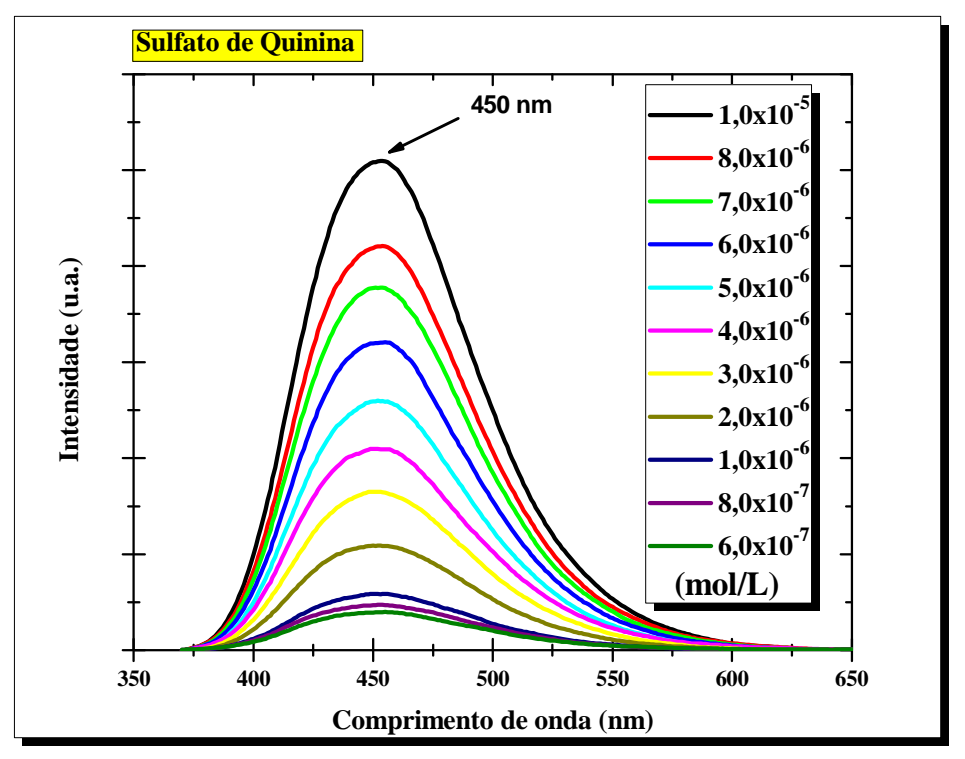

Figura 78 - Espectro de fluorescência do sulfato de quinina em diferentes concentrações.

A partir da equação 1 (apresentada no item 3.3.2.2.1 ), os dados de rendimento quântico foram obtidos:

$$
\phi_{\mathrm{a}}=\phi_{\mathrm{p}} * \frac{\operatorname{grad}_{\mathrm{a}}}{\operatorname{grad}_{\mathrm{p}}} * \frac{\mathrm{n}_{\mathrm{a}}^{2}}{\mathrm{n}_{\mathrm{p}}^{2}}
$$

$\phi_{\mathrm{p}}=0,546$

$\operatorname{grad}_{\mathrm{a}}=$ relação entre a área da amostra e sua respectiva concentração molar;

$\operatorname{grad}_{\mathrm{p}}=$ relação ente a área do sulfato de quinina com sua respectiva concentração molar;

$n_{a}=$ índice de refração do clorofórmio $=1,44$

$n_{p}=$ índice de refração da água $=1,33$ 
Na Tabela 9 estão apresentados os valores de rendimento quântico de fluorescência dos polímeros, o $\mathrm{PF}_{\mathrm{PF}}$ apresentou o maior rendimento quântico com $86 \%$, enquanto que o $\mathrm{PF}_{\mathrm{P}}$ com $80 \%$ e para o $\mathrm{PF}$ com $68 \%$.

Tabela 9 - Rendimentos quânticos dos polímeros

\begin{tabular}{|c|c|c|c|c|c|c|}
\hline Polímeros & $\boldsymbol{\phi}_{\mathbf{p}}$ & $\operatorname{grad}_{\mathbf{a}}$ & $\operatorname{grad}_{\mathbf{p}}$ & $\mathbf{n}_{\mathbf{a}}$ & $\mathbf{n}_{\mathbf{p}}$ & $\boldsymbol{\phi}_{\mathbf{a}}$ \\
\hline $\mathbf{P F}$ & 0,546 & $2,61 * 10^{9}$ & $2,48^{*} 10^{9}$ & 1,44 & 1,33 & $\mathbf{0 , 6 8}$ \\
\hline $\mathbf{P F}_{\mathbf{P}}$ & 0,546 & $3,07 * 10^{9}$ & $2,48 * 10^{9}$ & 1,44 & 1,33 & $\mathbf{0 , 8 0}$ \\
\hline $\mathbf{P F}_{\mathbf{P F}}$ & 0,546 & $3,34 * 10^{9}$ & $2,48 * 10^{9}$ & 1,44 & 1,33 & $\mathbf{0 , 8 6}$ \\
\hline
\end{tabular}

\subsection{Caracterização elétrica dos P-OLEDs}

\subsubsection{PLED com o polímero PF como camada ativa}

Os dispositivos contendo PF sem ETL como camada emissora apresentaram tensão de limiar relativamente elevada, entre 6 e $12 \mathrm{~V}$, a luminância por sua vez torna-se significativa (acima de $1 \mathrm{~cd} / \mathrm{m}^{2}$ ) apenas a partir de $15 \mathrm{~V}$, atingindo o valor máximo, $23 \mathrm{~cd} / \mathrm{m}^{2}$, a $19 \mathrm{~V}$ (Figura 79). A tensão de limiar de um dispositivo, indica a transformação do comportamento isolante para condutor e a eletroluminescência, é explicada pela ocorrência de transição eletrônica do estado excitado para o estado fundamental, ou seja, a recombinação entre o elétron e o buraco, dependente, das intensidades de corrente elétrica. Para estes dispositivos a eficiência luminosa atingiu o máximo, $8 \mathrm{mcd} / \mathrm{A}$, a $20 \mathrm{~V}$ (Figura 80). 


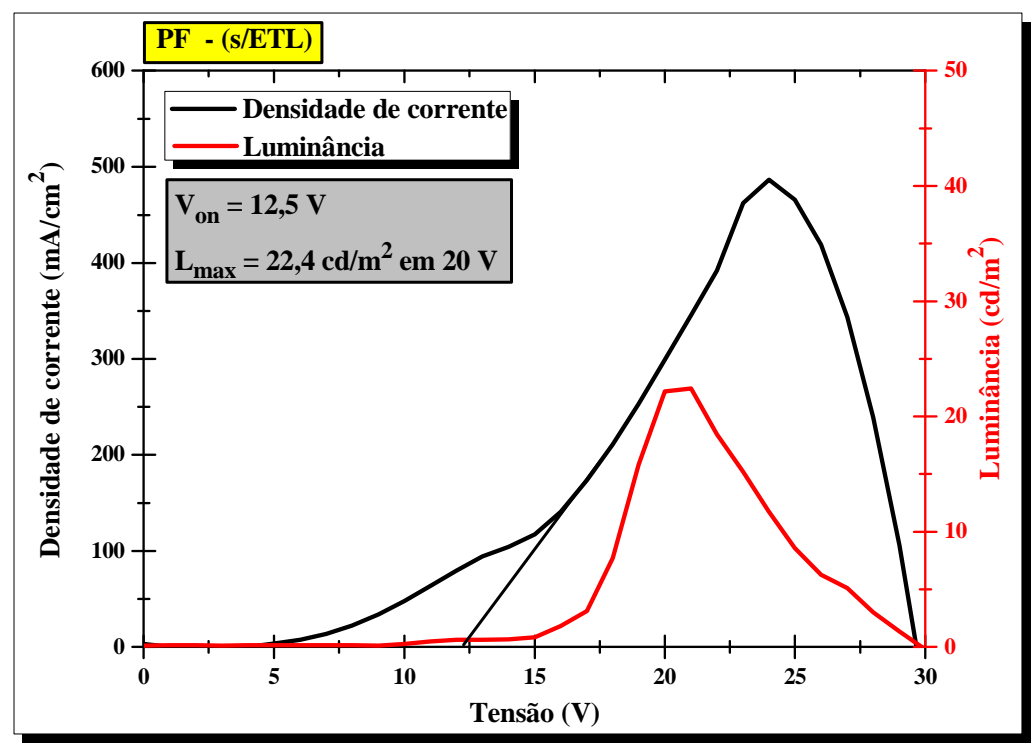

Figura 79 - Curva de densidade de corrente e luminância vs. tensão do PF (s/ETL).

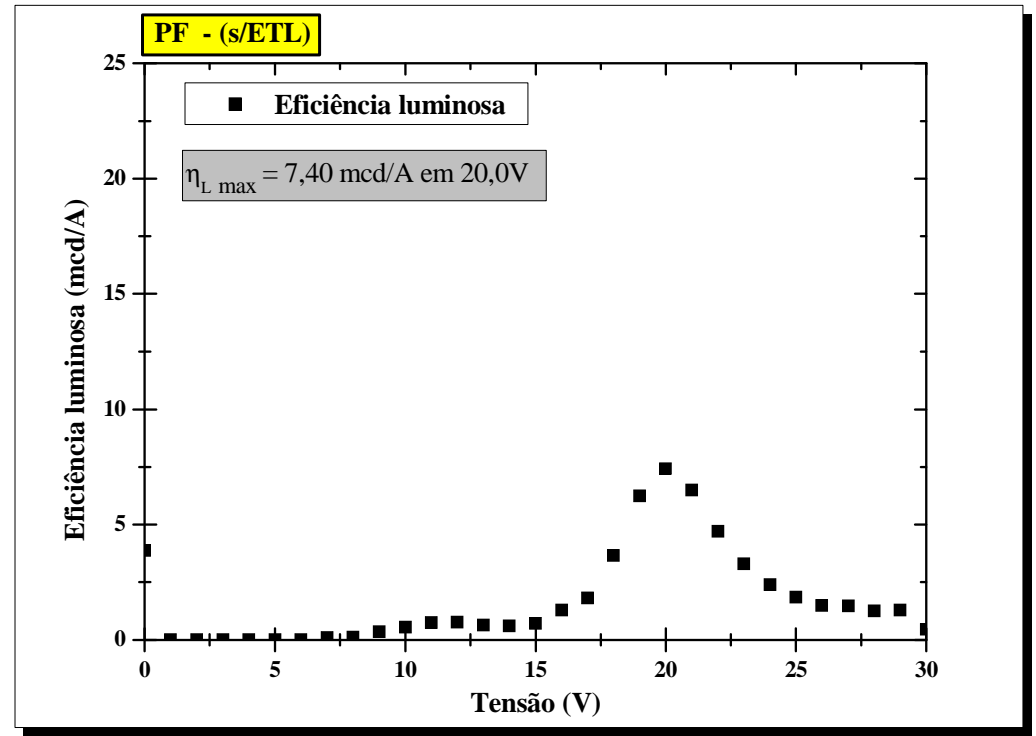

Figura 80 - Eficiência luminosa $v s$. tensão do PF (s/ETL).

Observa-se que o comprimento de onda máximo do espectro de eletroluminescência não mudou com o valor da tensão aplicada ao dispositivo, $530 \mathrm{~nm}$, entretanto as intensidades relativas das bandas observadas a $435 \mathrm{~nm}, 460 \mathrm{~nm}$ e $500 \mathrm{~nm}$ tornaram-se menores com o aumento da tensão (Figura 81), indicando um deslocamento da banda de emissão para comprimentos de onda maiores, ou seja, do azul para o verde. Este comportamento é mais facilmente verificado pela análise das coordenadas de cromaticidade (Figura 82). As fotos dos dispositivos polarizados estão apresentadas na Figura 83. 


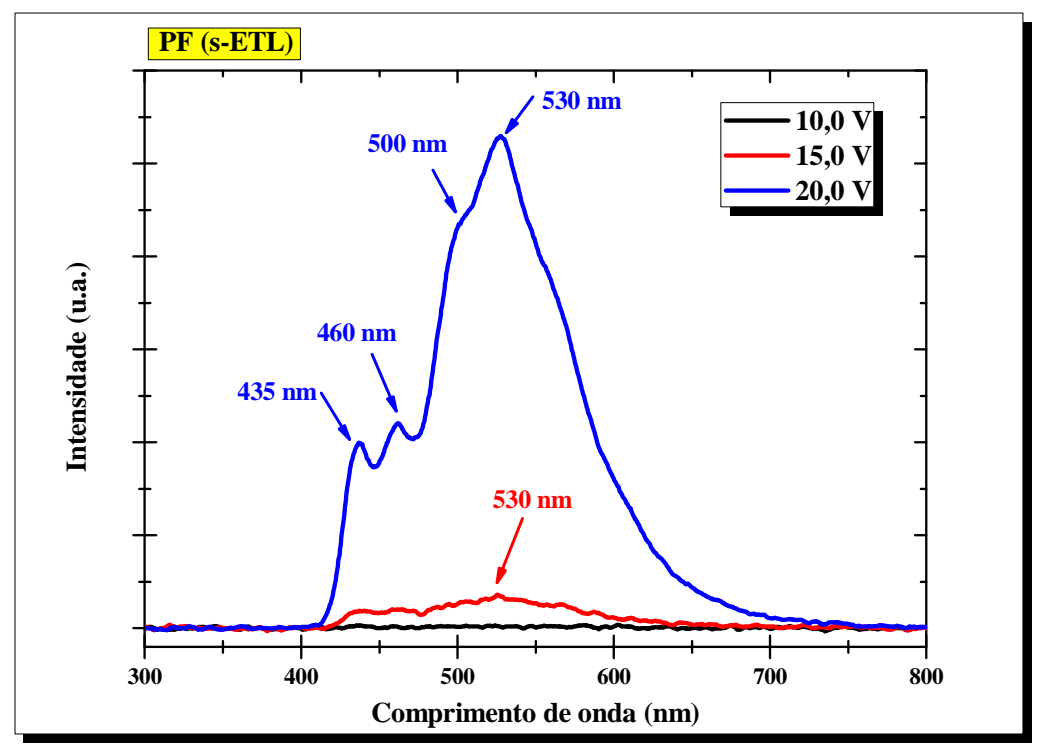

Figura 81 - Espectro de eletroluminescência do PF (s/ETL).

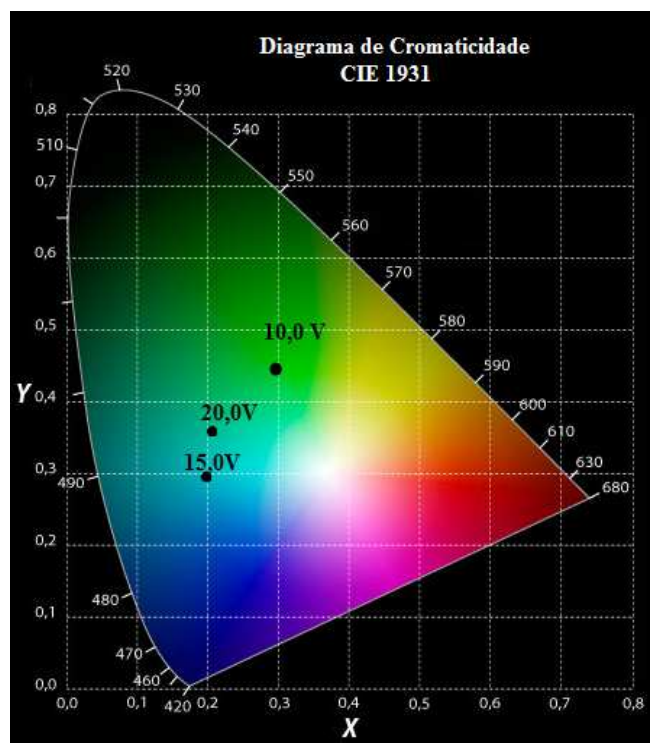

$\mathrm{x}=0,29$ e $\mathrm{y}=0,45 \mathrm{com}$ base no espectro de EL obtido em 10 volts.

$\mathrm{x}=0,19$ e $\mathrm{y}=0,29 \mathrm{com}$ base no espectro de EL obtido em 15 volts.

$\mathrm{x}=0,21$ e $\mathrm{y}=0,35 \mathrm{com}$ base no espectro de EL obtido em 20 volts.

Figura 82 - Coordenadas de cromaticidade do PF (s/ETL).

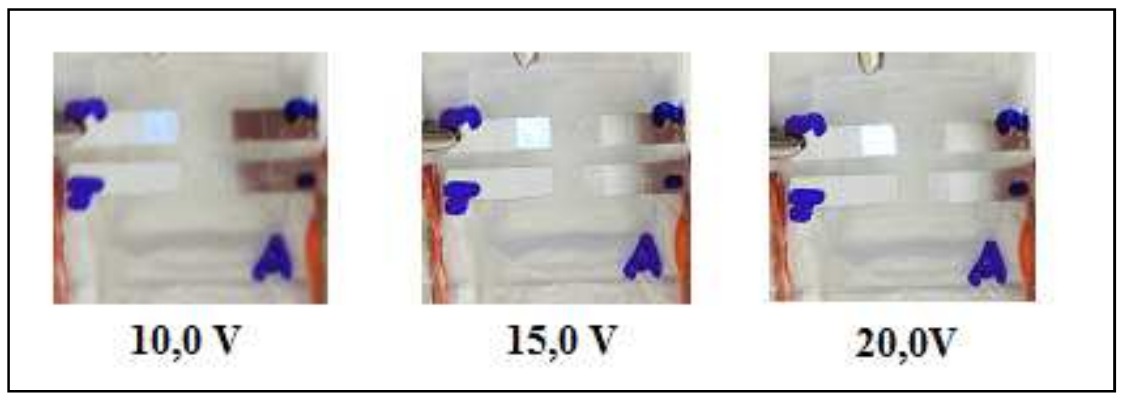

Figura 83 - Fotos dos P-OLEDs polarizados de PF (s/ETL). 
Os dispositivos contendo $\mathrm{PF}$ com $\mathrm{Alq}_{3}$ como camada emissora apresentaram tensão de limiar relativamente elevada, entre 7 e $15 \mathrm{~V}$, a eletroluminescência torna-se significativa a partir de $15 \mathrm{~V}$, atingindo o valor máximo, $22 \mathrm{~cd} / \mathrm{m}^{2}$, a $22 \mathrm{~V}$ (Figura 84). Para estes dispositivos a eficiência luminosa atingiu o máximo, $3 \mathrm{mcd} / \mathrm{A}$, a $22 \mathrm{~V}$ (Figura 85).

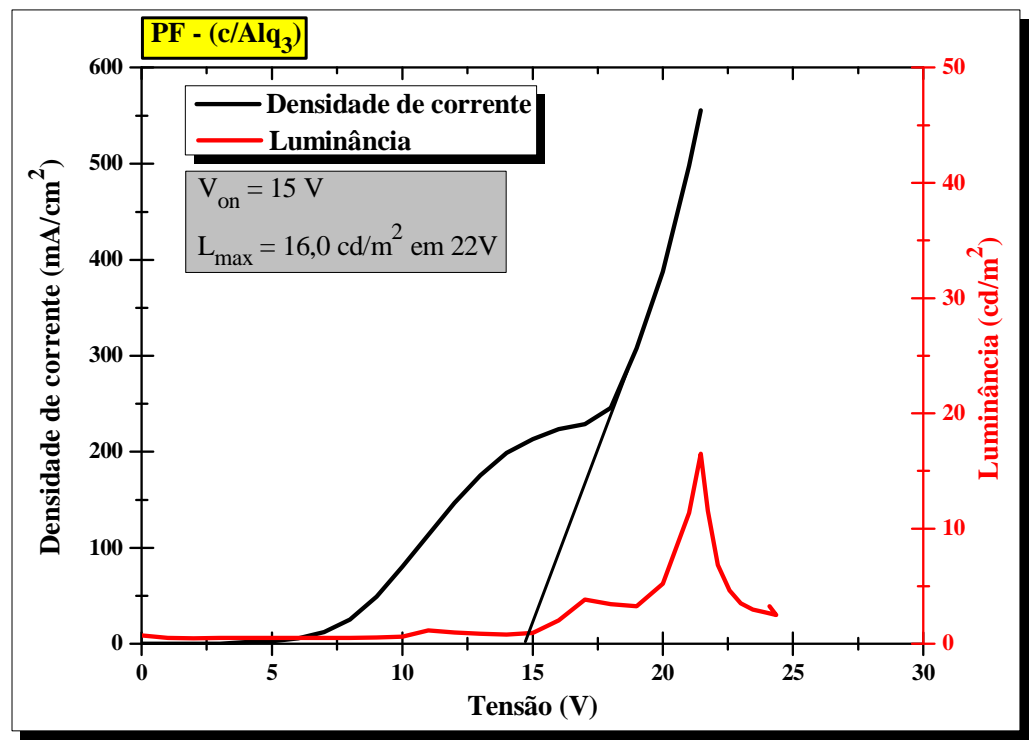

Figura 84 - Curva de densidade de corrente e luminância vs. tensão do $\mathrm{PF}\left(\mathrm{c} / \mathrm{Alq}_{3}\right)$.

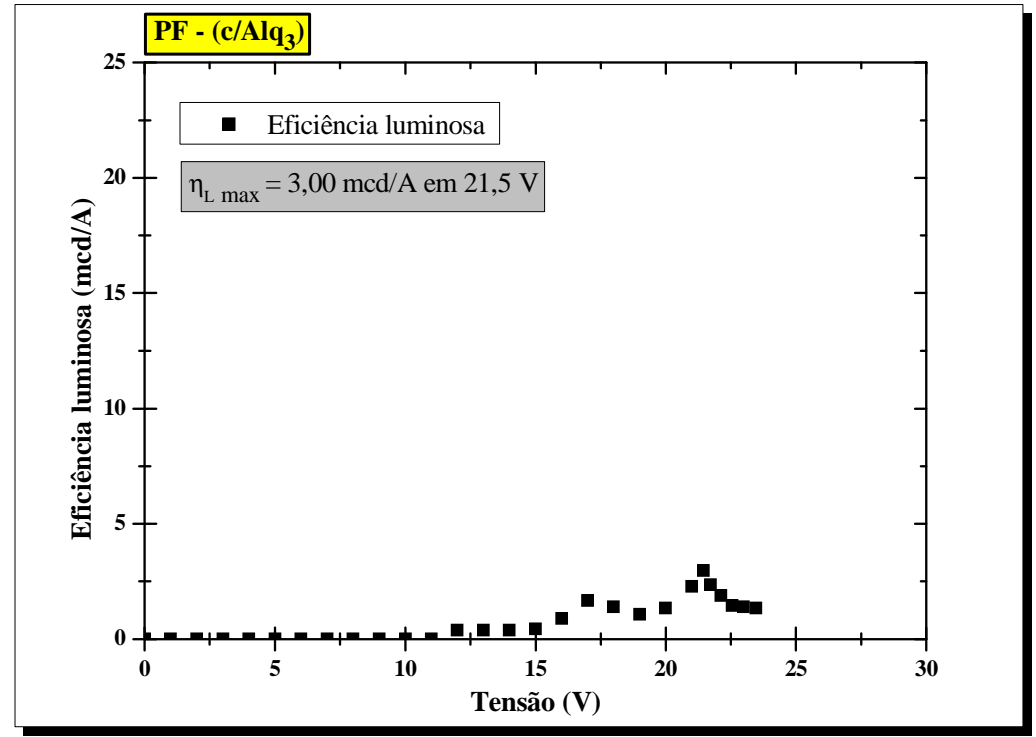

Figura 85 - Eficiência luminosa vs. tensão do PF (c/Alq $)_{3}$.

O comprimento de onda observado para o máximo do espectro de eletroluminescência não mudou com o valor da tensão, $530 \mathrm{~nm}$, entretanto as intensidades relativas das bandas 
observadas a $435 \mathrm{~nm}, 460 \mathrm{~nm}$ e $550 \mathrm{~nm}$ tornaram-se menores com o aumento da tensão (Figura 86), este comportamento é mais facilmente verificado pela análise das coordenadas de cromaticidade (Figura 87). As fotos dos dispositivos polarizados estão apresentadas na Figura 88.

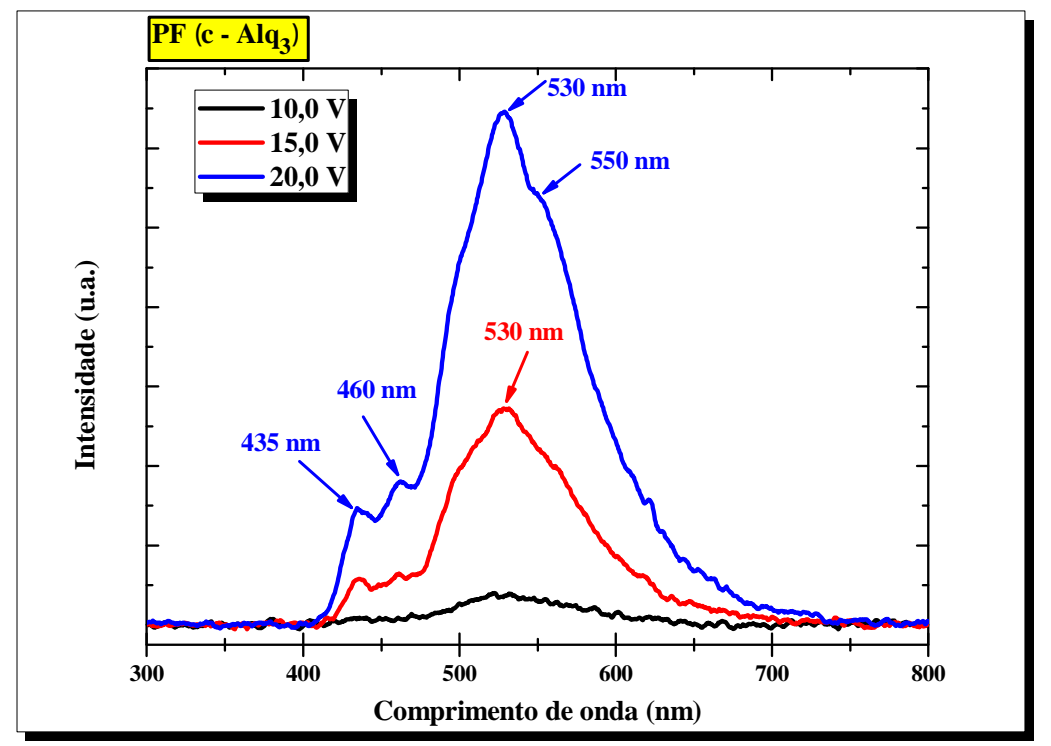

Figura 86 - Espectro de eletroluminescência do $\mathrm{PF}\left(\mathrm{c} / \mathrm{Alq}_{3}\right)$.

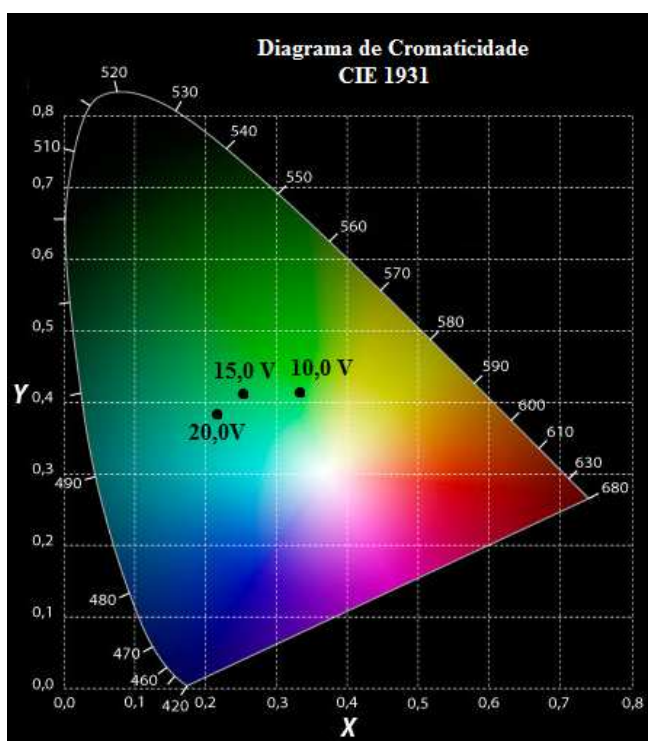

$\mathrm{x}=0,34$ e $\mathrm{y}=0,42 \mathrm{com}$ base no espectro de EL obtido em 10 volts $\mathrm{x}=0,25$ e $\mathrm{y}=0,42 \mathrm{com}$ base no espectro de EL obtido em 15 volts $\mathrm{x}=0,23$ e $\mathrm{y}=0,39 \mathrm{com}$ base no espectro de EL obtido em 20 volts

Figura 87 - Coordenadas de cromaticidade do $\mathrm{PF}\left(\mathrm{c} / \mathrm{Alq}_{3}\right)$. 


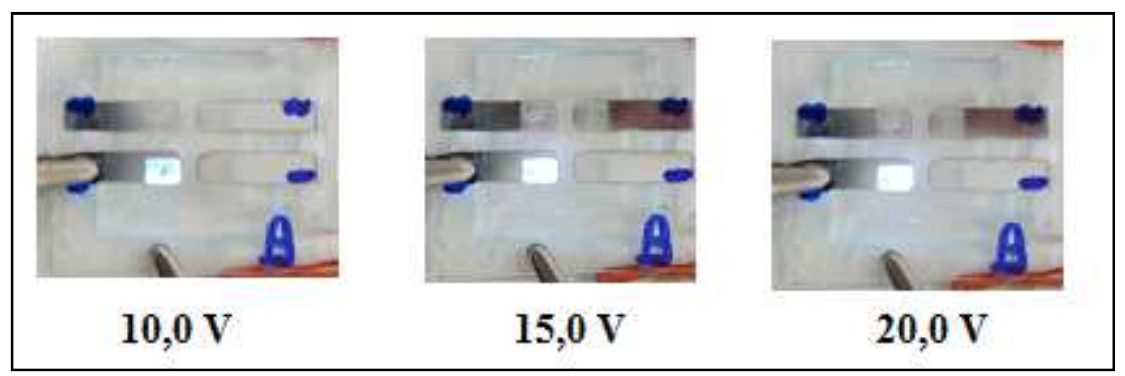

Figura 88 - Fotos dos P-OLEDs polarizados de PF (c/Alq $)_{3}$.

Os dispositivos contendo PF com butyl-PBD como camada emissora apresentaram tensão de limiar de $5 \mathrm{~V}$, a luminância torna-se significativa a partir de $10 \mathrm{~V}$, atingindo o valor máximo, $45 \mathrm{~cd} / \mathrm{m}^{2}$, a $14 \mathrm{~V}$ (Figura 89). Para estes dispositivos, a eficiência luminosa atingiu o máximo, $13 \mathrm{mcd} / \mathrm{A}$, a $14 \mathrm{~V}$ (Figura 90).

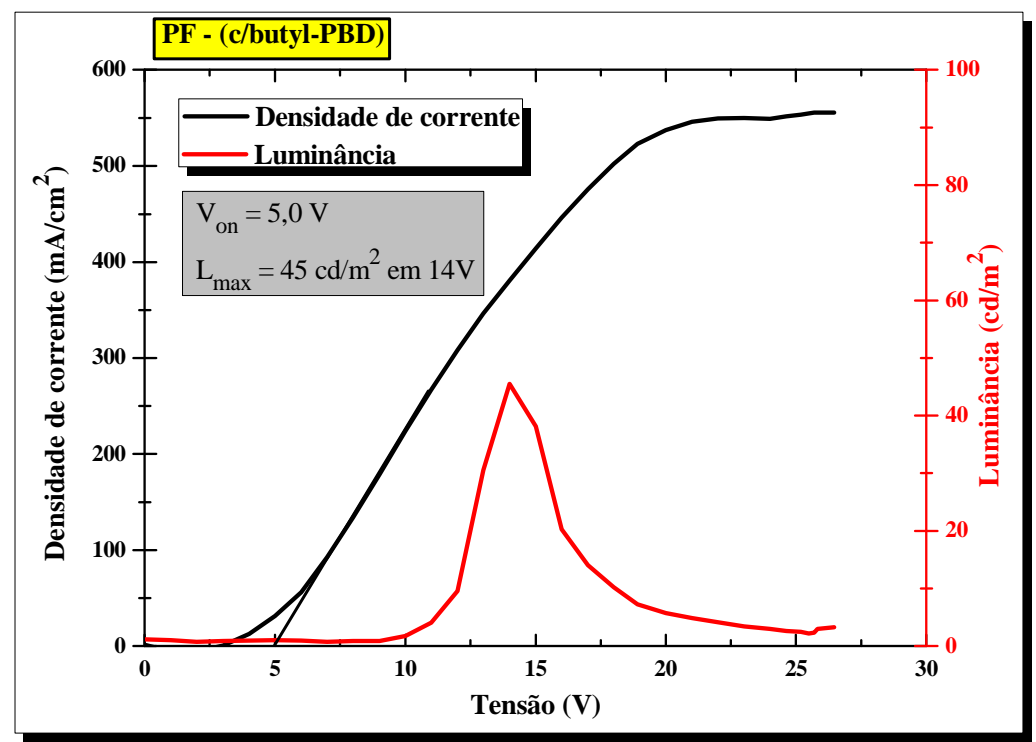

Figura 89 - Curva de densidade de corrente e luminância vs. tensão do PF (c/ butyl-PBD). 


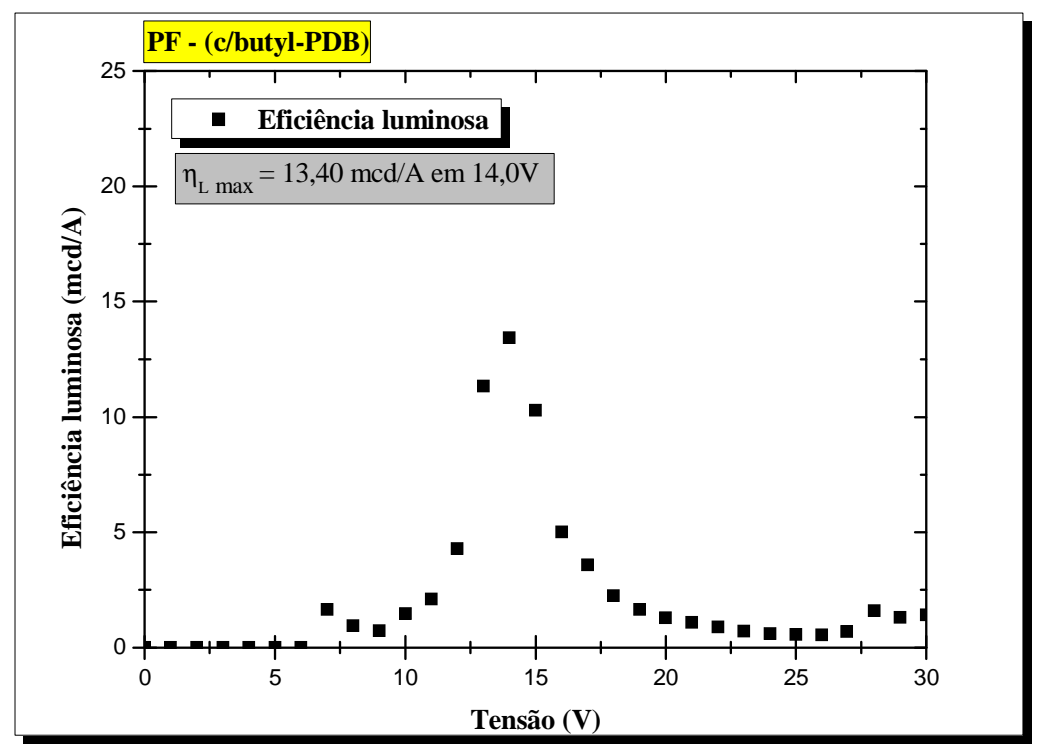

Figura 90 - Eficiência luminosa vs. tensão do PF (c/ butyl-PBD).

Observa-se que o comprimento de onda máximo do espectro de eletroluminescência não mudou com o valor da tensão, $525 \mathrm{~nm}$, entretanto as intensidades relativas das bandas observadas a $435 \mathrm{~nm}, 460 \mathrm{~nm}, 500 \mathrm{~nm}$ tornaram-se menores com o aumento da tensão (Figura 91). As coordenadas de cromaticidade foram identificadas na Figura 92, e as fotos dos dispositivos polarizados estão apresentadas na Figura 93.

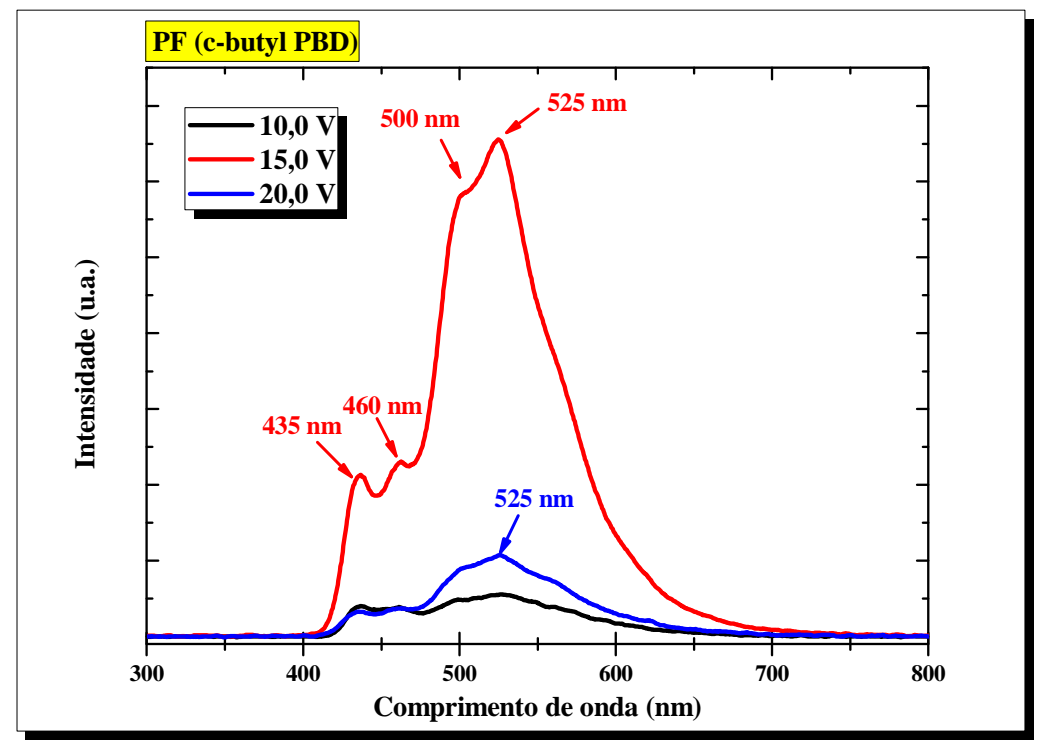

Figura 91 - Espectro de eletroluminescência do PF (c/ butyl-PBD). 


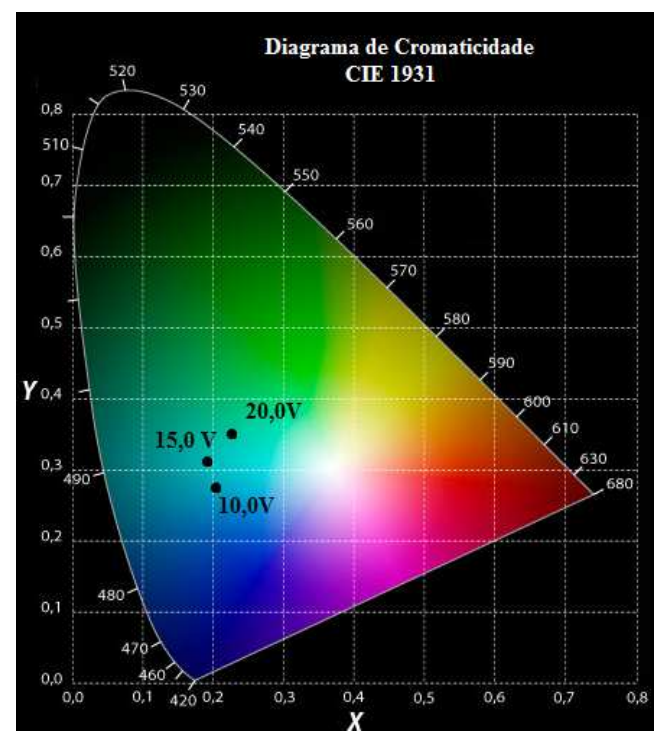

$\mathrm{x}=0,21$ e $\mathrm{y}=0,28 \mathrm{com}$ base no espectro de EL obtido em 10 volts $\mathrm{x}=0,19$ e $\mathrm{y}=0,31 \mathrm{com}$ base no espectro de EL obtido em 15 volts $\mathrm{x}=0,22$ e $\mathrm{y}=0,35 \mathrm{com}$ base no espectro de EL obtido em 20 volts

Figura 92 - Coordenadas de cromaticidade do PF (c/ butyl-PBD).

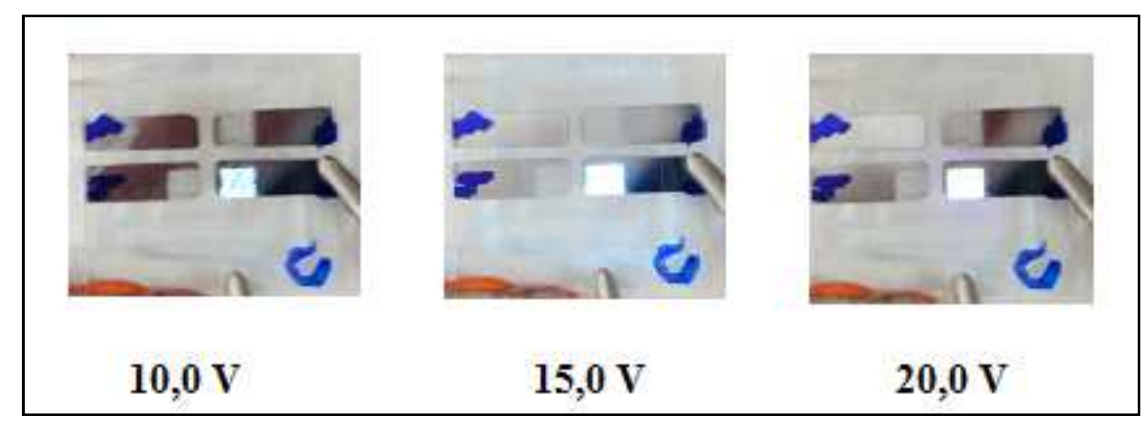

Figura 93 - Fotos dos P-OLEDs polarizados de PF (c/ butyl-PBD)

$\mathrm{Na}$ Tabela 10 foram listadas as características eletro-ópticas dos dispositivos de PF, comparando as diferentes camadas depositas. Assim sendo, o dispositivo mais eficiente que obteve uma menor tensão de operação, com maiores valores de luminância e de eficiência luminosa foi o que continha butyl-PBD com o polímero (PF).

Tabela 10 - Comparação entre as características eletro-ópticas dos P-OLEDs de PF.

\begin{tabular}{|c|c|c|c|c|}
\hline PF & $\begin{array}{c}\mathbf{V}_{\text {on }} \\
(\mathbf{V})\end{array}$ & $\begin{array}{c}\text { Luminância } \\
(\mathbf{c d} / \mathbf{m} 2)\end{array}$ & $\begin{array}{c}\text { Eficiência luminosa } \\
(\mathbf{m c d} / \mathbf{A})\end{array}$ & $\begin{array}{c}\text { Comprimento de onda de } \\
\text { Eletroluminescência (nm) }\end{array}$ \\
\hline s/ETL & 12,50 & 22,40 & 7,40 & 530 \\
\hline c/Alq 3 & 15,00 & 16,00 & 3,0 & 530 \\
\hline c/butyl-PBD & 5,00 & 45,00 & 13,5 & 525 \\
\hline
\end{tabular}




\subsubsection{PLED com o polímero $\mathrm{PF}_{\mathrm{P}}$ como camada ativa}

Os dispositivos contendo $\mathrm{PF}_{\mathrm{P}}$ sem ETL como camada emissora apresentaram tensão de limiar de aproximadamente $8 \mathrm{~V}$, luminância a partir de $15 \mathrm{~V}$, atingindo o valor máximo, $165 \mathrm{~cd} / \mathrm{m}^{2}$, a $15 \mathrm{~V}$ (Figura 94). Para estes dispositivos, a eficiência luminosa atingiu o máximo, $30 \mathrm{mcd} / \mathrm{A}$, a $15 \mathrm{~V}$ (Figura 95).

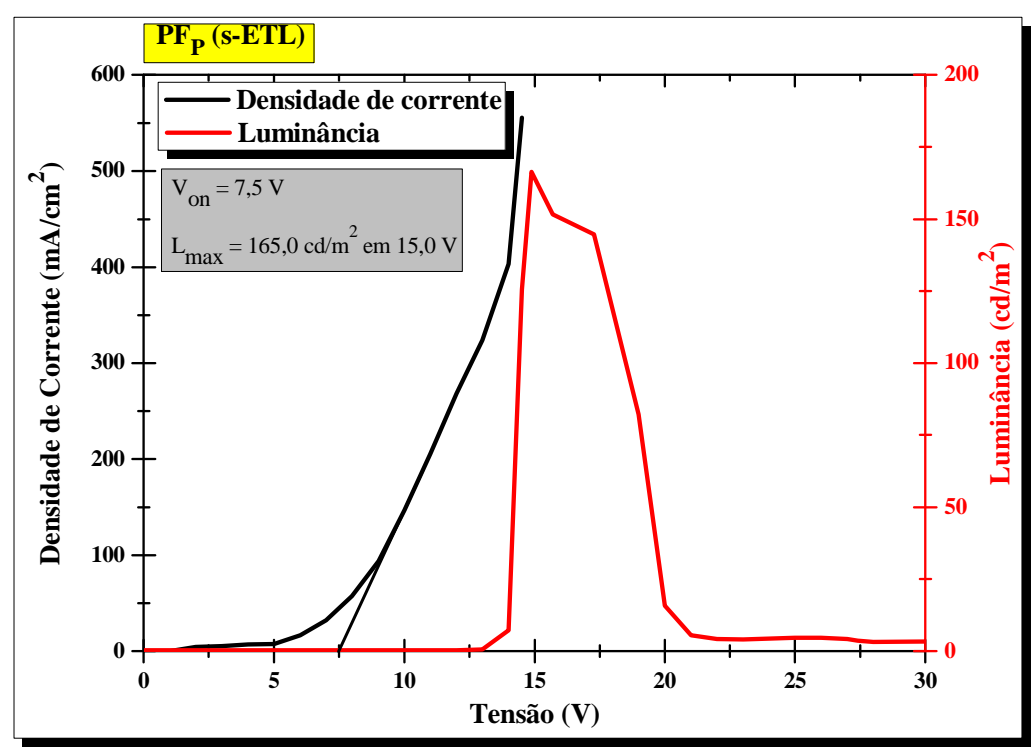

Figura 94 - Curva de densidade de corrente e luminância vs. tensão do $\mathrm{PF}_{\mathrm{P}}$ (s/ETL).

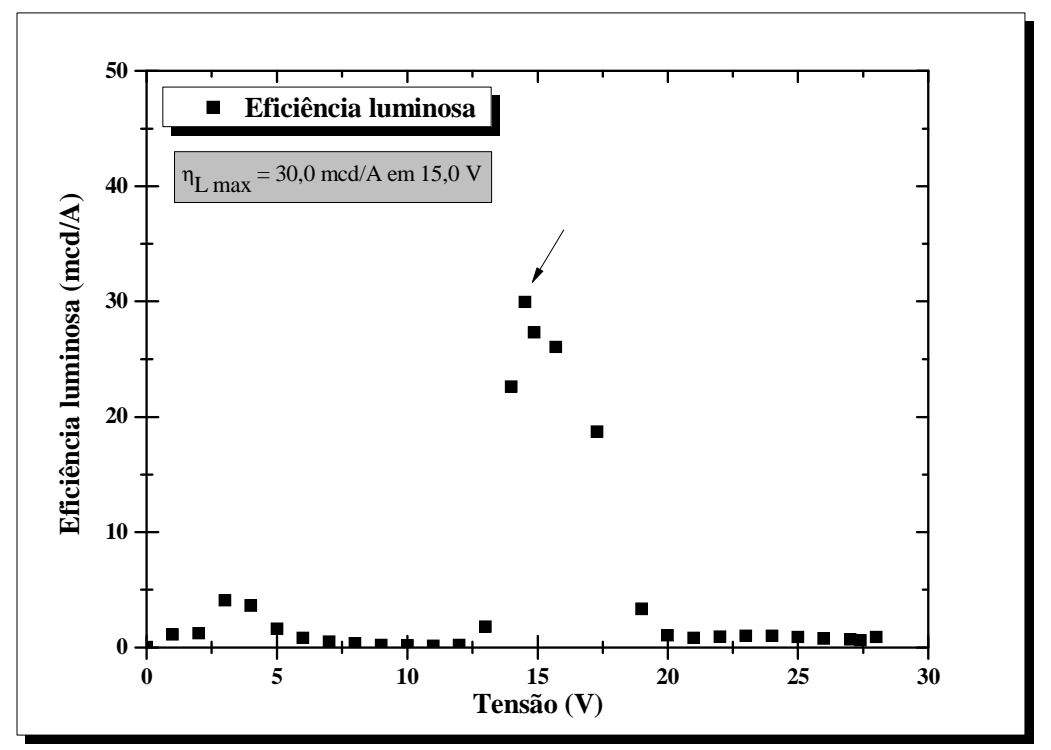

Figura 95 - Eficiência luminosa vs. tensão do $\mathrm{PF}_{\mathrm{P}}$ (s/ ETL). 
Observa-se que o comprimento de onda máximo do espectro de eletroluminescência não mudou com o valor da tensão, $525 \mathrm{~nm}$ (Figura 96). As coordenadas de cromaticidade foram identificadas na Figura 97 e as fotos dos dispositivos polarizados estão apresentadas na Figura 98.

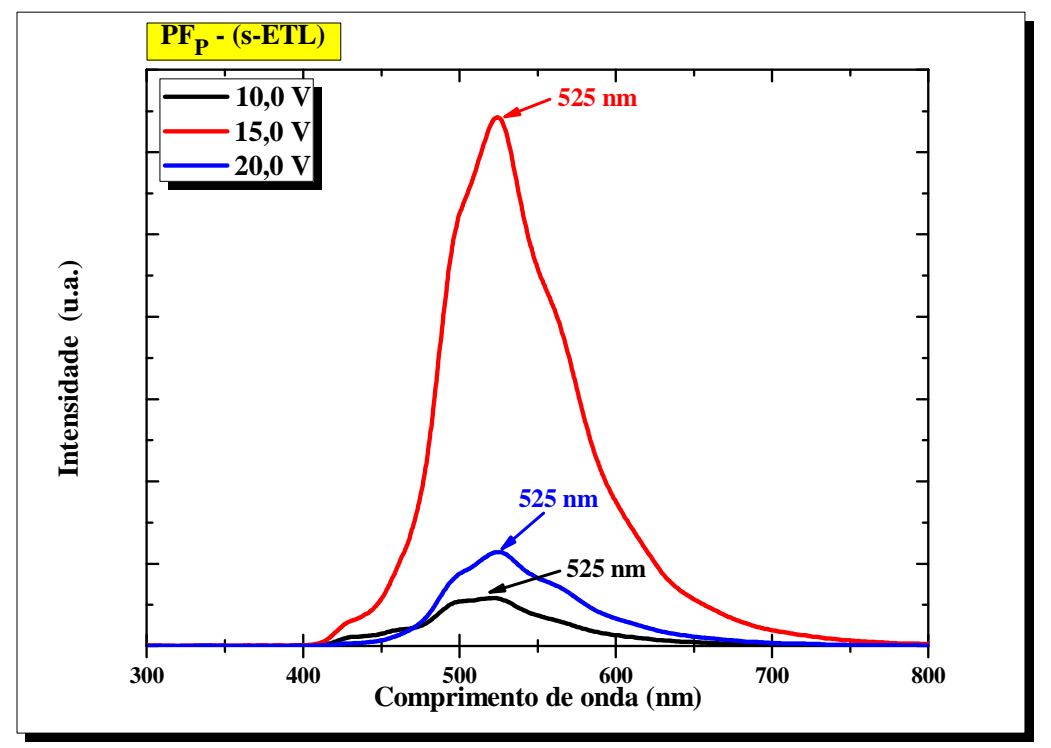

Figura 96 - Espectro de eletroluminescência do $\mathrm{PF}_{\mathrm{P}}$ (s/ ETL).

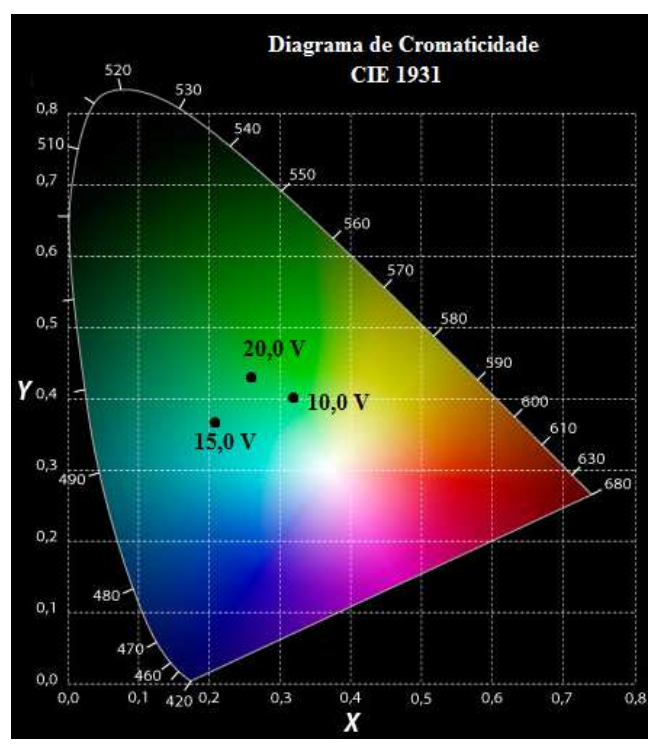

$\mathrm{x}=0,32$ e $\mathrm{y}=0,40 \mathrm{com}$ base no espectro de EL obtido em 10 volts $\mathrm{x}=0,21$ e $\mathrm{y}=0,38 \mathrm{com}$ base no espectro de EL obtido em 15 volts $\mathrm{x}=0,24$ e $\mathrm{y}=0,43 \mathrm{com}$ base no espectro de EL obtido em 20 volts

Figura 97 - Coordenadas de cromaticidade do $\mathrm{PF}_{\mathrm{P}}$ (s/ETL). 


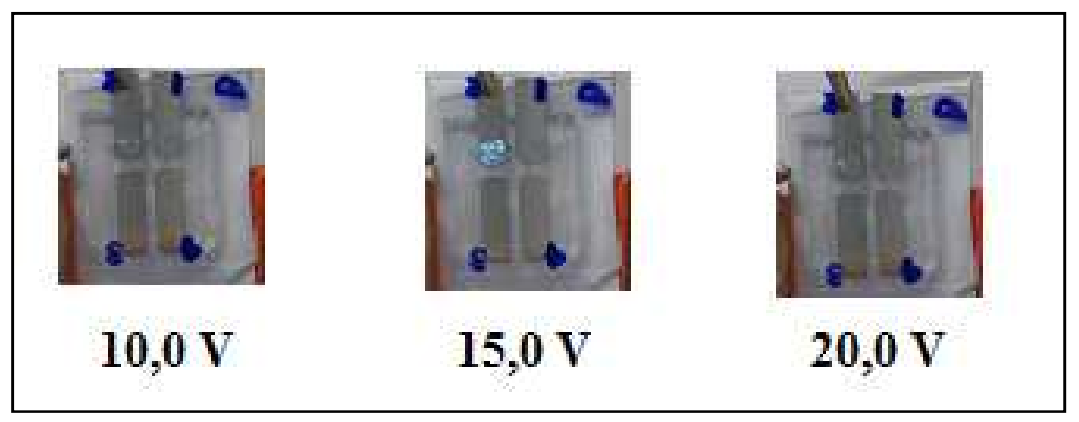

Figura 98 - Fotos dos P-OLEDs polarizados de $\mathrm{PF}_{\mathrm{P}}$ (s/ETL).

Os dispositivos contendo $\mathrm{PF}_{\mathrm{P}}$ com $\mathrm{Alq}_{3}$ como camada emissora apresentaram tensão de limiar de aproximadamente $8 \mathrm{~V}$, luminância a partir de $15 \mathrm{~V}$, atingindo o valor máximo, $160 \mathrm{~cd} / \mathrm{m}^{2}$, a $18 \mathrm{~V}$ (Figura 99). Para estes dispositivos a eficiência luminosa atingiu o máximo, $30 \mathrm{mcd} / \mathrm{A}$, a $18 \mathrm{~V}$ (Figura 100).

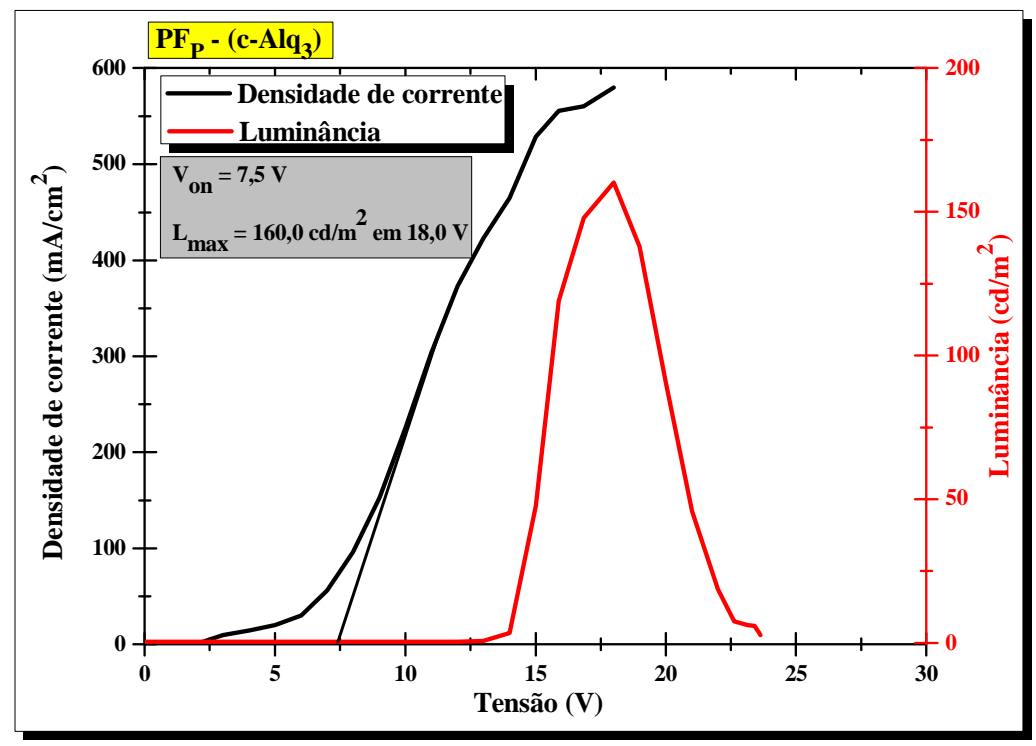

Figura 99 - Curva de densidade de corrente e luminância vs. tensão do $\mathrm{PF}_{\mathrm{P}}\left(\mathrm{c} / \mathrm{Alq}_{3}\right)$. 


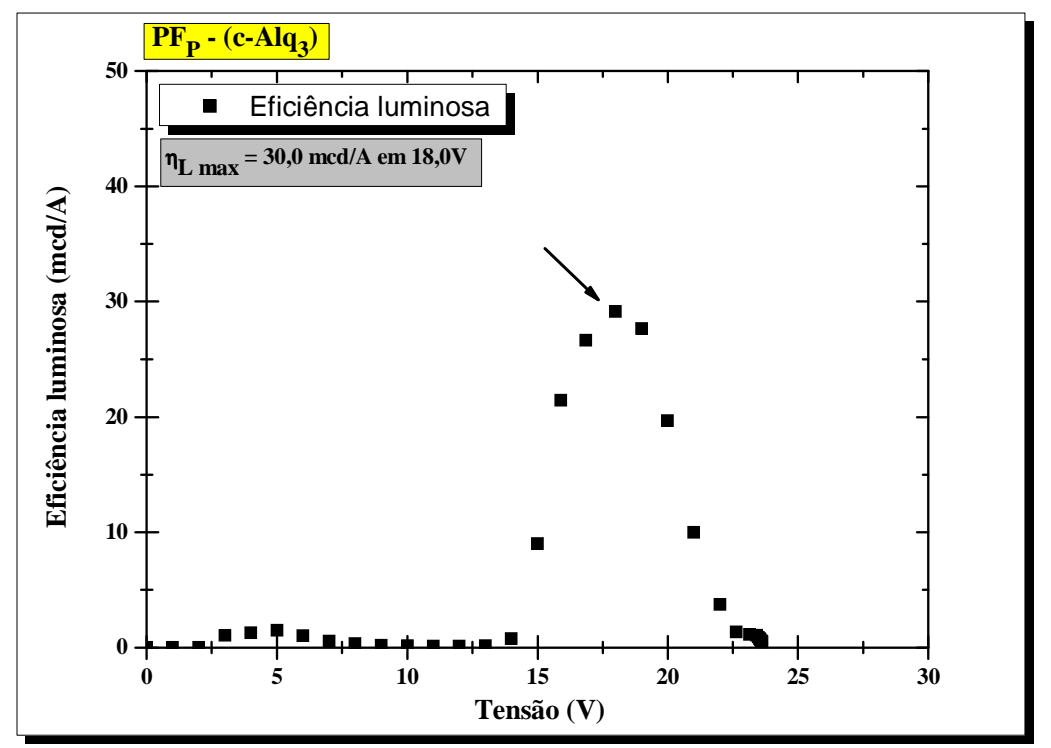

Figura 100 - Eficiência luminosa vs. tensão do $\mathrm{PF}_{\mathrm{P}}\left(\mathrm{c} / \mathrm{Alq}_{3}\right)$.

O comprimento de onda observado para o máximo do espectro de eletroluminescência não mudou com o valor da tensão, $525 \mathrm{~nm}$ (Figura 101). Os índices de cromaticidade foram identificados na Figura 102, e as fotos dos dispositivos polarizados estão apresentadas na Figura 103.

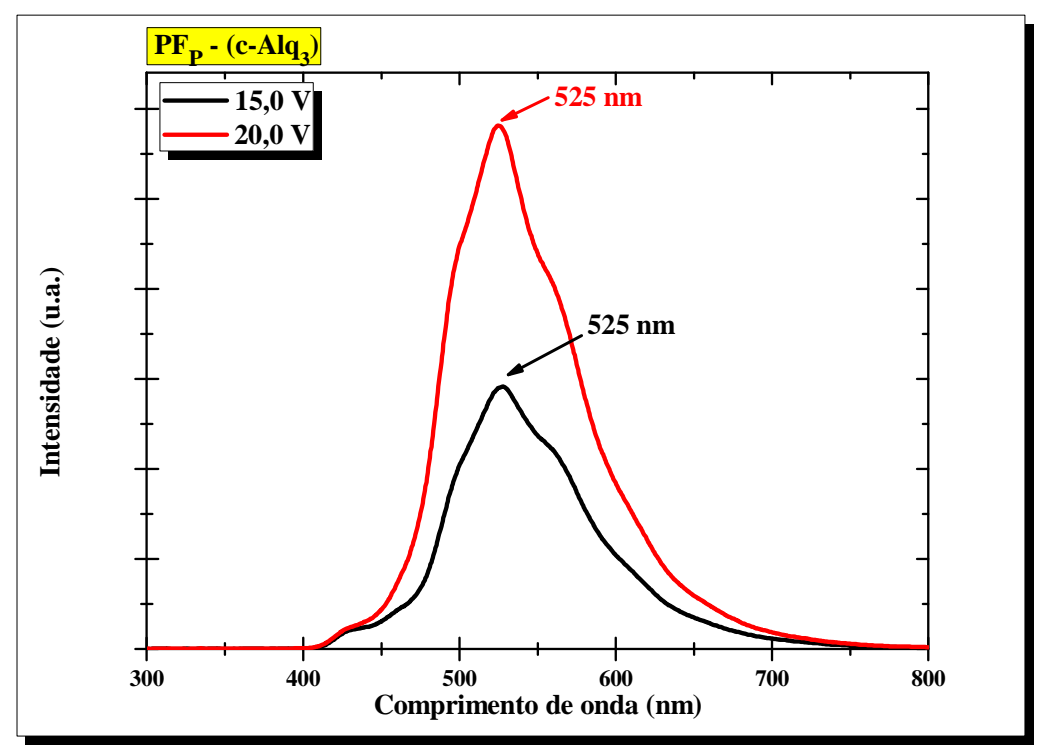

Figura 101 - Espectro de eletroluminescência do $\mathrm{PF}_{\mathrm{P}}\left(\mathrm{c} / \mathrm{Alq}_{3}\right)$. 


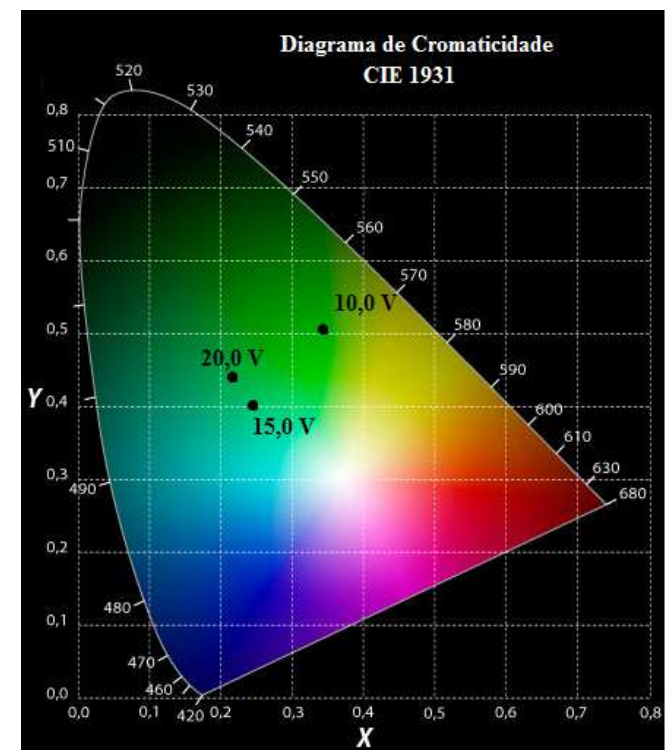

$\mathrm{x}=0,34$ e $\mathrm{y}=0,50 \mathrm{com}$ base no espectro de EL obtido em 10 volts $\mathrm{x}=0,24$ e $\mathrm{y}=0,40 \mathrm{com}$ base no espectro de EL obtido em 15 volts $\mathrm{x}=0,23$ e $\mathrm{y}=0,43 \mathrm{com}$ base no espectro de EL obtido em 20 volts

Figura 102 - Coordenadas de cromaticidade do PFP (c/ Alq $)$.

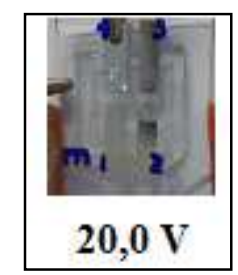

Figura 103 - Foto do P-OLED polarizado de $\mathrm{PF}_{\mathrm{P}}\left(\mathrm{c} / \mathrm{Alq}_{3}\right)$

Os dispositivos contendo $\mathrm{PF}_{\mathrm{P}}$ com butyl-PBD como camada emissora apresentaram tensão de limiar de aproximadamente $5 \mathrm{~V}$, luminância a partir de $15 \mathrm{~V}$, atingindo o valor máximo, $83 \mathrm{~cd} / \mathrm{m}^{2}$, a $16 \mathrm{~V}$ (Figura 104). Para estes dispositivos a eficiência luminosa atingiu o máximo, $37 \mathrm{mcd} / \mathrm{A}$, a $17 \mathrm{~V}$ (Figura 105). 


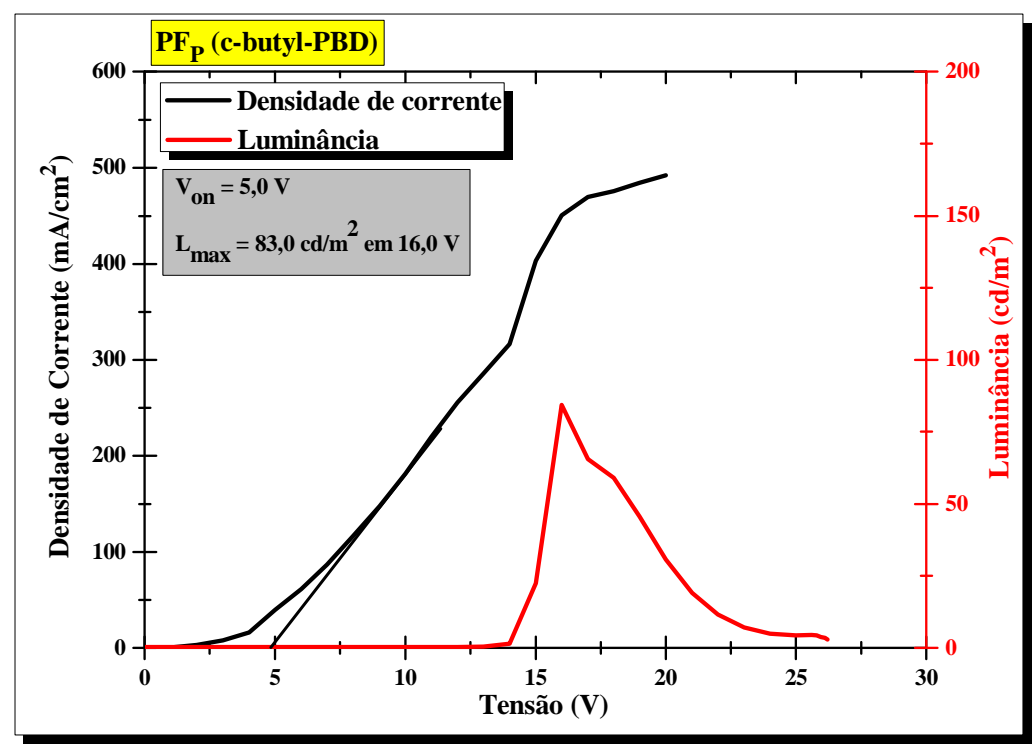

Figura 104 - Curva de densidade de corrente e luminância vs. tensão do $\mathrm{PF}_{\mathrm{P}}(\mathrm{c} /$ butyl PBD).

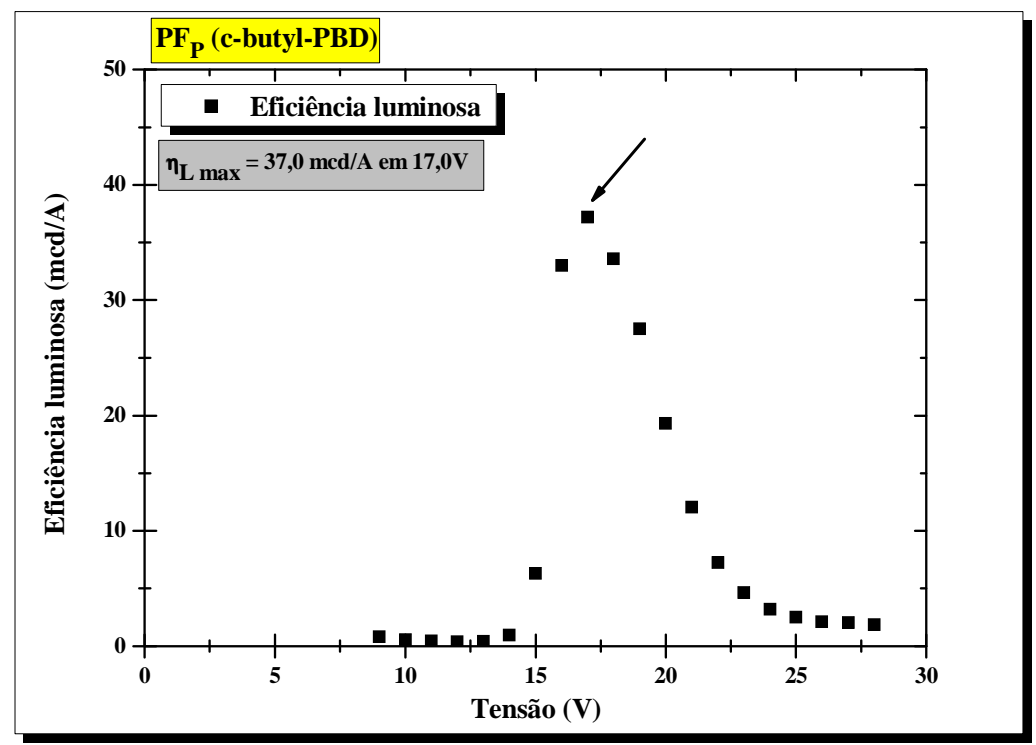

Figura 105 - Eficiência luminosa vs. tensão do $\mathrm{PF}_{\mathrm{P}}$ (c/ butyl-PBD).

O comprimento de onda observado para o máximo do espectro de eletroluminescência não mudou com o valor da tensão, $525 \mathrm{~nm}$ (Figura 106). As coordenadas de cromaticidade foram identificadas na Figura 107, e as fotos dos dispositivos polarizados estão apresentadas na Figura 108. 


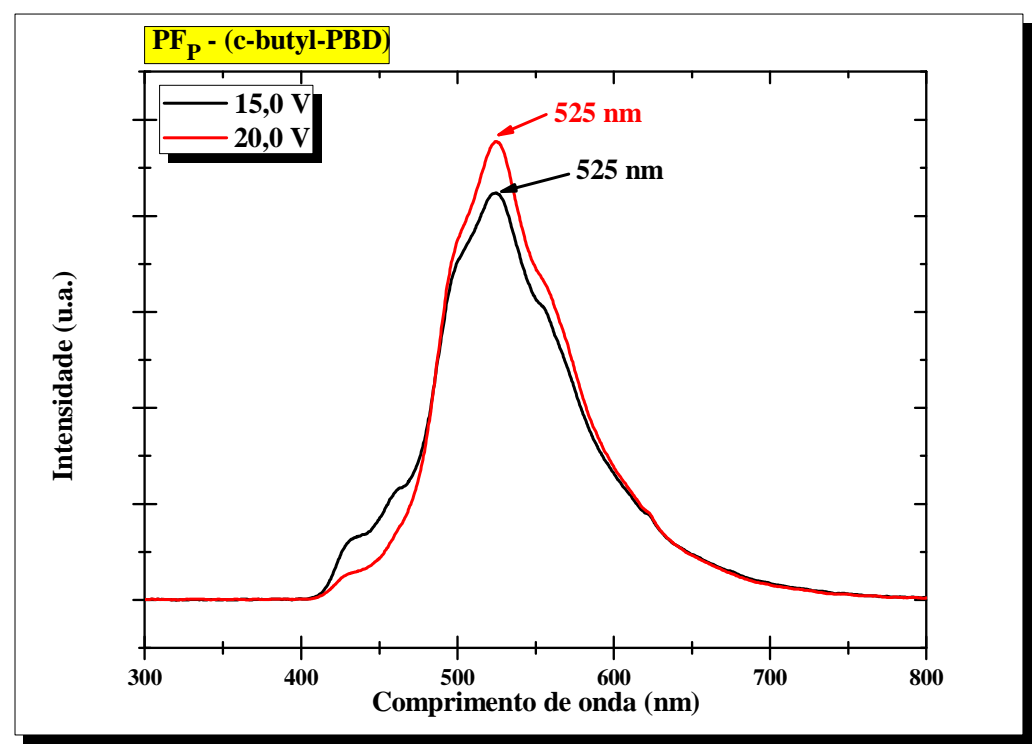

Figura 106 - Espectro de eletroluminescência do $\mathrm{PF}_{\mathrm{P}}$ (c/ butyl-PBD).

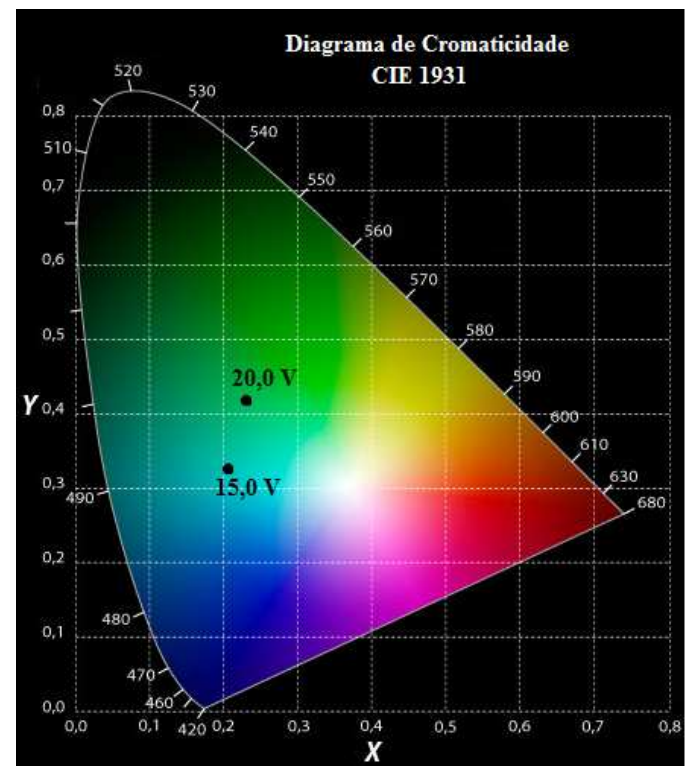

$\mathrm{x}=0,21$ e $\mathrm{y}=0,33 \mathrm{com}$ base no espectro de EL obtido em 15 volts $\mathrm{x}=0,23$ e $\mathrm{y}=0,43 \mathrm{com}$ base no espectro de EL obtido em 20 volts

Figura 107 - Coordenadas de cromaticidade do $\mathrm{PF}_{\mathrm{P}}$ (c/ butyl-PBD).

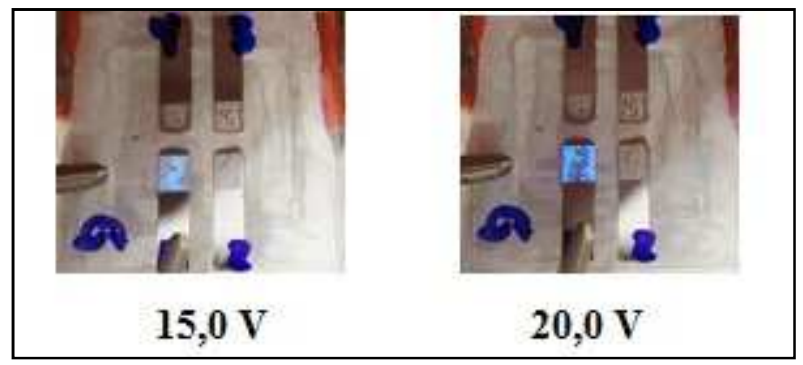

Figura 108 - Fotos dos P-OLEDs polarizados de $\mathrm{PF}_{\mathrm{P}}$ (c/ butyl-PBD). 
Na Tabela 11 foram listadas as características eletro-ópticas dos dispositivos de $\mathrm{PF}_{\mathrm{P}}$, comparando as diferentes camadas depositadas. Assim sendo, as camadas sem ETL e com $\mathrm{Alq}_{3}$ apresentaram comportamentos semelhantes, enquanto que a camada com butyl-PBD apresentou menor tensão de operação e menor luminância, porém apresentou um valor mais elevado de eficiência luminosa quando comparado aos outros dois tipos de camada emissora.

Tabela 11 - Comparação entre as características eletro-ópticas dos P-OLEDs de PFP.

\begin{tabular}{|c|c|c|c|c|}
\hline $\mathbf{P F}_{\mathbf{P}}$ & $\begin{array}{l}\mathbf{V}_{\text {on }} \\
(\mathbf{V}) \\
\end{array}$ & $\begin{array}{c}\text { Luminância } \\
\left(\mathbf{c d} / \mathbf{m}^{2}\right)\end{array}$ & $\begin{array}{c}\text { Eficiência luminosa } \\
(\mathrm{mcd} / \mathrm{A})\end{array}$ & $\begin{array}{l}\text { Comprimento de onda de } \\
\text { Eletroluminescência }(\mathrm{nm})\end{array}$ \\
\hline s/ETL & 7,5 & 165,00 & 30,00 & 525 \\
\hline c/Alq $_{3}$ & 7,5 & 160,00 & 30,00 & 525 \\
\hline c/butyl-PBD & 5,0 & 83,00 & 37,00 & 525 \\
\hline
\end{tabular}

\subsubsection{PLED com o polímero $\mathrm{PF}_{\mathrm{PF}}$ como camada ativa}

Os dispositivos contendo $\mathrm{PF}_{\mathrm{PF}}$ sem ETL como camada emissora apresentaram tensão de limiar de aproximadamente $5 \mathrm{~V}$, luminância a partir de $13 \mathrm{~V}$, atingindo o valor máximo, $135 \mathrm{~cd} / \mathrm{m}^{2}$, a $13 \mathrm{~V}$ (Figura 109). Para estes dispositivos, a eficiência luminosa atingiu o máximo, $38 \mathrm{mcd} / \mathrm{A}$, a $13 \mathrm{~V}$ (Figura 110).

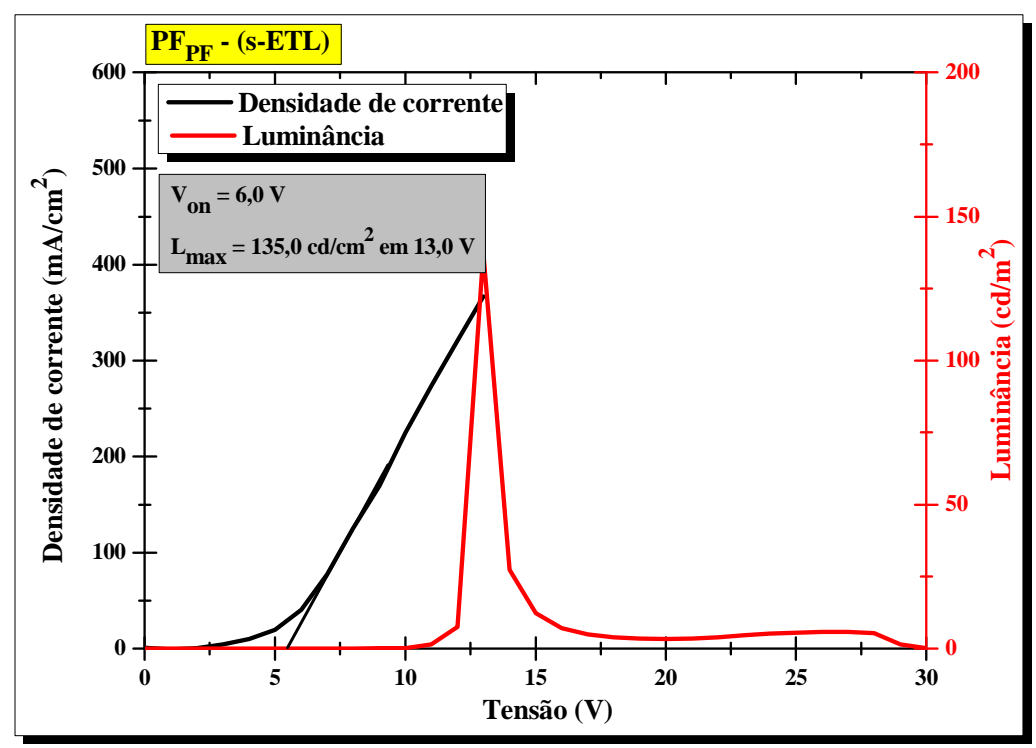

Figura 109 - Curva de densidade de corrente e luminância vs. tensão do $\mathrm{PF}_{\mathrm{PF}}$ (s/ETL). 


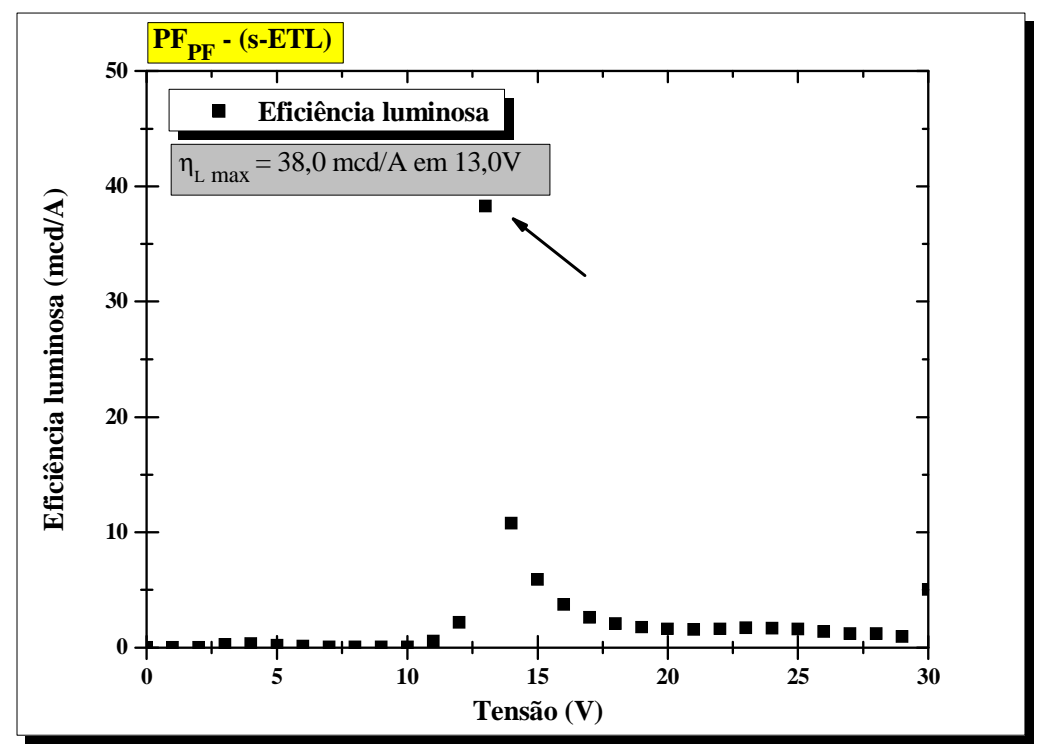

Figura 110 - Eficiência luminosa vs. tensão do $\mathrm{PF}_{\mathrm{PF}}$ (s/ETL).

Observa-se que o comprimento de onda máximo do espectro de eletroluminescência não mudou com o valor da tensão, $515 \mathrm{~nm}$ (Figura 111). As coordenadas de cromaticidade foram identificadas na Figura 112, e as fotos dos dispositivos polarizados estão apresentadas na Figura 113.

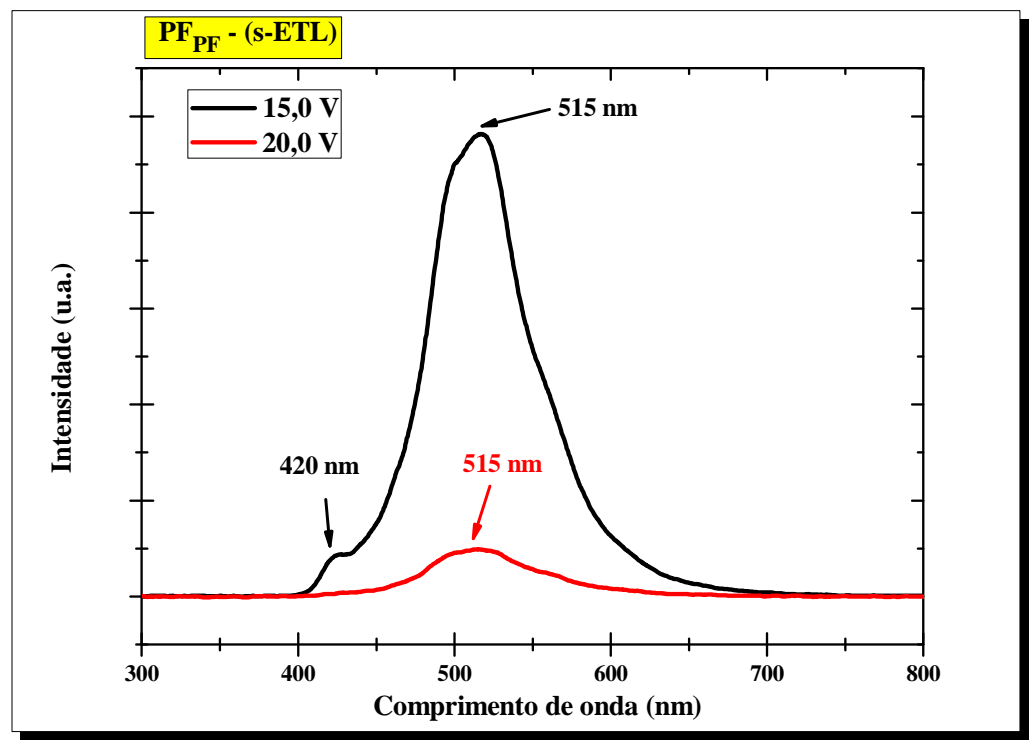

Figura 111 - Espectro de eletroluminescência do $\mathrm{PF}_{\mathrm{PF}}$ (s/ ETL). 


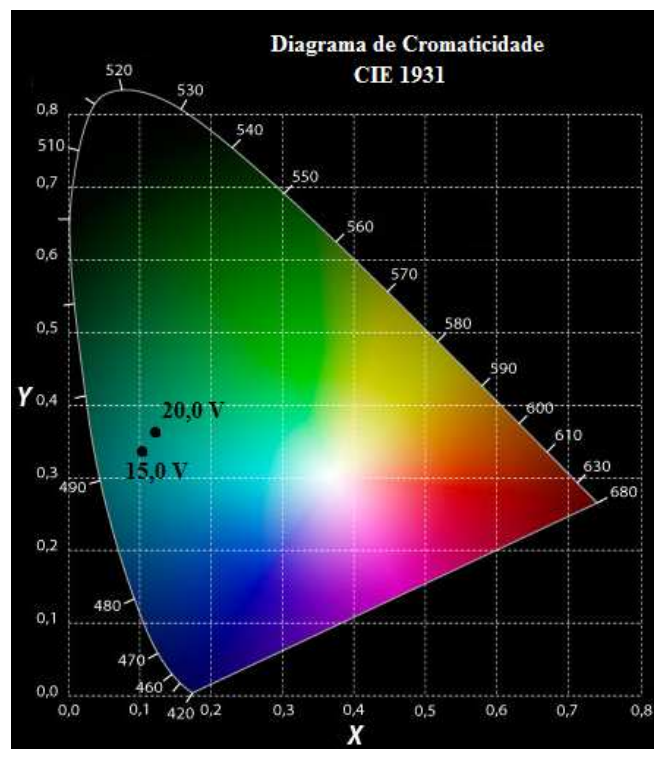

$\mathrm{x}=0,17$ e $\mathrm{y}=0,34 \mathrm{com}$ base no espectro de EL obtido em 15 volts $\mathrm{x}=0,18$ e $\mathrm{y}=0,36 \mathrm{com}$ base no espectro de EL obtido em 20 volts

Figura 112 - Coordenadas de cromaticidade do $\mathrm{PF}_{\mathrm{PF}}$ (s/ETL).

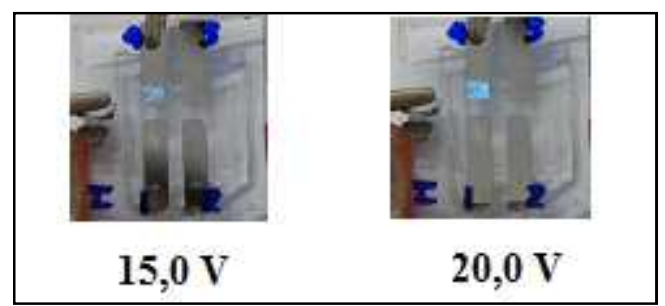

Figura 113 - Fotos dos P-OLEDs polarizados de $\mathrm{PF}_{\mathrm{PF}}$ (s/ ETL).

Os dispositivos contendo $\mathrm{PF}_{\mathrm{PF}}$ com $\mathrm{Alq}_{3}$ como camada emissora apresentaram tensão de limiar de aproximadamente $6 \mathrm{~V}$, atingindo o valor máximo de luminância, $81 \mathrm{~cd} / \mathrm{m}^{2}$, a 10 V (Figura 114). Para estes dispositivos, a eficiência luminosa atingiu o máximo, $15 \mathrm{mcd} / \mathrm{A}$, a $10 \mathrm{~V}$ (Figura 115). 


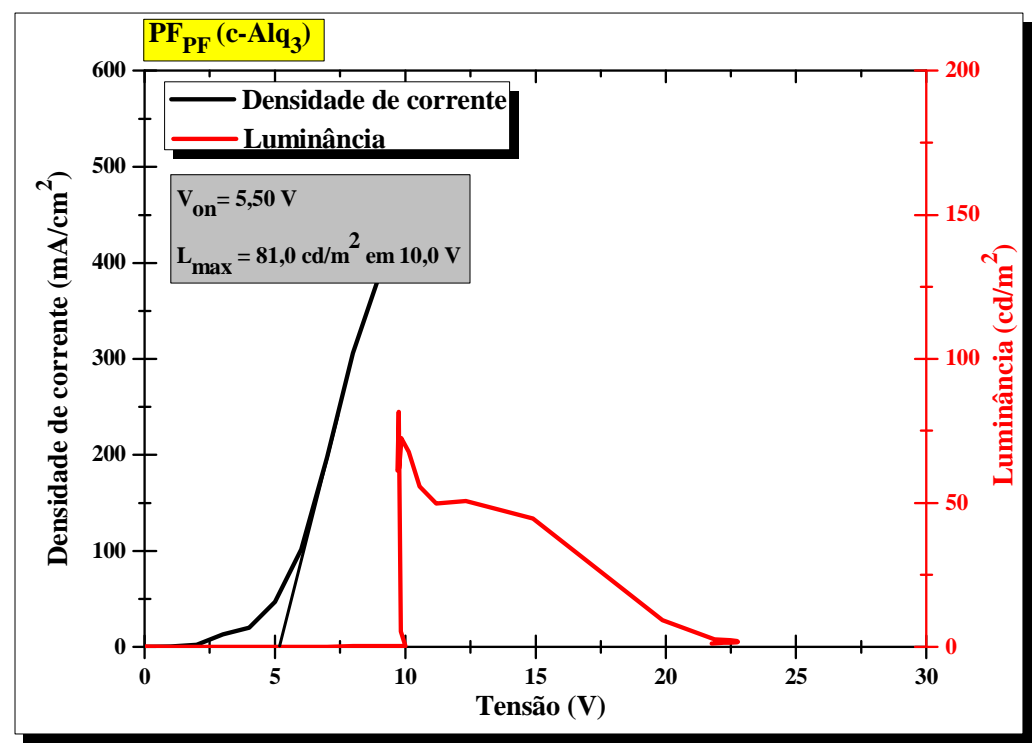

Figura 114 - Curva de densidade de corrente e luminância vs. tensão do $\mathrm{PF}_{\mathrm{PF}}\left(\mathrm{c} / \mathrm{Alq}_{3}\right)$.

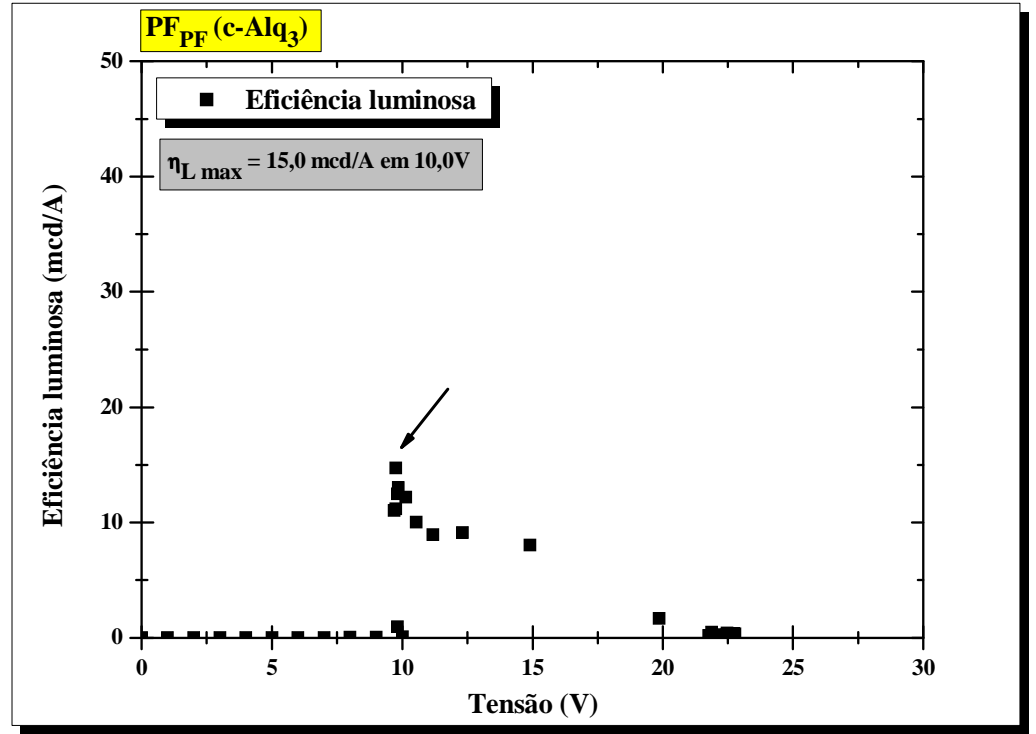

Figura 115 - Eficiência luminosa vs. tensão do $\mathrm{PF}_{\mathrm{PF}}\left(\mathrm{c} / \mathrm{Alq}_{3}\right)$.

O comprimento de onda observado para o máximo do espectro de eletroluminescência não mudou com o valor da tensão, $515 \mathrm{~nm}$ (Figura 116). As coordenadas de cromaticidade foram identificadas na Figura 117, e as fotos dos dispositivos polarizados estão apresentadas na Figura 118. 


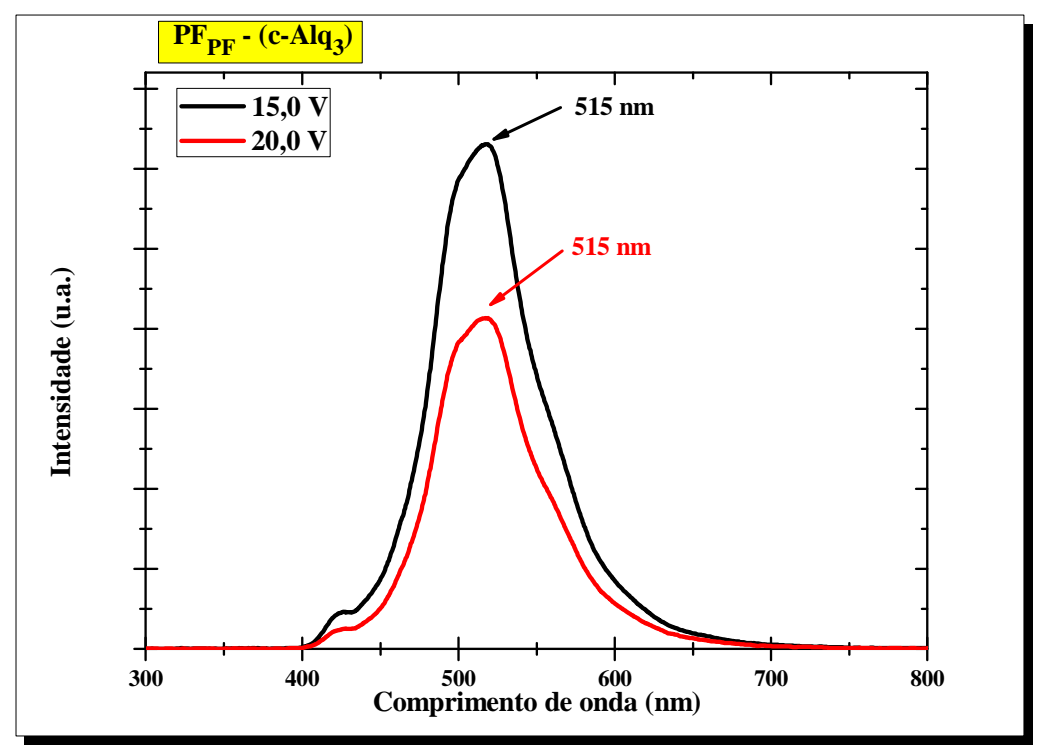

Figura 116 - Espectro de eletroluminescência do $\mathrm{PF}_{\mathrm{PF}}\left(\mathrm{c} / \mathrm{Alq}_{3}\right)$.

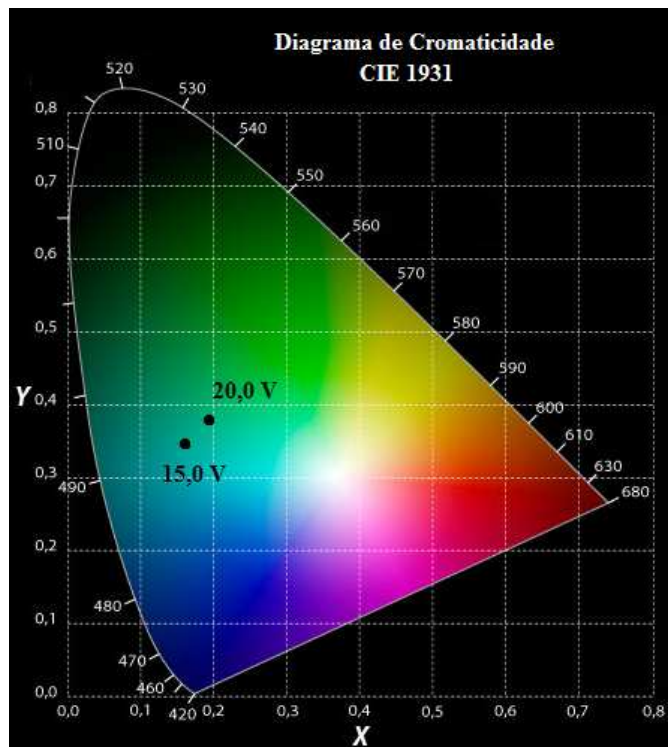

$\mathrm{x}=0,17$ e $\mathrm{y}=0,35 \mathrm{com}$ base no espectro de EL obtido em 15 volts $\mathrm{x}=0,18$ e $\mathrm{y}=0,37 \mathrm{com}$ base no espectro de EL obtido em 20 volts

Figura 117 - Coordenadas de cromaticidade do $\mathrm{PF}_{\mathrm{PF}}\left(\mathrm{c} / \mathrm{Alq}_{3}\right)$.

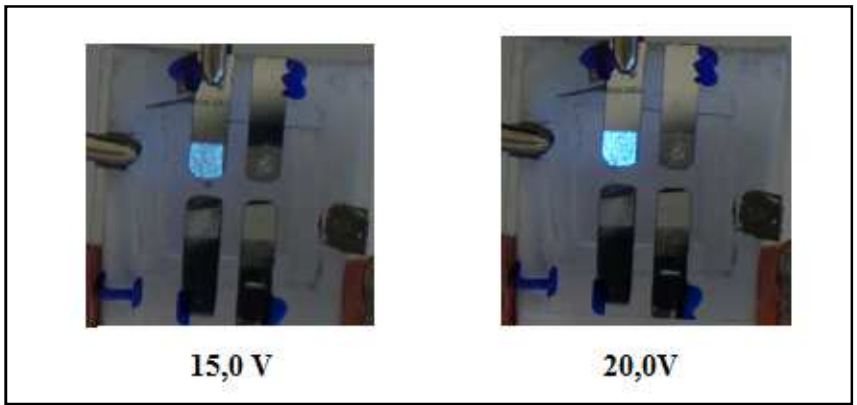

Figura 118 - Fotos dos P-OLEDs polarizados de $\mathrm{PF}_{\mathrm{PF}}\left(\mathrm{c} / \mathrm{Alq}_{3}\right)$. 
Os dispositivos contendo $\mathrm{PF}_{\mathrm{PF}}$ com butyl-PBD como camada emissora apresentaram tensão de limiar de aproximadamente $4 \mathrm{~V}$, luminância a partir de $10 \mathrm{~V}$, atingindo o valor máximo, $130 \mathrm{~cd} / \mathrm{m}^{2}$, a $10 \mathrm{~V}$ (Figura 119). Para estes dispositivos, a eficiência luminosa atingiu o máximo, $24 \mathrm{mcd} / \mathrm{A}$, a $11 \mathrm{~V}$ (Figura 120).

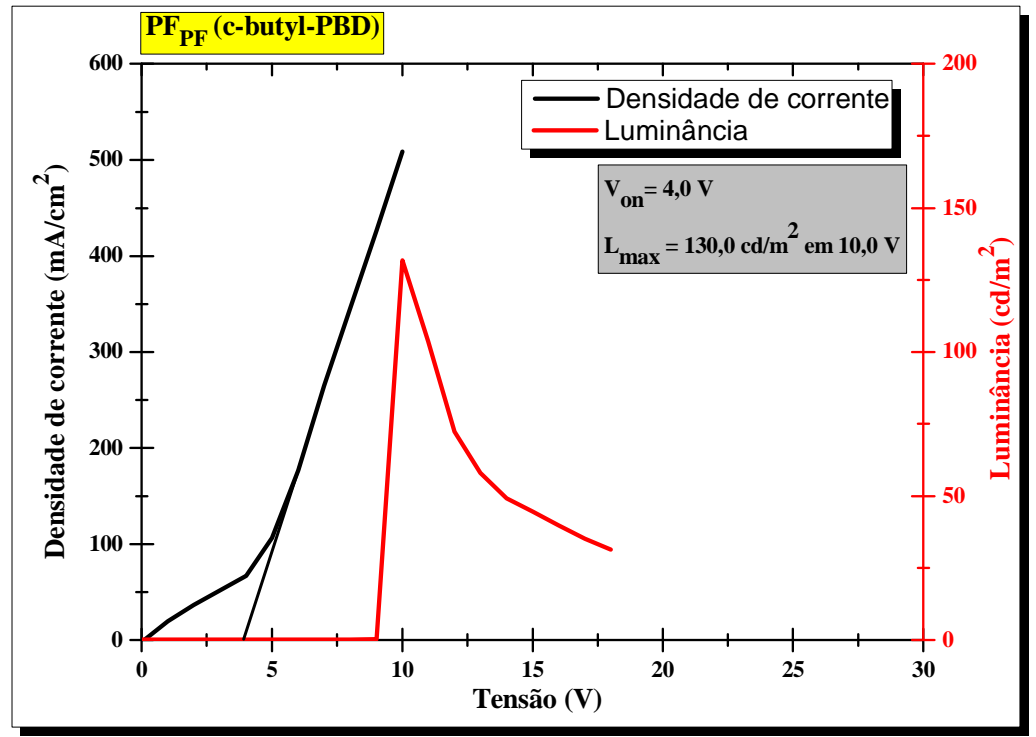

Figura 119 - Curva de densidade de corrente e luminância vs. tensão do $\mathrm{PF}_{\mathrm{PF}}(\mathrm{c} /$ butyl PBD).

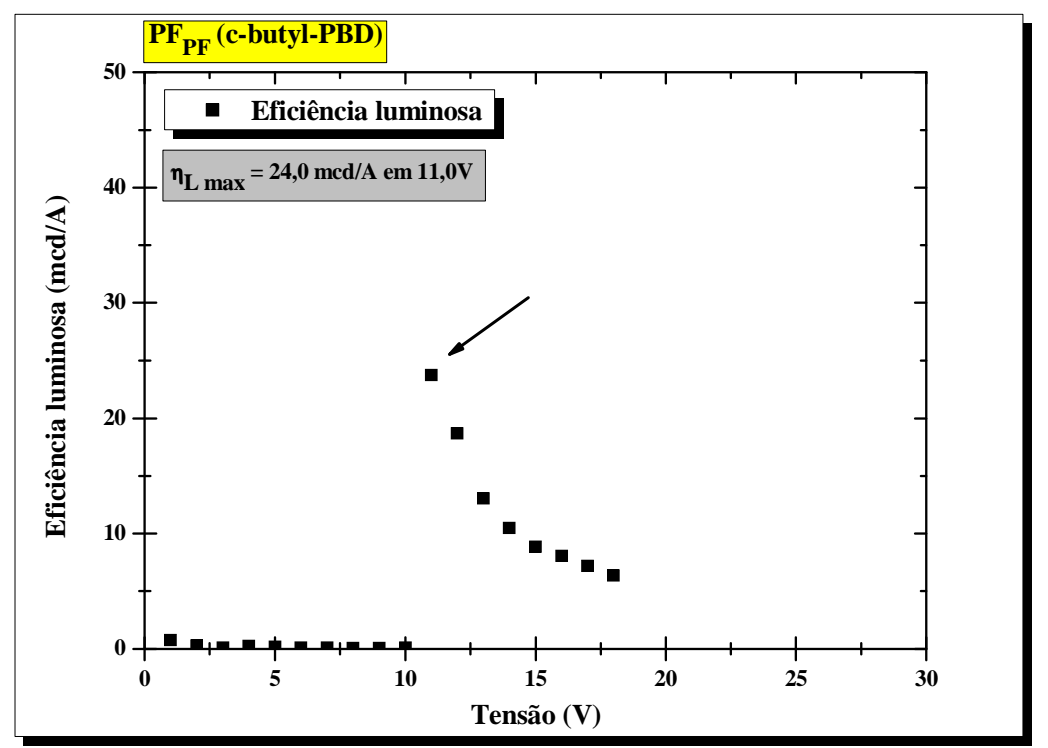

Figura 120 - Eficiência luminosa vs. tensão do $\mathrm{PF}_{\mathrm{PF}}(\mathrm{c} /$ butyl-PBD). 
Observa-se que o comprimento de onda máximo do espectro de eletroluminescência não mudou com o valor da tensão, $515 \mathrm{~nm}$ (Figura 121). As coordenadas de cromaticidade foram identificadas na Figura 122, e as fotos dos dispositivos polarizados estão apresentadas na Figura 123.

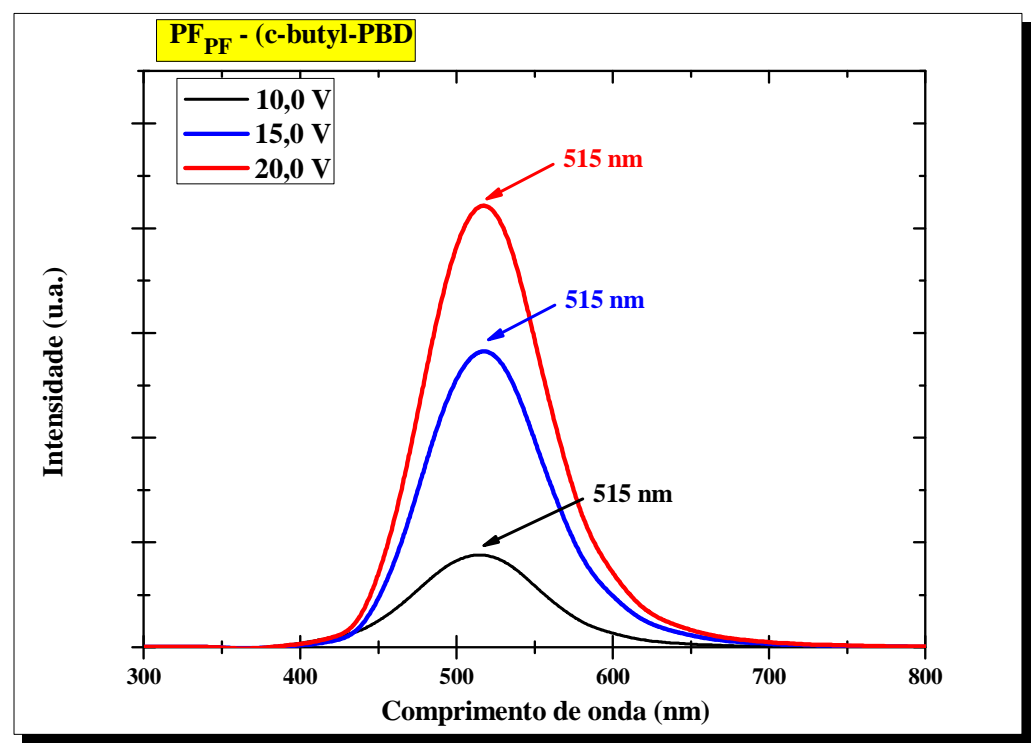

Figura 121 - Espectro de eletroluminescência do $\mathrm{PF}_{\mathrm{PF}}$ (c/ butyl-PBD).

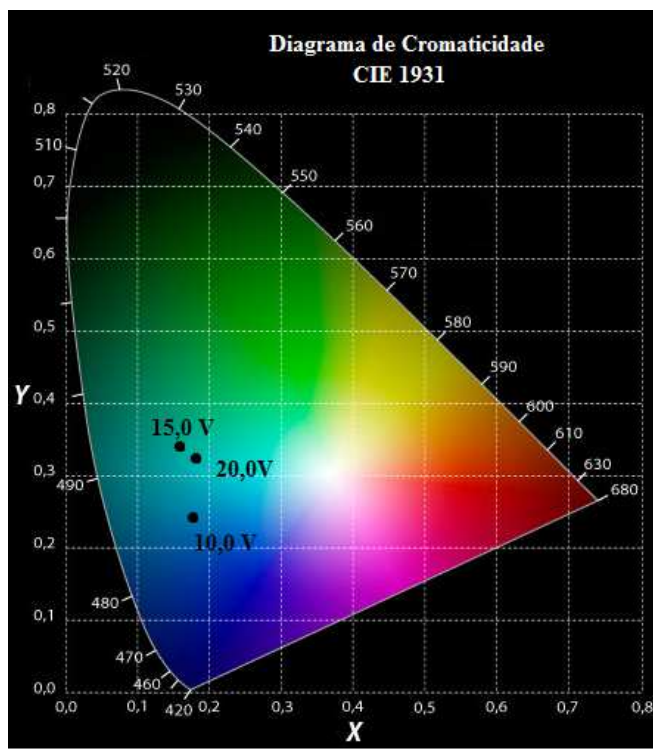

$\mathrm{x}=0,18$ e $\mathrm{y}=0,25 \mathrm{com}$ base no espectro de EL obtido em 10 volts $\mathrm{x}=0,17$ e $\mathrm{y}=0,35 \mathrm{com}$ base no espectro de EL obtido em 15 volts $\mathrm{x}=0,18$ e $\mathrm{y}=0,34 \mathrm{com}$ base no espectro de EL obtido em 20 volts

Figura 122 - Coordenadas de cromaticidade do $\mathrm{PF}_{\mathrm{PF}}$ (c/ butyl-PBD). 


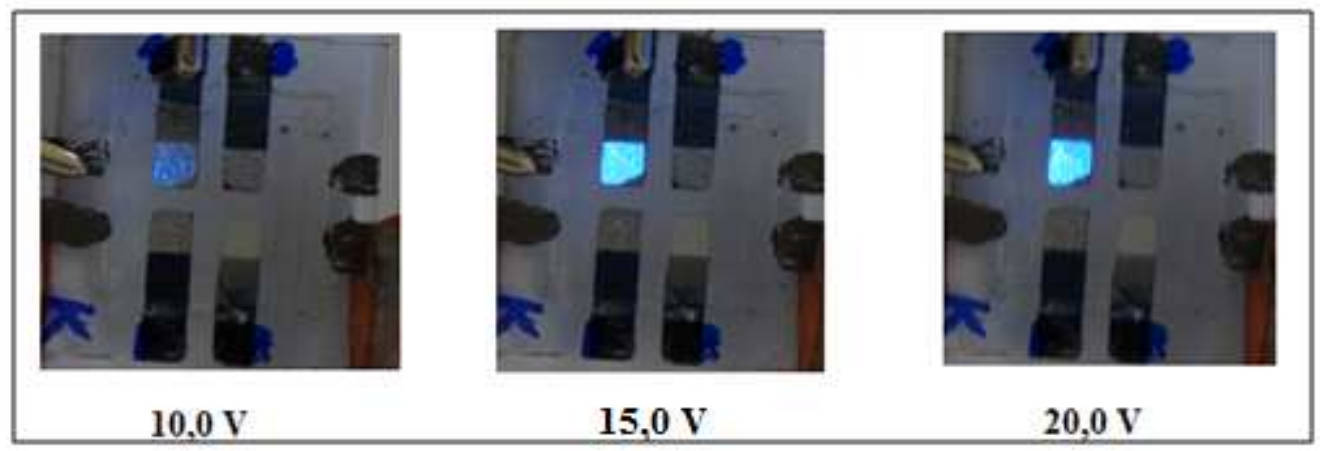

Figura 123 - Fotos dos P-OLEDs polarizados de $\mathrm{PF}_{\mathrm{PF}}$ (c/ butyl-PBD).

$\mathrm{Na}$ Tabela 12 foram listadas as características eletro-ópticas dos dispositivos de $\mathrm{PF}_{\mathrm{PF}}$, comparando as diferentes camadas depositadas. Assim sendo, as camadas sem ETL e com butyl-PBD apresentaram comportamento semelhantes, com maiores valores máximos de luminância e de eficiência luminosa quando comparada com a camada emissora que continha $\mathrm{Alq}_{3}$.

Tabela 12 - Comparação entre as características eletro-ópticas dos P-OLEDs de PF $\mathrm{PF}_{\text {. }}$

\begin{tabular}{|c|c|c|c|c|}
\hline PF & $\begin{array}{c}\mathbf{V}_{\text {on }} \\
(\mathbf{V})\end{array}$ & $\begin{array}{c}\text { Luminância } \\
(\mathbf{c d} / \mathbf{m} 2)\end{array}$ & $\begin{array}{c}\text { Eficiência luminosa } \\
(\mathbf{m c d} / \mathbf{A})\end{array}$ & $\begin{array}{c}\text { Comprimento de onda de } \\
\text { Eletroluminescência (nm) }\end{array}$ \\
\hline s/ETL & 6,00 & 135,00 & 38,00 & 515 \\
\hline c/Alq & 5,50 & 81,00 & 15,00 & 515 \\
\hline c/butyl-PBD & 4,00 & 130,0 & 24,00 & 515 \\
\hline
\end{tabular}

De um modo geral, os três tipos de polímeros ( $\mathrm{PF}, \mathrm{PF}_{\mathrm{P}}$ e $\left.\mathrm{PF}_{\mathrm{PF}}\right)$ apresentaram bons resultados como camada emissora de dispositivos eletroluminescentes. Em relação à adição de compostos como ETL na camada polimérica emissora, este não modificou o comprimento de onda de eletroluminescência dos dispositivos polarizados, porém tanto para o PF, quanto para o PFP, a utilização do butyl-PBD aumentou a eficiência luminosa dos dispositivos polarizados, já para o $\mathrm{PF}_{\mathrm{PF}}$, a utilização dos compostos de ETL diminuíram sensivelmente a tensão de operação dos dispositivos. $\mathrm{O}$ uso de $\mathrm{Alq}_{3}$ na camada emissora junto com o polímero, por outro lado, não contribuiu para reduzir a tensão de limiar, nem aumentar a eficiência luminosa dos dispositivos contendo $\mathrm{PF}, \mathrm{PF}_{\mathrm{P}}$ ou $\mathrm{PF}_{\mathrm{PF}}$. 
Adicionalmente, é importante ressaltar que os dispositivos aqui construídos com os copolímeros $\mathrm{PF}_{\mathrm{P}}$ e $\mathrm{PF}_{\mathrm{PF}}$ apresentaram melhores resultados quando comparados aqueles com $\mathrm{PF}$, de modo que valores de tensão de limiar maiores e eficiências luminosas inferiores foram observados para estes últimos.

Estes resultados de certa forma vêm a corroborar os resultados de rendimento quântico de fotoluminescência em solução dos polímeros, que indicaram os valores de $68 \%, 80 \%$ e 86 \% para $\mathrm{PF}, \mathrm{PF}_{\mathrm{P}}$ e $\mathrm{PF}_{\mathrm{PF}}$, respectivamente, em análises utilizando o sulfato de quinina como referência.

De acordo com estes resultados, aparentemente, a desativação do éxciton em solução ou no estado sólido sem a emissão de fóton ocorre através de mecanismo intramolecular, reduzindo a fotoluminecência e a eletroluminescência. $O$ fato dos copolímeros apresentarem maior rendimento quântico indica a ocorrência do confinamento do éxciton e, possivelmente, com aumento do seu tempo de vida.

Em relação ao $\mathrm{PF}_{\mathrm{P}}$ e $\mathrm{PF}_{\mathrm{PF}}$, ambos os copolímeros, a literatura indica que a presença de flúor na estrutura da cadeia introduz interações mais fortes (dipolo-dipolo) entre os segmentos de cadeia, o que usualmente leva a maior empacotamento ${ }^{59,60,61}$, e maior eficiência quântica para o polímero fluorado, no caso $\mathrm{PF}_{\mathrm{PF}}$. Esse fato pôde ser comprovado pelas análises de DSC e DRX para o $\mathrm{PF}_{\mathrm{PF}}$, através da existência de certa porcentagem de fase cristalina apresentada pelas temperaturas de fusão e cristalização e pelo espectro de raios-X. Diversos autores apontaram este fenômeno como responsável pelo aumento da eficiência de dispositivos orgânicos. 


\section{CONCLUSÕES}

Os polímeros eletroluminescentes, $\mathrm{PF}, \mathrm{PF}_{\mathrm{P}}$ e $\mathrm{PF}_{\mathrm{PF}}$, foram sintetizados, através da rota de acoplamento de Suzuki, e caracterizados quanto à sua estrutura química e às suas propriedades eletro-ópticas. Os rendimentos das reações foram superiores a $90 \%$ e com elevadas massas molares, comprovadas pelos resultados de GPC, com exceção do $\mathrm{PF}_{\mathrm{p}}$ da síntese 2, que obteve um rendimento de $40 \%$, sendo constatado posteriormente uma grande quantidade de grupos halogenados (grupos com Br) a partir das análises de EDX, e baixa massa molar verificada pela análise de GPC.

As análises de ${ }^{1}$ HNMR e de FTIR comprovaram a presença de anéis aromáticos, grupos $\mathrm{CH}, \mathrm{CH}_{2}$ e $\mathrm{CH}_{3}$, e, além disso, através da análise de FTIR também comprovou a presença de hidrocarbonetos fluorados, no caso do $\mathrm{PF}_{\mathrm{PF}}$.

Em solução, as análises de absorção e fluorescência dos polímeros $\mathrm{PF}, \mathrm{PF}_{\mathrm{P}}$ e $\mathrm{PF}_{\mathrm{PF}}$ apresentaram picos de absorção em 385, 360, 365 nm, e picos de emissão em 416, 408 e 404 $\mathrm{nm}$, respectivamente, e, utilizando o sulfato de quinina como padrão, foram calculados os rendimentos quânticos dos polímeros, $68 \%$ para o $\mathrm{PF}, 80 \%$ para o $\mathrm{PF}_{\mathrm{P}}$ e $86 \%$ para o $\mathrm{PF}_{\mathrm{PF}}$.

As análises TGA forneceram as temperaturas iniciais de degradação para os copolímeros, em torno de $210{ }^{\circ} \mathrm{C}$ para o $\mathrm{PF}, 210{ }^{\circ} \mathrm{C}$ para o $\mathrm{PF}_{\mathrm{P}}$ e de $200{ }^{\circ} \mathrm{C}$ para o $\mathrm{PF}_{\mathrm{PF}}$.

Os ensaios de DSC mostraram apenas a $\mathrm{T}_{\mathrm{g}}$ do $\mathrm{PF}$ e do $\mathrm{PF}_{\mathrm{P}}$, indicando tratar-se de materiais totalmente amorfos, enquanto que o $\mathrm{PF}_{\mathrm{PF}}$ apresentou pico de fusão e de cristalização a frio, sugerindo presença de fração de fase cristalina, que pôde ser comprovada a partir do ensaio de DRX, caracterizando 9\% de cristalinidade no material.

Os dispositivos com e sem ETL ( $\mathrm{Alq}_{3}$ e butyl-PBD) apresentaram curvas de corrente vs. tensão com características semelhantes para os três tipos de polímeros. Com a adição do butyl-PBD as tensões de limiar dos dispositivos diminuíram, e, com o $\mathrm{Alq}_{3}$, as tensões foram geralmente superiores aos dispositivos que continham apenas o polímero emissor. A adição dos compostos de ETLs, não alterou o comprimento de onda máximo observado quando os dispositivos foram polarizados. 


\section{PERSPECTIVAS DE TRABALHOS}

Sugerem-se as sínteses de novos materiais poliméricos, aumentando a quantidade de flúor nos anéis benzênicos, a fim de comprovar a interferência de fase cristalina originada por essa classe de polímeros conjugados.

Sugere-se o aprimoramento na fabricação dos P-OLEDs, com a finalidade deposição de filmes poliméricos mais uniformes e obtenção de dispositivos com melhores tempos de vida, e a utilização de outros tipos de solventes para compará-los com o clorofórmio. 


\section{PUBLICAÇÕES}

1. TAKIMOTO, H. G.; BARBERATO, F.; CORREIA, F. C.; SANTOS, E. R.; SANTOS, G.; ONMORI, R. K .; FONSECA, F. J.; ANDRADE, A. M.; HUI, W.S.; Polifluorenos - Síntese, Caracterização e Preparação de Dispositivos Eletroluminescentes, $11^{\circ}$ Congresso Brasileiro de Polímeros, 2011, Campos do Jordão;

2. BARBERATO, F; TAKIMOTO, H. G.; CORREIA, F. C.; SANTOS, E. R.; SANTOS, G.; ONMORI, R. K .; FONSECA, F. J.; ANDRADE, A. M.; HUI, W.S.; Poli(fluoreno) Fluorado Puro e Dopado com Rubreno; $11^{\circ}$ Congresso Brasileiro de Polímeros, 2011, Campos do Jordão;

3. TAKIMOTO, H. G.; BARBERATO, F.; CORREIA, F. C.; SANTOS, E. R.; SANTOS, G.; ONMORI, R. K .; FONSECA, F. J.; ANDRADE, A. M.; HUI, W.S.; Pleds of conjugated Polymers based in polyfluorene; XI Encontro da SBPMAT. 2012, Florianópolis;

4. BARBERATO, F.; TAKIMOTO, H. G; SANTOS, E. R.; ONMORI, R. K .; FONSECA, F. J.; HUI, W.S.; Preparation and Charcterization of doped conjugated polymer for OLEDs; XI Encontro da SBPMAT. 2012, Florianópolis;

5. SANTOS, E. R.; YOSHIDA, S.; TAKIMOTO, H. G.; BURINI, E. C.; ONMORI, R. K.; HUI, W. S.; Electrical and optical characterizations for different ITO fims deposited on PET substrates used in P-OLEDs; XI Encontro da SBPMAT. 2012, Florianópolis. 


\section{REFERÊNCIAS}

\footnotetext{
1 SHIRAKAWA , H.; IKEDA, S.; Infrared Spectra of Poly(acetylene), Polymer J. 1971, vol.2, nº2, p. 231-244;
}

2 ITO, T.; SHIRAKAWA, H.; IKEDA, S.; Simultaneous Polymerization and Formation of Poly(acetylene) Film on the Surface of a Concentrated Soluble Ziegler-Type Catalyst Solution, J. Polymer Sci., Polymer Chem. Ed. 1974, vol.12, p. 11-20;

3 ShIRAKAWA, H.; LOUIS, E. J.; MACDIARMID, A. G.; CHIANG, C. K.; HEEGER, A. J.; Synthesis of Electrically Conducting Organic Polymers: Halogen Derivates of Poly(acetylene), $\left(\mathbf{C H}_{\mathbf{x}}\right)$, J. Chem.soc.: Chem. Commun. 1977, p. 578-580;

4 CHIANG, C. K.; FINCHER, C. R.; PARK, Y. W.; HEEGER, A. J.; SHIRAKAWA, H.; LOUIS, E. J.; GAU S.C.; MACDIARMID, A. G.; Electrical Conductivity in doped Poly(acetylene). Phys. Rev. Lett. 1977, vol.39, n¹7, p. 1098-1101;

5 NALWA, H. S.; BLOEMBERGEN, N.; LAUREATE, N.; Handbook of advanced electronic and photonic materials and devices, Conducting Polymers, Academic Press, USA, 2001, vol. 8, chap. 1, p. 1-86;

6 YU, G.; GAO, J; HUMmelen, J. C.; WUDL, F.; HeEger, A. J.; Polymer Photovoltaic Cells: Enhanced Efficiencies via a Network of Internal Donor-Acceptor Heterojunctions, Science, 1995, vol.270, p. 1789-1791;

7 HALlS, J. J.; WALSH, C. A.; GREENHAM, N. C.; MARSEGLIA, E. A.; FRIEND, R. H.; MORATTI, S. C.; HOLMES, A. B.; Efficient photodiodes from interpenetrating polymer networks, Nature, 1995, vol. 376, p.498-500;

8 GARNIER, F.; HAJlAOUO, R.; YASSAR, A.; SRIVASTAVA, P.; All-Polymer Field-Effect Transistor Realized by Printing Techniques, Science, 1994, vol.265, p.1684-1686;

9 YANG, Y.; HEEGER, J.; A new architecture for polymer transistors, Nature, 1994, vol. 372, p.344346 ;

10 TESSLER, N.; FRIEND, R. H.; Polymer LEDs as Laser Media?, Synthetic Metals, 1999, vol. 102, p.1122-1123;

11 TESSLER, N.; HO, P. K. H.; CLEAVE, A.; PINNER, D. J.; FRIEND, R. H.; YAHIOGLU, G.; LE BARNY, P.; GRAY, J.; DE SOUZA, M.; RUMBLES, G.; Material and device related properties in the context of the possible making of electrically pumped polymer laser, Thin Solid Films, 2000, vol.363, p.6467 ;

12 CRONE, B.; DODABALAPUR, A.; LIN, Y.Y.; FILAS, R. W.; BAO, Z.; LADUCA, A.; SARPESHKAR, R.; KATZ, H. E.; LI, W.; Large-scale complementary integrated circuits based on organic transistors, Nature, 2000, vol. 403, p.521-523; 
BURROUGHES, J. H.; BRADLEY, D. D. C.; BROWN, A. R.; MARKS, R. N.; MACKAY, K.; FRIEND, R. H.; BURNS, P. L.; HOLMES, A. B; Light-Emitting Diodes Based on Conjugated Polymers, Nature, 1990, vol.347, p.539-541;

DAI, B. L.; WINKLER, B.; DONG, L.; TONG, L.; MAU, A. W. H.; Conjugated Polymers for LightEmitting Applications, Advanced Materials, 2001, vol.13, p.915-925;

15 DE OliveIRA, H. P. M.; COSSIElO, R. F.; ATVARS, T. D. Z.; AKCELRUD, L.; Dispositivos Poliméricos Eletroluminescentes, Química Nova, 2006, vol.29, n², p.277-286;

PARTRIDGE, R. H.; Electroluminescence from Polyvinylcarbazole Films: 3. Electroluminescent Devices, Polymer, 1983, vol.24, p.748-754;

17 CADBY, A. J.; LANE, P. A.; WOLHLGENANNT, M.; AN, C.; VARDENY, Z. V., BRADLEY, D. D. C.; Optical Studies of Photoexcitations of poly(9,9-dioctylfluorene), Synthethic Metals, 2000, vol.111-112, p. 515-518;

18 LEClERC, M.; Polyfluorenes: Twenty Years of Progress, Journal of Polymer Science. Part A : Polymer Chemistry, 2001, vol.39, p.2867-2873;

19 FRIEND, R. H.; Semiconductor Device Physicis with Conjugated Polymers, Physica Scripta, 1996, vol. 66, p.9-15;

20 BERNTSEN, A.; CROONEN, Y.; LIEDENBAUM, C.; SCHOO, H.; VISSER, R.;VLEGGAAR, J.; WEIJER, P.; Stability of polymers LEDs. Optical Materials, 1998, vol.28, p.125-133;

21 CALLISTER, W. D.; Ciência e Engenharia de Materiais: Uma Introdução, Sétima Edição - LTC, 2007, p.515-516;

22 NALWA,H. S.; Handbook of Organic Conductive Molecules and Polymers, vol.4 - Conductive Polymers. Transport, Photophysics and Applications. John Wiley and Sons Ltd., 1997, New York, USA;

23 SKOTHEIM, T. A.; ELSENBAUMER, R. L.; REYNOLDS, J. R.; Handbook of Conducting Polymers, Second Edition - Marcel Dekker, Inc, 1998;

24 ATKINS, P.; JONES, L.; Princípios de Química: Questionando a Vida Moderna e o Meio Ambiente, Terceira Edição - Bookman, EUA, 2006, p.208-215;

25 HALLS, J. J.; Photoconductive Properties of Conjugated Polymers, St John's College, University of Cambridge, 1997;

26 GREENHAM, N. C; Electroluminescence in Conjugated Polymers, Clare College, University of Cambridge, 1995; 
27 MIYAURA, N.; SUZIKI, A.; Palladium-Catalyzed Cross-Coupling Reactions of Organoboron Coumpounds, Chem. Rev., 1995, vol.95, p.2457-2483;

28 SUZUKI, A.; Recent advances in the cross-coupling reaction of organoboron derivatives with organic electrophiles, Journal of Organ. Chem., 1999, vol. 576, p.147-168;

29 YAMAMOTO, T.; MORITA, A.;MUYAZAKI, Y.; MARUYAMA, T.; WAKAYAMA, H.; ZHOU Z. H.; NAKAMURA, Y.; KANBARAT, T.; SASAKI, S.; KUBOTA, K.; Preparation of pi-conjugated poly(thiophenes-2,5-diyl), poly(p-phenilene) and related polymers using zerovalent nickel complexes. Linear structure and properties of the pi-conjugated polymers. Macromolecules, 1993, vol. 25, p. 12141223 ;

30 ASSAKA, A. M.; Síntese e Caracterização de Copolímeros Conjugados Contendo Fluoreno Para Aplicações em Dispositivos Eletro- Ópticos, Tese de Doutorado, Universidade Federal do Paraná, Paraná, 2006;

31 ASSAKA, A. M.; RODRIGUES, P. C.. OLIVEIRA, A. .R. M.; DING, L.; HU, B.; KARASZ, F. E.;AKCELRUD, L.; Novel Fluorine Containing Polyfluorenes with Efficient Blue Electroluminescence, Polymer, 2004, vol.45, p. 7071-7081;

32 PARKER, C. A.; Photoluminescence of Solutions. Elsevier Publishing Co., 1968, New York, USA;

33 FRIEND, R. H.; GYMER, R W.; HOLMES, A. B.; BURROUGHES, J. H.; MARKS, R. N.; TALIANI, C.; BRADLEY, D. D. C.; DOS SANTOS, D. A.; BREDAS, J. L.;LOGDLUND, M.; SALANECK, W. R.; Electroluminescence in Conjugated Polymers, Nature, 1999, vol.397, p. 121-128;

34 LÉVESQUE, I.; DONAT-BOUILlUD, A.; TAO, Y.; D’IORIO, M.; BEAUPRÉ, S.; BLONDIN, P.; RANGER, M.; BOUCHARD, J.; LECLERC,M.; Organic Tunable Electroluminescent Diodes from Polyfluorene Derivatives, Synthetic Metals, 2001,vol. 122, p.79-81;

35 RIEVESCHL, G.; RAY, F. E.; The Chemistry of Fluorene and its derivatives. Chemical Reviews, 1937, p.188-374;

36 SCHERF, U.; LIST, E. J. W.; Semiconducting Polyfluorenes - Towards Reliable StructureProperty Relationships. Advanced Materials, 2002, vol. 14, p. 477-487;

37 KLAERner, G.; MILleR, R. D.; Polyfluorene Derivatives: Effective Conjugation Lengths from Well-Defined Oligomers, Macromolecules, 1998, vol. 31, p. 2007-2009;

38 ATVARS, T. D. Z.; MARTELLI, C.; Espectroscopia de Luminescência. Disponível em Www.chemkeys.com; acessado em 16 setembro de 2012;

39 ATKINS, P.; TRAPP, C.; GIUNTA, C.; CADY, M.; Physical Chemistry, $8^{\text {th }}$ Edition; Oxford University Press, 2006, London UK; 
$40 \quad$ GLOGAUER, A.; Síntese e Caracterização Fotofísica de Dois Polímeros Eletroluminescen-tes: um Completamente Conjugado e Outro Multibloco, Tendo Como Unidade Cromofórica o Fluoreno-VenilenoFenileno, Dissertação de Mestrado, Universidade Federal do Paraná, Paraná, 2004;

41 DEICHMANN, V. A. F.; Síntese e Caracterização de Polímeros Conjugados Contendo Grupamentos 2,2-Bipiridina na Cadeia Principal, Tese de Doutorado, Universidade Federal do Paraná, Paraná, 2010;

42 GUILlet, J.; Polymer Photophysics and Photochemistry - An Introduction to the study of Photoprocesses in macromolecules. Cambridge University Press, 1985, London, UK;

43 MCKellar, J. F.; ALLEN, N. S.; Photochemistry of man-made Polymers. Applied Scienc Publishers Ltd., 1979, London, UK;

44 WIEHAUS, G.; Síntese e Caracterização de Novas Iminas com Aplicação em Óptica Não-Linear, Dissertação de Metrado, Universidade Federal do Rio Grande do Sul, 2010, Porto Alegre;

45 MARletta, A.; Propriedades Ópticas de Semicondutores Orgânicos a Base de Polímeros Emissores de Luz, Tese de Doutorado, Universidade de São Paulo, São Carlos, 2001;

46 AKCELRUD, L.; Electroluminescent Polymers. Progress in Polymer Science, 2003, vol. 28, p. 875962;

47 BRUTTING, W.; BERLEB, S.; MUCKL, A. G.; Device physics of organic light-emitting diodes based on molecular materials, Organic Eletronics, 2001, vol. 2, p. 1-36;

$48 \quad$ HUNG, L. S.; CHEN, C. H.; Recent Progress of Molecular Organic Electroluminescent Materials and Devices, Materials Science and Engineering, 2002, vol. 39, p. 143-222;

49 VALEUR, B.; Molecular Fluorescence: Principles and Application, Wiley, Alemanha, 2001;

50 DEMAS, J. N.; CROSBY, G. A.; The Measurement of Photoluminescence Quantum Yields, Journal of Physical Chemistry, 1971, vol. 75, p.991-1024;

51 MILLER, J. N. , Standards in Fluorescence Spectrometry, Ultraviolet Spectrometry Group, Great Britain, 1981;

52 SANTOS, E. R.; Estudos de Tratamentos Superficiais em Substratos de Óxidos Transparentes Condutivos para a Fabricação de Dispositivos Poliméricos Eletroluminescentes, Tese de Doutorado, Universidade de São Paulo, São Paulo, 2009;

53 GUERRA, E. V.; Estudo do desempenho de dispositivos diodos poliméricos-orgânicos emissores de luz utilizando-se camada PEDOT:PSS, Faculdade de Tecnologia de São Paulo, São Paulo, 2011; 
54 SCHUler, T. E.; Síntese e Caracterização de Copolímeros Randômicos Poli[bis(fenilenovinileno)-stat-(1,8-bis-(2,6-dioximetano-1,4-fenilenovinileno)-ioxioctano)-1,4-fenileno)] Aplicação em Diodos Emissores de Luz Orgânicos, Dissertação de Mestrado, Universidade de São Paulo, São Paulo, 2008;

55 CORREIA, C. F.; Copolímeros Emissores de Luz Contendo Grupos Fluoreno e Quinolina: Preparação, Caracterização e Montagem de LEDs, Dissertação de Mestrado, Universidade de São Paulo, São Paulo, 2009; Company, 1978;

59 ZHOU,H.;YANG, L.; YOU, W.; Rational Design of High Performance Conjugated Polymers for Organic Solar Cells, Macromolecules, 2012, vol. 45, p. 607-632;

60 KAMESHIMA, H.; NEMOTO, N,; ENDO, T.; Synthesis and Properties of Fluorene-Based Fluorinated Polymers, Journal of Polymer Science: Part A: Polymer Chemistry, 2001, vol. 39, 3143-3150;

61 ZHANG, T.; WANG, R.; REN, H.; CHEN, Z.; LI, J.; Deep blue light-emitting polymers with fluorinated backbone for enhanced color purity and efficiency, Polymer, 2012, vol.53, p. 1529-1534; 